University of Rhode Island

DigitalCommons@URI

Open Access Master's Theses

1997

\title{
AN URBAN DESIGN STRATEGY FOR THE MAIN STREET STUDY AREA, WORCESTER, MASSACHUSETTS
}

Sharon A. Lee

University of Rhode Island

Follow this and additional works at: https://digitalcommons.uri.edu/theses

\section{Recommended Citation}

Lee, Sharon A., "AN URBAN DESIGN STRATEGY FOR THE MAIN STREET STUDY AREA, WORCESTER, MASSACHUSETTS" (1997). Open Access Master's Theses. Paper 386.

https://digitalcommons.uri.edu/theses/386

This Thesis is brought to you for free and open access by DigitalCommons@URI. It has been accepted for inclusion in Open Access Master's Theses by an authorized administrator of DigitalCommons@URI. For more information, please contact digitalcommons-group@uri.edu. 


\title{
AN URBAN DESIGN STRATEGY FOR THE MAIN STREET STUDY AREA, WORCESTER, MASSACHUSETTS
}

\author{
b y
}

Sharon A. Lee

A Research Project Submitted in Partial Fulfillment of the Requirements for the Degree of Master of Community Planning

University of Rhode Island 1997 


\title{
MASTER OF COMMUNITY PLANNING RESEARCH PROJECT
}

\author{
of \\ Sharon A. Lee
}

Approved:

Major Professor

Acknowledged:

Director
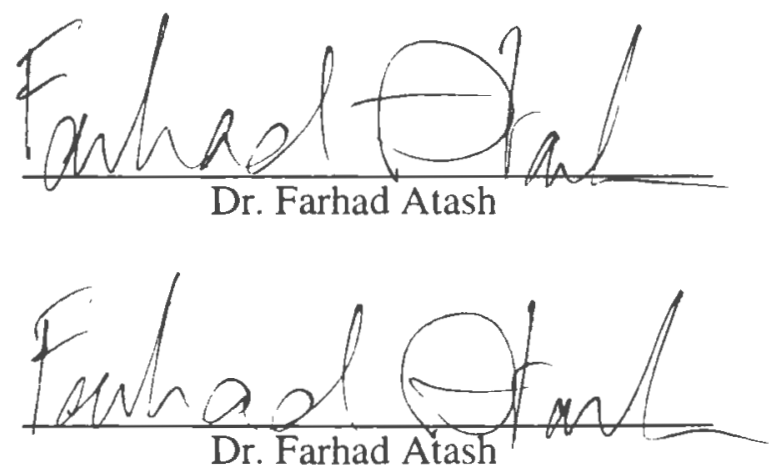


\begin{abstract}
The purpose of this study is to identify problems and potentials related to the physical environment in the City of Worcester. This study covers a significant time period. Research for this report was initiated in 1988 and since that time many changes have taken place both in the physical environment of the city but also in the governing structure of the city. The City of Worcester is interesting because like many cities in the northeast and in Massachusetts in particular, it has a long history. In addition, its central location in the State and in the region could be valuable asset to the city in the future.
\end{abstract}

The report begins with an analysis of the existing conditions in the City of Worcester. Describing the history of the City as well as current conditions this section provides the framework for the recommendations to be made in the rest of the study. ${ }^{1}$ The second and third parts of this study provide recommendations intended to improve and enhance existing conditions for a defined portion of the city, the Main Street Study Area. The area is so named because the primary thoroughfare is Main Street and because it offers conditions similar to those found in many cities throughout the United States.

The Main Street Study Area like many other American, 'main street cities' has been in a state of decline for a long period of time. City officials have and continue to strategies over the years in order to mitigate this decline. Most of these plans were not visible except in written form until very recently. And so currently, parts of the Main Street Study Area are being physically transformed to coincide with the many plans developed throughout the late 1980's and early 1990's. This study looks at the history of the city, the many planning strategies adopted and physical changes currently taking place. Recommendations are made in the second two parts of the study which are intended to complement and further the progress made so far and to address areas which are currently not being improved upon.

\footnotetext{
1 The city will be analyzed the way a painter surveys a painting in progress. Each part will be looked at and worked on in order to shape it into a more unified whole.
} 


\section{ACKNOWLEDGMENTS}

This paper has been a long time effort and is offered today due to a great deal of support from a number of people. Specifically I'd like to thank Dr. Atash, probably the best advisor a student in any field could ask for. Not only an intellectual but a supportive individual. I'd like to thank Dr. Foster who was kind enough to add himself to my team for his patience and time as well as all the staff in the Department of Community Planning. In addition I'd like to thank Deans Boudreaux-Bartels and Bibb. They had to have the most difficult job of providing essentially blind faith in a person they knew very little about. I'd like to thank the entire Deans Office and the Bursars and Registrars office who allowed me to return and complete this project. Finally greatest thanks goes to my family for being supportive of this project and encouraging me to finish. I would like to thank my mother especially who has always been there with immeasurable amounts of love and support. There is no way to express my gratitude to her or the many others who have helped me. Thank you all. 


\section{TABLE OF CONTENTS}

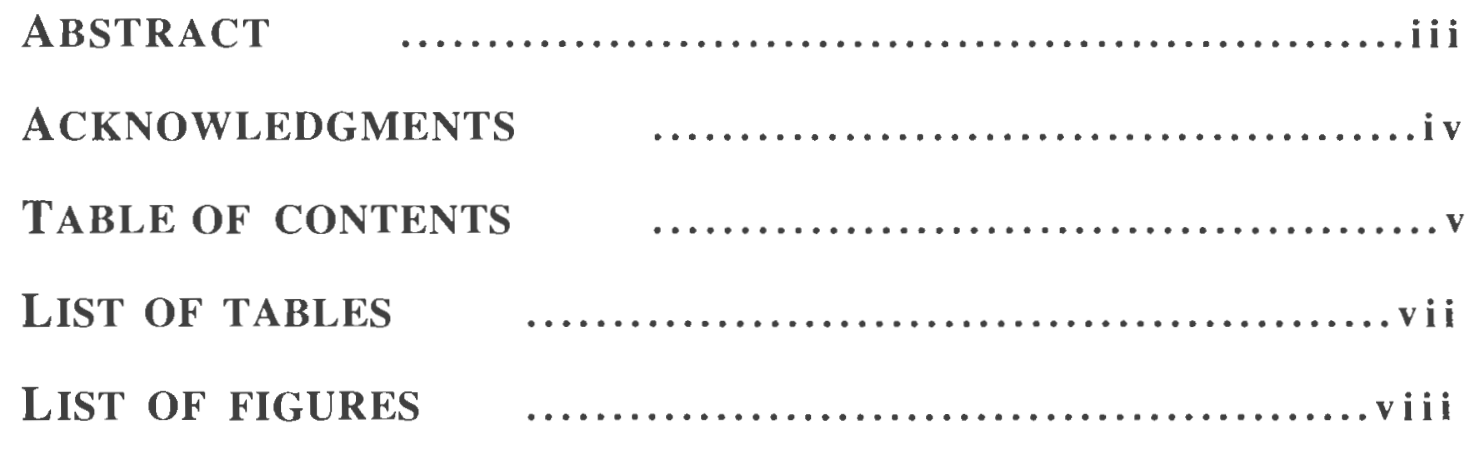

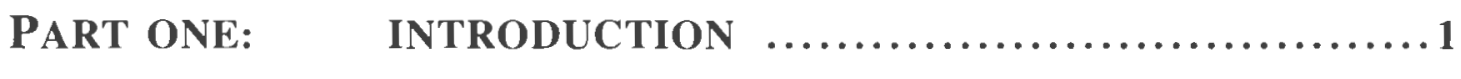

PART TWO: ANALYSIS OF EXISTING CONDITIONS $\ldots \ldots \ldots 6$

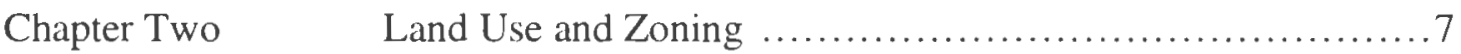

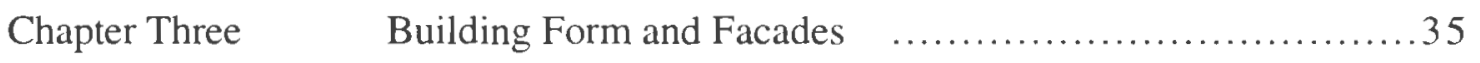

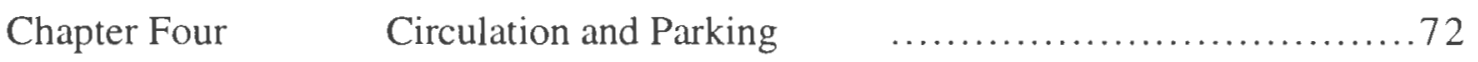

Chapter Five $\quad$ Pedestrian Ways and Amenities $\quad$....................... 86

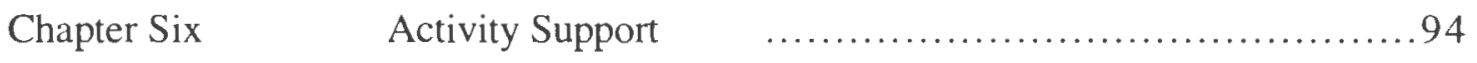

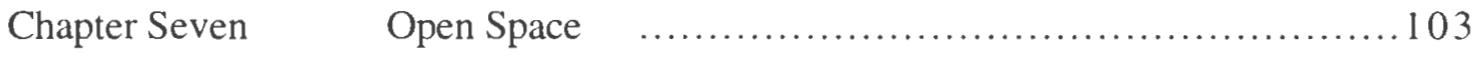

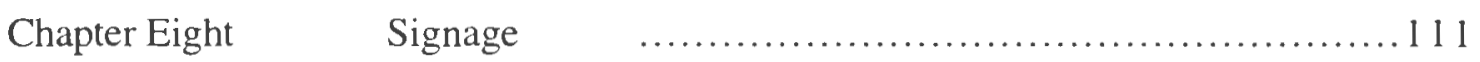

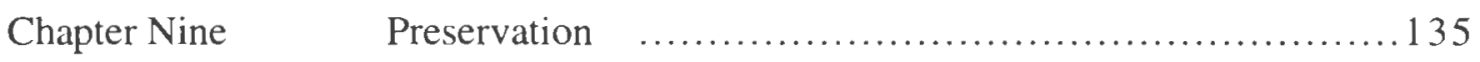

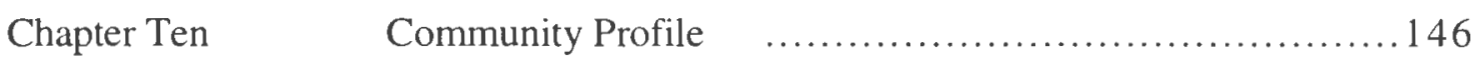

PART THREE: URBAN DESIGN PLAN $\ldots \ldots \ldots \ldots \ldots \ldots \ldots 161$

Chapter Eleven Design Principles: Improve the Aesthetic Quality of the Main Street

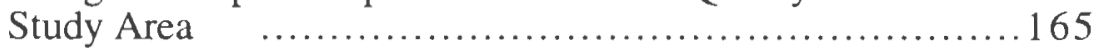

Chapter Twelve Guidelines to Improve Circulation and Public Amenities .......181

Chapter Thirteen Recommendations for Creating an Active and Viable Downtown

District $\quad$.........................................203

PART FOUR: IMPLEMENTATION MECHANISMS...........2 25

Chapter Fourteen Administrative Mechanisms $\quad$.............................226

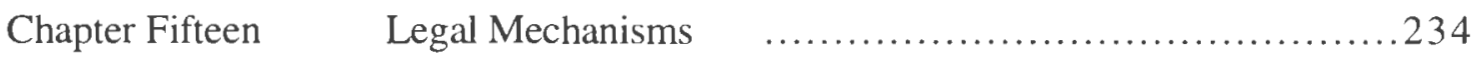

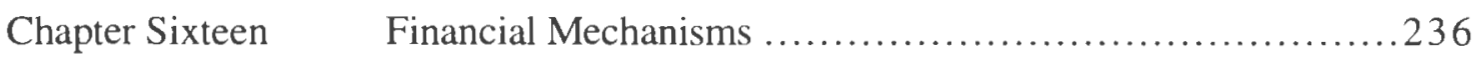

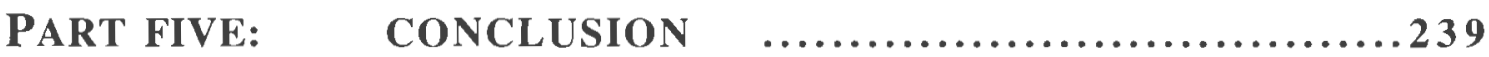




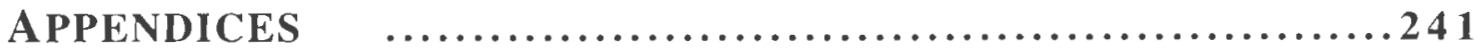

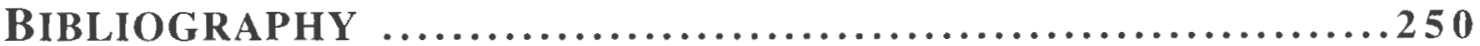




\section{LIST OF TABLES}

10.1 Worcester Population, 1790-1990

10.2 Worcester Population, by Age, 1960-1990

10.3 Worcester Population, by Race, 1980-1990

10.4 Population Households and Housing Stock

10.5 Worcester Household Income, 1960-1990

10.6 Residential Building Permits, 1986-1994 


\section{LIST OF FIGURES}

2.1 Diagram of Worcester

2.2 Map of New England

2.3.1 Land Use Map

2.3.2 Land Use Map

2.4.1 District Boundaries

2.4.2 District Boundary

2.5 Zoning Map

2.6.1 Worcester Convention Center

2.6.2 Worcester Convention Center

2.6.3 Worcester Convention Center

2.7 Design Proposal for Medical City

3.1.1 Map of Worcester, 1830-1840

3.1.2 Map of Historic Worcester, 1795

3.2.1 View of Main Street Study Area

3.2.2 View of Main Street Study Area

3.3 Partial View of Worcester Skyline

3.4.1 Union Station

3.4.2 Union Station

3.5 Interior View of Union Station

3.6 Plumley Village Housing

3.7 Plumley Village Housing

3.8.1 Mechanics Hall, Front Elevation

3.8.2 Mechanics Hall, Rear Elevation

3.9 Rear Elevation of City Hall

3.10 View of Urban Villages

3.11 Residential Commercial District, Commercial Buildings

3.12 Residential Commercial District, Commercial Buildings

4.1 Map of Worcester Roads, Traffic Volumes

4.2.1 Map of Parking in the Main Street Study Area

4.2.2 Map of Parking in the Main Street Study Area

5.1 Main Street Commercial District, Trees and Plants

5.2 Residential Commercial District, Front Yards

8.1 City of Pittsburgh, Street Signage

8.2 Interstate Commercial District, Signage

8.3 Interstate Commercial District, VNA

8.4 Main Street Commercial District, Signage

8.5.1 Main Street Commercial District, Commercial Signage

8.5.2 Main Street Commercial District, Commercial Signage

8.5.1 Main Street Commercial District, Commercial Signage

8.6 Residential Commercial District, Commercial Signage

10.1 Graph of Worcester Population, 1790-1990

10.2 Graph of Worcester Population, by Age, 1960-1990

10.3 Graph of Worcester Population, by Race, 1980-1990 


\section{LIST OF FIGURES (cont'd)}

10.4 Graph of Population, Households and Housing Stock

10.5 Graph of Worcester Household Income, 1960-1990

10.6 Graph of Residential Building Permits, 1986-1994

11.1 Proposal Map

11.2 Main Street Commercial District, Library in Garden (Proposal Sketch)

12.1 Examples of Signage

12.2 Examples of Bus Shelters

12.3 Examples of Planters, Benches

12.4 Street Sections

13.1 City of Pittsburgh, Urban Housing

13.2 Sample Business Facades

13.3 Past and Present Facades of the Home Federal Savings Bank 


\section{CHAPTER ONE \\ INTRODUCTION}

In the past, the focus of urban planning has been almost entirely on the physical environment and specifically land use. This is due to the fact that the planners role grew out of traditions such as the City Beautiful movement and political instruments like zoning.

Today, though, urban planners are and must be able to deal with a variety of planning issues beyond those specifically associated with the design and use of the physical environment. The planning field has become more all-inclusive embracing social, economic, political and environmental issues as well as the many challenges associated with physical planning. Therefore, planners while trained as generalists able to participate in all areas of the planning often select an area of concentration within the larger field in which to concentrate their efforts. As specialists planners can focus on specific aspects of the field and provide alternative perspectives from which to look at what appear to be common issues in the field of planning. Urban design, one such area of concentration.

Urban Design focuses on the physical environment. Urban designers work to "...create outdoor environments which are collective and unifying frameworks for new developments...."2 and for new and enduring communities. Thus urban designers must develop an understanding of human behavior. And given these parameters, naturally, other issues which are integral to communities and related to the planning process such as social and political issues, become variables. Nevertheless, an urban designers primary emphasis is on the physical environment. Thus the practitioner must determine, what other issues will become part of the analysis, establishing a hierarchy to determine to what degree the issues will be utilized or studied and how they will influence the final recommendations. Urban designers examine issues, such as location and accessibility of physical elements, which directly and indirectly influence the physical environments. An urban designer often begins a study with a land use analysis. This technique provides a succinct description of the elements which make

\footnotetext{
2 Roger Trancik. Finding Lost Space: Theories of Urban Design. Van Nostrand Reinhold Company, New York, 1986. p. 1.
} 
up the study area. A land use analysis identifies things such as schools, housing and recreational facilities. In addition to the types of things which occupy the land the analysis will identify two primary attributes of the area. They are location and accessibility. These attributes are the primary elements which determine the value of the land and influence regional development patterns. This land use analysis will provide the basis for the examination of the existing conditions in the City of Worcester. Following the land use analysis, a number of other features which contribute to the making of an urban area will be described as they directly relate to the City of Worcester.

\section{Problem Statement}

The City of Worcester has been in economic decline since the late 1960's. As Federal funding for programs declined and the employment sectors dramatically changed this had a major impact on the City. Manufacturing which once had been a major employment area was now replacing manpower with machines. This sector once the largest in the City now had fewer jobs to offer. Yet the population in Worcester has continued to increase. Families continued to move to the city to be close to other family members and there was also a significant increase in the numbers of births. But the existing populations having primarily been employed in manufacturing had little education and did not make the change readily to the new emerging job sector. The City also has made the change slowly, unable to encourage new

businesses to the city or existing businesses to remain in the city. Nevertheless, two important features which have assisted in slowing economic decline in the city of Worcester are its proximity to Boston and the fact that there are a number of colleges and universities in the city. Boston is a city with a strong economy and it continues to grow and expand. Ii is also becoming more and more expensive to live in the city of Boston. So people looking for affordable housing are having to go further outside of Boston to find homes. As a result, suburban Worcester has a growing number of housing developments and commercial services, in part due to this continuing need for affordable housing in the region as a whole. The second feature of the city is the high number of academic institutions located here. These institutions 
continue to attract new talent and vitality into the city. It is these features and other assets which suggest that there is tremendous potential for new growth in Worcester.

\section{Objectives of the Study and Its Significance}

The City of Worcester, specifically the downtown area shown in figure i.1, will be the focus of this analysis. The city's long history and proximity to the City of Boston are two of the reasons this city was selected for this analysis. And they help to support the assumption that the city has tremendous potential to become an active and vibrant center for the State of Massachusetts. The central issue to be studied in this paper is how to utilize the available resources in the City and build upon them and add to them as necessary in order to encourage people, both residents and visitors, to take advantage of these resources. The objectives of the study are to identity the strengths of the city and determine how best to minimize the weaknesses. One of the primary objectives towards accomplishing this goal is to encourage people to come back to the downtown area to live and shop. This study is significant for a number of reasons. When the research for this study began it was addressing potentials which were not yet being realized and now the city is changing drastically and it may help guide the process of change taking place in the downtown area, currently. The approach utilized in this study is a simple process of looking at what currently exists in the city using both primary and secondary sources and making suggestions about possible ways to make improvements in the city later in the document .

\section{Methodology/Approach}

Two basic techniques were used to complete this document, research was done of past and existing conditions and recommendations were developed for the future. A number of different research techniques were used to complete Part One, Analysis of Existing Conditions, of this study. A series of windshield surveys of the Main Street Study Area were done to identify, characteristics of the city, boundaries for the study and identify the existing land uses within the Study Area. Next a comprehensive of primary and secondary research materials was done throughout the project. This included review of the zoning codes which 
changed in 1988 when this research was initiated and again in 1994, the most recent changes. Books and articles which describe historic Worcester were also studied, appreciating that a solid understanding of the past could be an asset when planning for the future. The second part of the methodology involves making recommendations for the future. Using the information collected in Part One of the study, suggestions to enhance and improve the existing conditions are given in addition to substantive and new recommendations for each district. The recommendations made in Part Two were developed using primary and secondary research of cities of comparable size which have been more successful at revitalizing their downtown areas. Implementation strategies focusing on administrative, legal and financial aspects are provided in Part Three and were selected using the literature review process.

\section{Organization of the Study}

1. Part two provides an in-depth description of the current conditions in the City of Worcester. Many methods were used to complete this analysis and profile of the city including windshield surveys, discussions with planners and officials in the city, interviews with merchants, historians and others knowledgeable about the city. In addition, a variety of historical documents, papers, books, maps etc. were collected to add to and further substantiate the information provided in this chapter. Chapter two provides the foundation for the final two chapters of the report.

2. Part three contains the elements for an urban design proposal for the City. It is divided into 3 sections. They are Design Principles, Circulation and Public Amenities and Activity in the downtown area. The recommendations made here are intended to accentuate the positive aspects of the city and improve upon the negative ones. Based upon the findings in Part Two, this section provides very specific measures which may be utilized by a variety of interest groups from city officials in the local government to small business owners.

3. Part four, the implementation plan contains tools for accomplishing some of the recommendations/strategies offered in the urban design plan. This includes administrative,

fiscal and legal mechanisms needed to get things accomplished. What input from which groups 
is needed. How much does the proposal cost? What possible financial sources exist to solve funding issues? The urban design plan and the implementation mechanisms are both needed to affect change in the City of Worcester. The plan improves the beauty and comfort of the downtown area and the implementation mechanisms allow for the continued functioning of the city to finance and coordinate changes. 


\section{PART TWO \\ EXISTING CONDITIONS}

This section of the report provides a concise description of the existing conditions in the Main Street Study Area. There are numerous factors which influence the design and functioning of a city. Some of the ones to be considered in this part of the study include land use, circulation and open space. These issues will be described as they relate to and impact the Study Area. The problems and potential of the area should become more clear with the descriptions provided in each chapter. 


\section{CHAPTER TWO \\ LAND USE AND ZONING}

"Every city is characterized by a variety of land uses..."

(p. 273, Murphy)

A basic component of the urban design process is the land use analysis. The central business district (CBD) of a city is characterized by its diversity of land uses. This diversity attracts consumers to the city to make purchases and utilize the available services which increases the tax base of a city by generating much needed economic activity. This in turn helps to increase the income and profits made by individuals, businesses and the city as a whole. Land use also has a profound affect on the physical appearance of the city. Once uses for sites are designated this can affect the way in which structures are designed including what materials a building is made out of, the organization of exterior elements such as the windows and doors, etc.

There are many land uses found in urban environment including commercial, residential, industrial activities, open space, parking and transportation routes. The land use analysis identifies how the land is (or in some cases will be) utilized. It can show past uses but more commonly focuses on existing uses of the land. Using the information from the land use analysis an urban designer then tries to predict how the distribution of uses is changing or may change in the future and plan for or facilitate needed changes. Recommendations are then made, using the information from the land use analysis, which explain how the land could better be used to satisfy current and future needs.

The land use analysis performed for the Main Street Study Area identifies current land uses and discusses the current zoning regulations which are a major determinant of how the land will be used in the future. The information derived from this analysis will be used in Part Three to make recommendations to improve the appearance of the Main Street Study Area and assist the governing bodies in the City of Worcester.

A number of methods were used in this study to examine land use in the Main 
Street Study Area including primary research, literature review and a windshield survey. One of the methods used was the windshield survey. Driving through the study area, the uses associated with each structure were mapped onto a Worcester building map. Each land use was assigned a color, such as red for the commercial uses, in order to simplify the mapping process and to allow for complete coverage of the area. Later more information was added to these maps during a walking tour of the city. In their completed form these land use maps provide the basis for the analysis of the existing conditions and for the planning study as a whole. The first map was produced in Spring 1989. A second land use map was produced in Spring 1996 which identifies the changes which the city has made since the study began.

While performing windshield surveys, other characteristics of the buildings in the study area were identified. These included a detailed description of each building such as its height, massing, and architectural detailing. Next, any visible problems associated with the current land uses or the building's appearance were listed so the recommendations could be made. This information will be presented in later chapters.

In addition, a literature review was done and a questionnaire for local businesses and pedestrians in the Main Street Study Area was developed. The literature review provided information about the history of the buildings here and about prior land uses. The survey allows current owners to be interviewed on a regular basis in order to obtain the most up to date information about the buildings and how they are currently used as well as information about any future plans which the owner may have for the building.

\subsection{Land Use in Historic Worcester}

Worcester is known for having been a major industrial city. Unlike those cities which were established as major industrial towns, Worcester followed a pattern similar to that of other Eastern cities such as Boston, Providence and Springfield. The City of Worcester began as a self-contained village but virtually over-night was transformed into a major manufacturing and commercial center. The emphasis on manufacturing and commercial activities continued until the early 1970's when Worcester's economy began to decline. But the 
reminders of this era are still found throughout the city in the many buildings which remain.

During the Industrial Era, manufacturing was the primary employment sector in Worcester. The Industrial Era began in Worcester around 1789 when the textile manufacturing industry began to grow. Manufacturing in general then expanded a great deal over the next two decades. But significant growth in the manufacturing sector was hindered because there was no way to provide the power needed to run the advanced machinery being developed at the time. Specifically there was no access to waterpower in the city. This problem was solved in the early 19th century, though, and then the manufacturing industry again began to grow quickly. This rapid expansion was the direct result of three important discoveries. They were the discovery of steam power, the construction of the Blackstone Canal, and the building of a substantial rail network in the city. The discovery of steam power offered another alternative in order to provide power to machinery. The Blackstone Canal was opened in 1828 linking Worcester to Providence, Rhode Island a functioning seaport. And the new rail system provided an alternative means of transporting goods to and from companies. After the arrival of these technical innovations, many industries chose to locate factories in the City of Worcester.

Industries were built along the level land of the stream valley. These linear strips of industrial and manufacturing uses crossed through the heart of downtown Worcester.

Diagrammatically, when one looks at historic maps of the city, one sees a nucleated center with small linear connectors extending away from it. Slowly major streets, highways and rail lines were built along these flood plains through what was otherwise hilly and not easily accessible terrain creating a star shaped pattern on the city map. This pattern was further reinforced by developers who also chose to build along these transportation routes.

Most industries chose to locate their facilities along the level lands of the stream valley which runs in the north and south direction through the heart of the city. This again altered the map of the City of Worcester which had now become a nucleated center from which the many transportation routes extended, see Figure 2.1. This nucleated center has continued to grow 
Figure 2.1

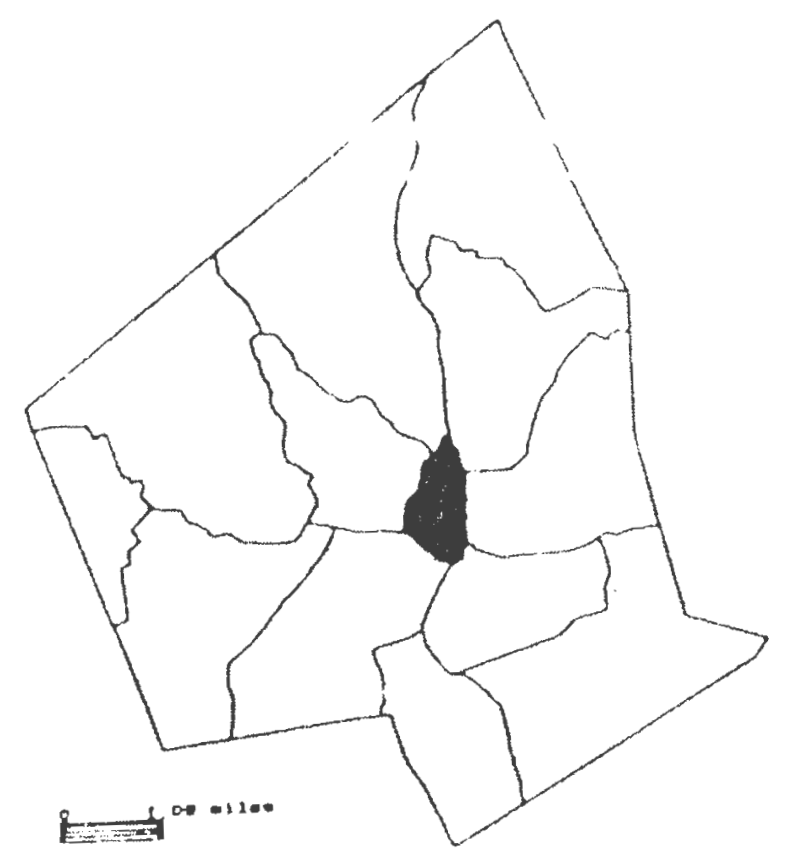

Diagram of the City of Worcester Showing Major Connectors Into and Out of the Downtown Area 
over the years and is centered today in downtown Worcester. ${ }^{3}$ Slowly important roadways and rail lines were also built along the flood plain (area) through otherwise hilly terrain, creating a star-shaped pattern seen in diagrammatic maps even today. This pattern has been further reinforced as additional transportation routes parallel to the existing ones were built. The central location of the city in both the state and the region made it an important node in the transportation network. As the city grew the roads and rail lines were extended to connect to other cities including Albany, Springfield and Boston. The Norwich and Worcester Railroad lines, providing service to Connecticut and Long Island, opened on March 9, 1840 and the Providence and Worcester Line began operating in October of 1847. Worcester became the center of a network of railroad and stagecoach ${ }^{4}$ lines. See Figure 2.2.

\subsection{The City Government and Land Use}

The first step towards understanding the land uses in a city or region is to understand the organizations who make the land use decisions, such as the elected representatives, city administrative departments and citizens groups. In the City of Worcester, the City Council is the administrative organization which determines policy and it is presided over by the Mayor, the head of the city. The City Manager, though, Thomas R. Hoover, is the person responsible for making the day to day decisions for the city and all municipal departments report to him. The groups which are involved with land use include The Office of Planning and Community Development (OPCD) which was created in 1972 to administer the Federally funded Community Development Block Grant Program (CBDG) and provides longrange land use planning for the city. In 1985, it also assumed the administrative functions of the Worcester Redevelopment Authority (WRA) and the two offices were combined in to one. In the early 1990's the WRA was again made a separate office as it is today and this office monitors and manages the new development projects currently underway in the city. The

\footnotetext{
${ }^{3}$ With its continued growth, the boundaries for the downtown area have become rather obscure. Thus for the purposes of this study, a specific section of the downtown will be analyzed called the Main Street Study Area.

4 The stagecoach was the primary means of transportation in those places where rail service was unavailable.
} 


\title{
Figure 2.2
}

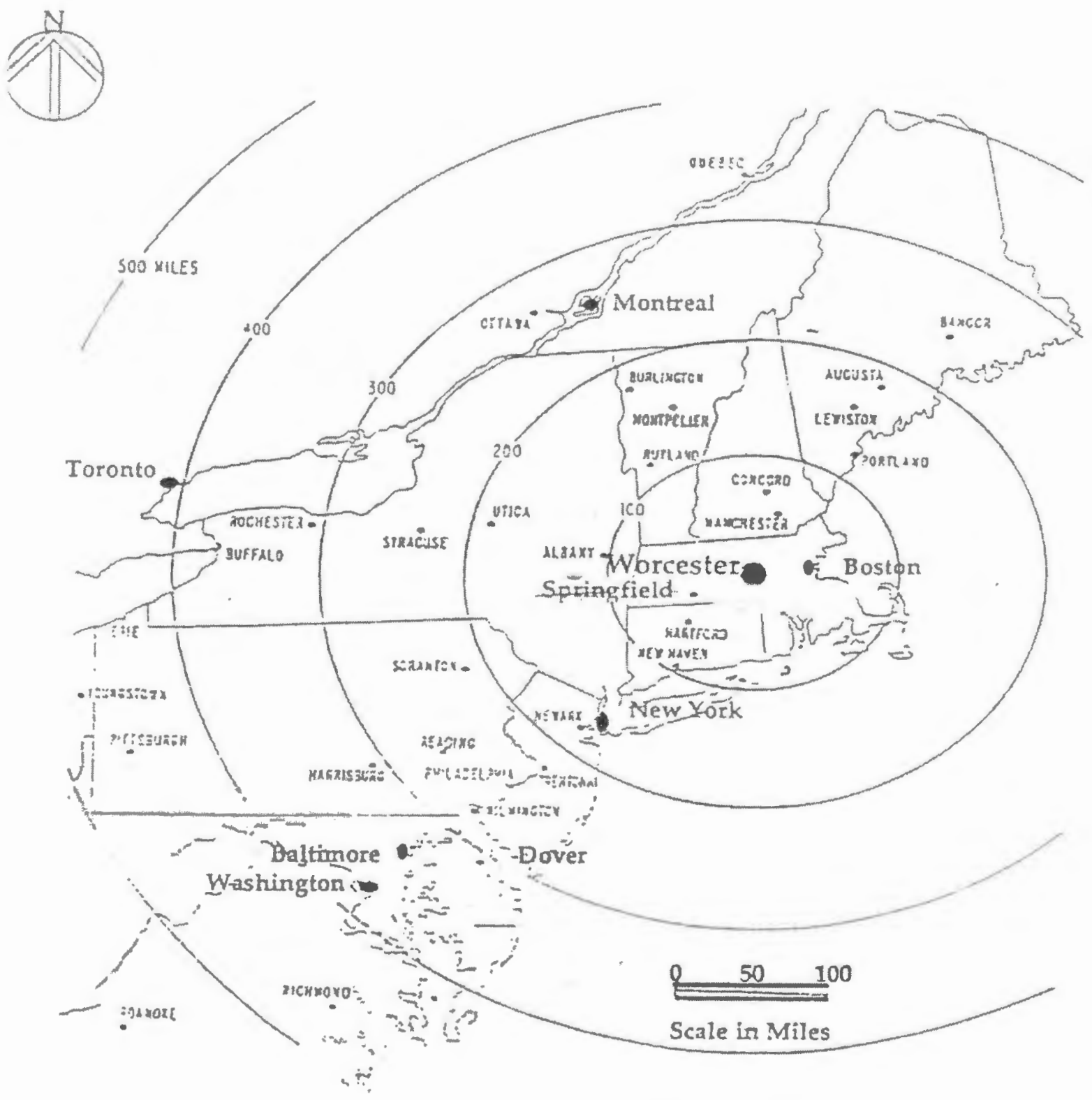

\author{
Map of New England \\ Showing the Location of Worcester and \\ Its Proximity to a Number of Other Cities
}


Bureau of Land Use Control, established in 1976, provides short-term land use planning to the public. For example this office can assist individuals who may be trying to obtain a building permit. Other municipal departments involved in the land use process are the Department of Parks and Recreation and the Department of Public Works.

The Planning Board for the City of Worcester is a five-member body which prepares planning reports on matters referred to it by the City Council or the City Manager. Because this board is not necessarily made up of professional planners, they work with OPCD to research land use issues. The Zoning Board of Appeals, also a five member organization, hears appeals on zoning issues and makes decisions on those appeals. The seven-member Conservation Commission has a variety of duties including administering the Wetlands Protection Act of 1986 and preserving the aesthetic and scenic features of the Worcester landscape. The Zoning board and the Conservation Commission are also assisted by OPCD and the Bureau of Land Use Controls.

\subsection{Land Use in the City of Worcester}

Worcester is a large diverse city which encompasses approximately 38 square miles of land. The Main Street Study Area and the city as a whole is noted for the wide variety of land uses including varying commercial, industrial, parking and residential uses. See the Land Use Map shown in Figure 2.3.1 and 2.3.2. But while many of the uses in the downtown area have remained the same there also have been many noticeable changes. The most obvious one being the decline in the amount of industrial uses found in the downtown area. Many of the industries which were once located here have closed over the years due to the declining economic conditions in the city. Nevertheless, current studies show that there are still 375 manufacturing plants ${ }^{5}$ in the city as a whole. Most of these industries, though, have re-located outside of the central business district where there is more land, land prices are significantly lower, and where the overall operating costs are less. Such moves have been made possible because of the many advancements in technology which allow businesses to locate either the

\footnotetext{
5 Americana Encyclopedia.
} 


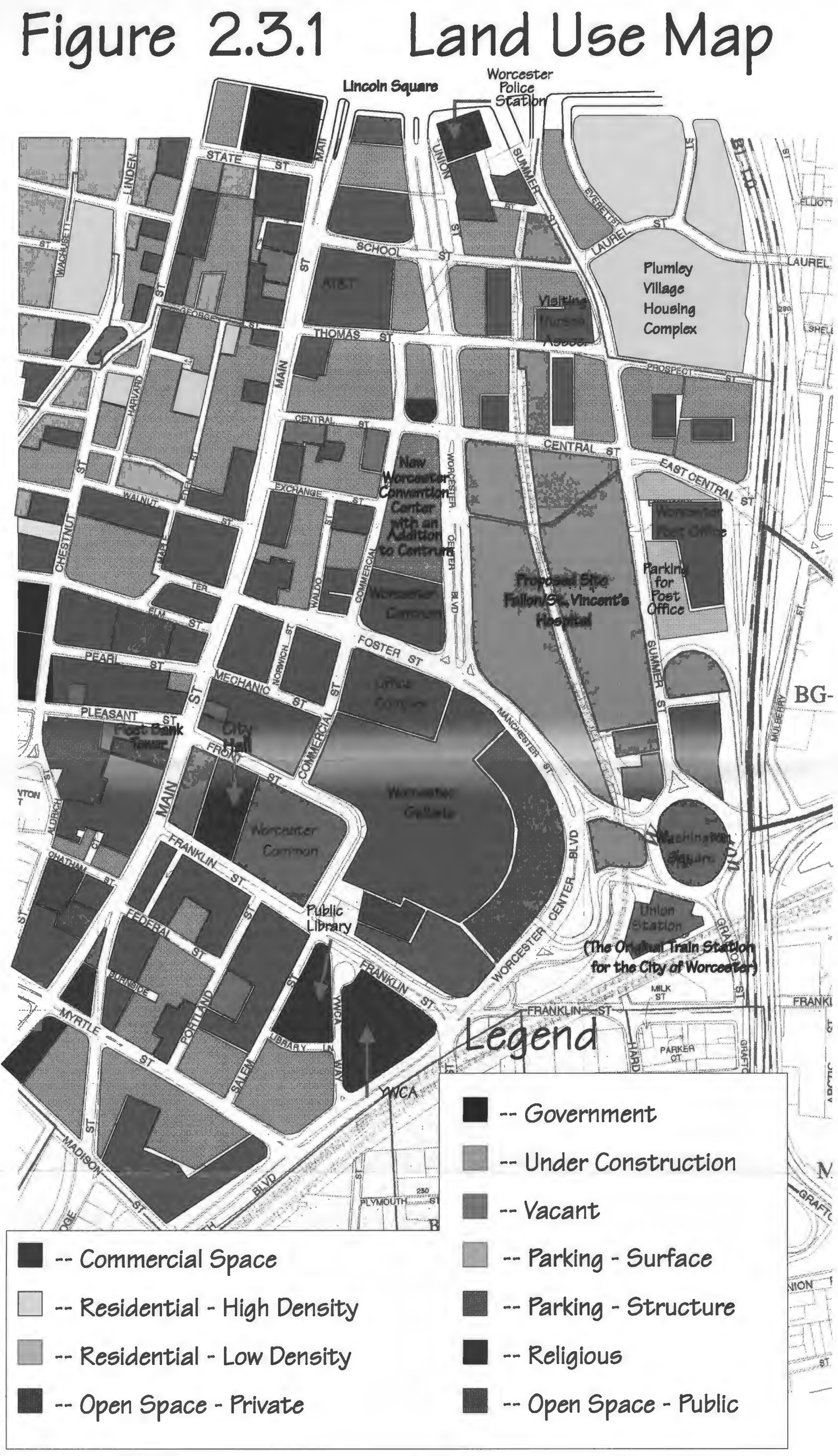




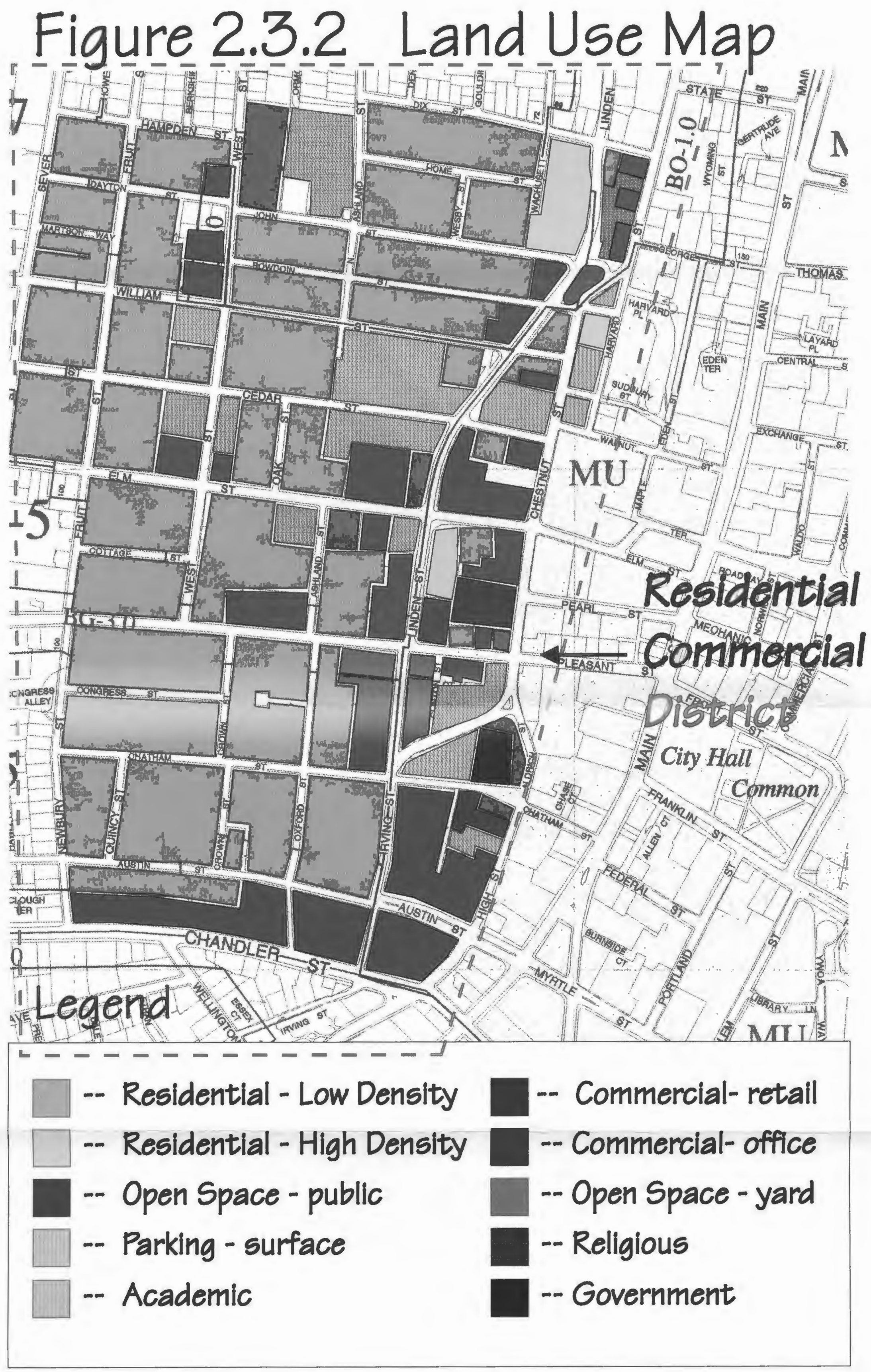


entire business or perhaps just the production part of the operation away from the central core of a city yet remain in close proximity to consumers by using telecommunications systems and transportation routes. Because transportation routes are still very important to the operation of these industries, one finds most of the industrial uses in the Worcester located along the major roadways such as Routes 9,20 , and 146 . The loss of the industrial base has hurt the City of Worcester and to a certain degree has diminished its importance as a commercial center in the County.

Today, manufacturing continues to decline in the Main Street Study Area, while other sectors, particularly the service sector, are growing. This trend is reflected in the current employment statistics which show that $40 \%$ of total employment is in the service and finance sectors today while only $14.1 \%$ of the local employment is found in the manufacturing sector according to the 1990 U.S. Census data.

\subsection{The Main Street Study Area}

Because of the size of the Main Street Study Area, for the purposes of this report, it has been divided into three districts. Comments which apply to all three districts will be made first, then issues which only apply to a specific district will be made in the second half of the section. The three districts, the Interstate Commercial District, the Main Street Commercial District and the Neighborhood Business District were selected and delineated based upon the rate of change which the area appears to be experiencing at this time. The Interstate Commercial District has undergone the most dramatic changes while the Main Street Commercial District has undergone more balanced changes in its character while the Neighborhood Commercial District has maintained most of its original character but is still experiencing some changes. These districts were also selected because they have similar types and scales of activities.

\subsection{Description of Districts}

The Interstate Commercial District is on the eastern side of the Main Street Study Area and is bounded to the east by Interstate 290 and to the west by Worcester Center 
Boulevard. See Figure 2.4.1, the Interstate Commercial District is indicated with a blue dotted line. This district which was once primarily residential, was transformed into a center of manufacturing and industry during the Industrial Era. As manufacturing grew and became an important part of the Worcester economy, industrial uses and structures replaced existing housing units. More recently, as the manufacturing uses have declined, the industrial buildings have been replaced, although but much more slowly than the previous transformation of this district from residential to industrial. The city suffered great economic losses due to the decline of the manufacturing industry. Thus new uses have only recently been planned for this district.

The new uses are mostly commercial and service related, although some residential uses were placed in this district in the 1970's. Parking could become a major use in the district because each of the proposed developments has a substantial parking requirement which must be met. The major use which dominates in this district currently, though, is vacant land. The largest parcel of vacant land is located between Summer Street and Worcester Center Boulevard and was recently cleared to make room for Medical City, a new hospital complex which is currently being designed. Thus there is tremendous potential and hope that this district will be revitalized and rebuilt in the near future. It seems that this district is periodically transformed on a large scale. This burdens the city economically and physically unnecessarily. In the future, the city should strive to make this district into a place in which small scale transformations can be made to accommodate the ever changing needs of the population and society as a whole. This would provide more stability within the Main Street Study Area both economically and physically.

The second district, the Main Street Commercial District, begins at Worcester Center Boulevard and includes the area just east of Main Street. This district is shown in Figure 2.4.1 and is outlined with the red dotted line. The largest buildings are found in this district, both in terms of the massing and height. The high intensity of land use in this district immediately identifies it as the center of commercial activity for the City of Worcester. The uses found here are quite varied and include a small amount of high density residential uses, 
Figure 2.4.1 District Boundaries

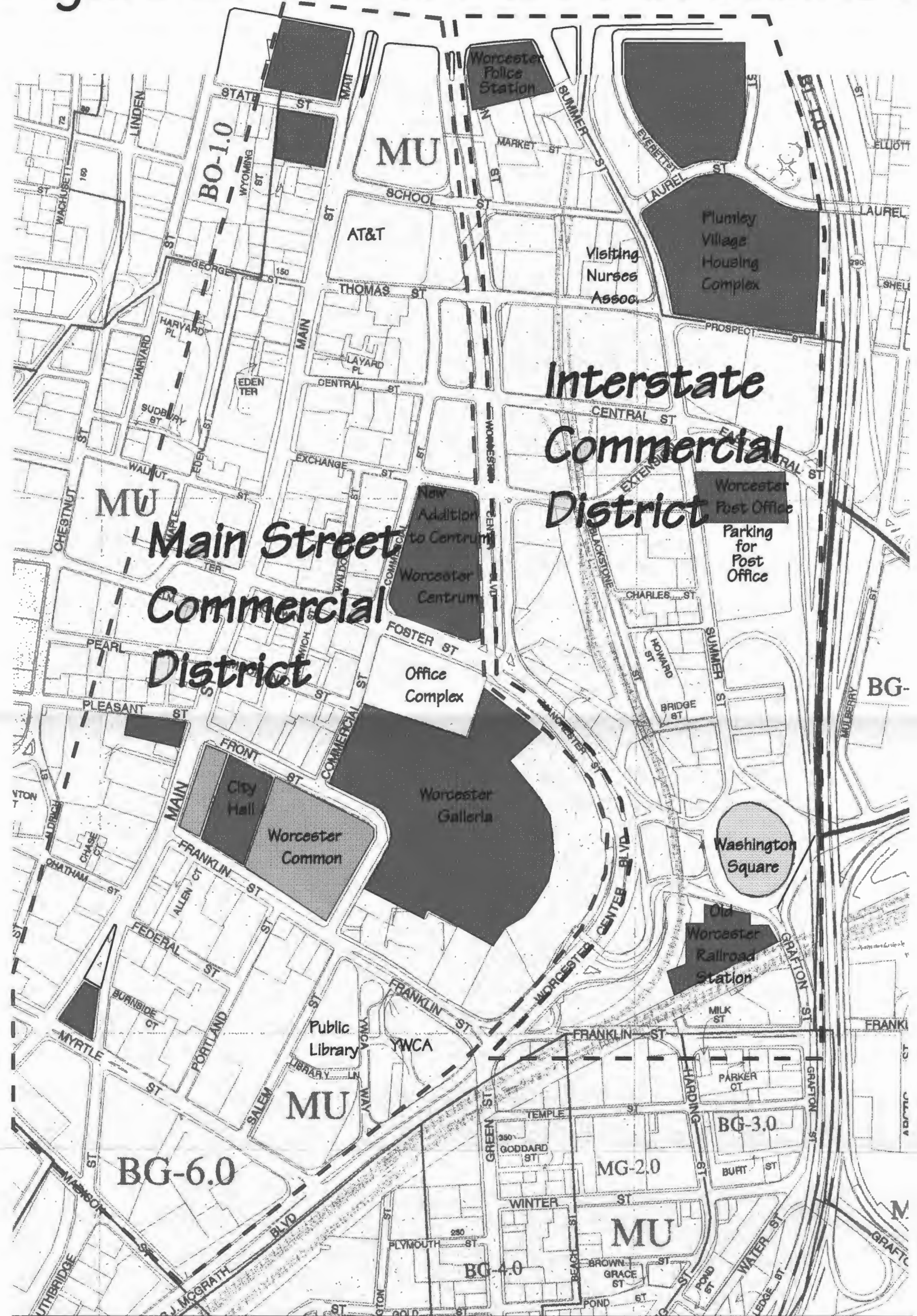

$=--$-- District Boundarys $\quad$-- Important Buildings

-- Important Space 
institutional uses, and civic uses. Commercial uses and parking dominate in this district. There are two problems immediately evident. First, given the central location of this district, it is likely that parking, particularly the amount currently found here, is not best use for the land. Second, there is an increasing number of vacant buildings and shops. Both of these issues will also need to be addressed.

The third district to be studied in this report is called the Residential Commercial District and is bounded by the yellow dotted line in Figure 2.4.2. Located on the Northwestern side of Main Street, this area, which was once entirely residential, now contains a variety of uses including institutional, commercial and civic activities. Nevertheless, it has a very different character than either the Main Street Commercial district or the Interstate Commercial District. Residential uses predominate in this district. And although a growing number of small commercial uses have located in this district, the residential character of this area has been maintained. This is due to the fact that these many non-residential uses have moved into the existing residential structures. For example, Becker Junior College, which is located in this district. has placed many of its departments in renovated houses rather than building new academic buildings and this has helped to preserve the character of the district.

Dividing the Main Street Study Area into three districts means that each district may be analyzed independently with specific recommendations made for a particular district in addition to the general analysis and recommendations which are to be made for the entire Study Area. A major factor which assisted in identifying and designating these districts, besides the many visual clues which serve to distinguish the three, are the specific zoning designations for which also serve also distinguish and divide the Main Street Study Area.

\subsection{Zoning in the Main Street Study Area}

Zoning is one of the most critical determinants of land development patterns in cities. Therefore, understanding the zoning classifications and regulations established by individual cities can assist researchers in analyzing land development patterns for urban areas. Recently, the question of zoning for the City of Worcester was in the forefront of the political 


\section{Figure 2.4.2 District Boundary}

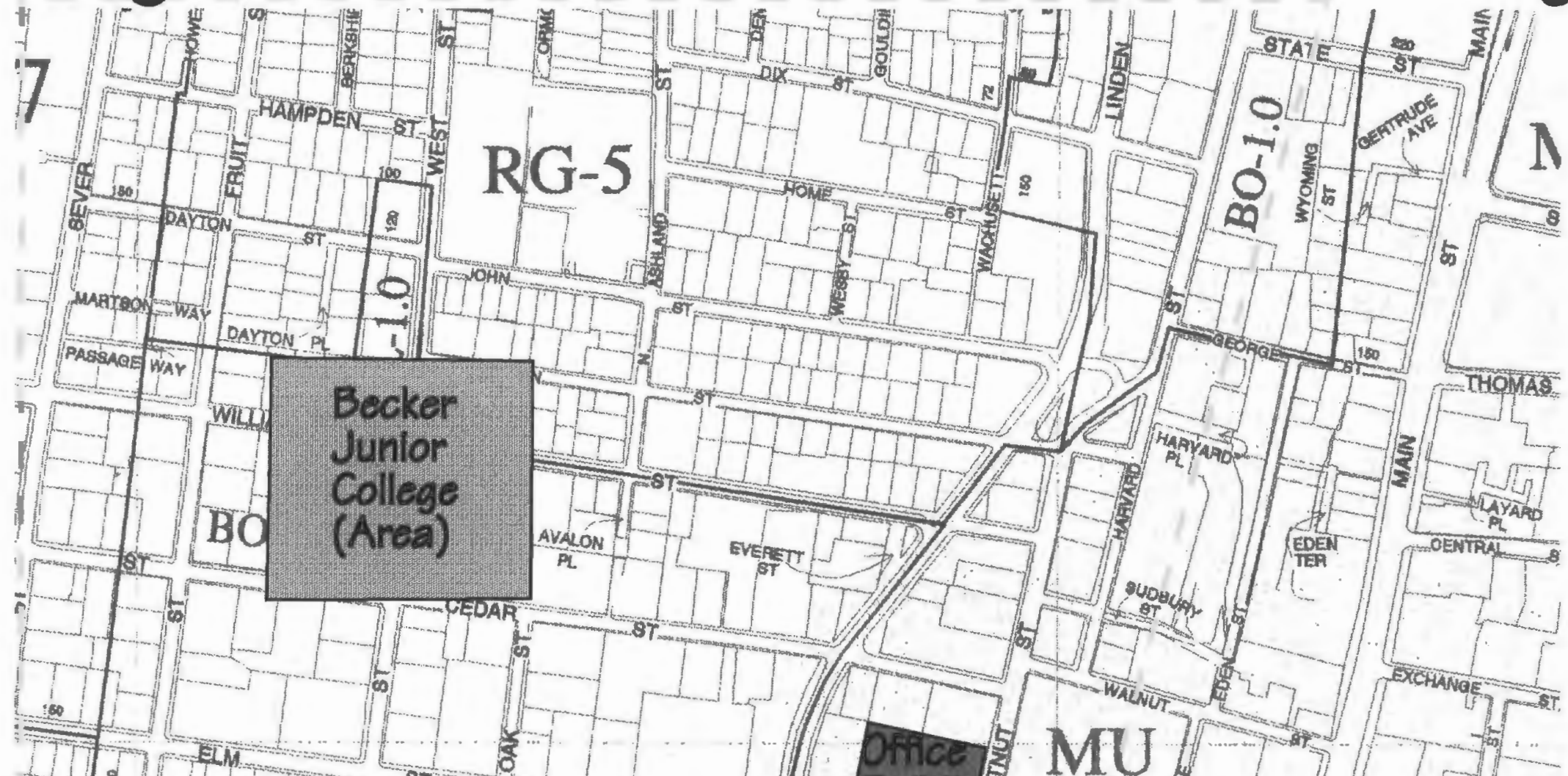

-5 Residential

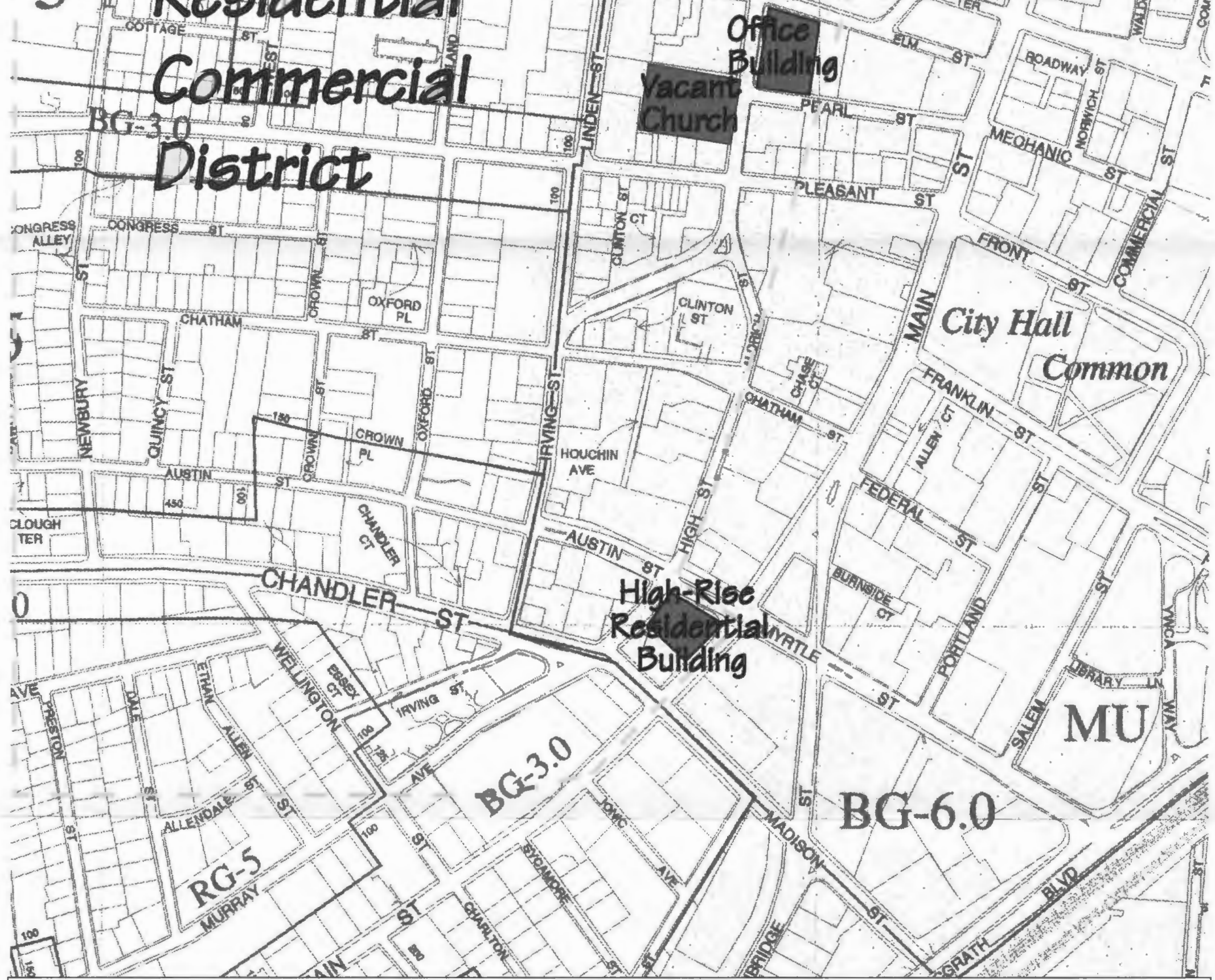

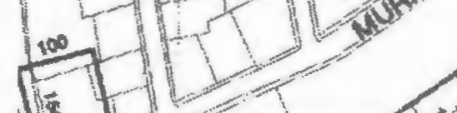

$x+$

-- District Boundary -- Important Buildings 
scene in the city because city officials were in the process of updating the zoning regulations (see Figure 2.5 for the present zoning designations) When compared to the district designations made in this report one can see that in part the district designations were determined because one can see that within each district the zoning classifications are fairly consistent.

\subsection{Zoning Classifications in the Individual Districts}

Zoning is one of the major determinants, if not the major determinant of land development patterns in the United States. Therefore, understanding the zoning classifications and regulations in each district greatly assists researchers in analyzing the existing patterns and conditions and in making proposals for the future. Zoning was at the forefront of the Worcester political scene two years ago, in 1994, when the zoning map for the city was in the process of being revised. The revisions to the zoning map according to the City Planner for the city of Worcester Alan Gordon were intended to encourage development. The most significant change in the zoning in the Main Street Study Area was the simplification of the zoning designations in order to encourage development. The administration, felt that the previous zoning code imposed too many restrictions which discouraged developers from initiating projects in the city. The zoning designations are as shown in Figure 2.5. The choice of the three districts used in this study was partially made because the zoning designations are fairly consistent within each of the districts and the zoning borders essentially coincide with the borders of the districts.

\subsubsection{Interstate Commercial District}

Due to the changes which have taken place here in the past decade, significant discrepancies between the old zoning regulations and the actual use of the buildings could be identified. The old zoning regulations identified three zoning classifications for this district, and they were MG-4.0, BG-3.0, BG-4.0, and ML-2.0 all of which allow for light industrial and business uses. But recent changes in the economy and the city have led to a significant decline in industrial uses within the central business district. Most manufacturing related businesses have moved outside of the downtown area, left the city entirely, or closed down. And instead 
Figure 2.5

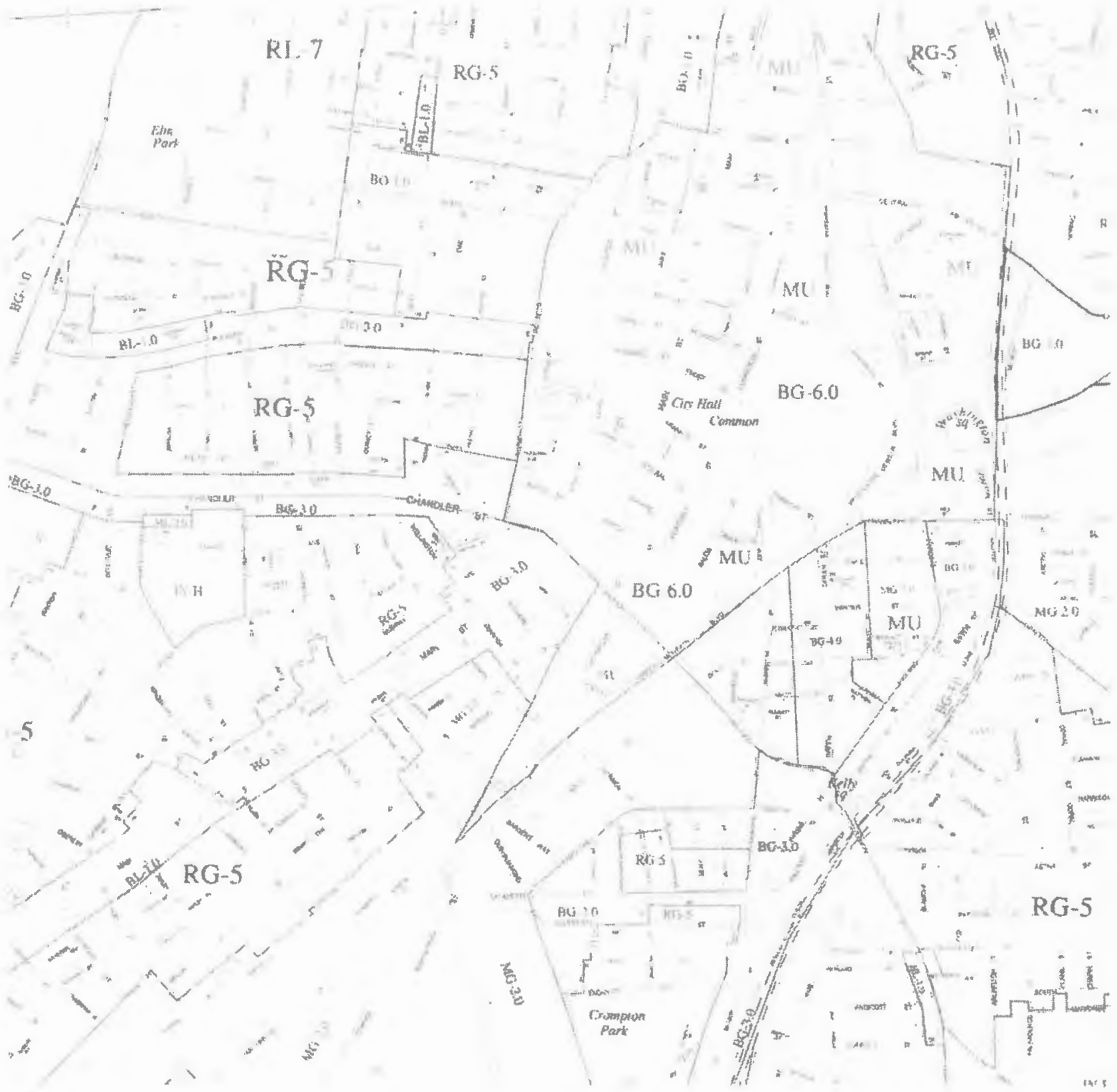

\section{Zoning Map \\ Main Street Study Area}


of being replaced by similar light industrial activity either the site remains dormant or a commercial activity has replaced the previous use.

The city government, acknowledging these changes, proposed new zoning legislation in 1994. The most significant change for this area being that the amount of land designated for light manufacturing uses was decreased significantly. In fact the only land which is still designated as light manufacturing, MG-2.0 and BG-3.0 and BG-4.0, is a small parcel which lies in the southern portion of the district between the railroad lines and Interstate 290. The remaining land is designated RG-5.0, which calls for residential uses and BG-6.0 which calls for small commercial activities. The 1996 zoning designation for the this district is most interesting. Except for a few remaining uses this area has been re-designated almost entirely mixed-use (MU) allowing for a wide variety of uses including commercial, residential, civic and public uses. There are few limitations within this designation in terms of the scale of potential projects seemingly in an effort to encourage development of this district. The Plumley Village Housing project retains the RG-5 zoning designation and two smaller areas retain their BG designation at 2 and 4 . This seemingly reflects the uncertainty about the potential for commercial development in this area.

\subsubsection{Main Street Commercial District}

The Main Street Commercial District is where currently the highest density of commercial and business-related activities are found. To encourage further development of this area into a commercial center for the city, the entire district has been designated MU similar to the Interstate Commercial District and in an effort to revitalize the downtown area. A small portion of this district retains the BG-6.0 zoning designation. This designation carries with a maximum floor-area-ratio (FAR) of six. Similar to the MU designation, the BG-6.0 designation allows for most commercial uses. But it restricts certain more specialized uses such as dormitories, mobile homes, hospitals, cemeteries and memorials parks. In addition, special permits must be obtained for uses such as fraternities, retirement homes, heliports and 'dedicated' storage facilities. The two specific areas which retained the BG-6.0 designation, are 
the Worcester Galleria complex and an interesting section on the edge of the district bounded by Chandler and Myrtle Streets on southwest and northeast sides of the parcel and bounded by McGrath Boulevard and Southbridge Street on the southeast and northwest sides of the parcel.

\subsubsection{Residential Commercial District}

This district is almost entirely classified RG-5.0 except for a small portion which carries the BG-6.0 designation. These zoning designations have prescribed height limits in addition to other restrictions some of which have been listed above. The BG-6.0 has a height limit of 200 feet or 10 stories and the RG-5.0 has a height limit of 90 feet or eight stories. A small portion of the district has the new MU designation. Almost entirely in the area between Linden and Chestnut Streets has the MU designation. So while there has been an effort to preserve the neighborhood character of the district, it has been recognized that there is the need for a transition area between the heavily commercialized Main Street Commercial District and the western portions of this district. The MU designation helps to create this transition area and accepts the commercial uses which have already crossed into this area and the RG-5.0 designation seeks to preserve the housing stock which has existed in this section of the Study Area for decades.

\subsection{Current Problems Affecting Land Use in the Main Street Study Area}

Land Use in the Main Street Study Area was greatly affected by the closing and relocating of industries, but it has also been influenced, negatively, by numerous other changes which have taken place here. The overall economic decline of the downtown has made the area less desirable for residents, merchants, and visitors. Given this climate, the Main Street Study Area, over the past few decades, has lost residents and other businesses in addition to the industrial ones. And it is the loss of business as a whole which has contributed to the cities declining tax base and the numerous economic problems associated with this decline. For example, during the 1980's, the State Mutual Life Insurance Agency once located in downtown Worcester relocated to a new building directly off Interstate 290 . This provided them with a larger facility in a cheaper location. And over the past five years, other large and important 
businesses have considered making similar moves. In 1993, the Worcester Telegram considered moving of the downtown area, also in search of a larger facility and cheaper land prices or rental space. Fortunately, company executives decided to keep the majority of the Telegram functions in the downtown area in the current location across from City Hall. In addition, the Worcester Post Office decided to build a major new facility in Shrewsbury rather than closer to the downtown area. Smaller businesses such as the Federal Savings Bank, leaving an unsightly building for the City to contend with, and the Main Street CVS have also closed. As a whole, businesses which ordinarily function better if located in a downtown area such as the Main Street Study Area are closing or opting to locate to the suburban areas which are currently experiencing unprecedented growth. Finally, there are many new development projects proposed and underway which like the existing businesses have the potential to cause whole new sets of problems for the city.

Over the years, there have been numerous proposals made to revitalize and stimulate the economy in the city of Worcester and the Main Street Study Area specifically. The physical manifestation of these plans began to be realized in 1995 and 1996 in the form of new construction in the Main Street Study Area. While new buildings and uses in the Main Street Study Area could potentially provide an economic boost for the city as a whole, there are also numerous risks associated with development and these risks need to be considered during the planning and implementations stages of the projects.

The first such project is the new Worcester Convention Center, see Figure 2.6.1, 2.6.2 and 2.6.3. This project, construction for which is almost complete, it is thought will attract new businesses and visitors to the area and boost the economy of the city. Connecting it to the Worcester Centrum, the city hopes to draw from the success of the Centrum, and create flexible space which can be used by either venue. Yet while there is a potential need for a facility such as this in Worcester, there are numerous issues associated with it which could hinder the success of the facility. The first issue is whether another large convention center was needed. A report commissioned by the state of Massachusetts and 
Figure 2.6.1

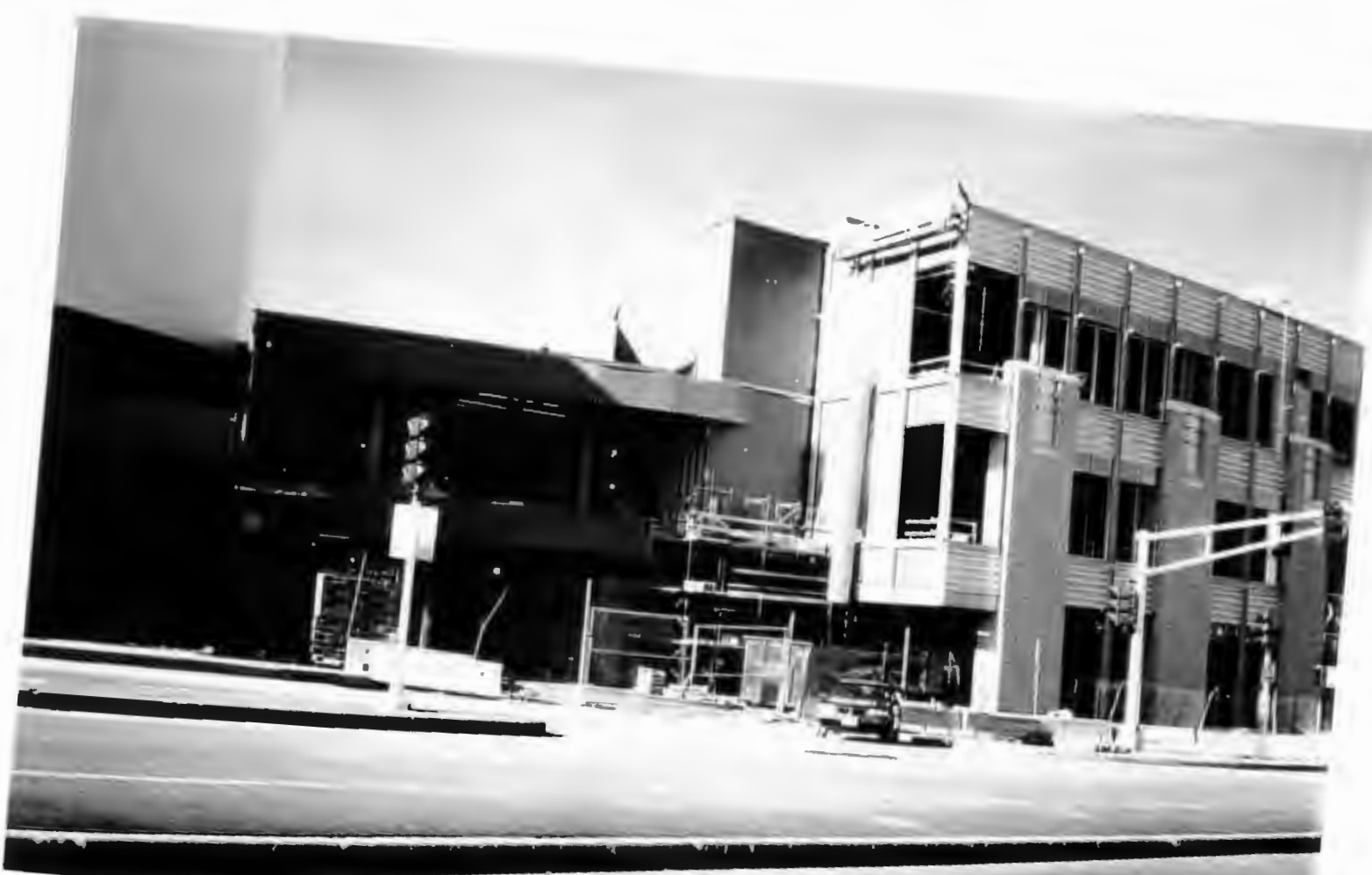

Worcester Convention Center
During Construction 


\title{
Figure 2.6.2
}

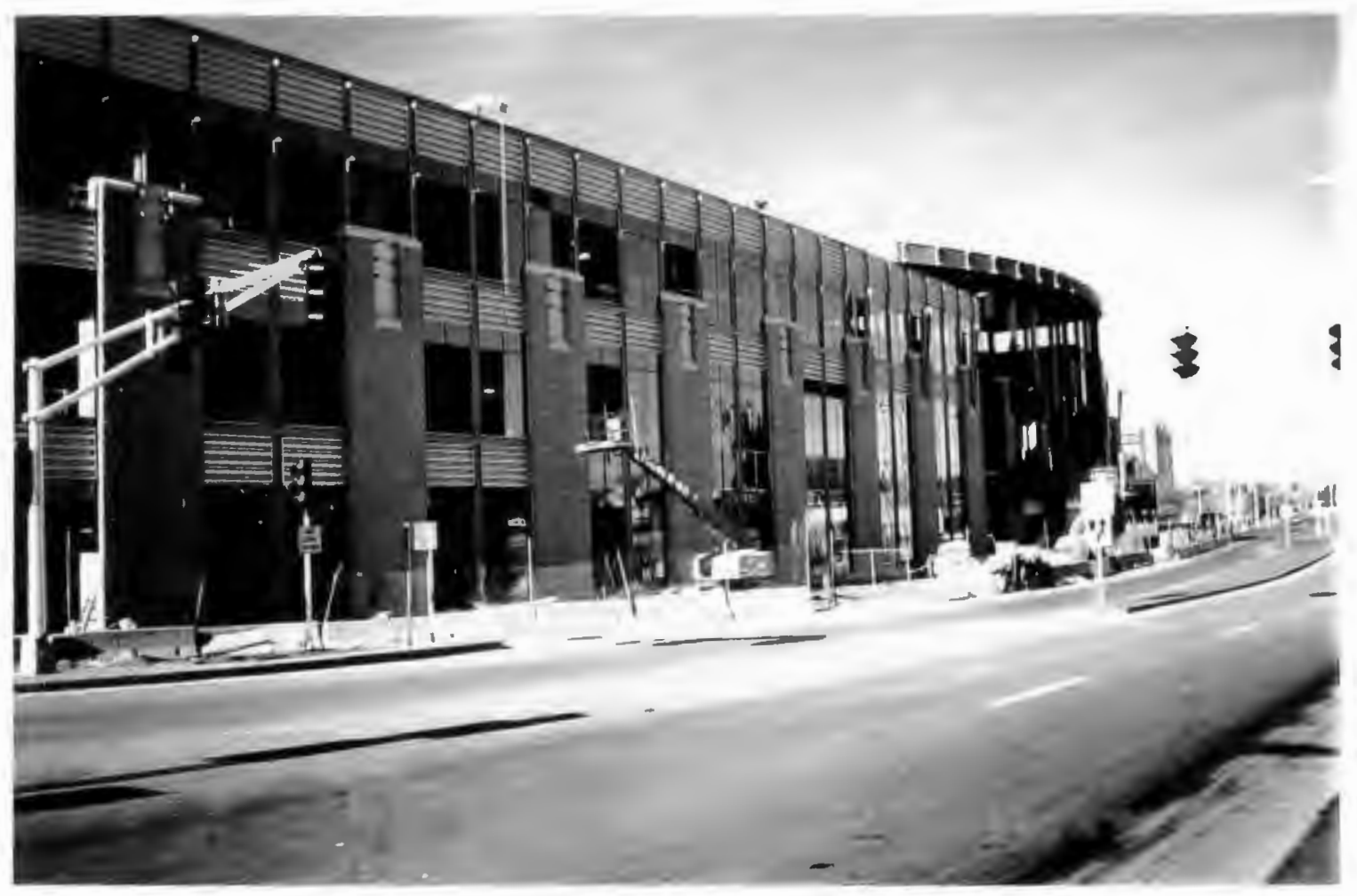

\author{
Worcester Convention Center \\ During Construction
}




\section{Figure 2.6.3}

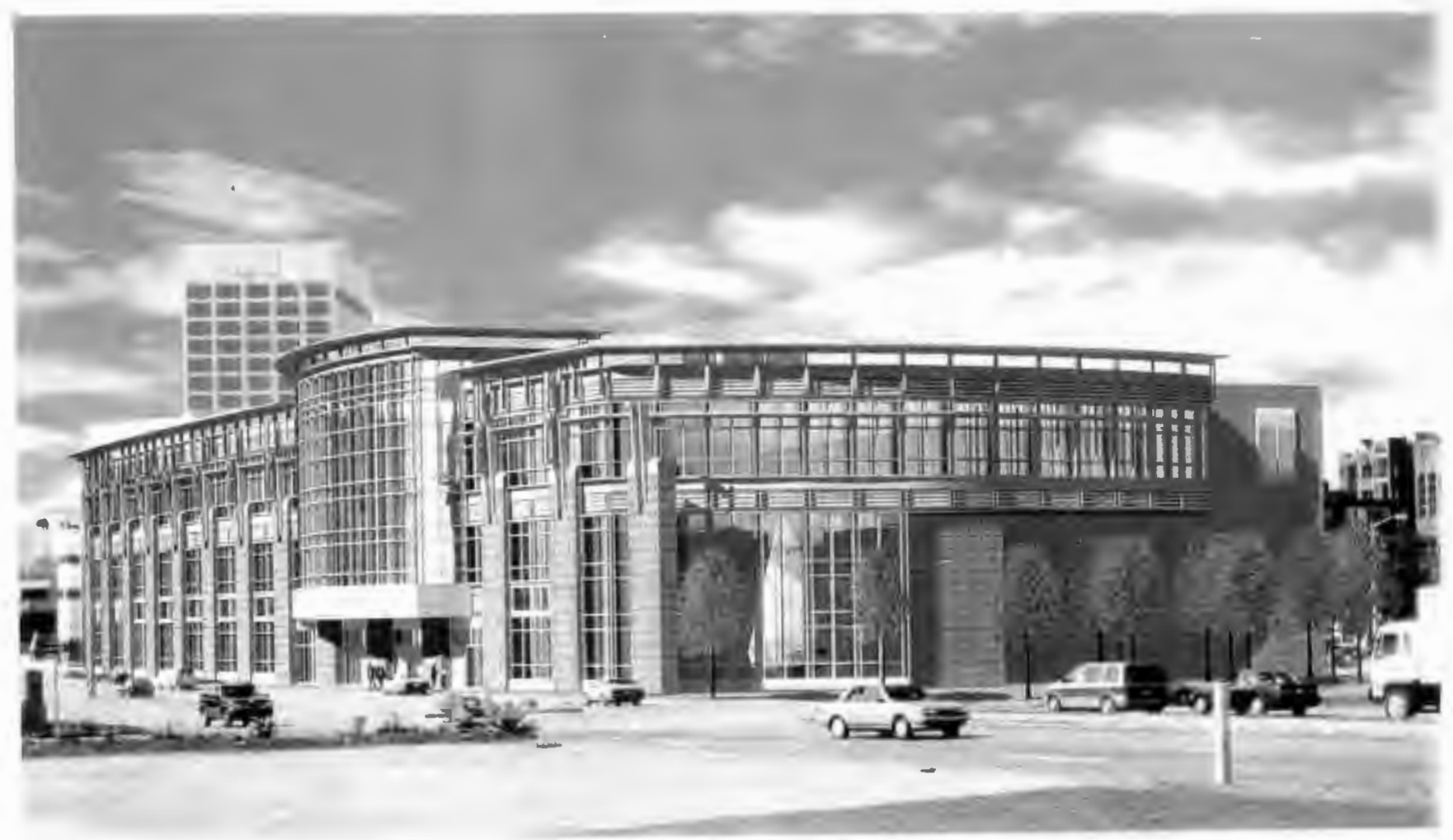

Worcester Convention Center

Computer Generated Image of the Final Building 
executed by a leading consulting firm in the late 1980's suggested that Worcester was a viable location for a convention center. But more than five years later, the business climate across the country has changed drastically. There has been a recession and businesses have been downsizing to become more efficient. While business analysts and large, expensive conventions are a thing of the past. Perhaps smaller conventions can be drawn? How will the convention spaces be used to adapt to the changing business trends? The second important issue which the city must contend with is that of competition. Both Boston, Massachusetts and Providence, Rhode Island have new convention centers and Worcester is located approximately 45 minutes from each of these cities. Boston is a thriving and popular city. It has numerous activities and areas which make it a desirable destination and has a constant influx of students to its many colleges and Universities, many of whom stay after graduation, which help to continuously rejuvenate the city. While Worcester has the potential to benefit tremendously from the continuing success of the city of Boston, it is doubtful whether it can of should compete with Boston. Providence, though a struggling city like Worcester, placed its convention center directly adjacent to one of the major highways in the Northeast, Interstate 95 . The ease of access to this facility could recommend it over Worcester.

The second major development project currently underway is the restoration and renovation of Union Station into the inter-modal transportation center. Funded with Federal, state and local money, this project is now in design development with construction expected to begin in early 1997. Saving this building and converting it into a transportation center were both important decisions which could in the future serve to considerably boost the economy in the main Street Study Area and in the city as a whole. More problematic issues associated with this project relate to the some of the design of exterior spaces and the programming of the interior spaces, decisions which are currently being made. In addition to providing space for the transportation uses, needed office and commercial space, and required service spaces, the design for Union Station proposes that remaining rooms be used as conference space. The reasoning being that smaller scale conference space is needed in the city in addition to the 
space that will be provided in the new convention center. This raises three questions. First, why wasn't smaller scale conference space integrated into the new convention center if this need existed? Second, how can these two centers mutually support one another rather than compete with each other? Third, is the additional conference/convention space really needed in the city? and fourth, is Worcester currently a strong enough draw to support these uses at the scales provided?

The third major construction project also underway is the new Medical Cities project, also called the Fallon/Saint Vincent Hospital project. A picture of the design proposals, from for this facility is shown in Figure 2.7. This project has received environmental approval. a site for the project has been cleared and cleaned of structures and toxic waste, and architects are currently in the schematic design/ design development phase of their work. This project could also help stimulate the local economy.

If this facility is completed it could be a tremendous asset to the Main Street Study Area and to the city of Worcester as a whole. A hospital, which is a 24 hour facility, would provide activity in the downtown area and due to the multiple needs of the many users and employees in such a facility should encourage and attract additional services and uses which are needed to support a hospital such as restaurants and pharmacies. And existing services such as the hotels would be better utilized. And beyond the positive economic ramifications, this hospital would also provide a tremendous service to the people in and around the area. Expanding the services offered by the existing St. Vincent's hospital and providing a more centralized location which is more easily accessible to more people. But like the two other developments, this facility will also provide numerous challenges. Significant issues at both the administrative level and at the design level need to be addressed.

Ownership of the hospital project has changed hands twice in the past year alone. First, the Fallon Medical Center organization, the original owners and developers of the project, was purchased by another major medical concern, called OrNda ${ }^{6}$. Most recently,

6 OrNda is an Indian name not an acronym. 


\section{Figure 2.7}

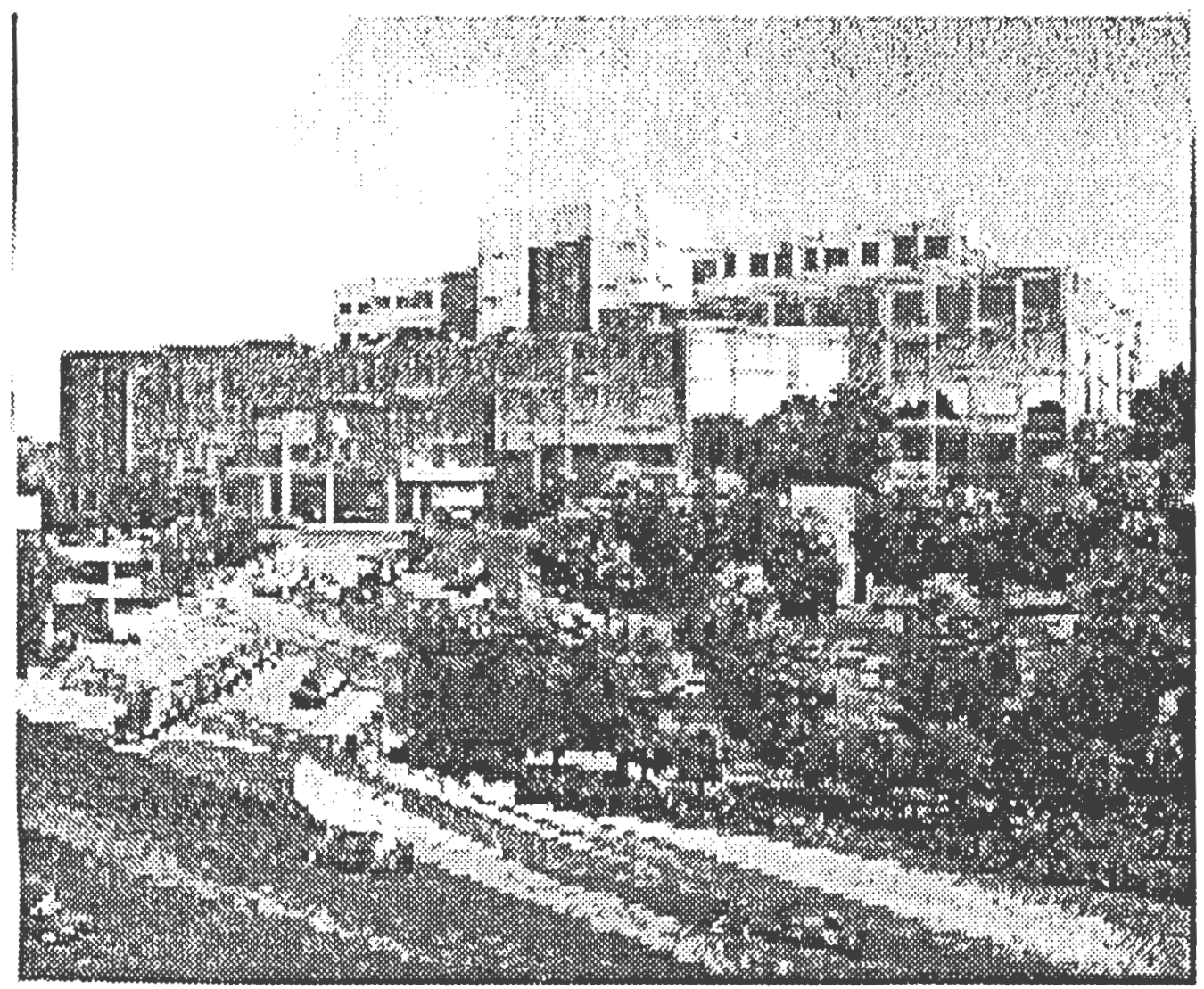

\section{Medical City Computer Image of Proposed Hospital}


OrNda was purchased by another medical services company called the Tenet Corporation. This instability at the administrative level has likely had an impact on the forward progress of this development and could potentially affect the execution, purpose and service of the facility over the long term. Thus the changes at the corporate level need to be closely monitored. A second area of concern is in the design itself. Current design proposals show a facility which is to be almost completely 'inward facing' and self-sufficient, with all or most of the needed support services designed into the facility itself. This could considerable decrease the economic benefits which the city could and should expect from a project such as this and of this scale. The city and its residents should expect more from this development, including generating nighttime activities, encouraging residential development in the downtown and the creation of additional uses and support services in and around the area.

The contribution of the new Worcester Galleria is an area which also needs to be studied. Like other downtown commercial areas throughout the United States, this center faces difficult and significant competition from its suburban counterparts. Shopping malls such as the Auburn and Greendale Malls in Worcester County are able to provide adequate parking, a variety of goods and services, a safe shopping environment, and protection from the natural elements. These same amenities, which should be provided in the Main Street Study Area as well, though perhaps in a slightly different way, are currently not provided and the amenities which do exist do not provide enough of an incentive to compete with the newer shopping malls outside of the city. Planners have long thought in fact that inner city malls can not be successful. The city of Boston recently dispelled this myth when it chose to build two such malls, one in downtown Boston and the other in Cambridge. Thus there was precedent for saving the mall in Worcester despite the many potential obstacles. And in fact, the City of Worcester has benefited from the renovation of Worcester Galleria.

Once almost empty and facing an uncertain future, the mall has now been converted to an attractive outlet mall. Rather than trying to compete directly with the existing suburban malls, the Galleria now provides only outlet shops which are not currently available in the area 
or at the suburban malls and thus has avoided directly competing with the suburban malls offering a different product to consumers. These stores are supposed to offer similar products to those found in regular department and retail stores but a significantly cheaper prices. The attractiveness of this concept is such that one now sees these outlet shopping facilities being built throughout the Northeast. Not only was Worcester successful in attracting a potentially lucrative type of shopping experience to the downtown area but the developers simultaneously avoided having to compete with the suburban shopping malls by offering a different product to the consumers. The major problems associated with the outlet mall since it opened are the prices. Small businesses can not afford to locate and stay in the outlet mall because the rent is too high. Also the stores in the mall are mostly upper end stores which offer more expensive products. In an unscientific survey, the prices in this mall tend to be higher than in outlet center in wealthier communities in the state of Connecticut, which has recently built a number of outlet shopping centers. A better mix of low, moderate and high end stores would better serve the residents in the city of Worcester many of whom make $\$ 25,000$ per year. The mall appears to cater to visitors and tourists who can afford the prices and only cursorily address residents of the city. This could be very problematic. Because the day to day business which most malls receive is from the local residents. Few shopping centers can survive over the long term by depending on visitors and tourists for their day to day business. The Worcester Galleria it seems also can not be successful over the long term if it continues to cater to visitors.

The last major change which has taken place in the downtown area is that the number of people who once lived in the Main Street Study Area has declined significantly. There are many reasons for this. Over the years, there has been a consistent decline in the amount and quality of housing in the Main Street Study Area and in the downtown as a whole. In addition, suburban areas appear to provide safer and cleaner environments as well as easy access to many services and amenities. In fact, there was such a dramatic increase in the amount of residential construction taking place in the suburban areas around the city that a one year moratorium was placed on all special permits and variances, in all residential areas from 1986 
to 1987 . These factors encouraged many residents to seek new housing outside of the city. This exodus has eroded the tax base and thus has caused a decrease in the funds available for maintenance and one result of this is that the downtown has become more unsafe and a less desirable destination. As a result, the land uses outside of the city replace those found in the Main Street Study Area (or compete with the uses here) rather than supporting them.

\subsection{Summary}

The land uses in the Study Area are varied but not stable. While there is some new construction which could help to revitalize the Study Area, both by creating new activities and encouraging other new developments, businesses, particularly smaller ones, continue to leave the Study Area. Housing is a very significant problem in the Study Area. Both the quantity and the quality of that which exists needs to be studied and recommendations made regarding how to maintain, improve and increase the housing stock in the Main Street Study Area. currently space does not seem to be used as judiciously as one might like. There seem to be far too many surface parking lots given the current density and commercial mix found there now. While many of these parking lots are filled during weekday business hours, these same lots are empty at other times. The highest and best use for the Main Street Study Area properties should be determined and plans made to achieve these this goal. The city should strive to maintain a strong mix of commercial uses. Small businesses need to supported, both administratively and financially, by the city in order to create and sustain such a mix. Commercial uses seemingly not addressing the needs of the residents first and instead are focusing on visitors and tourists. It seems that in order to ensure longevity that the needs of the residents should be of primary concern since they have the greatest potential of becoming regular customers. Finally, there does not seem to be clear understanding of the potential problems associated with the many new development projects. City officials need to determine what their expectations regarding these projects are and verbalize this to the developers. Potential impacts and risks also need to be discussed on a continuing basis so that they can be avoided. 


\section{CHAPTER THREE BUILDING FORMS AND FACADES}

"...every building needs to be subordinate to the overall blueprint - that is the scale and the architectural vocabulary must harmonize with the existing public space."

(p. 73, Trancik)

\subsection{Introduction}

The buildings in the City of Worcester are an interesting combination of the past and present. The three districts specifically analyzed in this study simultaneously offer three different perspectives of the city itself. The Interstate Commercial District once an industrial relic is now a blank canvas which could be developed in any number of ways. This district thus has the potential to become a symbol of the future of construction and activity in Worcester. It offers the largest amount of undeveloped land in the downtown area and thus offers many opportunities for development and new building construction. Examples of new construction in this district include the Fallon/St. Vincent's Hospital, also called the Medical City, and the Worcester Convention Center which is shown in Figures 2.6.1 and 2.6.2. Construction of the convention center is almost complete while the construction for the new hospital is not yet underway.

The Main Street Commercial District has a higher density than the other two districts thus there are more challenges in terms of addressing and reconciling issues of building form and appearance due the fact that there are simply more buildings in the district and hence more building types. Similarly, there are fewer opportunities for new development or construction projects in the Main Street Commercial District but there are numerous opportunities to renovate or redevelop existing buildings in this district, many of which currently are vacant. Given the existing density and spatial patterns already established in this district, when property is renovated or redeveloped in this district, careful study and documentation should be done prior to the initiation of the 
project and designs should fully take into account not only how the building will be improved and changed but also how the changes will impact and/or transform the appearance of the block and the city as a whole. The Residential Commercial District offers much of Worcester's old charm. But while it is still mostly residential, it also contains a growing number of commercial uses which are primarily distributed on the eastern side of the district next to the Main Street Commercial District. Decisions need to be made concerning how many more commercial uses will be added to the area. How the residential uses will continue to coexist with the commercial uses and how to improve the overall character of this district. One of the most pressing needs in this district is to preserve some of the existing structures in this district. There are many structures while not historic, they are structures which have historic value. The City needs to develop substantive strategies to preserve these buildings and uses. In addition, the local administration should consider developing a program which would encourage individual owners to maintain and when necessary rehabilitate their own buildings. Such a program should provide basic courses which emphasize and illustrate how to calculate and determine the value of property using a variety of indicators and variables, courses which provide instruction about simple improvements which can be done either by the owner or when it is best to hire a professional, and courses which discuss financing options, such as available loan programs.

This chapter describes the scale and the architectural vocabulary of the buildings in the Main Street Study Area. Having provided a two dimensional image of the city using the text and maps, this chapter will look at the Main Street Study Area as a three dimensional entity in order to provide a complete picture of how urban space in the area is defined. The term building form is used here to describe the physical presence which structures have on the street, the basic outline of a structure, its length, width, height, lot coverage, massing and setback amounts. These building characteristics will be described in this chapter along with details which distinguish the buildings from one 
another including fenestration types, architectural detailing and building materials. These factors determine what the buildings in a city look and thus impact the appearance of the city block and image of the city as a whole. While most buildings have four or more facades, the focus of this section of the report will be the front facade or on those facades facing primary streets, which will be referred to as the primary facade. Specific details of the other facades will be mentioned as necessary.

The facades of buildings, the exterior walls, determine what it looks like. The overall appearance of a building is determined by its size and the placement of window and door openings, the materials used, and the architectural detailing utilized in the design. The recommendations made in this study will provide general guidelines which can be used toward improving all exterior faces of the buildings in the Main Street but specific suggestions will primarily focus on the front facades of the buildings which directly influence the overall appearance of the street. This could be used to generate a set of guidelines for future building and renovation in the city.

Using the information collected during the windshield survey, this analysis of building forms and facades was developed. The study looks at the city from three vantage points in this chapter. First, Main Street Study Area as a whole, next it looks at individual city blocks and finally individual buildings are identified. Having identified those buildings and individual elements of the buildings which contribute and detract from the appearance of the study area, appropriate guidelines can be developed for enhancing the positive aspects and improving the negative ones.

\subsection{Historic Worcester}

Historic maps of the City of Worcester, when it had many fewer buildings, show that the relationship between solids and voids, buildings and open space, was much simpler in the past. Lots were similarly sized and there were fewer variations in the overall size of the structure primarily due to the limitations in building technology. In addition, there was more open space to work with at that time, thus many more 
choices for building locations. Buildings were comfortably scattered throughout the area creating moderate density. In addition streets were wider and were not cluttered with cars and buses which helped to enhance the appearance of the buildings and allowed people to view entire buildings more easily and therefore appreciate the elegance and detailing of the design.

Maps from the late 18th and 19th centuries, see Figures 3.1.1 and 3.1.2, show that the buildings were clustered together early on, creating the first, urban downtown in the City of Worcester. During this period, buildings were, in general, set back at equal distances from the street, they had similar heights, generally ranging from three to five stories, and were rectangular in shape. But nonetheless there were still many open spaces within the blocks to allow air and light into the interior spaces of the buildings. Signage and windows were similarly dimensioned or at least proportioned and dimensioned for buildings in the same block also often placed in similar locations on the facades of the buildings. Finally, building materials were fairly standard, primarily constructed out of brick, brownstone and/or wood. Despite the consistency in many of the elements of the buildings historic pictures show that they actually varied a great deal in their appearance. This variety was created by the varying levels of architectural detailing which was integrated into the individual designs of buildings and further accomplished by personal details, such as plants and lighting fixtures, added by individual owners. But these areas of similarity helped to make the city appear unified and structured. They created visual coherence in the city at three important levels, the individual building, the city block and the city as a whole. See Figure 3.2.1 The appearance of the Main Street Study Area will be evaluated in the following sections of this chapter using these three levels as guides.

\subsection{Worcester Today}

Today, there is less consistency in the overall composition of the city. New technology and innovation in the building industry have increased the types of materials 
Figure 3.1.1

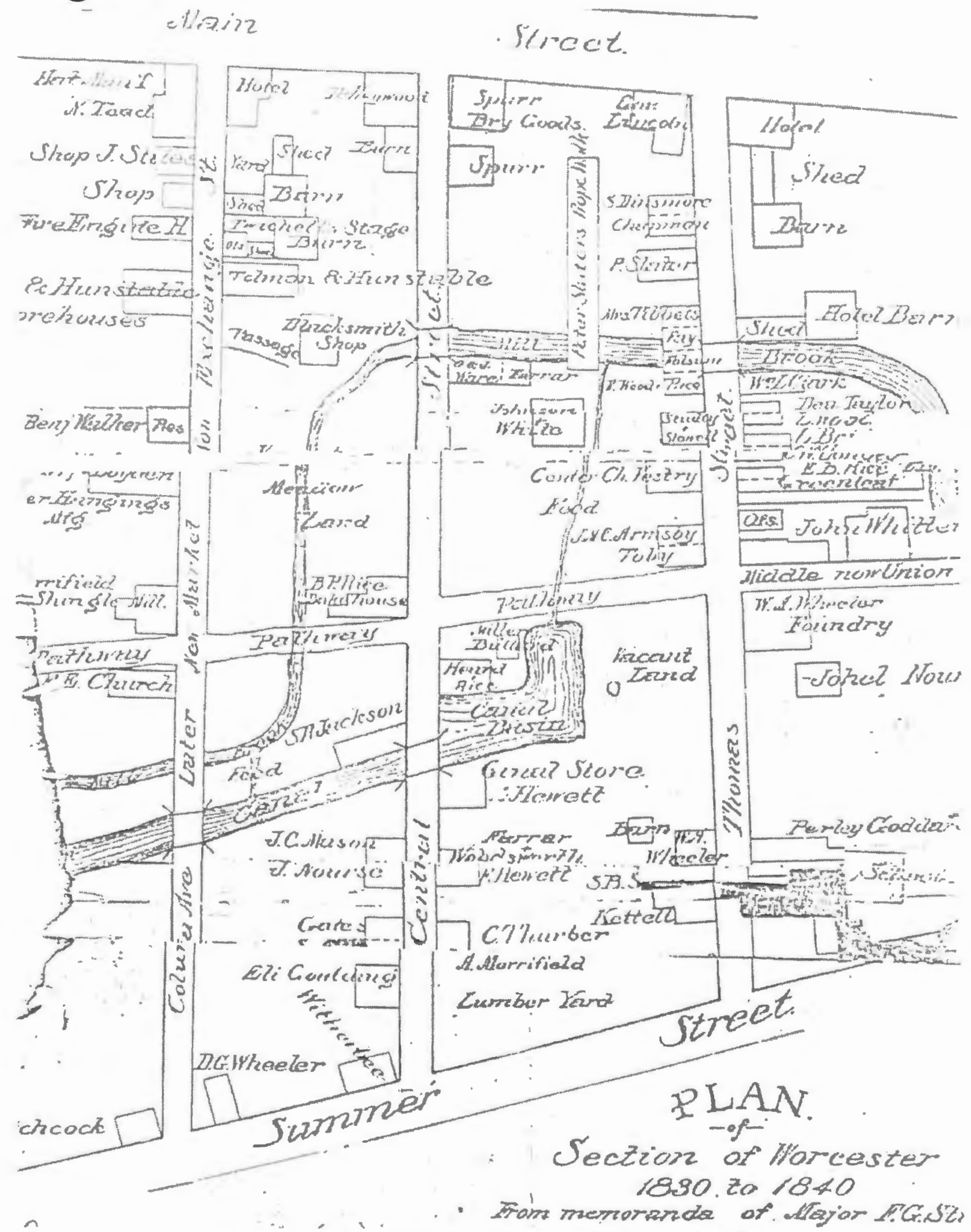

\section{Map of Worcester, 1830-1840}

Specifically Shows How the Canal Came Directly Into City 


\section{Figure 3.1.2}

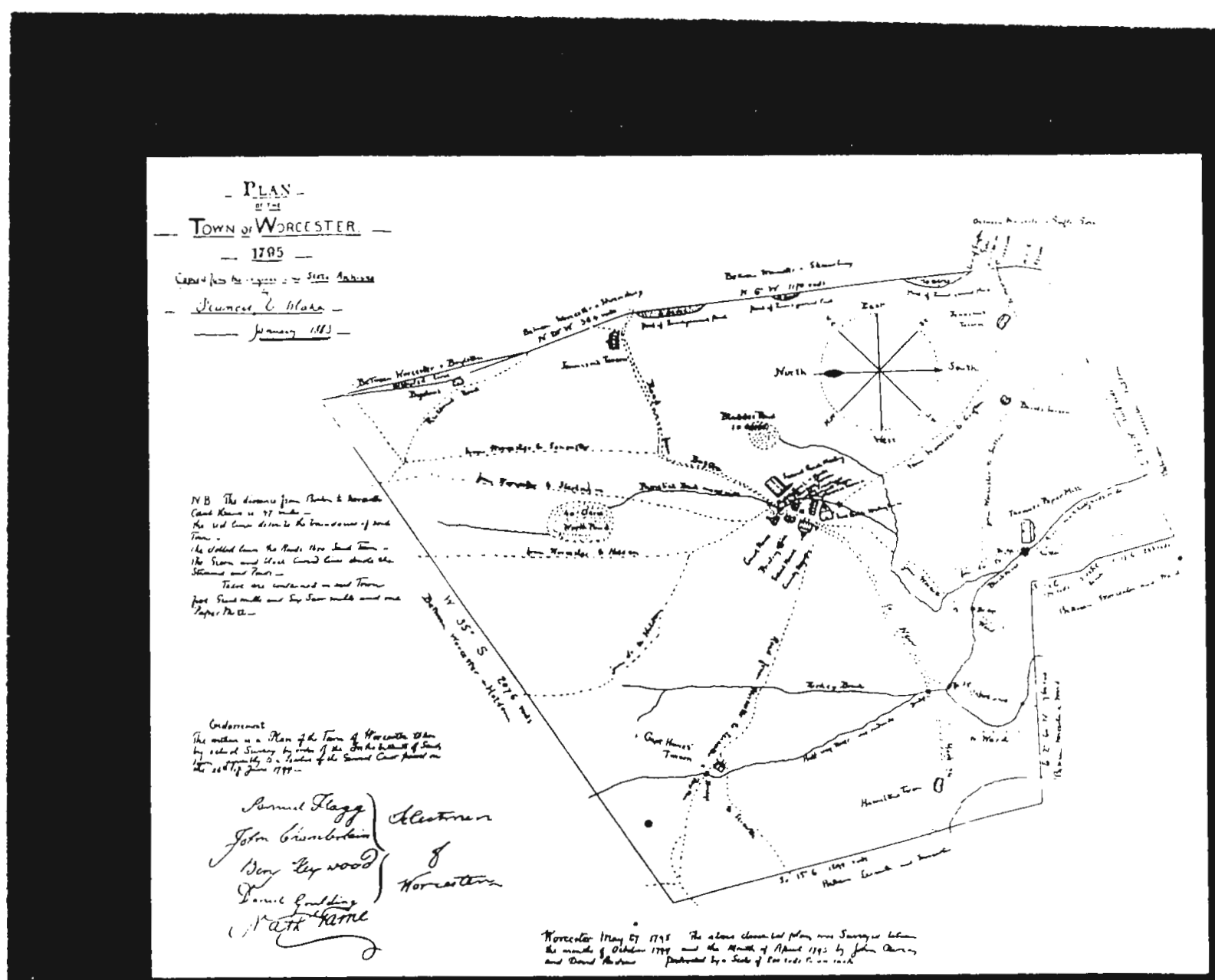

\section{Map of Historic Worcester, 1795 \\ Town Center}


Figure 3.2.1

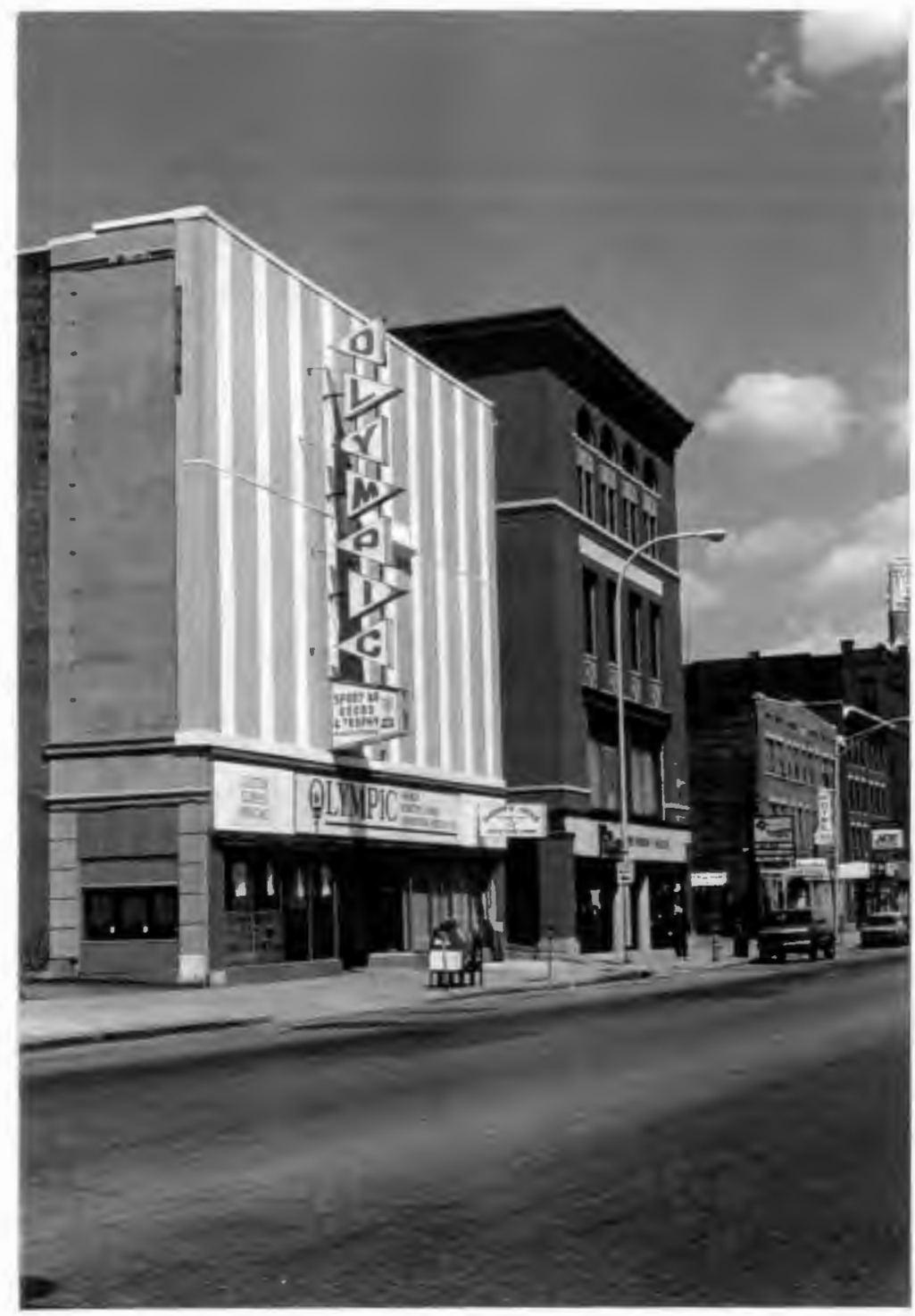

\author{
View of Worcester \\ Main Street Study Area
}


available to builders and changed construction techniques. Thus buildings can and do vary greatly in height, mass and other physical features. The Main Street Study Area provides a clear representation of the variety of building types which have and currently do exist in the City of Worcester as a whole. The Study Area provides a wide range of building types including old civic buildings and new office towers. See Figure 3.2.2 There are also residential structures and civic buildings and spaces which reflect both historic Worcester and the Worcester of today. Many of the newer buildings stand in direct contrast to the older buildings in the city both in terms of overall appearance and massing. This contrast can be positive but many times it is negative, detracting from the overall appearance of the City as a whole. The purpose of this chapter is to identify the visual affects of the buildings from three vantage points, the city as a whole, the city block and individual building footprints.

The Main Street Study Area, as a whole, has a high level of visual coherence to it. Any inconsistencies which exist between individual buildings are minimized by the overall image of the city as a cohesive whole. The hilly terrain provides the careful observer with many views of the city and views to surrounding areas when in the city. From the west one looks down onto the city from the east one can either view the city from above on the interstate or at ground level. From the north and south the views are tempered by building facades down the long streets which have this orientation.

Closer inspection of the buildings in the city show that there is a fair amount of variation in building height in the study area which creates a rather dramatic skyline from a distance, see Figure 3.3, and identifies this area as the downtown. But because there are actually very few tall buildings in the downtown area they do not adversely affect the micro-climate at the street level by generating high winds or blocking sunlight there. The fact that most of the buildings in the Main Street Study Area range in height between one and seven stories, also contributes to this urban environment. The continuity of building heights established in the Main Street Study Area creates 
Figure 3.2.2

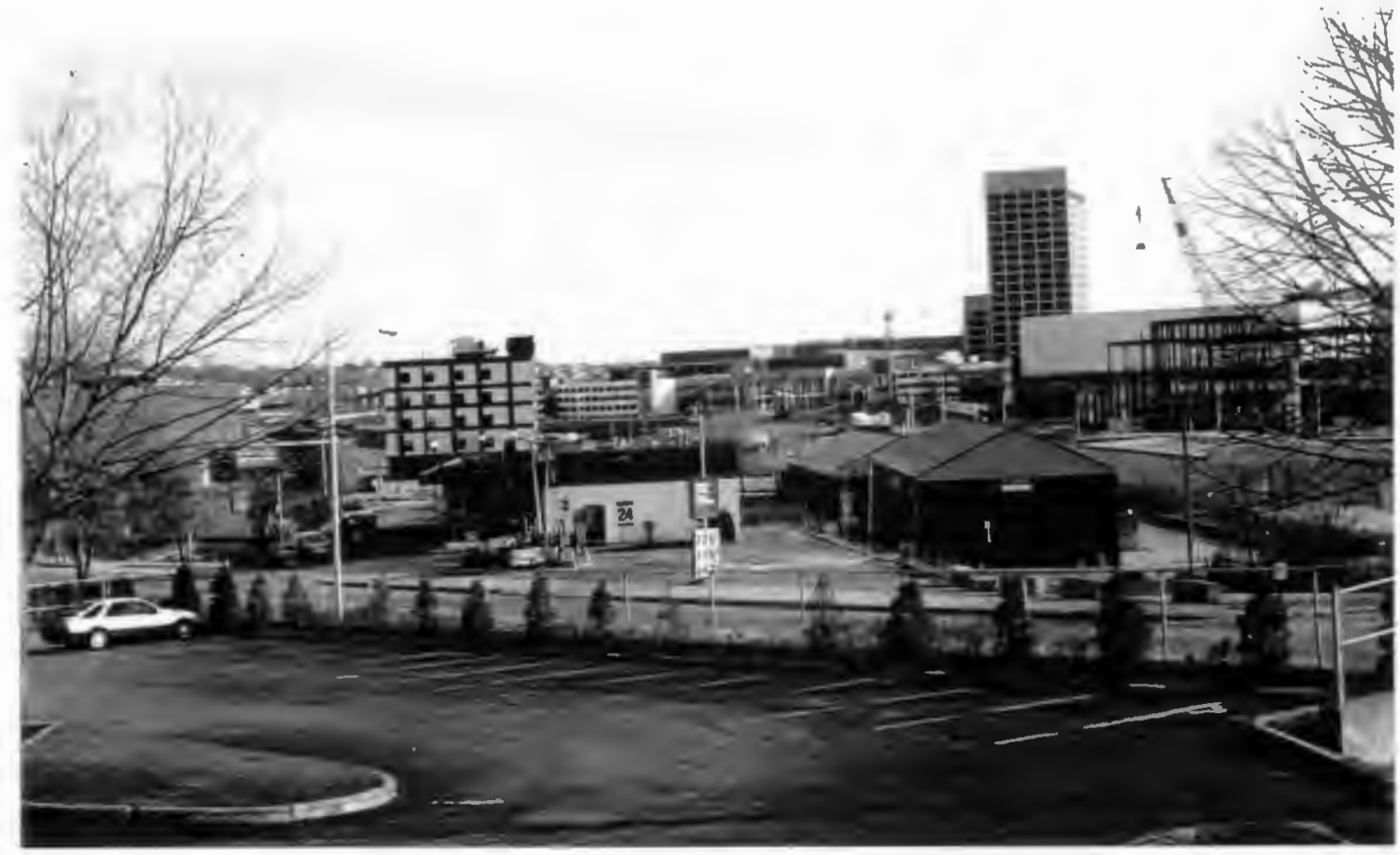

View of Worcester

Main Street Study Area 


\section{Figure 3.3}

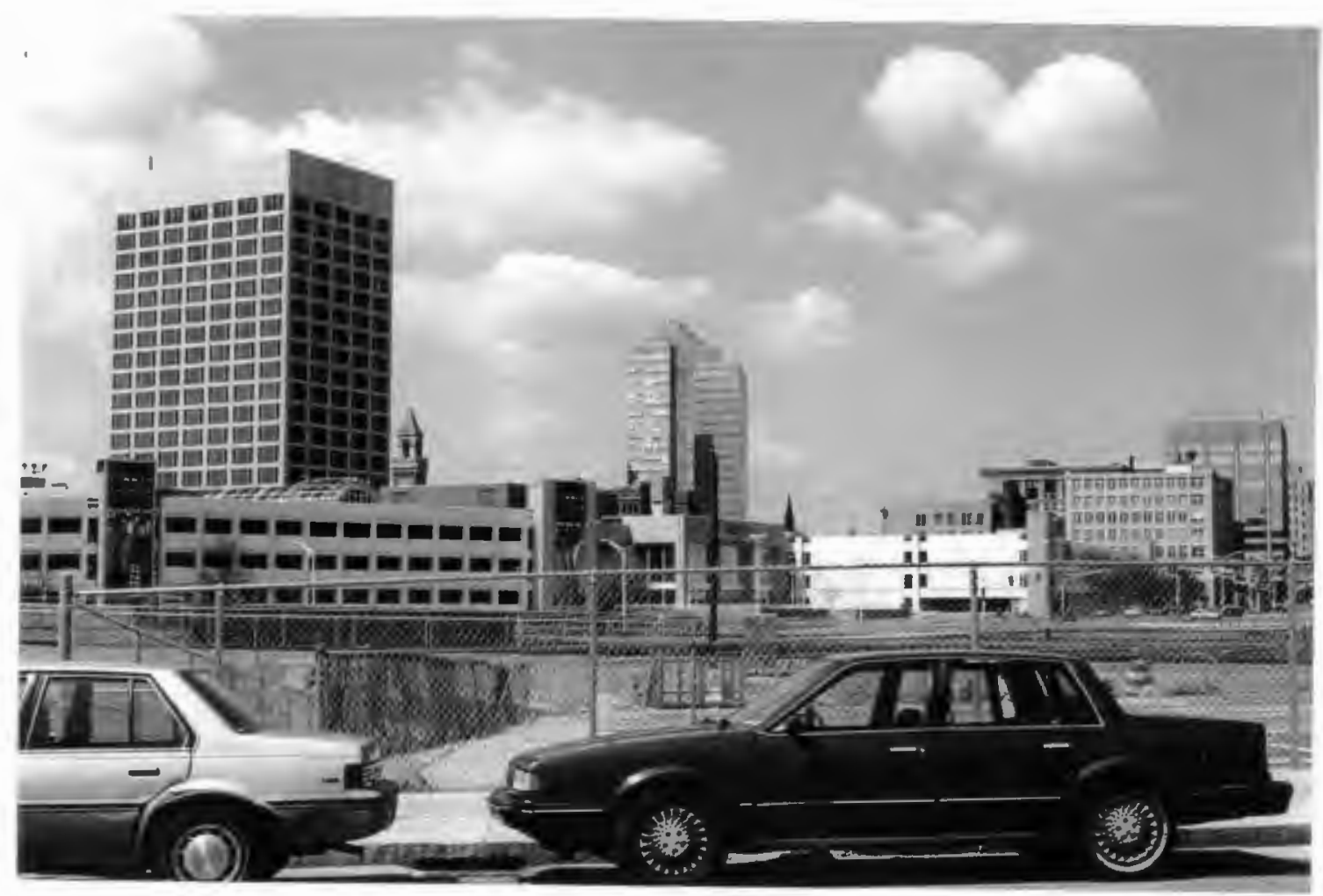

\section{Partial View of Worcester Skyline Taken from Interstate Commercial District}


coherence and allows for easy, visual transitions to the other blocks and areas in the city. In addition, except in a couple of cases, there is enough variety in terms of building heights to prevent a specific building from dominating a particular block or area in the Main Street Study Area. The two high-rise buildings which do exist dominate the skyline to a certain extent but do not overwhelm the city. The buildings along the edges of the Main Street Study Area also have an important quality. They at once have substantial presence to assist in defining the edge of the Main Street Study Area and simultaneously allow for clear visual transitions to other parts of the city of Worcester. Nonetheless, each district does have distinctive buildings which give the district its own character. These will be described in the following sections of this chapter.

\subsection{The Interstate Commercial District}

The building forms and facades have varied great deal in this district due to the many changes which have taken place here. The two things which seem to have had the most significant impact on the area in the recent past include the construction of the Interstate 290 Highway and the urban renewal which continues to change the face of this district. Interstate 290 creates a hard edge condition between this area and the more the residential part of the city to the east of 290 . While in other cities the construction of a major highway through the city has destroyed and divided large portions of the city. Worcester has been more fortunate in that the Interstate, while still divisive, seems only to have reinforced an existing edge which had been developing in the city for a number of years. Thus at least in the Main Street Study Area part of the city of Worcester there seem to have been fewer detrimental effects due to the Interstate, than perhaps in other areas or other cities. The one detriment of having the Interstate so close to this district is the ability to create a reasonable scale in the district. The speed with which cars move along Interstate 290 and the overall size of the highway make it very difficult to relate to a pedestrian level. Thus buildings which have been built here tend to be larger, because 
there is more land available in this district and because, there is a need to respond to the looming and large raised highway which is adjacent to the district. Unfortunately, these developments continue to be built in isolation. Each developer choosing a desired style with little consideration for the existing context, or the other, although few, buildings which are located here. Also the developers are not providing the smaller scale elements and amenities, such as trash containers, pay phones, and benches which would hopefully encourage pedestrian use and make it more attractive and pleasant for all users as the district becomes more dense and populated in future.

Urban Renewal, on the other hand, has had the same effect that it has had on most cities, namely of creating many vast and vacant areas within a city and within this district in particular. Most of the urban renewal sites still remain vacant in this district. More disturbing though, is the fact that that which does exist in the district is vulnerable to removal at any time it seems. The result of these two factors and other factors, is that this district is very inconsistent in terms of building form. The buildings which do exist are separated by the numerous vacant lots/parking lots which are present here. Thus there are very few references for developers to look to when building new structures or renovating older ones. The one common aspect of the buildings in this district is that they tend to be constructed out of masonry. Both new and older structures tend to concrete or brick, reflecting the adjacency to the highway and the need within this vast area to give the building a presence not only on the individual street but in the district as a whole. The buildings generally low in height one to seven stories. The one exception being the Plumley Village Housing complex which has a couple of high-rise towers.

The city has continued to encourage development of the district which had become a virtual urban wasteland. Under construction already is the new Worcester Convention Center, see Figures 2.6.1 and 2.6.2, which includes a new addition to the Worcester Centrum. Again large structures which are attempting to define a character for this district. Currently in design development is the new Fallon/St. Vincent's 
Medical Cities complex. It is for this huge complex that numerous existing structures in this district were torn down. Occupying approximately 21 acres along Worcester Center Boulevard this hospital will be approximately 625,000 square feet offering 378 hospital beds. The few references and the fact that there are few scale changes, there are only large scale elements, in this district has left each developer to establish its own set of design guidelines or standards. While potentially risky these structures also could be the structures which help to turn around this district and the Main Street Study Area as a whole. These new building keeping within the central coherent factor of the district are masonry, varying mixtures of brick and concrete. The convention center is approximately 5 stories which serves to continue lines of adjacent buildings. The design for the hospital complex, thus far appears to be approximately 7 stories, but current design proposals make it appear that it could be significantly taller.

The Interstate Commercial District currently has numerous vacant lots. Some of these properties have been fenced to prevent vandalism and loitering particularly on those properties where new developments have been proposed. Many of the older buildings in this area were sacrificed to make room for the newer complexes currently being developed. A few older buildings remain which it can be assumed given the extreme devastation of the area, the city hopes to keep in tact. They include a renovated industrial building, a commercial use, the Plumley Village Housing complex and an important historic structure the original Worcester Train Station building which will be referred to as Union Station hence forth.

\subsubsection{Union Station}

Union Station was designed by Philadelphia architect Samuel Huckel Jr. and was constructed in 1911 . The building originally had two towers which were removed in 1926 when they began to crack. The original building is rectangular in plan and had a vaulted central interior space. The architect enclosed this central lobby with a stained glass roof so as to allow natural light to penetrate into the into the interior spaces of the 
entire building. See Figures 3.4.1, 3.4.2, and 3.5. The base of the building is made of granite while the upper stories are constructed out of a combination of; marble, terra cotta and yellow brick. The front of the building and the facade of the western portion of the building are made out of marble and terra cotta while the rest of the walls are yellow brick. It was anticipated that the form of the building as well as its overall scale would help to enclose Washington Square. But the removal of the towers and the lack of further development around the square, there is little sense of enclosure to this space. The level of architectural detail of the facade is not matched by any other building in the Main Street Study Area but the current condition of the facade detracts from the appearance of the building, Washington Square and the city. Nevertheless, the architectural detailing, the overall building form and scale, and the important place in Worcester's history that this building occupies, are unique and important considerations which made this building worth preserving. The old Union Station building is one Worcester's most attractive historic buildings.

In the late 1980 's, city officials considered tearing the building down fearing that it was far too expensive to renovate or restore. The main problem which the city had to address was whether an appropriate and viable use could be found for the building. And although the building had been allowed to deteriorate up to this point, it has always been a positive visual addition to Washington Square and the City of Worcester as a whole. reminiscent of historic Worcester. The fine detailing, craftsmanship and construction of the original structure have contributed to the longevity of this building. The Union Station building also provides a strong edge for the district. It is large enough to address but not compete with the highway adjacent to it and Washington Square offers convenient access to the Main Street Study Area. Given the buildings proximity to the highway and the fact that it is a major entry to downtown, this building is an excellent location for a new transportation center. Fortunately, they chose not to demolish the original structure and the building is 


\section{Figure 3.4.1}

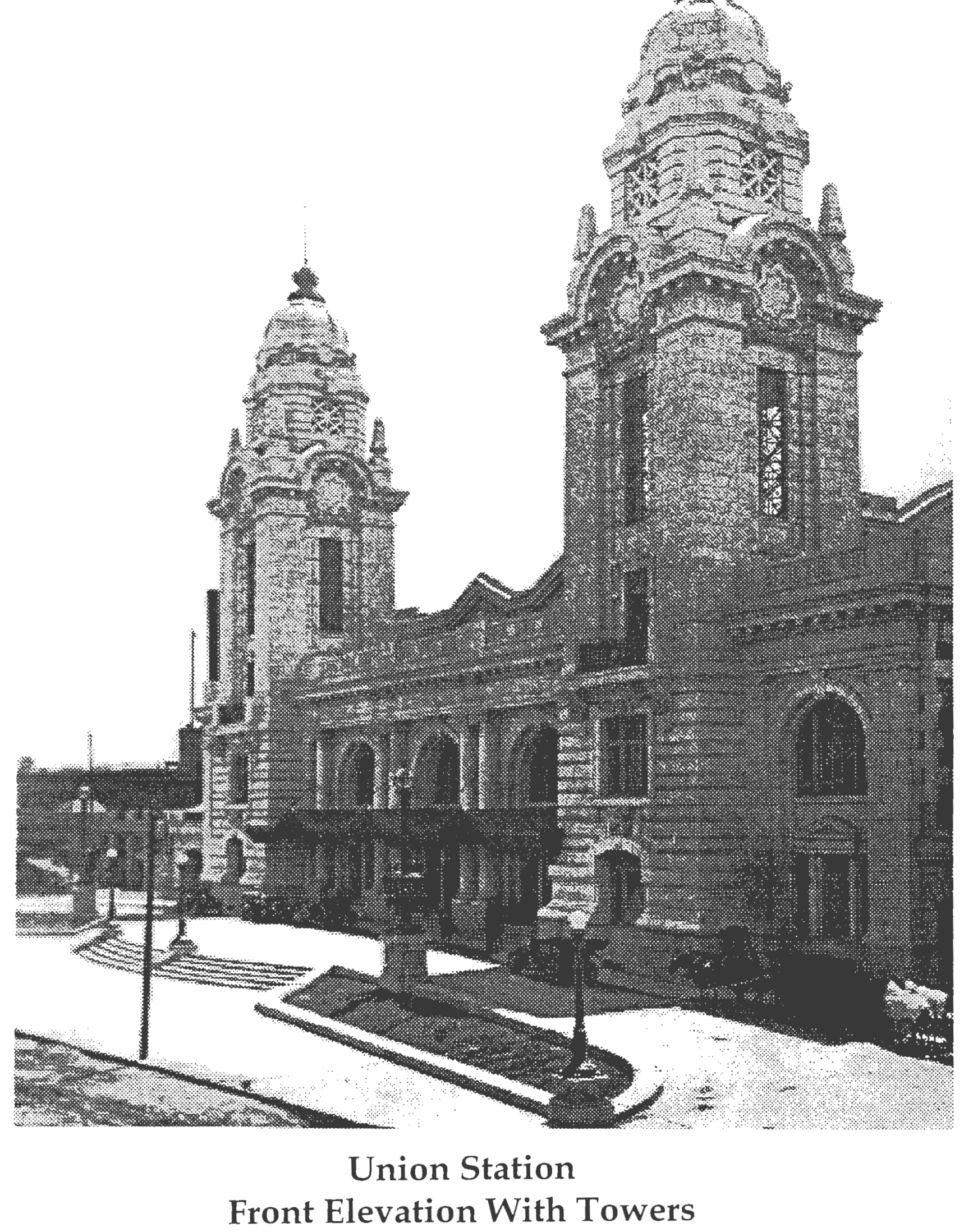




\section{Figure 3.4.2}

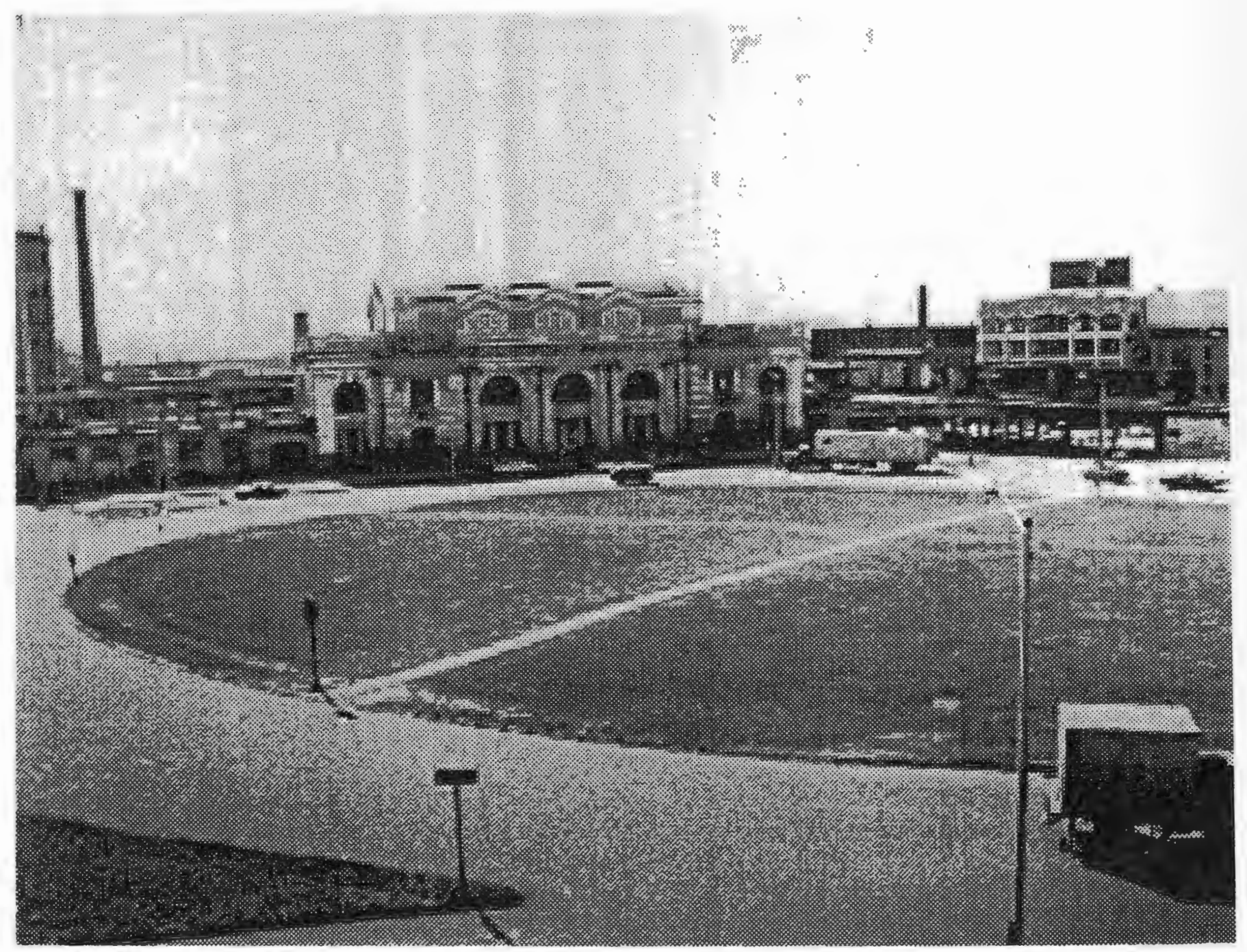

\section{Union Station \\ Front Elevation Without Towers}




\section{Figure 3.5}

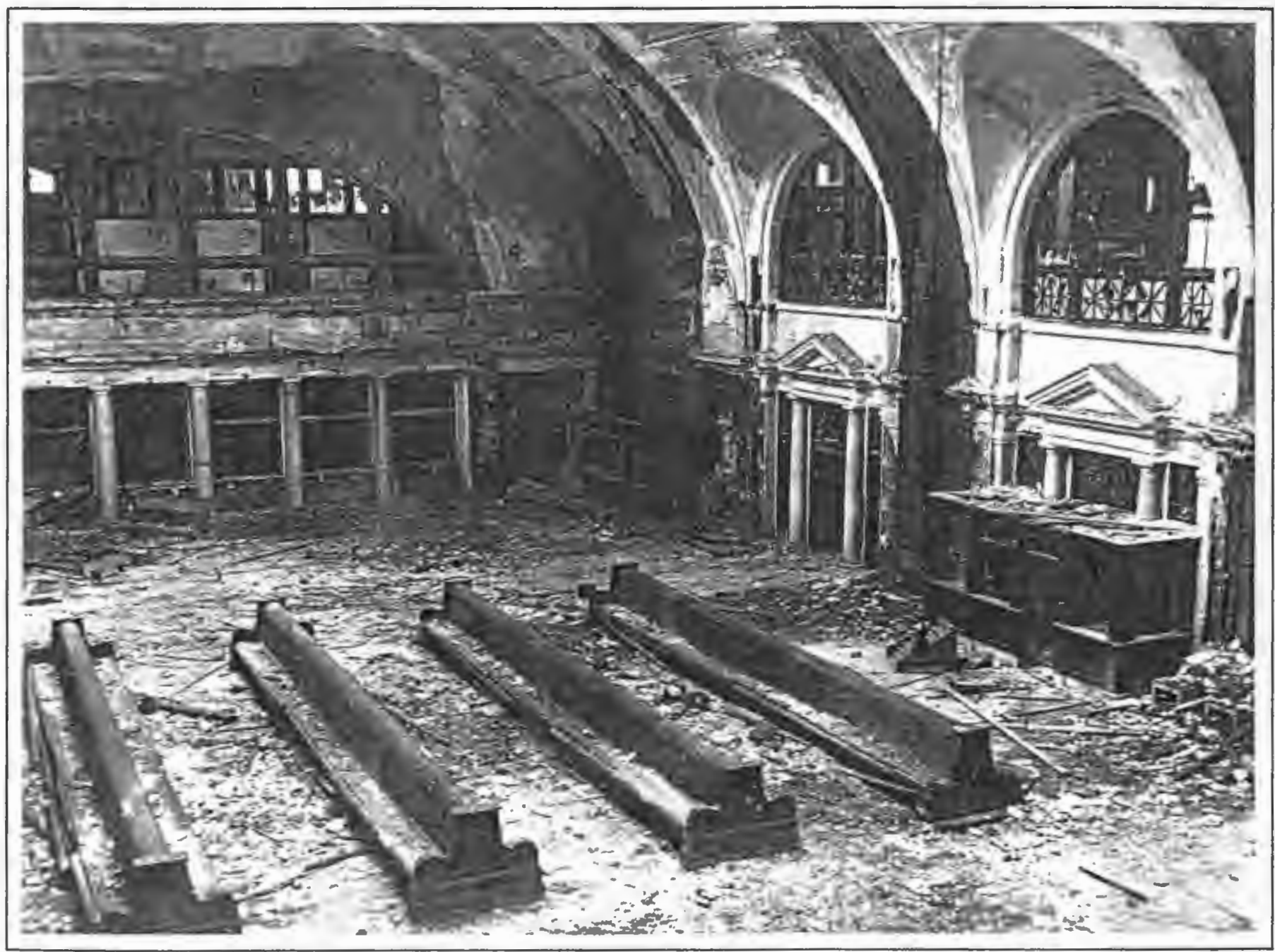

Interior of Union Station View of Central Vaulted Space 
in the process of being partially restored and renovated into and Inter-modal Transportation Center for the city. Being near the highway, should encourage use of this facility by people outside of the city, but the fact that it is in walking distance of the downtown could encourage travelers to utilize the goods and services there. The building had become a place where homeless people lived and with its partially exposed roof and walls it was a danger to the community. The building has been secured now so that rehabilitative efforts can begin. A central part of Worcester's past, it has potential to become an integral part of the city's future also.

\subsubsection{Plumley Village Housing Complex}

The Plumley Village Complex, Figures 3.6 and 3.7, is the one set of buildings which will most likely never become a positive visual addition to this district or the City of Worcester. The notion of a entirely low-income housing complex has been rejected by most housing researchers as an impossible way to provide homes to people and reintegrate them into society. There is little incentive for tenants in such complexes to maintain the apartments and they often end up looking as Plumley Village looks today. The Plumley Village complex has 15 hexagonally shaped buildings. These buildings seemingly were intended to create visual interest in the area. What was built instead were unusable spaces and comers on the interior of the units. This is a problem seen in numerous housing projects throughout the country.

The use of unusual shapes in low-income housing not only creates unusable space but also serves to alienate the residents. In the past, little attention was paid to design details such as the number of closets, the amount of storage space and the number of bedrooms provided in these projects. Instead, designers seemingly were more interested in making interesting objects (buildings). And when the spaces mentioned above did not meet the needs of the tenants, it became impossible for the transition from house to home to take place. Unplanned open space was also a problem. The open spaces provided were often too large and not designed for specific 


\section{Figure 3.6}

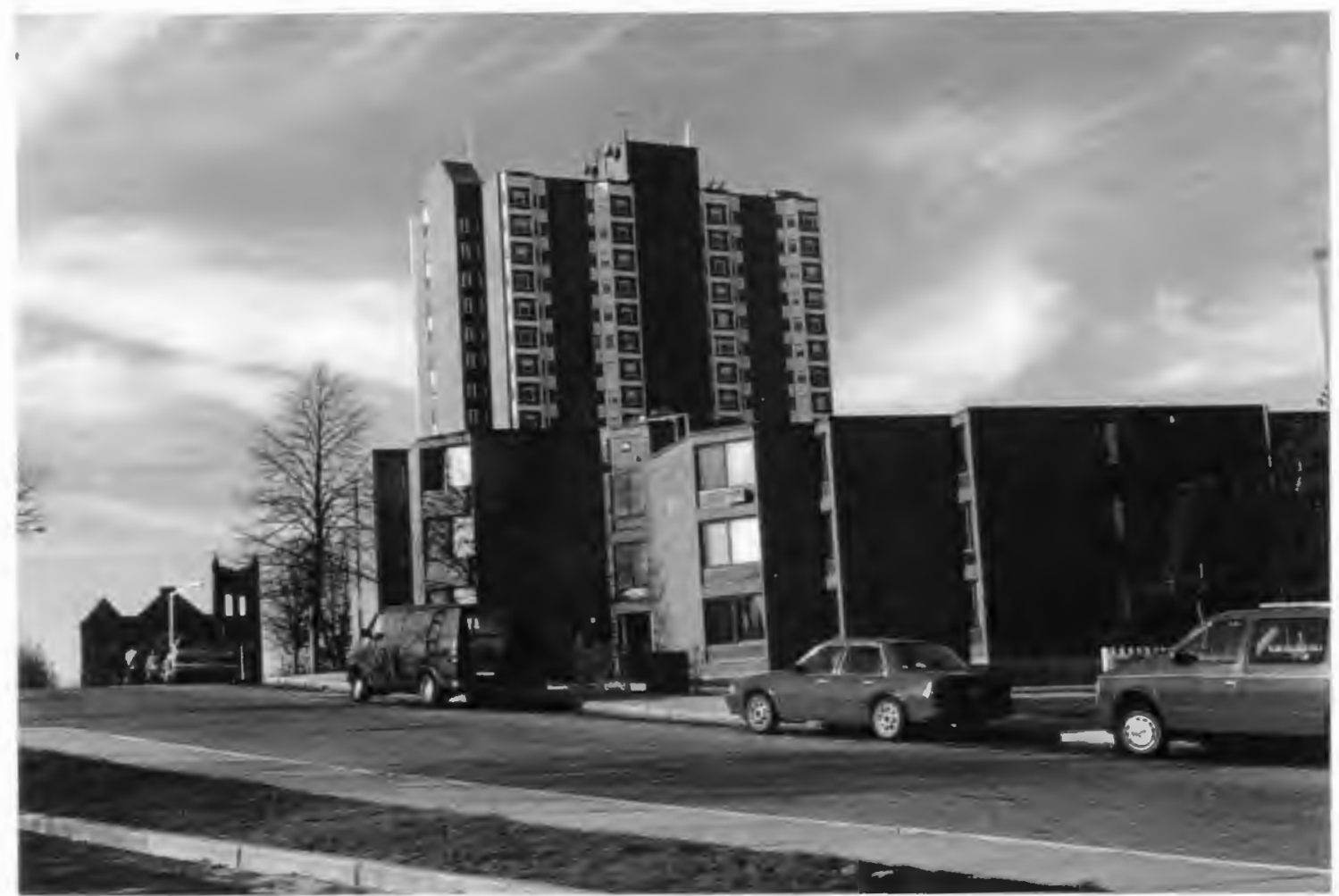

\section{Plumley Village Housing Low-Rise Buildings}


Figure 3.7

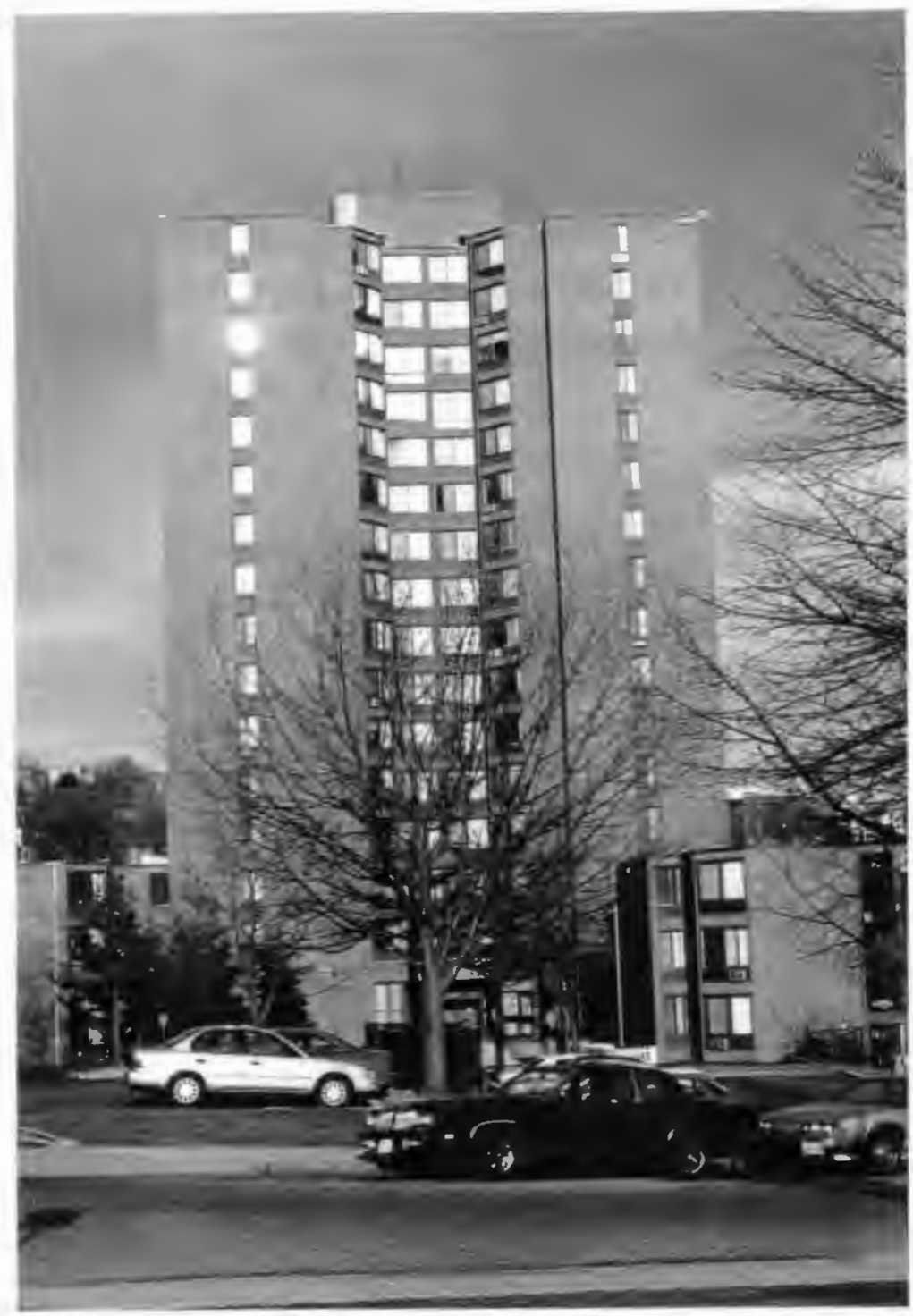

\section{Plumley Village Housing High-Rise Building}


activities. Slowly these spaces became too expensive for the government to maintain. Therefore, in housing projects across the country, the grass was not tended to and after a time no longer grew and the trash in these open areas was not collected. Plumley Village, while not as dire as other housing projects across the country, has some problems. At the urban scale this project does little visually to contribute to the district as a whole. The building forms are too distinct they are set too far away from the street for this urban location.

\subsubsection{Other Buildings}

The many vacant lots in this district increase the visibility and the perceived importance of the few buildings which are located here. Thus buildings which normally would not be the focus of a discussion of this district, but instead would be grouped with other buildings in more dense areas for a discussion about a block or portion of the district, have greater importance and have become defining elements in this district. Some of the buildings found in this district which have this elevated level of importance are the Worcester Post Office, the Visiting Nurse's Association building, and the Worcester Police Station. Although not distinctive architecturally, they currently are the structures which help to define this district. As a group. these structures have few similarities in terms of architectural style and detailing, but these buildings do have similar massing and do utilize similar materials. And it is these similarities which begin to unify the district and could provide design clues to guide developers in the future. Identifying and understanding the similarities and the differences between the existing structures in the district could be beneficial to future planners and developers doing projects in this district. This information could help create new buildings and blocks within this district which are related to one another and woven into a unified pattern, rather than constructing more singular buildings.

Some of the similarities which exist between these buildings are as follows: First, the massing of the buildings tends to be fairly large. The footprint of these 
buildings is typically large occupying all or most of the available lot. Also, these buildings typically have between one and five stories. These buildings have a strong presence in the district due to the large building footprint and the moderate number of stories which the buildings tend to have. Thus buildings such as the Worcester Post Office and the Worcester Police Station make a strong statement allowing the to be seen and compete with the raised highway. Similarly, these buildings are not so large that they would overwhelm smaller uses which exist or could be constructed in or adjacent to the district. Uses such as smaller residential or commercial businesses. In addition to the definitive massing, most of the larger buildings in this district are masonry buildings, brick or concrete, which reinforces the powerful massing. And because they are surrounded by vacant lots, they appear even more grand and object-like. If some new buildings which use light construction techniques are built in the vacant lots this will help to reduce and minimize the presence of the larger structures. The introduction of other building materials and building scales, specifically smaller scaled elements, would assist in making the district more physically diverse, less redundant and overall more visually interesting.

The last characteristic which is shared by a number of buildings in this district is the use of moderate setbacks. Most of the buildings in the district, including the small portion of residential uses, have a small setback from the street edge which allows small open spaces to be integrated into this urban area. The post office and the Union Place complex have small parking lots in front of them, while the residential uses and the Visiting Nurse's Association building have small grassy areas in front of them. These setbacks could be a characteristic which is integrated into future developments, but needs to prescribed, not becoming too large and antithetical to the urban nature of the district.

The new Worcester Convention Center and the soon to be built hospital are two large projects which will help to fill much of the existing vacant land in the district. The 
Convention Center, which is almost complete, is a steel and masonry building which has glass integrated into the facades. This will be beneficial in the effort to encourage pedestrian use of the area and helps to minimize the scale of the building. The building, though, unlike others in the district, is not setback from the street edge. This is perhaps appropriate for the use of the building and will not be problematic as long as a pattern can be defined for and integrated into the district. The design for new hospital complex also currently calls for steel and masonry constriction. But there is a substantial setback proposed in the latest drawings, which if properly proportioned could help to minimize impact of the convention center which does not have a setback at all. Looking at the pictures, though, the setback could be too extreme to allow this facility to be properly integrated into the district. The designers of the hospital should carefully consider the setback amounts around the facility as a whole and the height and massing of this building so that it can be integrated into the pattern which is evolving in the district. Having a strong massing and carefully utilizing minimal setbacks could be successful for this district given its location and the types of uses which currently exist here and the uses which could come in the future.

\subsection{The Main Street Commercial District}

The buildings form a continuous wall which helps to define the exterior spaces created by the streets, pathways and other open areas found in the city. The buildings form walls which define these exterior spaces. This spatial definition is further enhanced by the architectural detailing and decoration on the facades of these buildings. The height of the buildings in this district contribute to the "urbaness" of the district. The buildings here range in height from two to twelve stories having an average height of anywhere between four to six stories. These building heights when seen from a distance create the image of the city and stress the intensity of the land uses found in this district. Once in the downtown area the sense of city is further stressed as the buildings effectively work together creating a sense of enclosure. But the variation in 
building heights allows is indicative of the fact that Worcester is a medium-size city and allows for connections between the two adjoining districts. These variations in building height reflect the many advancements made in technology in the past decades. The more recent buildings, dating from this century are taller using the more modern steel construction techniques while the lower structures reflecting technology of the previous decade. The older structures in this district have been fairly well maintained in contrast to the Interstate Commercial District. Many have been renovated and continue to be well utilized. Pictured in Figure 3.8.1 and 3.8.2 are the front and back facades of Mechanics Hall which was first built in 1857. Refurbished in 1977, this building continues to make a positve economic and visual contribution to the Main Street Study Area and to the City of Worcester as a whole.

This district, in terms of the overall massing and heights of the buildings, having retained a number of important structures from the city's past still remains very coherent. The are few areas to place additional buildings thus there have been few opportunities to contradict established patterns. Much of the emphasis thus is on renovation, which as shown in the exhibits has been undertaken in most cases with great care. As seen in the following exhibits, most of the buildings have been renovated so that they retain their old charm and make a positive contribution to the street.

The new buildings which have been built often are lacking in the craftsmanship and detailing of their older counterparts. But the predominance of the older buildings overshadows the flaws in the newer structures. Nevertheless there is much to be learned from the new structures to prevent more mistakes from being made in the future. The greatest error prevalent in many new buildings in this district is the blank wall. This is a major problem in both of the glass buildings, the Fleet Bank Building and the former Federal Savings Bank Building both built in the early 1980's and in other structures such as the Worcester Centrum. These buildings have neglected the 


\section{Figure 3.8.1}

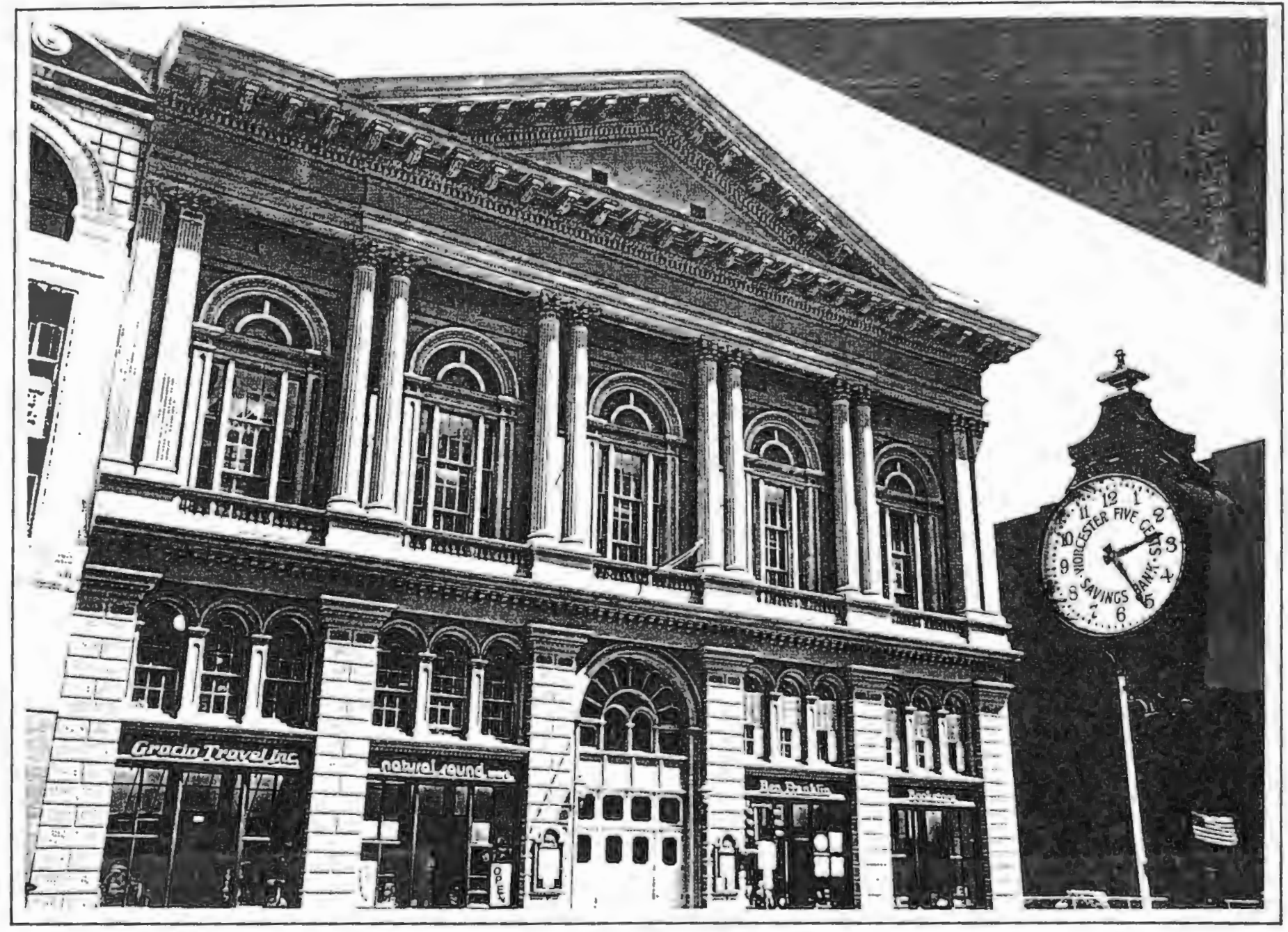

Mechanics Hall

Front Elevation 
Figure 3.8.2

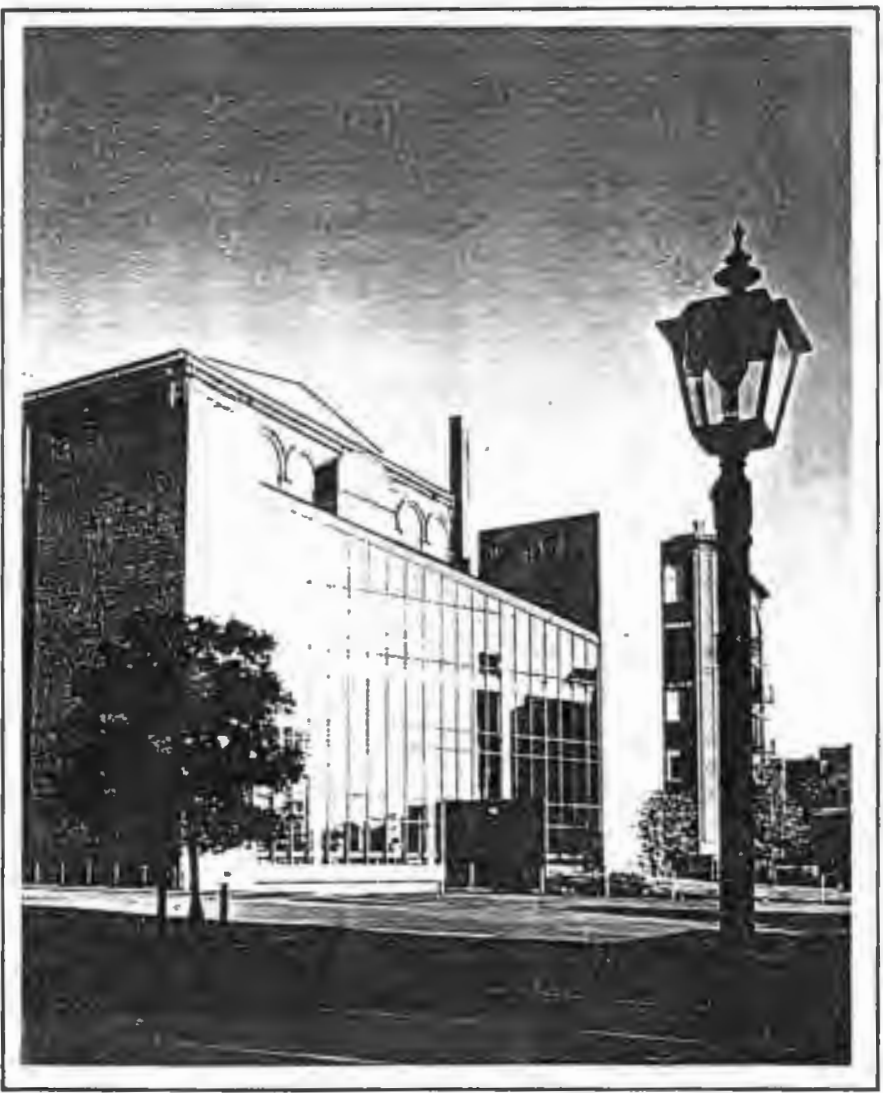

Mechanics Hall

Rear Elevation 
pedestrian scale which encourages pedestrian use of a city and make the pedestrian feel at ease walking by. But even those buildings which do not have blank walls lack detailing which mediates the various scales which need to be negotiated in a city, including the block scale and the pedestrian scale. The new high-rise residential tower is one such example. It has created ground floor shopping but has raised its ground floor above the actual street level which required that a wall be built at the street level. Thus the effects generated by creating ground floor commercial, rather than continuing street facade and contributing to the city as a whole, are lost. The ground floor commercial while of use also does little to improve the character of the building itself. The opening are too given the height of the building and the commercial uses located there. The materials in general and the small windows used on the upper stories do not make this an attractive piece of architecture from a distance. Thus this building is unsuccessful at all levels, the building level, the block level and city scale. The building is very overwhelming to pedestrians and visually lacks architectural character.

While few of the new structures in the Main Street Commercial District contribute to the overall image and character of the district at all levels, the building block and city levels, the designs of some buildings do address one or two of the levels. The tallest buildings in the city, pictured in Figures 3.9 and 3.10 are less problematic acting more like sculptural elements in the Study Area, they are visually engaging and successful from a distance. At the pedestrian level, at street level, where one is unable to see the entire building, these buildings tend to be more problematic. The base of these buildings is no different from the upper stories. Thus there are no scale changes, specifically scale reductions, made to address the pedestrian and general ground floor activity. The windows and doors are too large and no shading devices or screening elements are integrated around the buildings to make them more pleasant to walk near. Reflective glass was used in the Fleet Bank building even at the ground level which does not allow pedestrians to see into the space and thus the glass actually 


\section{Figure 3.9}

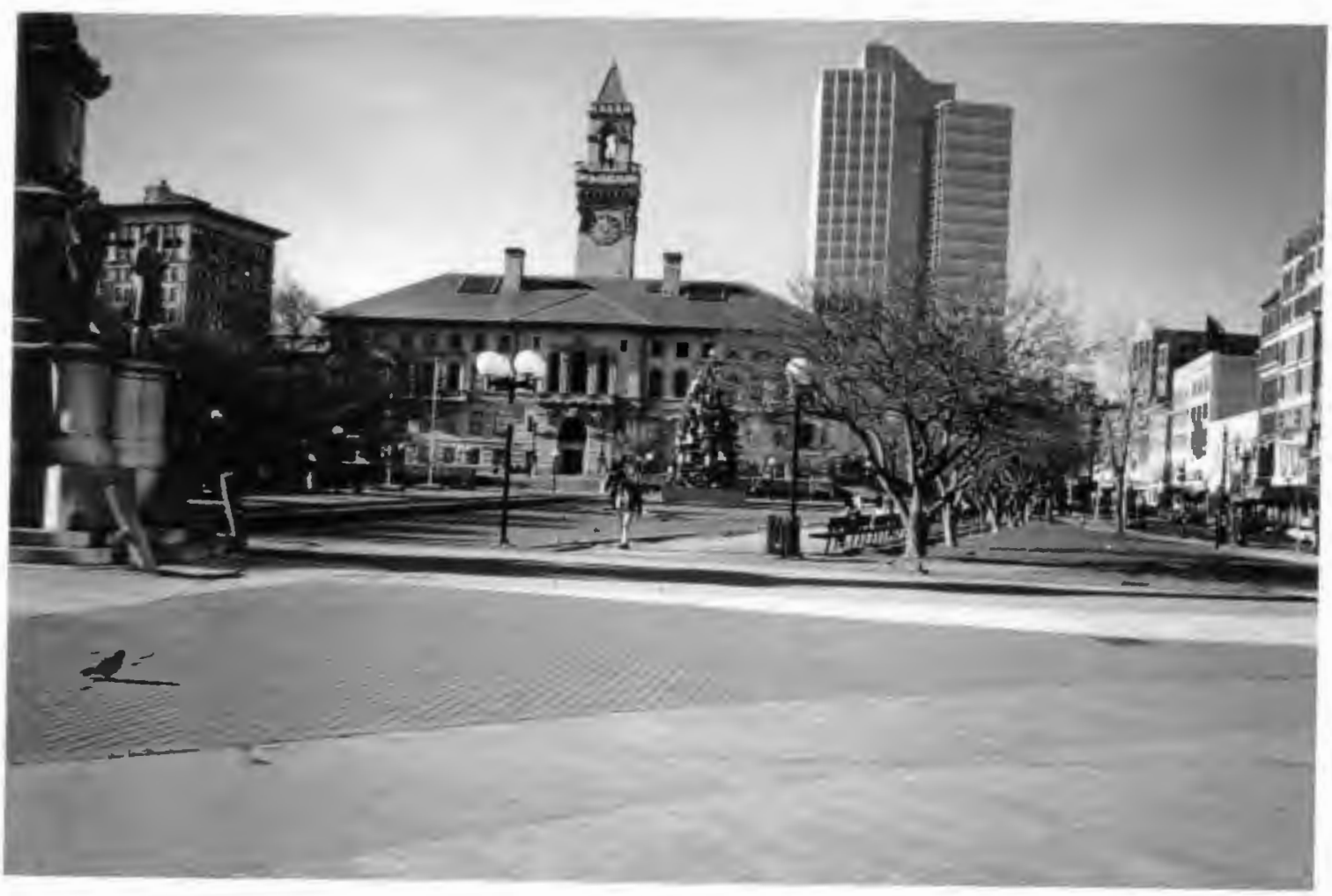

Rear Elevation of City Hall With Fleet Bank Tower (One of the Tallest Buildings in the City) in the Background 
Figure 3.10

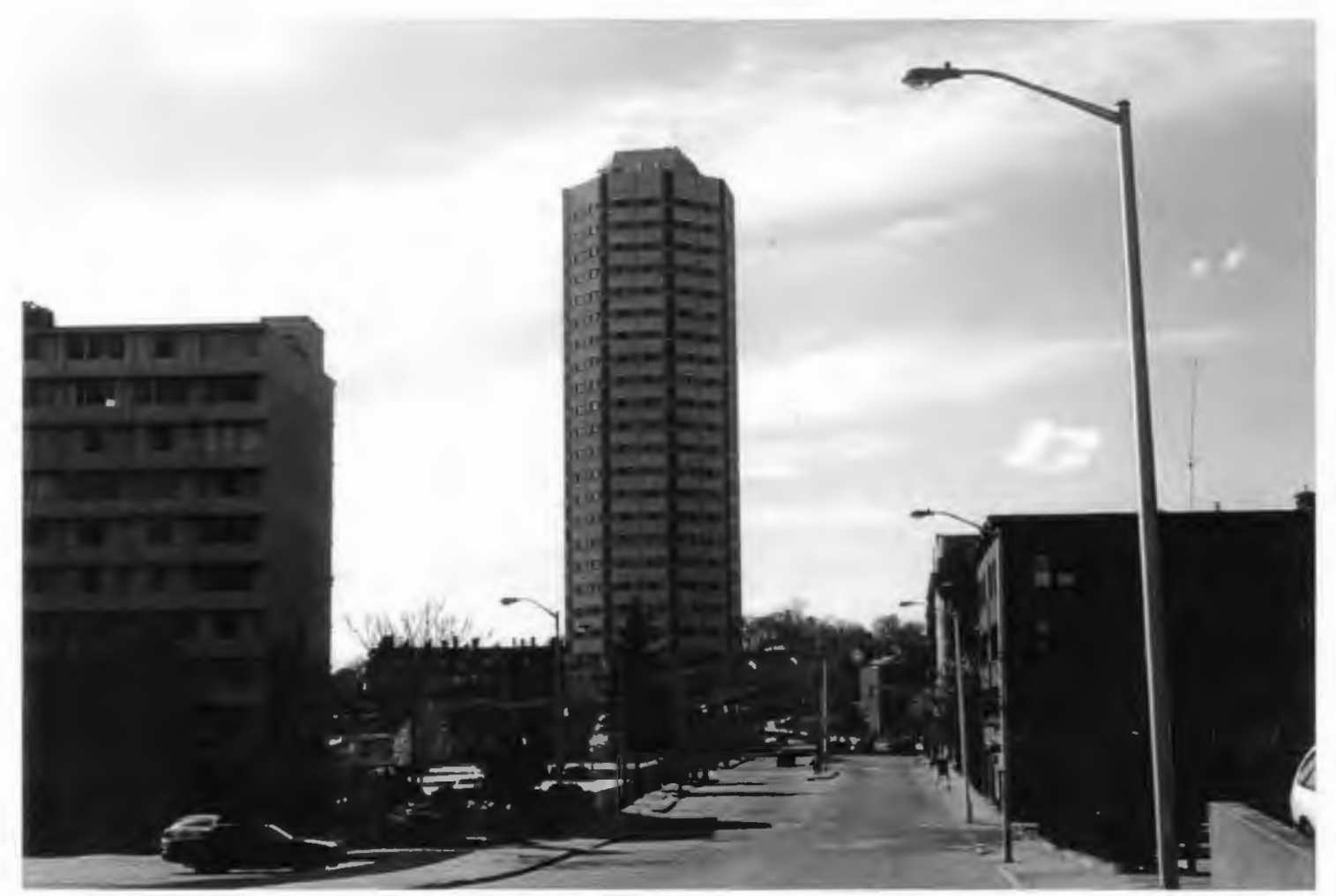

View of Urban Villages
80 Unit Residential Tower 
functions more like a wall than a window. The reflective glass is not comfortable for pedestrians or users on the inside who are never sure whether someone can actually see inside or not. The park which was built at the same time as and adjacent to the Fleet building, occupies a central location in the city. But it has been fenced off in a manner that discourages pedestrian use, so it is almost always empty. The interior of the Fleet Bank Building is also confusing and thus rather alienating, not offering the type of comfort or clarity which help to improve the quality of interior or exterior spaces. In general, today, developers fail to take into account the enormous responsibility which a single building has in a city. The older structures in this district contribute most to the overall appearance of this district, although some are not well maintained, because they address all three urban levels.

Buildings constructed in an urban context have three levels of responsibility, and all three levels must be addressed in some fashion for the building to successfully contribute to the overall appearance of the area. The first level of responsibility is the most obvious and that is at the level of the building itself. The building should be designed to satisfy the needs of the clients and users of the building and create a viable interior spaces. On the exterior the building both address pedestrians and motorists, but pedestrians should be the priority in dense districts such as this one. The second level of responsibility is to the block as a whole. Many buildings do not occupy an entire city block but rather have other buildings on either side of them, particularly in dense urban district. Thus the building, while not necessarily mimicking adjacent buildings should enhance rather than compete with adjoining buildings and create an overall pleasant block environment for pedestrians and a attractive image for motorists. Finally, at the third level, the building is responsible to the area as a whole, to contribute to the overall character of the city. While a grand gesture may not be made at each level, a building contributes to the overall effect at all levels and thus each level must be considered and designed for. The density of this district, the numerous historical buildings, the scale 
changes which address both the pedestrian and the motorist, and the generally consistent amount of the setbacks of the buildings here are perhaps this districts strongest assets. By maintaining these areas of consistency, diversity in other areas such as in the building heights, materials etc. can be accommodated while still maintaining the coherence of the district as a whole.

\subsubsection{Worcester City Hall}

Worcester City hall is not only an important and central building in the Main Street Commercial District, it is a center for the city as a whole. A beautiful example of the American civic architecture, its fine detailing and craftsmanship from the early 18 th century the building exemplify the historic architecture in the City of Worcester. The front facade which faces Main Street is a magnificent stairway which was intended to allow people to process into the building, similar to buildings seen throughout Europe. The back facade faces the Worcester Common one of the few remaining open spaces in the Main Street District. The back facade shown in Figure 3.9 illustrates the majesty of the design but what the photo fails to show are the years of neglect which have also becoming more obvious. Despite the quality construction and although not apparent in most photographs the City Hall building is in need of extensive repairs and upgrading of facilities, both to improve the appearance and the efficiency of the structure. Special care needs to be taken in terms of preserving and restoring the details of the building but efforts to incorporate new technology and the extensive amount of wiring which comes with it need to be studied. Renovation of the building is about to begin but it is unclear how the technological aspects of the renovation are being handled. The exterior of the building also needs work given the discoloration of the stone and the generally poor maintenance over the years.

\subsubsection{Mechanics Hall}

Mechanics Hall is one of the more interesting buildings in the city of Worcester because it is one of the few buildings which successfully combines historic and modern 
architecture. When the building was renovated and a new addition built, the architect understood the importance of maintaining the existing character of Main Street and the need to further enhance the exterior environment by providing pedestrian amenities. On the exterior of the building thus is where the addition was placed and here more freedom of expression was allowed. The result is a building which melds two very different architectural styles in a positive way. The new exterior piece has helped to activate the back facade of the building making it attractive and inviting.

\subsection{Residential Commercial District}

The residential commercial district perhaps has the most diverse forms of all the three districts yet it is the most cohesive of the three. Having the most diverse uses, there are some commercial uses, civic buildings, and a large proportion of residential buildings. This has created essentially three different building types which can be categorized as commercial and public buildings, commercial buildings which have a residential character and residential buildings.

\subsubsection{Commercial and Public Buildings}

These structures include the Worcester Art Gallery and commercial uses including such as AT\&T telephone company and a nursing facility. These buildings area typically newer but have maintained the qualities of the district by adhering to established patterns of height and setback. The buildings in this category tend to have a larger building footprint and fewer stories. This change in massing allows these buildings to coexist with the many small homes without overwhelming them or the district as a whole. See Figure 3.11.

\subsubsection{Commercial Buildings with a Residential Character}

These buildings were originally built as residences but over time have been converted into other uses. These structures tend not to house retail uses but instead house professional services and office uses. Their residential character provides a 


\section{Figure 3.11}

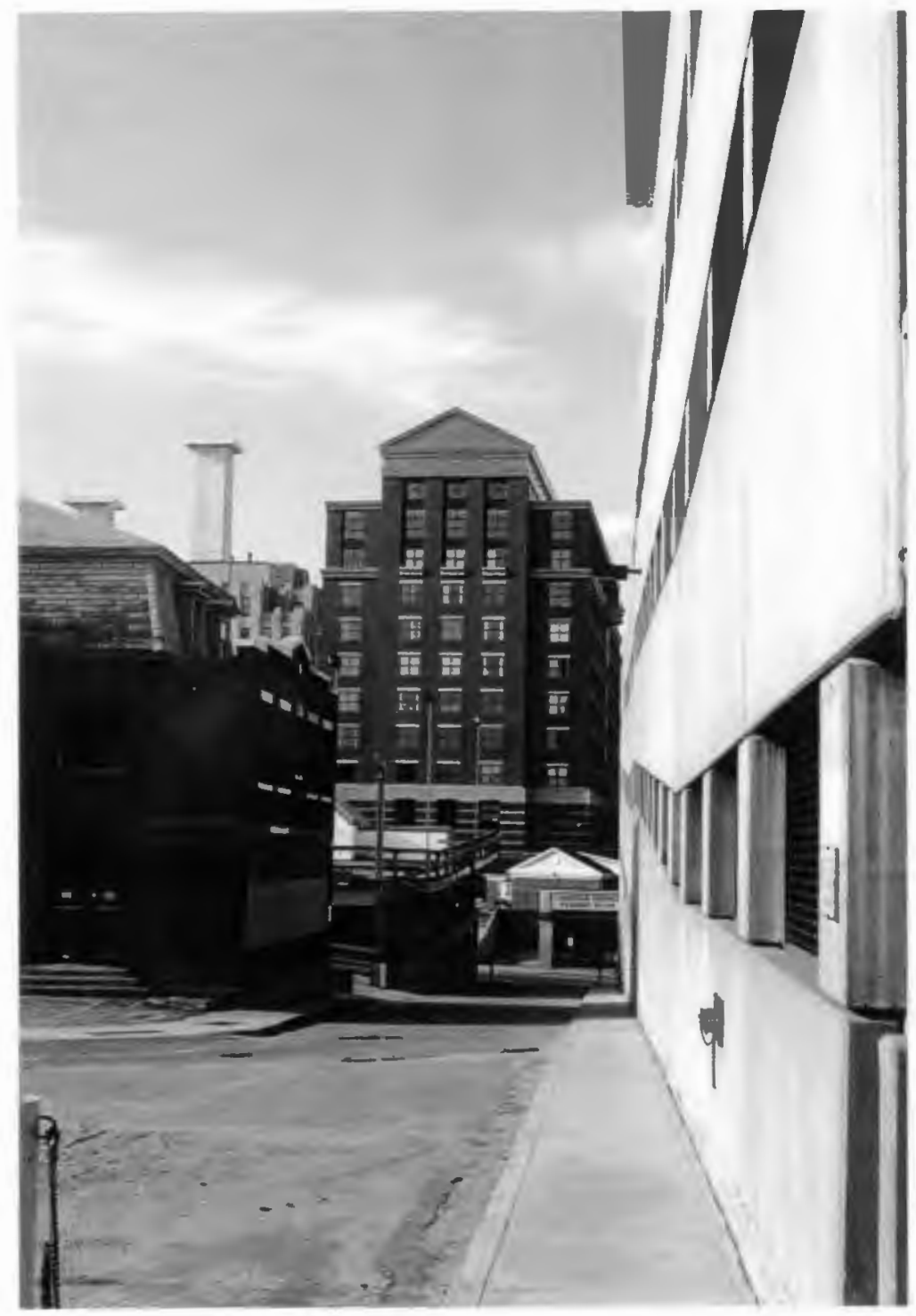

\section{Residential Commercial District Commercial Buildings}


attractive transition from the downtown retail center found in the Main Street

Commercial District to the more residential areas on the western side of the Residential Commercial district. See Figure 3.12.

\subsubsection{Residential Buildings}

The majority of the buildings in this district are residential. And many of these buildings are single family houses. Many of these structures date back to the early part of this century and some to the previous century. There is a wide variety of house types which are carefully integrated into this district. The buildings while different are not dramatically different and the large trees, building setbacks and other landscaping techniques help to weave this district together in a positive way. Recently, multi-family units have become more common in this district. They generally are of two types. There are the single family homes which have been converted into multi-family units and there are the newly constructed multi-family units. The new construction has been less successful, not adhering to the standards established by the existing house types. While diversity is potentially an asset it can also be a detriment to a neighborhood. Some structures on Linden Street such as the large, concrete apartment are less attractive, but the large trees and plants help to minimize the impact of these buildings on the street. In general, though, these buildings is too large and the materials are too distinct and severe to be adequately integrated into this district. The strength of the neighborhood has been maintained to this point but if additional housing is built here which does not consider scale and/or materials the appearance of the district could be affected.

\subsection{Summary}

There is a great deal of diversity within the Main Street Study Area. Building facade styles, building materials and even dates of construction vary greatly in the districts. Elements which help to unify the districts include the building heights, the building setbacks and the number of trees found in the area, all of which can help to 
Figure 3.12

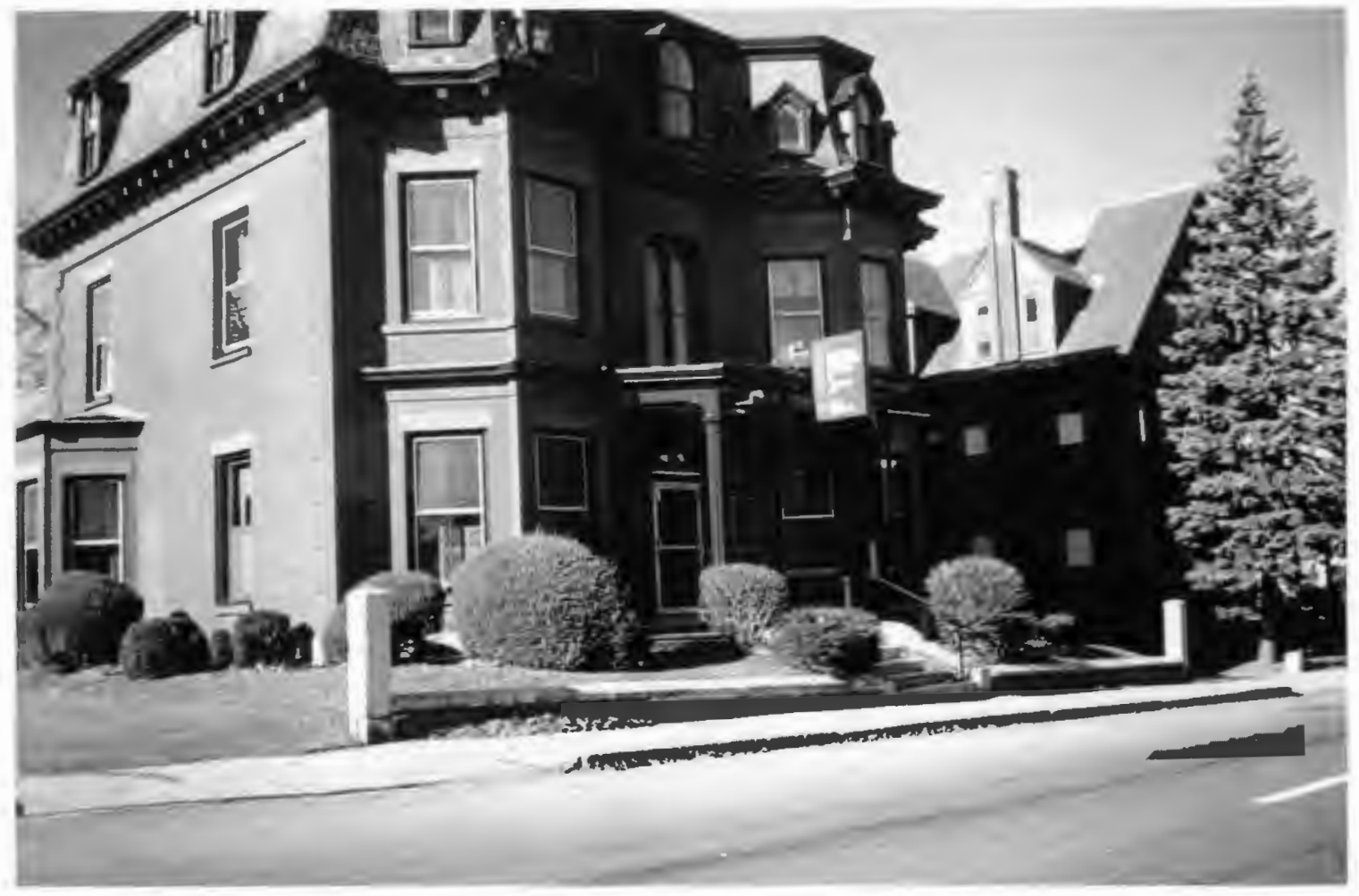

Residential Commercial District Commercial Buildings 
obscure significant differences. The building heights in the three districts seemingly vary greatly but there is consistency in specific areas within districts that not only help to unify the district but also allow for smooth transitions between adjacent districts. The larger buildings on the edge of the Residential Commercial District are integrated within this district itself but they also help to make a smooth transition to the Main Street Commercial District. The residential uses to the far west of the district help join this district to the next residential neighborhood further to the west.

The setbacks in the Main Street and Residential Commercial Districts are fairly consistent and further enhance the quality of these districts. It will be important in the future that a standard setback amount be established for the Interstate Commercial District. This will help to knit the district together in a coherent and unified way. Because there is the potential for a greater diversity of land uses in this district than are perhaps found in the other two districts, it is also possible that a greater variety of setbacks could be accepted here. Nevertheless, a standard setback amount will provide a general guide for developers and builders initially. For example, buildings with residential uses could have larger setbacks than those buildings which have commercial uses in them. Site design, building design and quality of construction will need to be emphasized in this district in order to ensure that it will never again be necessary to tear down a significant portion of the district in order revitalize the area.

Each district has potential if the existing problems can be solved and future ones anticipated. Visual coherence should be created within the Main Street Study Area as a whole, within each district and within individual city blocks. The height, massing and designs of the individual building facades should work with the larger architectural systems already established in the Study Area to create a cohesive urban environment within individual city blocks and in the larger urban context. The individual buildings and building facades can and should be innovative and unique to a degree, but they should respect and address the existing context. New buildings and building elements, 
such as re-designed storefront facades, should acknowledge and enhance the architectural styles and building types which already exist within the Main Street Study Area. This will allow the city to be seen by both residents and visitors as complex mix of unique elements within a coherent and unified structure. 


\section{CHAPTER FOUR \\ CIRCULATION AND PARKING}

"...positive visual open space elements which are safe and functional."

(Shirvani, p.26)

\subsection{Introduction}

Automobiles provide people with reliable and efficient transportation to and from various destinations. Unfortunately, in addition to the many conveniences automobiles afford individuals they also tend to impact the environment in a negative way. As in most cities the automobile continues to provide the most significant and pervasive problem for the city because the number of cars on the roadways continues to increase and the impact physically and environmentally is significant. Since their introduction, automobiles have dominated the urban and rural landscape. Not only a result of their physical presence, but automobiles affect future planning initiatives in towns and cities throughout the United States and have in fact the focus of community plans and designs. A great deal of planning had to be done to accommodate cars into the urban environment and that continues to be the case today. Therefore, improving circulation and parking in an urban center is an important part of the urban design process.

Downtown areas had to be changed significantly in order to allow for automobile travel. The most significant change was the widening of the streets. In order to do this in most already developed downtown areas, it was necessary to reduce the amount of sidewalk space and remove many or all of the pedestrian amenities which once had been provided there. The faster speed required additional and in many cases larger signage than once had existed in the city. The growing amount of signage, both directional and commercial changed the appearance of cities, often for the worse. Highways were introduced to allow motorists to bypass the city and to further alleviate the growing traffic problem. But automobile traffic continues to be a problem in urban areas. In addition to the congestion, they increase pollution levels in the city, obscure views of open spaces and buildings, create parking dilemmas and deter pedestrian usage. In fact, the accommodations made for the automobile have systematically made downtown areas less desirable for pedestrian use and less attractive overall. Thus it is a 
responsibility of urban designers to mediate between the needs of pedestrians and motorists, to make the city safe and attractive for all modes of transportation. Today one of the first considerations with any new development is the impact on the traffic patterns. When initiating a design proposal, designers immediately determine the amount of space needed for parking, loading docks, roadways etc. and pedestrians' needs often are considered secondarily. For example, the Union Station project has already determined that a new four-way intersection will replace the circular park which exists now. This is due to the traffic expected to be generated by train station but also the traffic anticipated by the new Medical City/Fallon Hospital project. It is still uncertain what types of pedestrian access ways will be provided with this project, although it is expected that an above ground walkway incorporated into the design at some point. As stated previously, the Fallon center has yet to offer a new design proposal to the city for review.

Worcester has a variety of transportation modes but they are not as efficient and organized as they could be and thus not utilized to their fullest potential. In addition to cars, there are intracity and intercity buses and trains which service the area. Intracity bus service in Worcester is operated by the Worcester Regional Transit Authority (WRTA). There are a number of bus routes within the system which assist students, the elderly and working people as they move through the city. Intercity Bus service is provided by a number of bus companies including Trailways and Greyhound. Intercity Rail service is provided both for passengers and freight in and out of Worcester. The passenger service is provided by Amtrak which makes connections to cities such as New York City and Albany. Commuter rail service offered by the MBTA (Massachusetts Bay transit Authority) began in the Fall of 1996. This connection with Boston could greatly improve the desirability of the Worcester area for working and living. There is tremendous potential for this area to become a desirable residential and commercial area again given the growth and development which has taken place along other rail lines. Having this alternative to driving provides another incentive for individuals who are choosing living areas, and places to work. The commuter rail links could potentially spur a great deal of 
development in and around the Worcester area.

Currently though the alternative transportation modes are not as well utilized as they could be in the city. The new inter-modal transportation center should help to consolidate and improve the services which are offered and forge the city into a destination and travel node for many passengers.

\subsection{Vehicular Circulation in the Main Street Study Area}

The circulation system in Worcester has elements which both contribute to and detract from the city. In general, those unfamiliar with the Worcester will find driving through the city somewhat difficult. The main reason is that most of the streets are one-way streets which makes driving through the city confusing and difficult. To reach a destination in the downtown, it is often necessary to take circuitous routes which are time consuming and cumbersome. The primary arterials in the north-south direction are Interstate 290, Summer Street, Worcester Center Boulevard, Main Street, and Linden/Lancaster Street and Chestnut/Harvard Street. Linden and Chestnut Streets are each one way in opposite directions. Interstate 290 and Linden Street bound the Study Area. The primary arterials in the east-west direction, shown in blue on the map are Highland/Belmont Street, Central Street, Exchange Street, Foster/Maple/Elm Street, Front Street, Franklin Street, Pleasant Street, and Austin/Myrtle Street. There are two reasons why there are such a great many of important streets in the study area. First, the names of the streets change fairly often so it appears that there are many more streets than there actually are. Second, many of these streets are only one way so it requires one to identify two streets in order to cover both traveling directions when describing an important route. The one way streets and the direction in which travel is allowed are identified on Figure 4.1 with black arrows. The two way streets in the study area vary greatly in width. Worcester Center Boulevard is a large divided highway with minimal traffic due to the lack of development there, while Summer Street and Main Street appear much narrower due to the higher density of uses along them and the large volume of traffic. Main Street has one or two lanes of traffic in each direction depending on where you are on the 


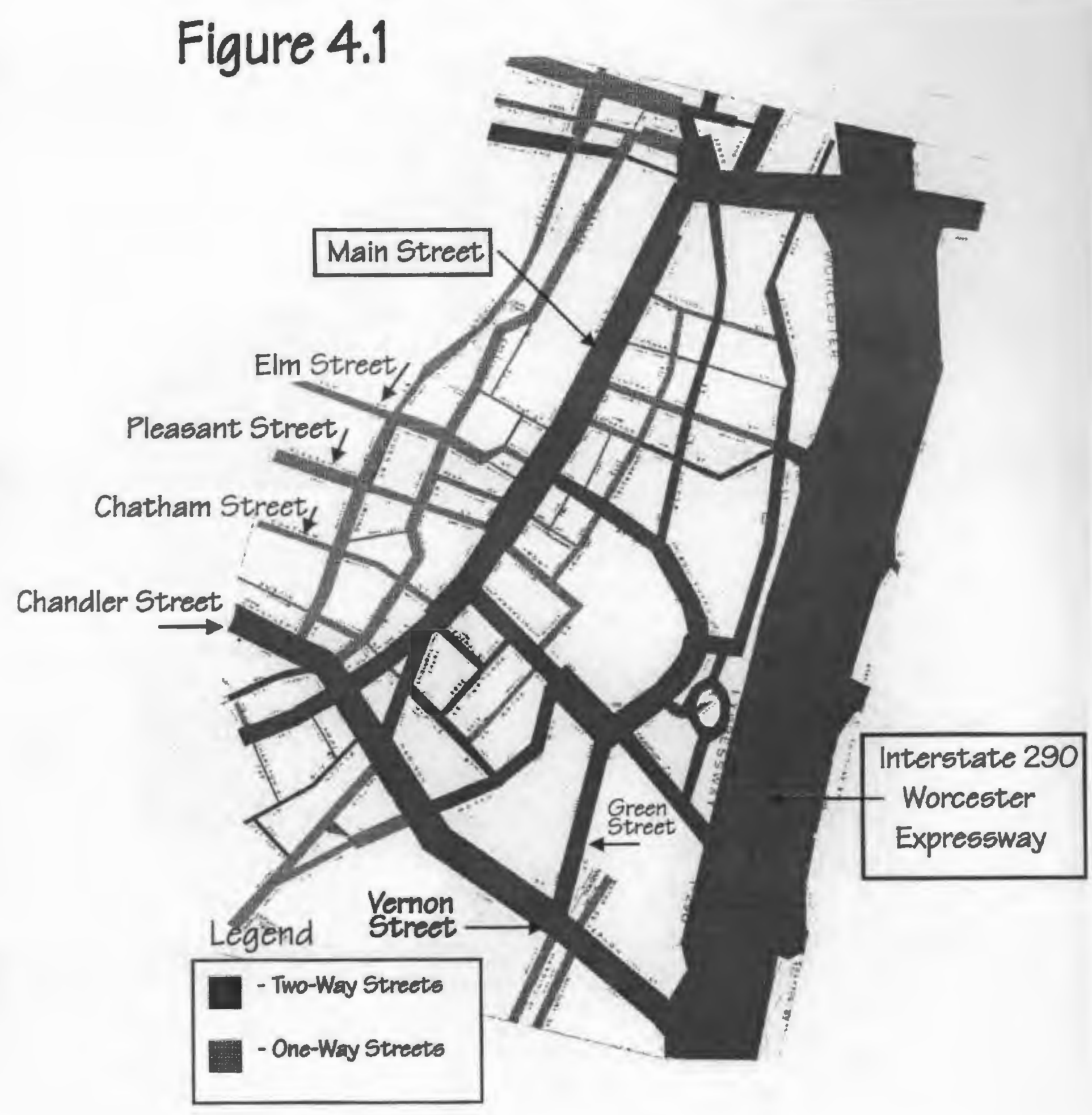

Major Arterials in the Main Street Study Area Width of Line Indicates Approx. Road Capacity 
road. There is also parking on both sides of the road at various locations on the road. The streets in the Main Street Study Area vary in width and length. This variety is desirable because each street provides different views through and around the city for both pedestrians and motorists. In addition, each street has a different character and spatial quality and these characteristics are determined by the size of the street and the density of the uses and the buildings along the street.

There are a number of problems in the Study Area related to circulation. First, there is a very unequal distribution of cars on the roadways. So there are many cars traveling on certain roads and very few cars traveling on others. The appearance of the streets is another problem faced by the entire study area. In general there are very few trees, or other amenities on the streets of Worcester. The lack of such amenities not only detracts from the overall appearance of the street but discourages use by pedestrians. Circulation in downtown Worcester is complex for a number of reasons. First during certain times of the day there is a great deal of congestion on many of the streets. Second, many of the streets in the downtown area are one way which forces drivers to take often circuitous routes to get to their destinations. Third, the street lights are not adjusted for peak hours of traffic. Lastly, congestion is a major problem in the study area. Clearly streets such as Worcester Center Boulevard were created to alleviate some of the congestion on the older roads but the limited uses found along this route and the types of uses found there generate traffic at specific times. To date this street is underutilized, still a feeder road to areas where there is more activity. Even when there are events at the Centrum this road is not used to capacity because many users choose to park before arriving at the Centrum and walk there.

Vehicular circulation is also problematic due to the condition of the streets in the Worcester Study Area. The streets are not well maintained and many streets need repair. The harsh climate in this part of the country, heavy snow and rain as well as hot and humid weather makes it essential that the roads be maintained. There is an overall lack of coordination to this maintenance. Streets such as the circle in front of the old train station have recently been re- 
paved although three years from now it will again be dug up and the whole intersection redesigned. There are other streets, in greater need of repair, in the city which could have been re-surfaced.

\subsection{Parking}

Parking in the Main Street Study Area is ample as shown in Figures 4.2.1 and 4.2.2.

There are a number of parking garages and as shown on the Land Use Map even more surface parking lots in the city. And many of these parking lots occupy valuable lots in the Main Street Study Area. These lots are not particularly will maintained and add little to the overall character of the city. Similarly sized cities such as Pittsburgh discourage large parking areas in the downtown and in fact if one surveys the area, most of the surface parking is located on the edge of the downtown district underneath the highways or across the river from the downtown and people walk to their destination. Most of the parking within the city is short-term for shoppers. In Worcester it is the opposite, most of the parking is utilized by business people during the week and they stand empty at night and on weekends. More parking is being added with the individual facilities currently being proposed for development such as Medical City/Fallon Hospital and the Worcester Convention Center. Unfortunately, this additional parking does not address the basic problem that the parking which currently exists in the city is underutilized. There is significant use during business hours but generally the lots are underutilized at other times because the city as a whole is under-populated after business hours and on weekends. There are some basic problems with the existing parking. First many of the parking facilities do not offer the sorts of amenities that encourage use except for people employed in the area, such as reduced parking rates for short term parking if a stamp from a shop is obtained. Second the lack of amenities further enhances the sense that these are not safe facilities. Lastly many of the lots are unattractive additions to the city.

\subsection{Buses and Train}

There are two types of bus service offered in Worcester today. There is the intercity buses operated by the WRTA. They provide local bus service to residents and visitors 


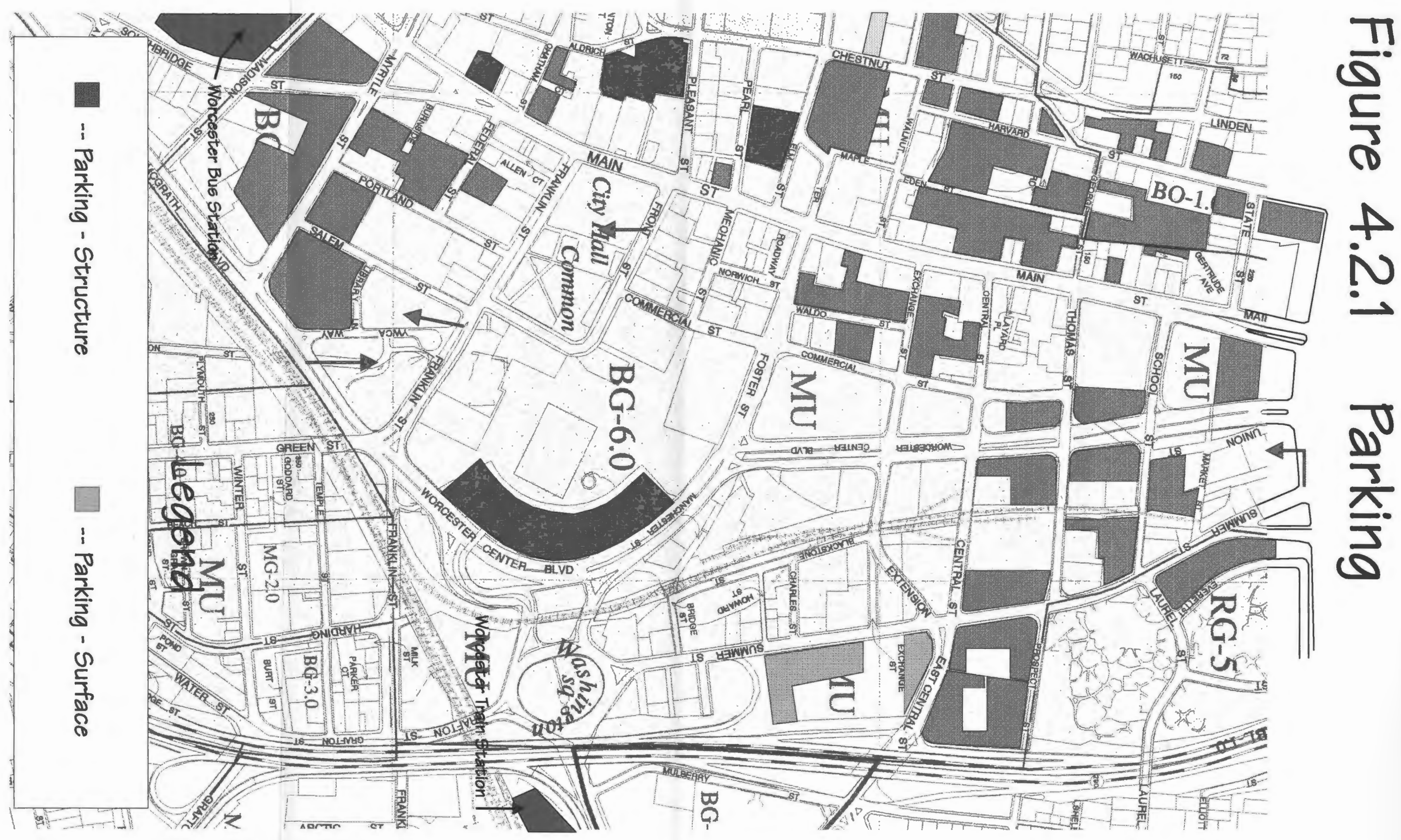




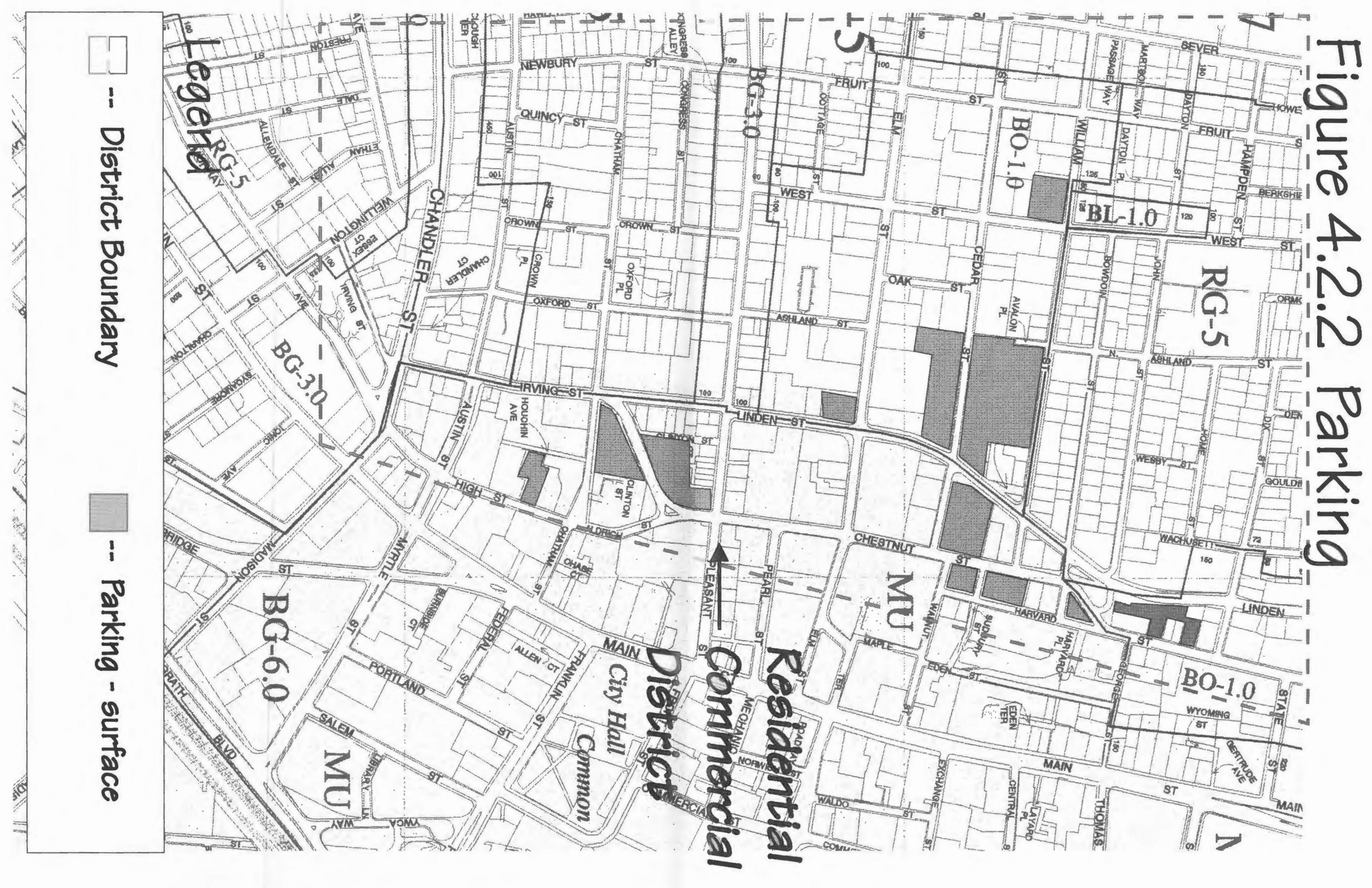


throughout the city. The service according to passengers is fairly reliable and generally on time. And over the past five years the routes have remained virtually unchanged. is important to evaluate the routes and see what adjustments are needed. The bus costs $\$ 1.00$ for ones initial ride and transfers are $\$ 0.10$. Buses are the most efficient mode of transportation offered by any city and can be a good alternative to automobile use in the downtown area. Currently most people working in downtown drive to work. Thus it seems that more research is needed in order to encourage people to utilize this system more. There is a strong network of buses running through the Worcester downtown. This provides an integral mode of transportation in the downtown area since it is the only means of public transportation offered in downtown Worcester. The bus system serves a variety of age groups but is particularly patronized by the elderly and the young people in Worcester. Many business people do use buses to get to work but the majority seem to drive. ${ }^{7}$

There is both passenger and freight train service in the City of Worcester. And based upon current proposals as well as figures from Amtrak rail service could continue to expand in the future. Currently, Amtrak provides passenger service to a variety locales including New York, Springfield and Albany. Ridership, although somewhat steady over the past five years, declined by over 2000 people 1988 and 1996 according to the Amtrak consumer information. The commuter rail is operated by the MBTA (Massachusetts Bay Transit Authority) and offers limited service between Worcester and Boston. Service was scheduled to begin in the Fall of 1994 but it did not actually start until Fall 1996. There are three morning trains to Boston and three mid-afternoon trains back to Worcester. Beginning with morning and afternoon service, it is expected that in the future commuter service could be offered throughout the day. Freight service operates to a number of the local businesses using some of the same tracks as the passenger trains.

The most problematic aspect of both the rail and the bus service are the stations themselves. The Worcester bus and train stations are located in separate parts of the city, both

\footnotetext{
7 See description and map of Worcester bus routes in Appendix A
} 
just outside the Main Street Study Area. See Figure 4.2.1. Thus travelers who do use these facilities are not coming into the downtown area and taking advantage of the many additional services offered in the Main Street Study Area. This has meant a loss of revenue for downtown shop owners as well as inconvenience an discomfort for travelers using these stations. Access to both facilities is difficult enough by car and almost impossible if one has to use some other form of transportation. The stations are small and not well maintained offering limited seating and few services for passengers and other users. The bus station is south of the study area and the train station is currently located across Interstate 290 from Union Station. They are unattractive and insignificant additions to the city. And at the same time the old train station building. a historic and beautiful building has sat deteriorating. Currently the Worcester Redevelopment Authority (WRA) is overseeing renovation and restoration efforts for this building in order to create an inter-modal transportation center. Here all of the transportation modes would be unified. A symbol of Worcester and its history efforts are in the works to restore the building. Completion of the Environmental Impact Statement (EIS) determined that only partial restoration of this building was possible and that the rest must be renovated due to the limited documentation available for the building. ${ }^{8}$ Once completed, this building would be the primary transportation center for the entire region, increasing the importance of the City of Worcester for travel. Ideally, all train and regional bus travel would originate from this location with many of the city buses having stops or this location as their final destinations. In the station itself, shops and eating facility are being proposed, making it similar to train stations in other cities which have recently be renovated. Current design proposal have recommended that upper floors of the building be used as small conference space.

\subsection{Interstate Commercial District}

Circulation is the defining characteristic of this district, specifically the streets and cars. Unlike the two other districts, there is little public transportation in this area and the streets (and

\footnotetext{
8 Other solutions considered included no renovation or restoration, partial restoration and full restoration.
} 
parking areas) are very broad. The streets which run east and west through the district such as Central and Vernon streets provide access to and from the highway, Interstate 290. These are most heavily used for business travel and thus one finds little traffic there on weekends and holidays. These roads are not the typical connectors. Generally, planned arterials which provide the major access into and out of a downtown area from a highway would have some basic characteristics. They would be wide enough to accommodate the necessary traffic, perhaps having two lanes of traffic in each direction, they would have services and uses along them which would assist motorists but not hinder the flow of traffic. They would be attractive additions to the city, foreshadowing what one is to find in the city itself. Vernon Street is problematic in that it is not wide enough to both accommodate the many uses along it as well as provide access to and from the highway. Many people double park along this street in order to access the many businesses located here. This internupts the flow of traffic. In addition driving is treacherous along this road since there are many potholes and bumps along it. There is little if any directional signage and the signage which is available is difficult to read. Central Street is unusual in that it offers enough travel lanes for traffic but has very few uses along it. Thus it is underutilized after business hours. Similar to Vernon Street it has poor signage and is not an attractive addition to the city currently offering few amenities for pedestrians or motorists.

Another important transportation route in this city is the rotary in front of the old Union Station building. This series of roads is important in that it currently provides access from the residential neighborhood to the east, into and out of the city. The rotary itself was re-paved by the city last year. But due to the potential traffic generated by the redevelopment of Union Station, designers are considering removing the rotary and replacing it with a four point intersection. The lack of coordination suggests that options be carefully studied and presented before a final decision is made.

The main roads running in the north/south direction act as connector roads between the residential areas which bound either side of the city. These roads are unusually wide made specifically to accommodate the traffic generated by the Worcester Centrum. With the 
construction of the new hospital facility and the addition to the Centrum, and the expected additional traffic generated by the renovation of the Worcester Galleria, although underutilized now the streets could have a very important role in the future.

\subsection{Main Street Commercial District}

One of the most congested streets in the Study Area is Main Street which is the center of commercial and business activity. Main Street is a two-way double lane arterial along which most of the downtown traffic circulates at one point or another. There are nine lights on this road which control the movement of traffic. These lights allow for a continuous flow of traffic between Main Street itself and the connecting side streets but currently the sequence of the traffic lights seems to worsen the traffic rather relieving it.

Another reason there is a great deal of congestion on Main Street is that most of the side streets which cross Main Street are one way streets. This forces motorists to use often very circuitous routes to get to their destinations. Although this is an inconvenience there does seem to be some basis for this street layout. Many of the one-way streets, particularly on the eastern side of Main Street, are narrow and extremely steep making it preferable to have all traffic move in one direction on them, particularly in inclement weather. The remaining streets seem to have been designated one-way in order to correspond the narrower ones. The street are laid out in a pattern which slightly conforms to the natural landscape and this basically determines the form of the remaining land. Besides the many one-way streets in the Worcester downtown, there are also a number of other factors which contribute to the congestion there. They include: the limited use of the area by pedestrians most people choose drive into and around the downtown(too many cars and too few pedestrians), the timing of the traffic signals and the on-street parking, the delivery trucks making deliveries to the various shops and offices in the area.

As noted in a preceding section of this report, pedestrian use of the Study Area is limited because many of the public amenities which once were provided on the sidewalks and other pathways in the downtown area are no longer found there. Thus the streets do not 
encourage a great deal of pedestrian use. So, instead of parking in a parking lot and walking to various destinations along Main Street and on other streets, people choose to drive to each place they want to go. In addition, along some streets, there is limited on-street parking to accommodate the short-term visitor but in many cases parking directly in front of the building is not available. When parking is unavailable, many people will park illegally in front of a building rather finding legal parking further away and walking back to the building. This directly interferes with traffic on Main Street because in those places where parking is not provided in front of the building, the area is either used as a lane of moving traffic or it is a bus zone. And if either of these use is blocked even for a short period of time this can cause a tremendous traffic problem.

The traffic signals also cause tremendous congestion in the city. The signals are not synchronized in such a way to facilitate the flow of traffic along this road. Some of the lights on side streets are very short which creates traffic in the intersections as cars run the light after it has turned red. This hinders the continuous flow of traffic on Main Street by stopping the cars at various lights for too long. There are no sensors at the intersections to distribute cars on an as needed basis.

\subsection{Residential Commercial District}

The circulation in this area works relatively well. The main problem seems to be the overall condition of the streets. They have not been re-paved in many years according to the traffic department. According to a representative in the Traffic Department, the city of Worcester does not have adequate funding to re-pave the streets as needed. Instead, developers proposing new construction or the rehabilitation of an existing building or parcel of land are encouraged to re-pave those streets which are adjacent to or will be impacted by the development. There is little remaining space in this district for new development and thus the city is going to have to make great efforts to raise the funds necessary to maintain and upgrade these streets as needed.

The street layout in this district appears to be quite functional. There are a couple of 
unusual intersections created by too many streets coming together and weaving around existing buildings. One such intersection is the intersection of Linden, Chestnut and Harvard Streets. Although it could be improved, the fact that there is minimal traffic on Harvard Street and that the intersection is mostly green space helps to make it more successful than chaotic. The one way streets in this area Chestnut and Linden Streets, function in a positive way. They allow business traffic to occupy this edge of the district and move with out impediment through the area. It also creates an additional buffer from the more residential section of the district to the east. In general the streets in this district are well utilized and not too over-burdened with vehicular traffic despite poor road maintenance.

\subsection{Summary}

Circulation and parking will continue to be very important factors in planning for the Main Street Study Area. Currently the roads in general are not as functional and attractive as they could be. The general lack of landscaping elements the poor condition of many of the streets detract from the appearance of the Study Area and can hinder the flow of traffic. The Main Street Streetscape Program will improve Main Street and some adjoining streets to a certain degree but maintenance will be very important. Plans need to be made for the Study Area as a whole though which could be perhaps initiated over time. 


\section{CHAPTER FIVE \\ PEDESTRIAN WALKWAYS AND AMENITIES}

“...successfully pedestrianized downtown retail districts attract significant additional spending because they are an integral part of a functioning central business district..."

(p. 142, Garvin)

\subsection{Introduction}

The Main Street Study Area, as it has already been noted in previous sections, caters much less to the pedestrian than it once did. The impact of the automobile has been great, providing an efficient and effective means of transportation. But to accommodate automobiles, streets had to be widened, signage enlarged and increased, and traffic signals put into place and parking facilities had to be constructed. These modifications requiring significant amounts of space necessitated the removal of much of the existing sidewalks, street furniture and landscaping in the area. Slowly such amenities retained a lower and lower place in terms of the allocation of funds and people were less inclined to walk in the downtown.

Road improvements became a number one priority for city administrators and parking close to one's destination became important for drivers as cities became less and less comfortable places to walk in. Looking at the street furniture and landscaping provided in the Main Street Study Area, although some amenities are provided, they are not well planned or designed.

Street furniture and landscaping include a variety of elements which improve the appearance of roads and open space in an area. These items include benches, trash containers, lighting units, newspaper dispensers, telephones, trees grass, and shrubbery which should be integrated, in some reasonable combination, in and around all pedestrian walkways and smaller urban green spaces in cities. These elements along with the other public amenities assist in making the area more pleasant and comfortable for pedestrians and help to improve the overall appearance of streets. The three districts, having developed very differently have varying amounts of public amenities. Each district is at a different level of development and thus there are varying amounts of these amenities in each district. But in general the Study Area as a whole currently provides very few pedestrian amenities, though there are some changes 
being made in certain areas.

\subsection{Interstate Commercial District}

The public amenities found in this district are scattered throughout the district, randomly placed rather than placed where they are needed and most efficient. Trash containers have been provided by some businesses which provide take out food or other such items. These businesses specifically the Honey farms Market and the Donut Shop have placed trash containers adjacent to their entrances so they are more readily accessible to patrons of these establishments. An additional trash container has also been placed at the corner of Central Street and Summer Street. Having seen both motorists, although it can be extremely dangerous to stop along this street, and pedestrians use this container it is apparent that there is a need for amenities in this district. These amenities need to be planned for during the design phases of the proposed projects in order to ensure that they are integrated with current proposals.

There are approximately 12 benches located in this district. Five of these benches are located in the Washington Square Park, which is scheduled to be removed with the renovation of Union Station. These benches are not easily accessible but seem to be used on a fairly consistent basis by residents and visitors. There are very few other benches found in this district. Approximately three benches have been integrated into the wall on the west side post office parking facility from the street. This is a successful screening unit and is the only example in the city showing how public amenities can be designed in with other amenities. Currently, these benches are not used to their fullest capacity primarily because there is very little pedestrian traffic along this part of Summer Street. Also there is no reason for people to sit here currently, there are few attractive views and little activity around this location. One could picture people using these benches to sit and have lunch or to wait for a bus but the surroundings currently are not pleasant enough to encourage people to walk and sit here. There are too many vacant lots which are not well maintained or simply covered with dirt. The other benches in this district are located next o the Union Place parking lot. Seemingly these have 
been placed here for employees of this complex. Also a place for them to sit and take a break or have lunch.

There are no trash containers or telephones in this district. Street lighting is found on the primary roadways such as Worcester Center Boulevard and Summer Street but not on the secondary roads. There used to be more green spaces in this district, but now there is only one, Washington Square Park in front of Union Station. Thus for there to be an additional green spaces added to this district it will be necessary for them to integrated into new development projects or the city will have to reclaim some of the land which is currently held by private developers. So it is unclear what the potential for landscaping and green space is in this district. But there is space available for new public open space in this district as shown on the Land Use Map, Figure 2.3.1. Well maintained open spaces add to the beauty of buildings, blocks and an entire districts. And if open space is carefully planned and integrated into an area, a network of landscaped elements can be created adjacent to paths and sidewalks rather than simply providing individual parcels which are not connected. The coordination of these spaces could greatly enhance not only the appearance of the district and the city but could increase the value of adjacent properties.

\subsection{Main Street Commercial District}

There is very little street furniture or landscaping to be found in this area. The sidewalks in this area are approximately the minimum width, twelve feet, which is only enough room for pedestrian traffic in each direction. The street furniture found in this area includes benches, street lighting, trash receptacles, newspaper dispensers, and telephones. Benches are only provided in two areas in this district. These are the Worcester Common located behind City Hall and across Main Street adjacent to the Fleet Bank Building Park area. On the Common, pedestrians can find a number of benches surrounding the reflecting pool and grass area. The other place where benches are found is adjacent to the Fleet Bank Park. These benches are for passengers waiting for city buses. But because there are no benches provided at any of the other bus stops in this district, not even across the street in front of City Hall, it 
seems likely that these were placed here to discourage passengers from sitting on the grass in the Fleet Bank Park since it is fenced off. Lighting fixtures can be found on all streets in this district. Unfortunately, these fixtures are actually intended to light the streets for motorists rather than pedestrians. So the street lights are placed high above the streets in order to increase the street coverage and as a secondary result, the sidewalks are lit to a certain degree, although not adequately for pedestrians.

Telephones, trash containers and newspaper dispensers can be found intermittently along Main Street but to a much lesser extent on other streets. It is fortunate that these items are available to a certain extent along Main Street but still there are two basic problems. The first is that generally, these items are unattractive and detract from the appearance of the street. The main reason for this is that it is apparent that very little time was taken to choose designed materials that would enhance the appearance of the buildings nearby. The second problem with the placement of these elements is that they are often randomly placed along the street. Instead of clustering elements to accommodate the needs of pedestrians and create a visual attractive stopping area along a sidewalk, one finds a single amenity (or no amenities)such as a newspaper dispenser, a bench or a telephone at different points in the Main Street Study Area. And although these amenities are used by pedestrians they are probably not used as much as they would be if their layout were designed, planned and well integrated into the city fabric.

There is some landscaping in the Main Street Commercial District which are quite beautiful when in bloom, see Figure 5.1. Many of these landscaped areas in this district are adjacent to local government and institutional buildings, such as City Hall. The grounds around these types of public buildings area typically well maintained which allows the plantings to continue to flourish. These areas have a combination of grass, trees and shrubbery usually. In general, though, one finds fewer examples of this in the Main Street Commercial District. There are few amenities or landscaping elements such as trees or plantings in this district. Instead, sidewalks are merely another paved surface which connects the street to the buildings. There are some examples of street furniture and landscaping found in the district, 


\section{Figure 5.1}

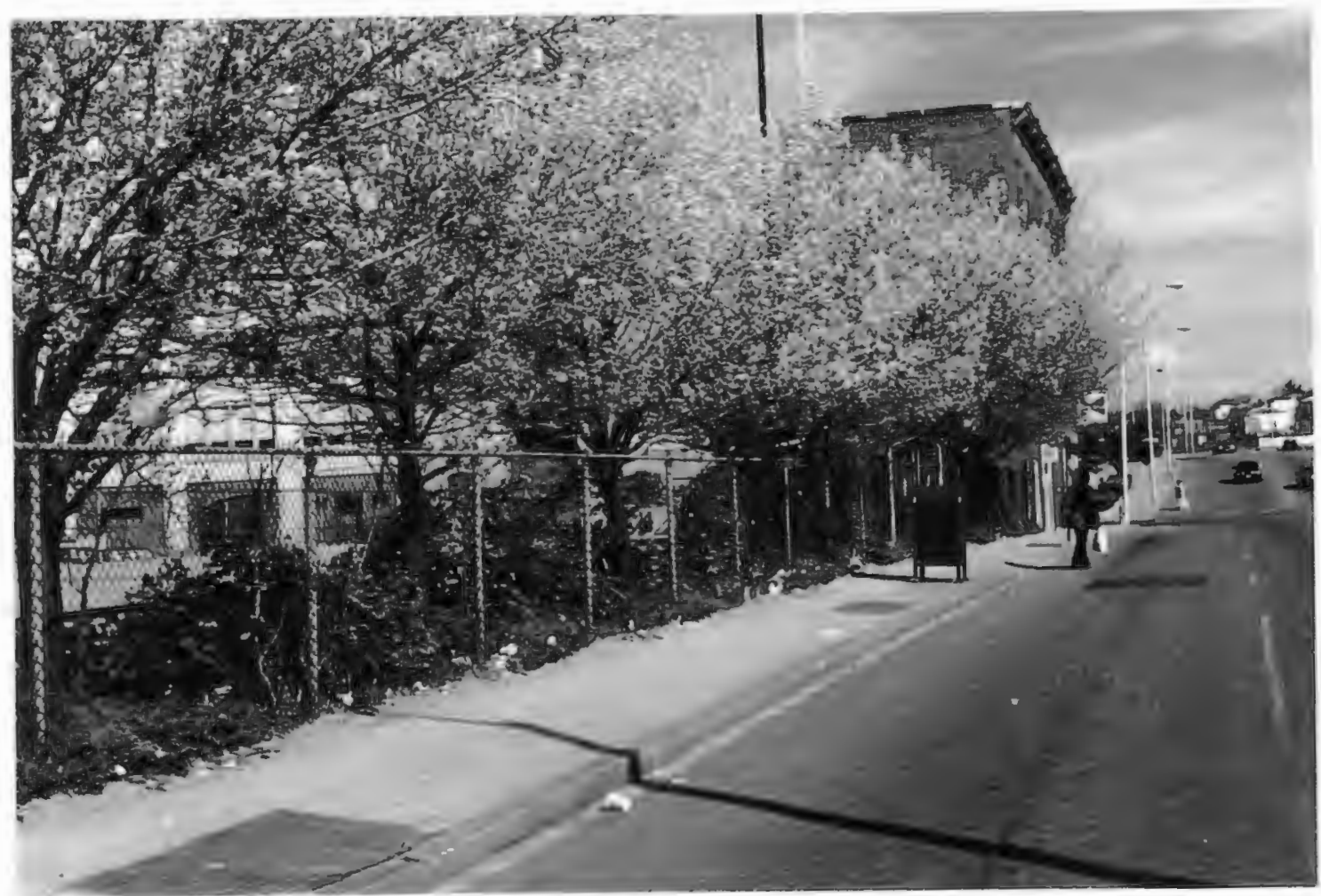

\section{Main Street Commercial District Trees and Plants Are Attractive Screening Elements Trash Detracts From Appearance}


where the landscaping is used as a screening element and to visually accent the space. But these areas are often not well maintained and thus lose their effectiveness quickly. For example, behind the bus stop which is adjacent to the Mechanics Hall is a row of small plans and bushes. If these plants are cared for an continue to grow, they will adequately screen the parking lot and cars which are on the other side from the people who sit and wait at the bus stop. But maintenance will be of primary importance if this technique is to be effective.

Currently the plants are not large enough, so they may need better maintenance or they may be the wrong type of plant for this climate and for the amount of space available.

\subsection{Residential Commercial District}

This part of the study area has considerably more landscaped areas but like the first two areas is lacking street furniture. There are no benches, telephones or other such amenities found here at all. As stated earlier, few people choose to walk in this area because of the exposure to the traffic on the sidewalks and the lack of amenities. There are also significantly fewer street lights found in this section which makes walking less desirable in the evening.

Landscaping in this area is handled by the individual resident or business owner. And because most businesses in this district have moved into converted single family houses, the network of small front yards once connected to the residential uses still remains attached to the new commercial use. Thus the network of green spaces which defines this district is still present in all areas of the district. See Figure 5.2. But there are few open spaces or landscaped areas which are maintained by the city in this district to complement and ensure that a network of green spaces remains as a defining characteristic in this district. In addition, while this district does have more landscaped green spaces, there are still few other amenities found here such as benches, telephones or trash containers.

\subsection{Summary}

There are very few examples of street furniture and landscaping in the Main Street Study Area. But while there are certain problematic areas there are also some places where these elements are provided. First, there are many civic, institutional and private enterprises 
Figure 5.2

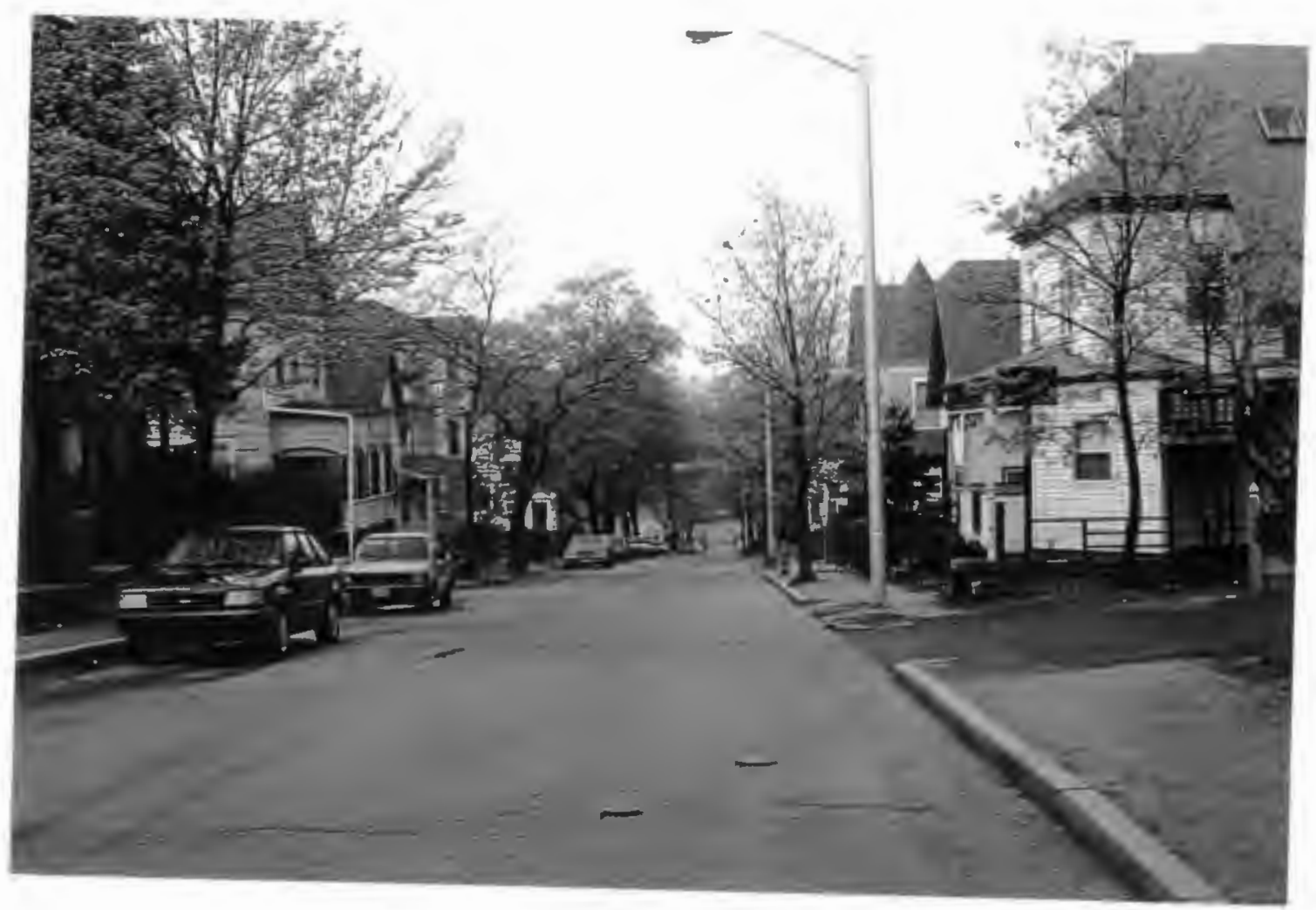

Residential Commercial District Front Yards Create A Visual Open Space Network 
which maintain the landscaped areas around their property. Although this does not replace the need for landscaped public areas along the street itself, this does significantly improve the visual quality of the 'streetscape' as well as making it more pleasant for pedestrians. Second, these amenities are most needed in the Main Street Commercial District and one can see that there has been attempts made to provide some of these amenities. Third, lighting is consistently provided in the study area. There are a number of problems also.

The most significant problem related to pedestrian amenities and street furniture is that there are limited public amenities provided in the Main Street Study Area. And in those places where amenities are provided, they are not well maintained on a regular basis. The Interstate Commercial District and the Residential Commercial District provide very few amenities for pedestrians. The Main Street Commercial District provides more amenities for pedestrians but the intensity of land use by pedestrians is also substantially greater here so proportionally there is still a shortage similar to that found in the other two districts. A second problem is that most of the sidewalks in the study area are not wide enough to provide needed amenities and still accommodate the daily pedestrian traffic. Third, in those places where amenities such as benches are provided there is no planned distribution which would guarantee that the location will provide the most efficient use of the amenity. Fourth, the amenities currently provided along Main Street have not been designed so that they contribute to the overall appearance of the street and make the best use of the space available. For example perhaps one or more amenities can be integrated into one unit thereby taking up less space on the street. Lastly, sufficient landscaping is not provided in the study area. Natural elements such as trees and plantings not only improve the city visually but help remove many of the toxic elements generated by motor vehicles and other activities in the area. These problems further encourage people to drive through downtown Worcester rather than walking and make the streets appear stark and desolate. 


\section{CHAPTER SIX \\ ACTIVITY SUPPORT}

"... the project is located and designed in a manner that ensures its occupants will generate additional market activity in surrounding areas."

(p. 122, Garvin)

\subsection{Introduction}

Cities throughout the United States offer special events, activities and sites to entertain and attract both residents and visitors. These events contribute to the overall success and character of a city but also serve to distinguish one city from another. Business and commercial uses are the primary activities which occur in downtown areas and are generally considered the most important activities taking place downtown because they directly contribute to the cities economic growth, vitality and prosperity of the area by attracting shoppers, workers and tourists to that area. And although these activities are essential to the basic operation of a city, there are numerous other activities which also contribute to the vitality of cities. These events generally occur at special times during the year and in specialized locations in a city and help to make the city unique. Even those events which happen in a number of cities, such as First Night, are (and should be) made unique by the difference in the, theme, the planning committee, the attendees and the scale of the city and the event itself. These events should specifically be designed to cater to and attract residents of the city primarily and visitors to the city secondarily. Activity support, when fostered in an urban environment contribute to a city's character and also contribute to a city's economic vitality. Such events identify a city as a destination, make it distinctive and can help to improve the overall impression one has of the city. The broad term activity support will be used to describe these many and varied events.

Events included in the broad category defined here as activity support share a number of general characteristics. First, these activities tend to be unique, if not in type than in execution reflecting the character of the people living in the area. For example, the running of the bulls in Pamplona, Spain and the Palio Horse Races in Siena, Italy are unique events which are not offered in other cities around the world. First Night, on the other hand, is an 
event which is offered in many cities in the United States including Worcester and Boston. But because the planning and the number of people expected to attend differs greatly the events themselves are very different.

Second, these events are not necessarily associated with any or one permanent physical structure but instead can occur in a building, in open structures such as in tents or gazebos, or outdoors entirely. And the fact that these events often take place outdoors means that the number of suitable for them in the downtown is usually limited. The last shared characteristic of activity support events is that the length of the event varies depending on the type of event. These events can be weekly, bi-weekly, yearly or one-time events. The most beneficial types of events are those which are successful enough to make them worth repeating more than once. Haymarket in Boston, Massachusetts is an example of activity support for that city. The market is open every weekend in the same location. It occupies a city street between the popular tourist site Fanueil Hall and the Interstate 93 Highway. Offering fresh fruits and vegetable from local farmers, it offers a consistent event which attracts people into town on a regular basis to take advantage of the fresh produce and potentially save some money. Movable tents and tables are used to house this event and the street is blocked off. The key to this event is that it does not depend on the tourist population for its success but is instead focuses on the resident population. Only secondarily does it take advantage of wandering tourists who may be in the area.

New Haven, Connecticut, a city which is similar to Worcester both in size and economic vitality, nevertheless has continued despite the many economic problems to offer the weekly concerts on the New Haven Green for residents and visitors. ${ }^{9}$ These concerts alone

\footnotetext{
${ }^{9}$ This summer activity is extremely important to the city of New Haven, which has been in decline for decades. Like Worcester, it was also adversely affected by major government programs such as urban renewal and the construction of the interstate highways. In addition it has a problem which Worcester could also soon have. It has a large entity, Yale University, which has essentially tumed its back on the city of New Haven and contributed to the decline of that city. Other Universities such as George Washington University in Washington, DC have integrated their campuses in with the fabric of the city and utilized the many sevrices offered in the downtown. Yale has attempted to provide most services on campus and utilizes very little offered in New Haven.
} 
provide both residents and visitors to the city with a positive image of the New Haven despite the many other problems which the city has. These musical concerts range in type from classical to country and people from both the city and the outlying suburban attend these concerts some every weekend. Despite the poor condition of the downtown currently, these concerts contribute to the revitalization efforts and help to improve the overall quality of the downtown area. By bringing people into the downtown, the concerts also help to stimulate the local economy in a small way. They bring people into the many businesses in the area, for gas food etc. Also, each weekend, small street vendors open up carts in and around the Green for these concerts. These vendors sell food, programs and other small gifts such as balloons and pennants which are related to the current offering on the Green. In addition to generating additional revenues the souvenirs help to involve the listeners in the program and they add to the festive atmosphere created at the performance.

\subsection{Activity Support in Worcester}

Worcester County is a noted cultural center having many institutions including the Worcester Art Museum. The Worcester Science Center, the Woodman Higgins Armory, which has a well known collection of medieval armor, and the Worcester Historical Society Museum. These institutions provide most of the activities currently offered in the Main Street Study Area. The city over the past few years has attempted to offer other events in the Study Area but most have not been successful and are no longer offered. Two events which it was thought would be yearly offerings in the city were the Worcester Culture Fest and Celebrate Worcester.

\subsubsection{The Worcester Culture Fest}

The Culture Fest was a project designed to bring residents and visitors into the downtown area and to highlight the City's cultural resources as it is expressed in its many institutions and in the performing arts in Worcester. Originally sponsored by the Worcester Business Development Corporation, the Culture Fest lasted for a week in June 1988, and was supposed to become an annual event. A wide variety of events ranging from theater

presentations and concerts to basketball games and a fashion show were provided there. These 
events took place in a variety of locations throughout the city including the Worcester Common, the Worcester Centrum, the Sneiderman Auditorium, and Mechanics Hall. This event was not as successful as anticipated. Planners expected 40,000 spectators to attend and only 5,000 actually participated. This type of program had a number of innate problems. First it stressed the differences between people too much. There is enough divisiveness in the city already and it seems that unity should be a major theme of any planned event for a large number of people in this city. In addition, did not attempt to provide family activities. There were too many different activities which separated adults and children. Thus individuals came to this event rather than families which discouraged use of the other offerings in the city such as restaurants and movies since entire families did not attend. This event should have emphasized the family much more.

\subsubsection{Celebrate Worcester}

Celebrate Worcester was offered for two years in downtown Worcester on the Worcester Common. Unlike the Culture Fest, this festival was geared towards bringing families as well as the business community into the downtown. Ethnic foods and crafts from the New England area were provided as well as hands-on activities for children and other entertainment including a major concert. Admission to all activities was free which made this event slightly more popular. It was also anticipated that this event would be offered on a yearly basis and thus it was held in the Fall and was to be the second major downtown festival in addition to the Culture Fest. Tourists visiting the area and looking at the Fall foliage were expected to attend this event also. A tremendous success in its first year Celebrate Worcester also is no longer offered.

Despite the failure of these activities in the city, Worcester continues to develop events to encourage the gathering and celebration of its residents. Most of the events seem to happen outside of the Main Street Study Area though, which is not beneficial to revitalization efforts in the Study Area. The events which still do take place in the Study Area are smaller and with few exceptions focus on particular interests groups rather than on a unified Worcester. Events in the 
Worcester as a whole continue to be documented in various pamphlets and publications in the city including "What's Happening in Worcester County, a BI-annual bulletin put out by the Worcester County Convention and Visitors Bureau and the Worcester Magazine which is published by the Worcester Telegram and Gazette.

\subsection{Latin Festival}

The Latin Festival is currently offered each summer in the Main Street Commercial District and as the title indicates offers food music and other events which highlight Latin culture. This event has been a success to date and will again be offered in 1997.

\subsection{Shriner's Parade}

A Parade offered by the organization in September travels along Main Street to Lincoln Square. This parade is also well attended according to the Convention Bureau and will be offered again in 1997.

\subsection{First Night}

A popular way to ring in the New Year in many cities, First Night is also a major event in Worcester. There are a variety of performances including mime acts and musical entertainment. There are also storytellers, a parade, ethnic foods and a fireworks display at the end of the evening. This event is oriented exclusively towards families and is intended to attract a large number of residents into the downtown.

\subsection{The Worcester Common - City Hall Plaza}

Worcester Common is the site used for many activities in the summer and was also the site of some culture Fest activities. Providing a substantial amount of seating and a natural setting which includes trees and a reflecting pool, many people are drawn to this area. Besides the events for the cultural Fest, a number of other activities also take place here. In the summer, a bandstand is erected for concerts and other types of entertainment. This encourages spontaneous performances which allows individuals to show their talent and adds a unique quality to the city itself. Unfortunately, the fact that all of these events are not organized also detracts from the success and quality of the performances. The reasons for this are first, 
because an organization has not been established or designated to monitor these performances, the talent is not screened so that the quality of the performance is not guaranteed and elements of the performance, such as the noise level, can not be controlled. Second, because a formal contract is not made with the performers, performances are not guaranteed. And finally, because all of the events are impromptu a schedule can not be provided to inform people of the type of performance, the date and the time, allowing them to plan to attend. These problems are significant enough to prevent such activities from making a positive contribution to the activity support component of the city.

The street vendors and the Worcester Lunch Car restaurant have provided activity support in the Common in the past. They encouraged activity in the plaza around lunch time and encouraged people to use the Common on nice days as a meeting place and a place to eat lunch. Located on the eastern corner of the Worcester Common this movable car is shaped like an old railroad car and was declared a historic landmark by the Worcester Historical Society. The restaurant located in the car served lunch for sit down customers but offered a take out menu for those who could not fit in the car. Because the food has been good in the past and the prices reasonable, the restaurant could be very crowded during the summer. Street vendors sell individual items such as hot dogs and soft drinks and serve a variety of people including students and business people. Both encourage the use of the Common by a variety of people by offering them an interesting selection of foods at lunch time and a pleasant setting to eat in. In the winter there is little activity in the Common. The city considered having ice-skating on the reflecting pool but this was not considered to be viable use in this location. Thus the Common is still rarely used during the winter months.

The Common is an important part of downtown Worcester adding to the life and vitality of the city in many ways. First it is the largest green space in the Main Street Study Area, a large exterior space which can accommodate a wide variety of activities. The natural and the limited pedestrian amenities which include benches and trash receptacles encourage people to sit in and stroll through the Common. As stated above, the street vendors and the Worcester 
Lunch car, and impromptu events encourage people to use the area. Finally, planned events, such as the Culture Fest, which make use of the Common for particular segments of the event also encourage patronage of this park. But despite these positive aspects, a great deal more could be done to bring people into the city and to the Common by solving some of the problems associated with the design, maintenance and scheduling for the Common.

The problems associated with the Worcester Common basically fall into two categories: problems caused by what exists and problems caused by what does not exist. Based upon this research, when looking at Worcester Common there appears to be three things missing: 1) a controlling body or an organization 2) an adequate number of activities taking place in the Common on a regular basis and 3) security. The second two problems are really a result of the first. Without an organization or group that is specifically in charge of the Common it is difficult to plan, coordinate and monitor the activities that do take place. Security is a problem in that currently people do not feel safe using the Common after sunset.

There are also a number of problems with the activities which currently take place on the Common. First, they primarily take place in the summertime. There are almost no comparable activities in the Fall and Winter except ice-skating but it is often not cold enough in the downtown to freeze the reflecting pool. Second, besides only operating in the summertime, the Worcester Lunch Car and the sidewalk vendors have very limited hours, usually only open during lunch time. Therefore, with the exception of some spontaneous events and the events planned for the two weeks of the Culture Fest on the Common, there are few activities to bring people together there. Finally, particularly in the summer, there appears to be a large number of elderly people and students who make use of the Common and the current activities do little to address these groups.

\subsection{The Worcester Music Festival}

The Worcester Music Festival is the oldest festival of its kind in the United States and is the best example of activity support in the city of Worcester. Started in 1858 the festival is held annually, usually during the month of October. Concerts are offered in venues such as 
Mechanics Hall during the week of the festival. The concerts vary in type from classical to modern to attract a wide audience.

\subsection{The Eastern Sprints Rowing Championship}

This world-class rowing competition involving the most prestigious colleges and universities is hosted by the Worcester Chamber of Commerce and sponsored by a number of business concerns including the Worcester Business Development Corporation. Although not held in the Main Street Study Area this event is included because it is expected that the spectators drawn to this event could, "...prove valuable to the city's economic development." (Worcester Telegram 3/13/89) As further encouragement VIP passes were provided to the first 1,500 executives and alumni who responded to the invitation entitling them to brunch and parking and cups sweatshirts etc. were made with the eastern Sprints logo. These measures would hopefully encourage these business people to invest in Worcester at some point. So this event could potentially influence the downtown's economic growth and it reflects the fact that the City administration is looking both to the present and the future.

\subsection{Summary}

There are few events offered in the Worcester Main Street Study Area which encourage residents and/or visitors to utilize the valuable resources and services provided here. The many attempts to initiate events in the past and the continuing efforts to do so indicate an awareness

of the need for such activities. Thus far though there few events which occur on a regular basis and are designed to attract residents and visitors as whole rather than based upon cultural and/or economic differences. Family activities and events need to be promoted on a regular basis. The city should determine the appropriate goals and objectives of such events and then design events to meet them. Two basic categories for the goals and objectives should be taken into consideration. They are issues related to the users or people and spec-related issues. Based on the past the success and failure of past events, some of the goals for these events should include, bringing people into the Main Street Study Area, providing entertainment to the users, encouraging the well-being of the users, and encouraging families to attend. Activities currently 
provided here are well attended by the segment of the population they address. Free activities should be included in the events where possible in order to attract larger audiences and should be catered specifically to the needs of families. Efforts should be made to attract families into the Study Area as much as possible.

The primary goal or objective with regards to space should be to contribute to the economic and social regenerative efforts already begun by the city in the downtown area. Thus the events should be well planned and executed so that the event will be well attended and financially profitable for organizers. A second goal should be to make better use of the under utilized spaces in the Study Area. Looking at the many pamphlets advertising activities, one sees that most of the activities, with the exception of those in places such as Mechanics Hall and the Worcester Art Gallery, take place outside of the Main Street Study Area and the city as a whole. The Worcester Common and the many surface parking lots in the could be utilized for additional activities and events. Particularly, the surface parking areas although full during the weekday business hours, are empty of the weekends and in the evenings and could potentially be used for planned activities. The specific problems associated with the Common need to be addressed. This is the largest open green space in the downtown area and it is underutilized and poorly maintained. Proposals should be submitted to re-design the Common so that it will become a more attractive and functional part of the downtown.

Residents and visitors must be encouraged to visit the Main Street Study Area on a regular basis, over the long term, because people contribute to the economic and physical vitality of an area and make successful cities. This requires that the proper mix of activities, services and events be offered to attract people to the Study Area on a regular basis. 


\section{CHAPTER SEVEN \\ OPEN SPACE}

"A Park is but one of many public improvements that serve to give character to a City."

-- Frederick Law Olmstead and Calvert Vaux

"...public open space remains an effective tool for shaping the American City. "

c. 1850

(p. 30, Garvin)

\subsection{Introduction}

The term open space can be used to describe any empty parcel of land but it specifically refers to those areas which are designated in city ordinances to remain open or are created by the buildings or roadways which surround them. The main goal of open spaces is to provide high quality comfort zones to pedestrians. Looking at the many well-designed and wellmaintained open spaces found in cities today one can clearly see that they are highly valued spaces in cities and help determine the character of the area. The importance of these parcels is readily apparent when one looks at larger cities such as New York and Washington D.C. Central park in New York City is a park designed by Frederick Law Olmstead which is utilized a great deal both by residents and tourists. And although there are problems with the park, people enjoy using it and living near it since it is one of the few substantial green spaces in the city. Washington D.C. is very fortunate to have not only a fairly large quantity as well as many different types of open spaces. These include the mall in front of the Capitol and the area surrounding the Washington Monument. Some are paved and some are grassy while others are mostly dirt and gravel. And in these spaces one will find people performing, participating in sporting events, listening to concerts etc.

In general the activities which take place in these areas vary from strolling, to peoplewatching to eating. Open space allows people to get away from the many imposing structures found in a city which can make people feel closed in and restricted. The success of these spaces can be measured by how much people use them. While it is difficult to predict usage when planning such an area, there are ways to design open spaces so that they are inviting to people. In general, the overall size and scale of the space should conform to the dimensions established 
by the adjacent buildings and the heights associated with those buildings. Also amenities should be provided for pedestrians which assist in giving the space a scale, specifically a human scale.

Amenities identified by William Whyte and other researchers as contributing in a positive way to open spaces include seating, a water source and places to buy food. Further the way in which these amenities are integrated into the open space itself determines how successful the area can be. Some of the standards set forth by Whyte are as follows: 1) the amount of seating should correspond approximately to the length of the perimeter of the area. The seating should be varied in terms of its location in the site therefore, some should be in sunny areas while others are placed in shady areas. And if there is a grade change in the site then the seating can vary along the grade change. The design of the seating itself is also of great importance. Seating which is made out of other elements in the site such as a low dividing wall or a set of stairs appeals to people. Having some contact with the natural environment, specifically plant life and trees, is another important factor in creating a viable open space. Natural elements such as these contribute to the overall experience of the space, and experience which Burgess defines as, "the pleasures of contact with nature and the natural world." Finally the location of the open space is extremely important in determining the success of the space. Recent articles focusing on a variety cities, such as the city of Pittsburgh, indicate that the way open spaces relate to each other and are integrated into the street system and the built environment of a city are important factors. They will determine how successful the area will be and how well it will contribute to the success of the city as a whole. For example, raised plazas, such as the plaza designed by Philip Johnson for the PPG Plaza in Pittsburgh, it was determined tend to be less successful in terms of attracting users because they isolate the user and are more difficult to enter and leave. The open spaces in the Worcester Main Street Study Area will be identified and described to determine their viability and effectiveness. 


\subsection{Fleet Tower Park}

A beautifully manicured lot which is approximately one and a half acres in size and sits directly adjacent to the Fleet Bank Tower building across from City Hall. There are two walkways in the park which divide it into three unequal portions of green space. The first section is adjacent to an access road to the far left of the site. Here there are carefully placed trees and flowers located along the edge of the walkway. In the center of this space is a large pine tree which itself is surrounded by small plants and flowers. The second section of the site is semicircular in shape and also has trees lining the edge. In the center, is an area of small plants and flowers. The last parcel is a narrow strip of land which is directly adjacent to the Fleet Bank Building. Here there are only one or two trees. Each area is surrounded by a chain and balustrade fence. Visually, this park is a very positive addition to the City of Worcester and the Main Street Study Area. This area is very clean and well-maintained and well-executed partially because it is fenced off from the public. In addition it serves a major function adding natural beauty to the downtown area.

Despite the fact that this park make a positive visual contribution to the city it does not make as significant a contribution as it could. The main problem is that it is not open to the public. The lot is fenced in to prevent people from randomly walking on the grass. There is no seating or other public amenities provided there although it is directly adjacent to a major bus stop and this further deters people from making use of the park. It is clear that it is not intended for public use, and it is not used as a result. This has the unfortunate result of making this park and object like the adjoining building. It is visually attractive but not functional. And because this park has not been made accessible to the public, this area is not as successful and does not make as great a contribution to the Main Street Study Area as it could be. In fact it seems very inconsistent to have an essentially private open space in such a public location, across from City Hall and near at least 4 major bus stops. 


\subsection{The Worcester Common}

This park, located on the western side of the City Hall building, is a major node in the city. First created in the late 18 th century this space has long provided a substantial area for people to gather and events to take place and it continues to be an extremely valuable and beautiful part of downtown Worcester. Within the Common are many of the elements which Whyte identifies as leading towards a successful open space area such as adequate seating, a reflecting pool and a large amount of green areas. There is a great deal of seating in the Common. The majority of the seating is located around the edge of the reflecting pool but there is additional seating further away from the reflecting pool. There are a great deal of trees around the periphery of and in the Common itself which serve to enclose the park to a certain extent and protect it from the traffic which wraps around the park on three sides. In addition to providing this enclosure and being pleasing in and of themselves, the trees help to frame views both in and out of the park which adds variety and privacy for pedestrians and motorists.

Overall. the grounds are well-maintained and this is a pleasant park in which to sit. But beyond the many positive aspects of the park, it is still not used as much as it should be.

There are many reasons why this park is under-utilized. One of the main factors which restricts use is that it is surrounded on three sides by traffic, and often heavy traffic. As noted above, the park used to be considerably larger than it is today and thus in the past was able to support itself through its size. Today, since it is considerably smaller those surrounding buildings and activities need to help support the activity in the park to ensure that the park is used and does not get any smaller. Also the pollution from cars could be damaging to the plants in the Common and discourage users. Another very important problem with the park is that it is not well lit. People have stated that they feel very unsafe walking through the parking even in the early evening hours. This not only limits usage of the park but further discourages people from utilizing other nearby services near the park in the evening such as the library and shops. Because this park is in the center of the city and to help the city in general, these problems need to be addressed in order to make this a thriving downtown area. 
A landscape architecture firm submitted a proposal to redesign the Worcester Common in 1992. The primary focus of the design was based around the suggestion that the art pieces which are now scattered about the City Hall grounds be organized into a logical pattern which would encourage people to walk through the Common. To initiate the design process, the Common has been divided into two parts. The first being the reflecting pool area of the Common, the smaller portion of the park and the second parcel being the area currently lined with trees. Renovating the reflecting pool segment will involve removing the reflecting pool entirely and dividing this area into three segments. The first being a stage which would have lawn seating in front of it. The second would be the war memorial with a fountain and the third would be a lawn are which is slightly depressed into the ground. The lawn in the winter could be filled with water which would freeze and ideally become an ice skating area for residents and visitors. The second segment of the Common posed a different set of problems in that this area is what is left of the old central burial ground, so among all of these trees there are dead bodies underneath the ground. Therefore, landscape architecture firm has proposed that the trees be left where they are and closest to the City Hall building a possible rose garden be developed and in the back more of a botanical garden be planted. This would provide visitors with lush green surroundings which could both be studied and enjoyed.

\subsection{City Hall Plaza}

There is a large paved area in front of City Hall which functions in a variety of ways. Not only is it the major access to the building but it is also the major bus stop and waiting area for riders as well as just a place where pedestrians can walk by or sit. Thus it has a dual nature in that it is both a formal place where City officials enter to go to important meetings or to their offices, but it is also an informal waiting area for pedestrians and bus riders. Given this dual nature any design suggestions should address these uses.

Currently, the area is extremely dirty and unattractive. The large space encourages people to come and sit in front of the building but unfortunately there are only a few places to sit and these are not very clean. 
The landscape architecture firm recommended that this area be divided into two sections similar to the way it is now with a few steps separating the two parcels. The upper section in their proposal would provide seating and have small food vendors so people could seat their and perhaps eat lunch yet not interfere with the pedestrian traffic. The lower section would have bus shelters and trees planted at the street edge. The entire area is to be re-paved with the concrete block and granite runners in between just as is proposed for the rest of Main Street.

\subsection{Washington Square}

Older pictures show that the original green space within the rotary was once much larger. This space, often considered to be leftover space, has a memorial with sixteen benches around it and it makse a significant visual contribution to what otherwise is a rather desolate area. People at times sit here when it is warm and watch the traffic or read. In addition, Washington Square functions as a formal transition space into Union Station. With renovations to the Union Station building proceeding, this space should be preserved, not necessarily in its current form, but an attractive open space should be designed for the front of the station. This open space is an attractive addition to this area where streets and cars are the main visual stimulation. Sometimes, the grass is overgrown and not cared for, making the space less inviting. Maintenance will have to be addressed in the future if Washington Square is to survive.

\subsection{Federal Plaza}

This plaza is located at the intersection of Main Street and Southbridge Street. Here the plaza had been underutilized for a long time. The plaza over the years had become a small parking area for the Federal Building providing mostly short term and special parking. This area could accommodate approximately five to seven cars at any one time. Two years ago this lot was re-designed and re-built as a small urban park. Designed to be open while also providing users with a sense of protection from the street traffic, the architect utilized both landscaping and structural elements to achieve this goal. The incorporates a number of elements including a fountain, trees, and a semi-circular columnar structure which creates a porous 
barrier where Main Street and Southbridge Street meet. This park increases the amount of usable open space in the Main Street Study Area and provides a pleasant place for people to sit and have lunch. Although, a matter of taste it seems as though the design is slightly overdone. The structure is too large for the size of the park and the spaces in the park are under-protected and could have been greatly improved in a number of less costly ways. First given that the park is bounded on both sides by busy streets a screening element is necessary. A dense symmetrical, arrangement of trees would have been more effective at defining and enclosing this as park space. And a grouping of trees would have also been more attractive and pleasant for users and a better juxtaposition to the masonry Federal Building than another masonry structure. Second, natural vegetation helps to filter the air, more and more an important concern as the numbers of cars on the roads continues to increase and environmental, specifically air quality is becoming more important. In addition, as the crowns of the trees continued to grow, they would provide significant shade and protection for users of the park and the park itself. Finally, trees are more subtle elements and they help to soften the already hard edges of the Study Area.

Federal Plaza is an important addition to the Main Street Study Area offering additional public open space, which is limited here. It also provides a symbolic entrance to the Main Street Study Area and the downtown as a whole. Thus it is likely to become a part of Worcester's long history. Nevertheless, more careful planning of the space, although initially less formal10 than the current design, would have improved made the park a more comfortable place for people to sit and relax and over the long term become more .

\subsection{South Lincoln Square Open Space}

This space referred to in this section is located between the Holiday Inn and Lincoln Square. Although, this area is currently overgrown with shrubbery and trees, it does have the potential to become part of the gateway into the city. The lack of care and maintenance for this

10 As trees continue to mature, they often provide a more formal atmosphere than the structure currently imposed on a space because the light quality in the space is cnstantly changing, and while screening it also allow's views through to other areas. 
area is suggests that the potential of this space as attractive visual open space is not realized. It may not be appropriate to design the space so that it is directly accessible to pedestrians, but plans should be undertaken which will develop this space in to an attractive visual open space perhaps providing needed directional and informational signage for motorists entering and exiting the downtown.

\subsection{Summary}

There are a number of spaces in the Worcester Main Street Study Area which have been and could provide better open spaces for the city and its residents to use and look at. Some initiatives have led to the conversion of space such as in Federal Plaza. Currently the Interstate Commercial District offers the best opportunity for new open space to be developed in the city. Now that much of what once existed there has been removed, new designs could incorporate designed open space into this district. 


\section{CHAPTER EIGHT \\ SIGNAGE}

"The easy availability of local-area information..."

(p. 464, Garvin)

\subsection{Introduction}

Signage is an extremely important means of communication in communities today. Signs provide important information to residents and visitors including information about, "... business identity, location, and goods and services provided..." in a region. (Shirvani p.42) In addition, signs, through their, "...image character and form..." (Shirvani p.42) function to further enhance the appearance of businesses, street facades/walls and the city as a whole. Therefore, when well planned signage can be used to improve the overall appearance of a building, to provide coherence to the street facades, and to direct people through an entire city. There are many types of signs found in cities today including free-standing signs such as highway signs, window signs, projecting signs, billboard or building signs and canopy or awning signs. And these are the types of signs found in the Worcester Main Street Study Area.

Signage in the Main Street Study Area serves two main purposes; to advertise, providing information about events, local sites and resources; and to give directional information. Advertising signage includes those signs which identify businesses, their locations and products, events etc. Advertisement signage can be found throughout the city, the location of the sign not necessarily corresponding to the location where the product can be purchased or to a specific business location. Directional signage provides motorists and pedestrians with the necessary information to travel through the city, identifying streets, important intersections landmarks, buildings, etc. The term directional signage will be used here to refer to signs which provide information such as streets names, speed limits, bus stopping areas, warning information and any other information which assists in guiding motorists and pedestrians through the Main Street Study Area. Directional signage is an 
essential part of any city or town. It determines how accessible the area is and will be to motorists and pedestrians. When properly designed and integrated into an area it can provide comprehensive information about streets, buses and other important information residents and visitors might need.

\subsection{Directional and Locational Signage}

Directional signage though present in the Main Street Study Area is not utilized as fully as it could be here. Similar problems exist in all three districts and thus they will be discussed as a whole in this section of the report. There are three major problems with the directional signage in the Main Street Study Area. First, there are too few signs provided in the district to properly instruct and guide users in the area. Directional signage in this district is very limited which makes navigating through the Study Area difficult at times. One of the main reasons for this is that there are numerous one way streets here which can make it difficult or impossible for motorists who are unfamiliar with the area. Therefore, having adequate numbers and types of signs which are easy to read will make travel easier and safer. Second the signage which is provided is not designed and integrated. Thus the information which does exist is hard to find and often difficult to read. The size of many of the signs in the Study Area are often to small to read from any measurable distance. Street signs and bus stop signs are relatively small and are difficult for motorist especially to decipher and are also hard for pedestrians to read if they are more than three of four feet from the sign. The colors and lettering styles have not been well thought out and thus none of the signage really makes an attractive addition to the overall appearance of the downtown area. Finally, there little or no signage which is devoted to identifying important city landmarks specific points of interest or areas in the city. Thus there is a basic problem of unavailable and unclear information. There are no signs to guide people to City Hall, Worcester Common or Federal Plaza. Therefore it is very easy to overlook these destinations when one visits the city. These problems will be discussed in greater detail in the following section of the report. 


\subsection{Problems with Directional Signage in the Main Street Study Area}

\subsubsection{Insufficient Information to Guide Pedestrians and Motorists}

The Main Street Study Area has a number of landmarks and places woven into the city fabric. Thus, the many one-way streets, which are also a part of the complex urban network, make navigating the area even more challenging, particularly for those who are unfamiliar with the area. The most common problem found in the district is the change in the street names. The Study Area has many street which have one name on one side of a crossing street and another name on the other side of the crossing street. For example, if one travels east on Foster Street to Main Street, the name of the street changes from Foster to Elm Street upon crossing Main Street. To know this, the driver must notice the change before crossing Main Street, otherwise there is not another street sign indicating the name change until after the driver crosses High Street. And one is not always able to read the street signs while driving, particularly when there are heavy volumes of traffic on the road. Also, the size of the street sign and the speed at which traffic moves along the road make reading the signs more difficult. Pedestrians can also have a problem seeing the street signs at intersections, particularly if one is standing across the street from the sign. This problem is made worse when street signs are missing entirely, which has been a problem in the past. The Elm Street street sign which is located at the intersection of Elm, Foster and Main Streets was missing for a period of time which made travel more confusing and difficult since the name of the street changes at this intersection. Such confusion can deter visitors from coming into the city and utilizing the services which are available here. Thus it is important that all signage be provided and maintained. This includes signs which designate one was streets, bus stops, and other important information. One way signs are not provided as often as one might like in the Main Street Study Area. Though they are found at least once on most streets, reminders are needed along the lengths of these streets. Currently, one can often find motorists making wrong turns onto one-way streets due to the minimal information which is currently available in the Study Area Directional signage to major roads such as Interstate 290, Grove Street or Highland Street is also difficult to find in the Study 
Area. And there are almost no signs to guide users to important places such as the police station, the bus station or the train station. Some of this may be remedied when the new Union Station project is completed, nevertheless since these issues have not been addressed to date, it is unclear how well they will be addressed in the future.

The problems for pedestrians are even more pronounced since most of the directional signage here is oriented towards motorists. There are no signs or maps to direct pedestrians to the important sites or streets in the study area. In fact almost no information is provided for pedestrians at all beyond the basic street signs. Even important services such as the police station and restrooms are not called out currently or distances to sites provided. And because this information is not provided, people are discouraged from walking to their destinations since the distances are unknown and are not specified.

The need for this large amount of information in cities to better assist both residents and visitors further requires that the signage be designed and then integrated into a package which is functional and attractive, enhancing the appearance of the area rather than detracting from it or overwhelming the area.

\subsubsection{Poorly Designed Signage}

Poorly designed signage is a problem throughout the Study Area. There are three basic problems. First, much of the directional signage is too small to adequately assist either motorists or pedestrians. Throughout the Main Street Study Area and the city of Worcester as a whole the typical green street name signs are found as are found in most cities across the United States. These signs are easily identifiable and, in a cursory way, a continuity with other cities has been established. Unfortunately these signs are often difficult to read which is the case in the Study Area. Currently in the Main Street Study Area one finds the traditional green street name sign which are approximately three inches by eight inches in size. While these signs are functional many cities have opted to use larger signs which are visible from great distances. Street signs in Pittsburgh, Pennsylvania have been changed to large blue signs which not only distinguish the city but are very easy to read. (See Figure 8.1) Street signs in 
Figure 8.1

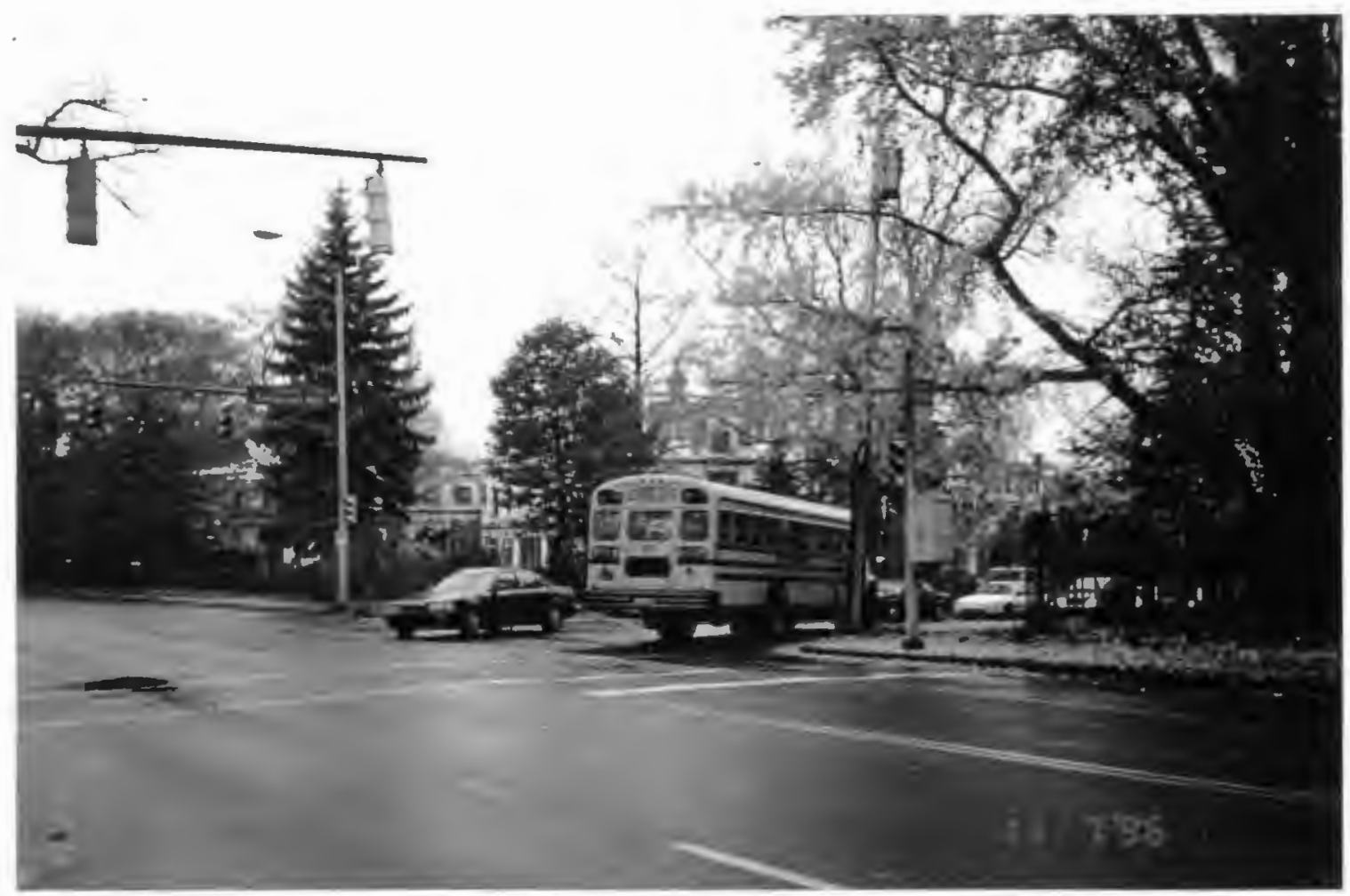

\section{City Of Pittsburgh}

One Example of Larger Street Signage 
the Study Area are almost illegible compared to the signage which is provided in Pittsburgh.

A second problem with the directional signage in terms of design is the signs

themselves. They are as a whole unattractive additions to the Study Area. And because they do not contribute to the appearance of the Study Area they are not functioning to their fullest potential. Currently the colors are drab and the sizes do little to indicate what types of information they are communicating. For example, the signs which identify bus stop locations are not only are very plain and do little to capture the attention of the viewer. This signage could utilize the colors of the WRTA in a more dramatic fashion in order to improve the look of signage as a whole in the Study Area and the city. More importantly, they are confusing because they look very much like the parking and the no parking signs found in the city, both in terms of the lettering and the overall size of the sign. These signs, examples of which is shown in figure 8.3 , are too small to viewed at a distance and their close resemblance to the parking signs, which are found in similar locations throughout the Study Area, heightens the confusion. This can be very confusing for both motorists and pedestrians, particularly to elderly users whose vision may not be as strong as it once was. While parking signs tend to be more traditional in cities, one sees much more experimentation with bus stop signs, one example being the bus stop signs found in the Washington, D.C. area. Experimentation with the parking signage is also not out of the question.

The organization of signage in the Main Street Study Area is the last problem related to design of the directional signage. Currently, directional signage is randomly distributed throughout the Study Area. Placed on individual poles often the information is not coordinated in an intelligible way for the users of the information. Using the example of Pittsburgh, one knows to always expect a large signage unit at all major and secondary intersections on which one will find the major street names, one-way information, and other information about upcoming places coordinated into the sign. Thus users always know what basic information they can expect to find when approaching an intersection. Within the Main Street Study Area it is necessary to search for each bus stops sign, one-way street information etc. Users do not 
know where to find needed information and this makes the area less desirable and more confusing as a whole.

\subsubsection{Unavailable Information}

Directional signage in the Main Street Study Area is at a minimum. Basic street signage and parking information is provided in a unorganized fashion throughout the districts but additional information which would be helpful to visitors and residents has been completely left out. Directional signage to places such as City Hall, Worcester Public Library and the Worcester Art gallery are basically non-existent. Even signage for the Centrum is limited. Not only does this make it more difficult for potential users of this information, but it suggests that officials in the city do not see these places as the destinations they are. Signage for pedestrians is particularly absent. One is hesitant to walk through the Study Area, because locations and distances are not provided which would allow users to plan their time.

\subsection{Signage which Identifies Businesses, Goods and Services}

Signage in the Worcester Main Street Study Area which identifies businesses, goods and products is varied in style size and location. This variety is partially indicative of the many changes which have taken place in the city and in the changes in the technology of signage construction over the years. Looking at historical pictures of the city, it is clear that signage in Worcester has changed with the city. In the mid to late nineteenth century signage appears to have been very clear and unified in the city. Pictures indicate that the signs on the shops and throughout the city used similar color schemes and lettering styles. The options in these areas were very limited, the end result was a positive one in terms of the appearance of the city blocks and that of the city as a whole. Today the variety of choices which are available to buyers is quite broad. There are an unlimited number of colors, materials and lettering styles available to perspective buyers which allow individual business owners to relay information in a variety of ways. This has led to major changes in the appearance of downtown Worcester.

Looking at shop signs found throughout the Main Street Study Area today, it is apparent the unity once found here has been lost. Instead, decisions concerning signage are 
being made by individual business owners with little consideration for the appearance of the block or the city as a whole. To evaluate this type of signage in each district, this study will primarily focus on the overall design and placement of the sign. These two components are pivotal in determining the impact which a sign has both in terms of communicating its message to the public and on the appearance of the district. Unlike directional signage, the types and styles of the signs vary from district to district, so this section of the report will analyze each district separately.

\subsection{Commercial Interstate District}

The signage in this area reflects the transitional stage of this district. Over the past five years this district has been transformed dramatically as highlighted in previous chapters. These changes have also changed the signage found here. In the recent past, this district had a kind of eclectic combination of new and old signage, a combination sometime found within the signage of one building. The many sign types reflected the many changes which this district has been through including the placing of the highway and the changes in signage types. The old signage was primarily found on the older industrial buildings, many of which have closed. Before their demolition, these industrial uses had expanded over time. And rather than replacing the older signs, more signs were added to the newer buildings. In addition, these uses needed to change most significantly when the highway was built. Most of the goods for the industries were transported on the new highway and thus there was an attempt to make the signage legible from the highway since the buildings were close to it. Yet they also had to continue to address motorists and pedestrians on the neighboring streets. This yielded many clever signage types which have now been removed to make way for the new hospital. Some signage was painted directly onto the buildings such as the sign for the White \& Bagley Company. This company which was once located in this district has now been relocated to the edge of the city. Companies such as the Prime Value Mart and the R \& R Plumbing Supply, which also had numerous and varied signage on and around their buildings have also relocated outside of the Study Area. Understanding how the signage for these companies changed and 
progressed over the years may be informative when planning for new uses and businesses which may locate in this district. See Figure 8.2.

As companies such as the R \& R Plumbing Supply grew and built new buildings, rather than re-evaluating all of the existing signage as a whole, companies would add additional signage to the new building and where ever else space was available on the property. And often a number of signs were added to address pedestrians and motorists both on the local streets and motorists on the highway. They were also probably intended to compete with the signage of other businesses in the district. The end result was that business businesses in this district had multiple signs and the district appeared slightly cluttered with information. The Prime Value Mart Store has 5 different signs altogether, four facing Worcester Center Boulevard and one facing Central Street. The owners of these businesses were seemingly more concerned with getting the customers attention than with the appearance of their property, the street, or the district. Much of the original signage for these companies was well designed and well thought out. For example, the R \& R Plumbing Supply store, once located in this district, has charming sign which has the name of the store integrated into a faucet which has little water droplets emanating from it. These original signs were like signatures, reminiscent of the past uses and character of the district. This type of signage is classic and adds a level of charm which is missing from the signage found in the district today. The newer signage tended not to be as well designed.

The signage for the newer uses found in this district is very diverse, one sign having little or no relationship to another. Some signs such as the Visiting Nurse's Association (VNA) logo sign are more distinctive and reminiscent of the signature signage once found in this district. See Figure 8.3. But currently, most is still rather generic. Given the limited number of uses currently found in this district, signage types are currently a minor problem. In the future, though, as the number of uses increases the fact that there are no guides in place to control what types of signs are placed in the district could lead to the type of cacophony of signage which existed in the past but without the charming signage types. 
Figure 8.2

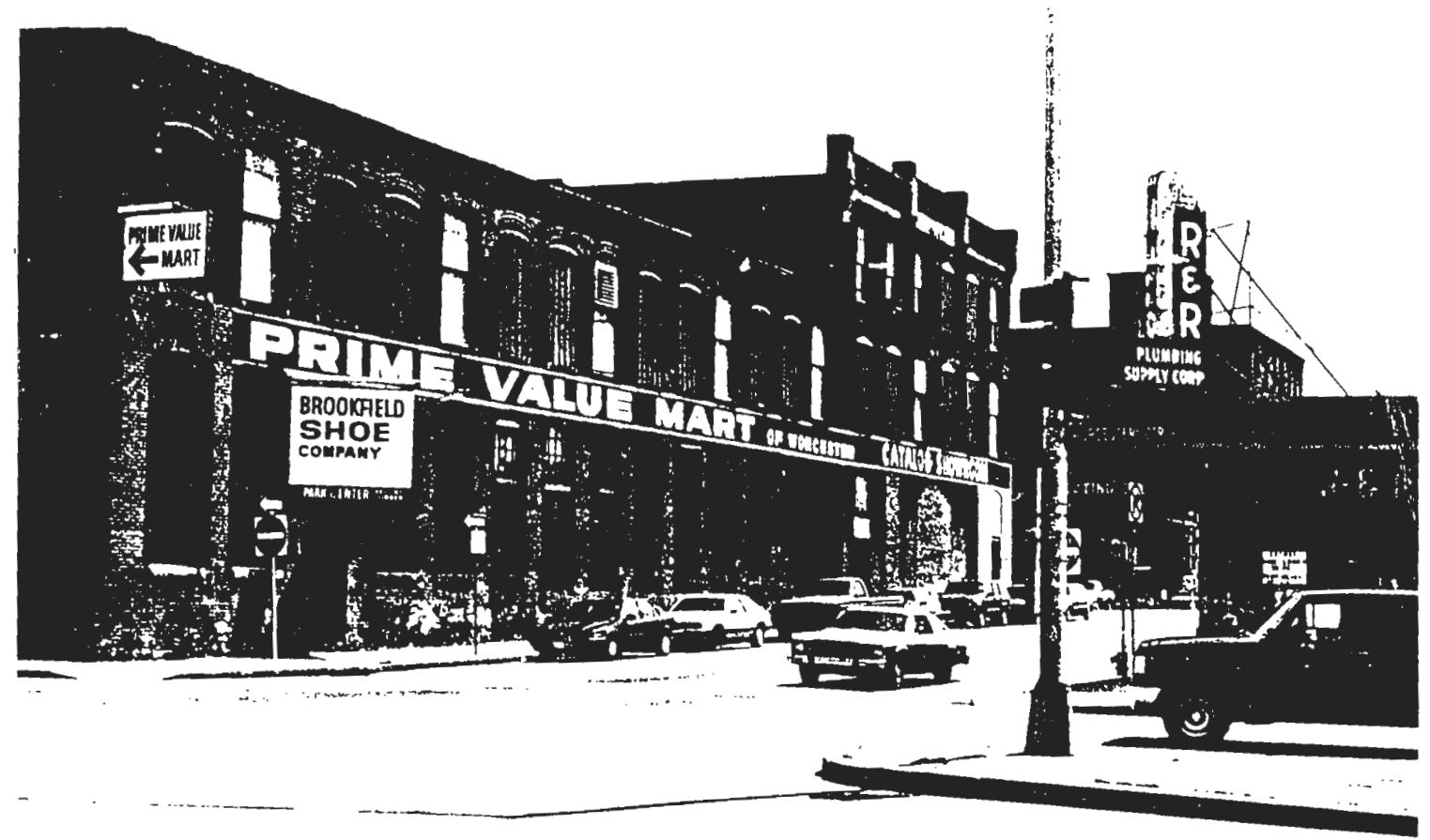

Interstate Commercial District

Examples of Signage Once Found in This District 


\section{Figure 8.3}

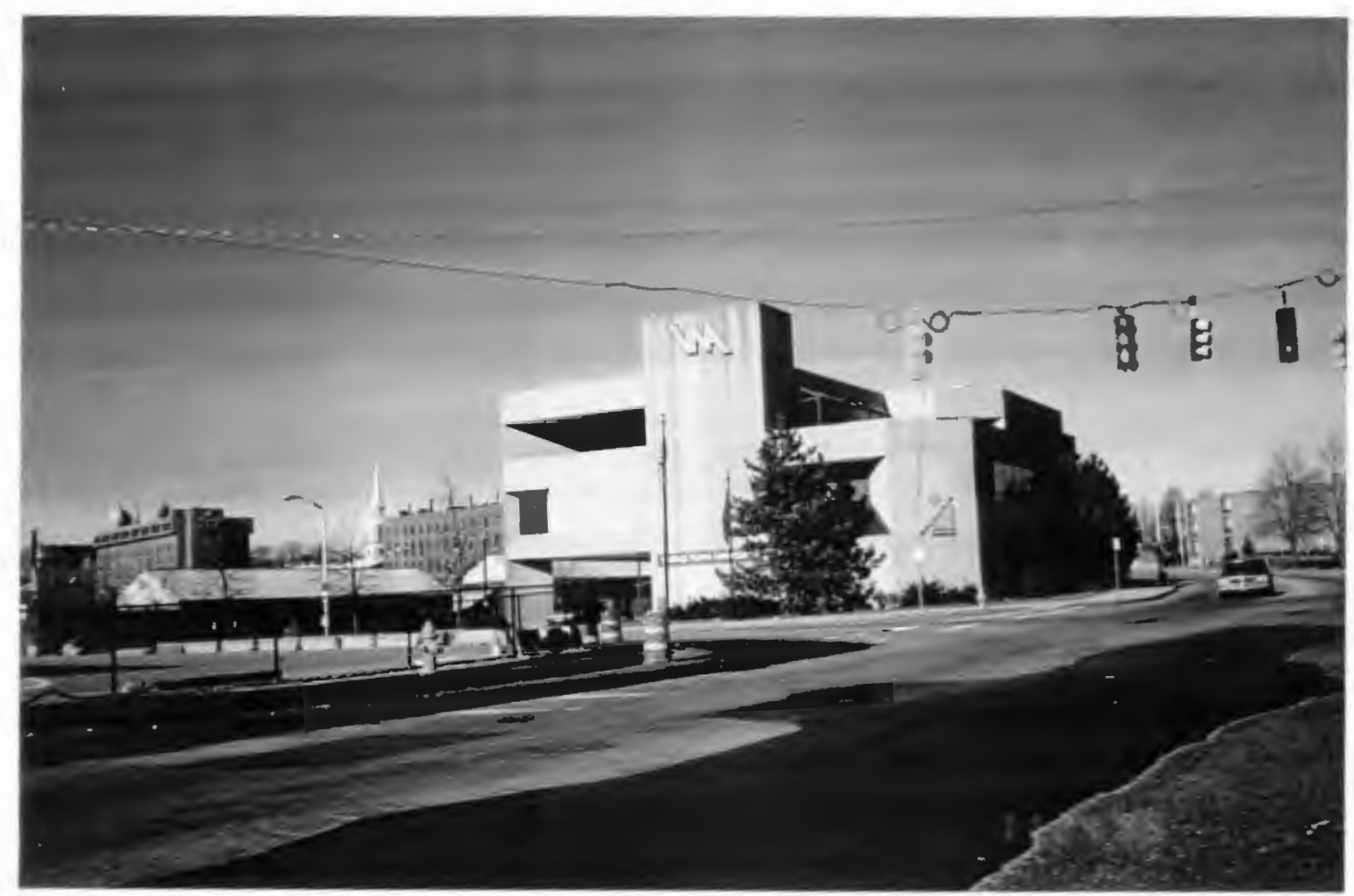

Interstate Commercial District Visiting Nurse's Association 
Already there are indications that some of the same old problems found on the industrial buildings are beginning to re-surface in the uses which do exist in this district. This is due to two major problems which currently exist. First there is the problem of how to address the many passing consumers. Given the location of this district, there are three groups of people which can be addressed through signage provided in this district. As in the other two districts, there are pedestrians and motorists on the neighboring streets. The third group, which is more specific to this district and more difficult to address with signage, is the motorist on the Interstate 290. It is this third group which creates difficulties in signage design. And thus those uses which are attempting to address all three groups typically have at least three signs. One tall. free-standing sign which addresses highway motorists, one large sign on the building itself which addresses adjoining roadway motorists and typically a ground level sign located at the entrance to the use which addresses both the pedestrian and the local motorist. ${ }^{11}$ The AkuAku Restaurant has all three types of signage distributed on and around the building. And as the district becomes more dense, the current owners of commercial uses in this district may consider adding additional signage to make their individual businesses more visible.

The Post Office, Fallon Medical Association and the Visiting Nurse's Association have chosen the opposite tactic in terms of signage presentation. Their primary sign is a freestanding sign adjacent to the building which primarily addresses pedestrians and motorists on the neighboring streets. Signage addressing highway motorists has been integrated into the building in more subtle fashion than the selected by the restaurant. The building sign for the Visiting Nurse's Association has only the company's initials VNA. These signage choices partially reflect the fact that these uses offer less immediate services than do other types of commercial uses. Services which can not be directly utilized by passing motorists. But these have also served to improve the overall appearance and character of the district. In these cases there in fact seems to be almost too little information provided in terms of signage. In the case

11 The signs at the entrys to the uses are oriented less towards the pedestrian than towards th motorists, guiding them into adjoining parking lots. 
of the Medical Center and the Visiting Nurse's Association, this is primarily due to the vacant spaces which currently define this district. In the case of the Worcester post office too little information does seem to be a problem. The Worcester Post office sign is currently oriented towards the traffic coming down Central Street from the west and I-290 going into the city. While this is a very busy route it is somewhat difficult to get to the post office from this direction. Thus, when possible, it seems that most people try to stop at the post office when leaving the city. In fact, one of the busiest times at the post office is just after 5pm on weekdays. People leaving work stop here on their way home coming from the downtown area. But the Worcester Post Office sign does not face in this direction and so there is no way to identify it as a post office except by looking for the postal trucks parked in the back or knowing it to be so. So there too little information provided to identifying post office in certain directions.

A second problem with the signage in this district which could lead to a similar type dissonance in signage found in the district previously is the problem continuing problem of how to advertise new products. Currently, when businesses in the district wish to advertise a new product, they place an additional sign on the building or lot. The Worcester Post Office and the Visiting Nurses Association uses temporary signage to advertise new products offered by the companies. As a temporary measure, this type of signage can add color and a dynamic character to a building and to the district as a whole because they can use colors, lettering styles and materials which one would not use on permanent signage. As the product becomes more mainstream, though, these signs should be removed from the building and if necessary a permanent sign designed which works with or replaces the current signage and enhances the building, street and district as a whole. Approximately, five years ago when express mail service was added to the post offices list of services, they placed a temporary fabric sign, which read "Express Mail Service", on the building to advertise this new service to customers. This direct communication to customers was an acceptable solution as long as the sign did not become permanent. The Visiting Nurses Association has recently been advertising their day- 
care services using a similar cloth sign. Although very colorful and attractive as a temporary measure it should not become permanent.

Thus far signage advertising multiple use buildings in the district has been less successful. Although a more difficult advertising problem the solutions need to be as successful as individual signage. The Union Place Complex which is the last industrial building in the district and has been renovated into commercial use space has a disappointing compilation of signs in front of the building. The first, the original sign was very small and used even smaller lettering to identify each commercial use in the space. Realizing the illegibility of this sign to motorists, another larger sign was added in front of the building which also lists all the commercial uses in the building. These signs are in no way related in terms of design. The color lettering style and size are all different. In addition, signage recently been placed in the district which advertises the newly renovated Galleria Mall complex is similarly not integrated with anything specific. As more signs are added this will continue to be an issue. Particularly at issue will be how the new Union Station project will advertise the many uses in that building and how the signage will work with the existing signage in the area.

This area has a great deal of potential if growth is properly planned for. Signage is an integral part of Worcester's continued growth because it will relay important information to the public, shoppers and potential residents of the city, and if well designed can be used to help improve the overall appearance of the city. The problems identified here can be categorized as follows: 1) Lack of continuity of signage. Although not an extreme problem as of yet, it will be one in the future as the vacant land in this district is developed. 2) Who is the audience? Who is the sign addressing, motorists on the highway or city streets, pedestrians, or some combination of the three. The abundance of signage types suggests that instead of making a choice or establishing a hierarchy, business owners are attempting to address all of them at the same time. This means that businesses often have too many signs which can overwhelm the building and the block. As new uses and buildings are placed in this district, there is the opportunity to design and integrate attractive and informative signage into the overall designs 
for the site and the building. The city should ensure that this is a design priority.

\subsection{Main Street Commercial District}

Signage in this district is very different from that found in Interstate Commercial

District. The main reason for this is that land use is more intensive in this area so there is more signage but they tend to be smaller since lots are smaller. Business owners can not have multiple signs because they have less space to work with. This requires them to more efficient with their signage. In addition, there are only two audiences which need to be addressed in this district, the motorist on the road and the pedestrian. Here, each business tends to have only one sign. The signs in this district vary a great deal in style, color and materials, see Figure 8.4. Often the signage reflects the overall character and appearance of the building of the building on which it has been placed. The problems with the signage here are easier to discuss because there are standards for the district which can be applied. In the Interstate Commercial District it was clear that business owners were grappling with the issue of what audience to address. In that district, owners have three audiences which they can address if they so choose. They are the highway drivers, the city drivers and the pedestrians. In this district there are only two, the city drivers and the pedestrians. And in trying to create a vital downtown area businesses should first strive to address the pedestrians. In this section, signage will be analyzed on this basis. The other two criterion looking at in this study are how the sign works with the individual shop and how it works with the other signage in the block.

All the signage in this area identify businesses and owners here have used signage more effectively to enhance the appearance of their businesses than in the previous district. There are no signs or billboards which advertise goods or services. In general the signage here is accenting the appearance. There is a diversity in styles and sizes but they are unified in that most are placed just above the first story and are proportioned according to the width of the store front. Some of the many good examples are shown in Figure 8.5.1 and 8.5.2. Many of the blocks have organized their signage just above the first story which creates a consistent flow across the facades. But there is also a new trend which seems to be growing in the 
Figure 8.4

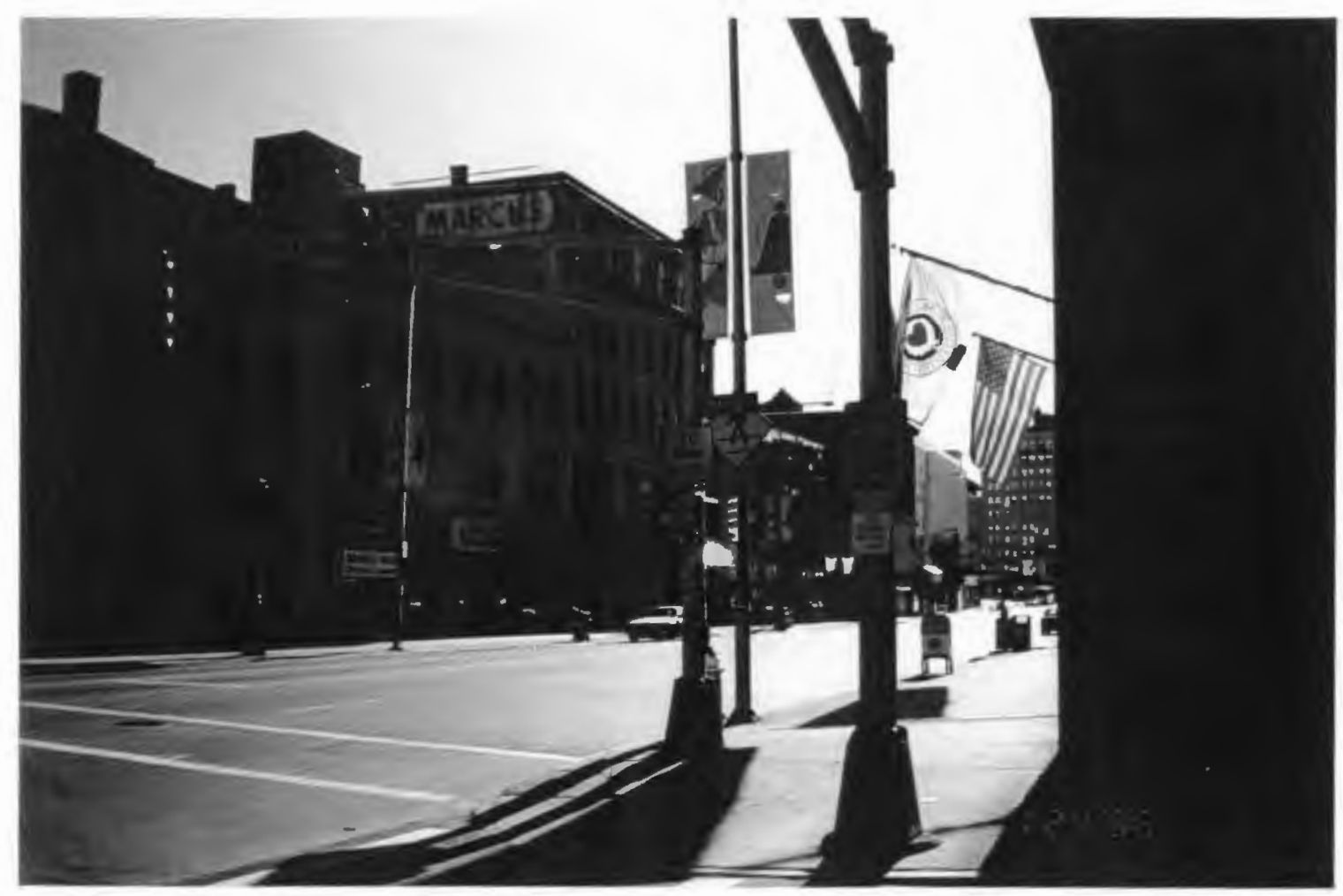

Main Street Commercial District

View of Signage Along Main Street 


\section{Figure 8.5.1}

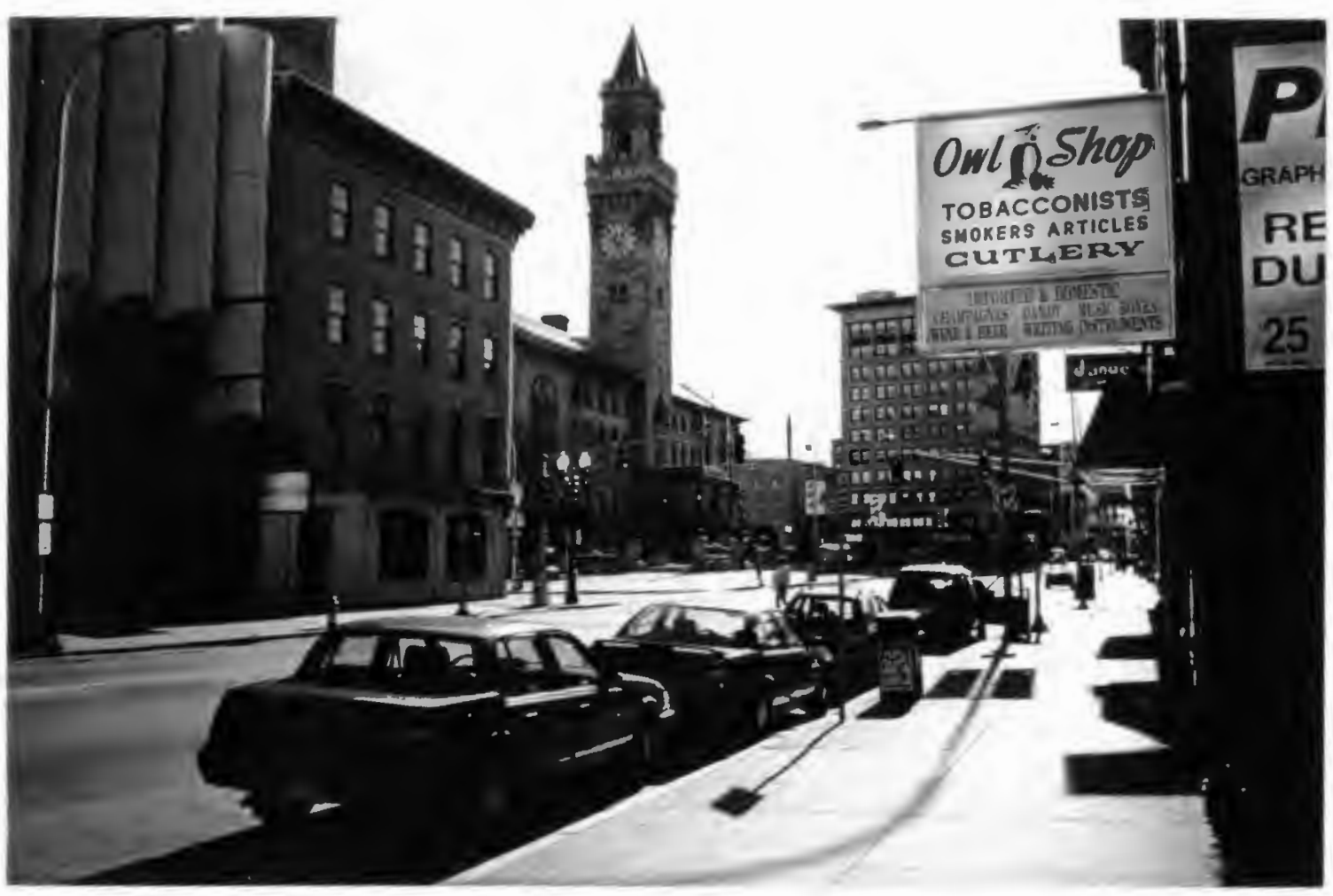

\section{Main Street Commercial District Commercial Signage}


Figure 8.5.2

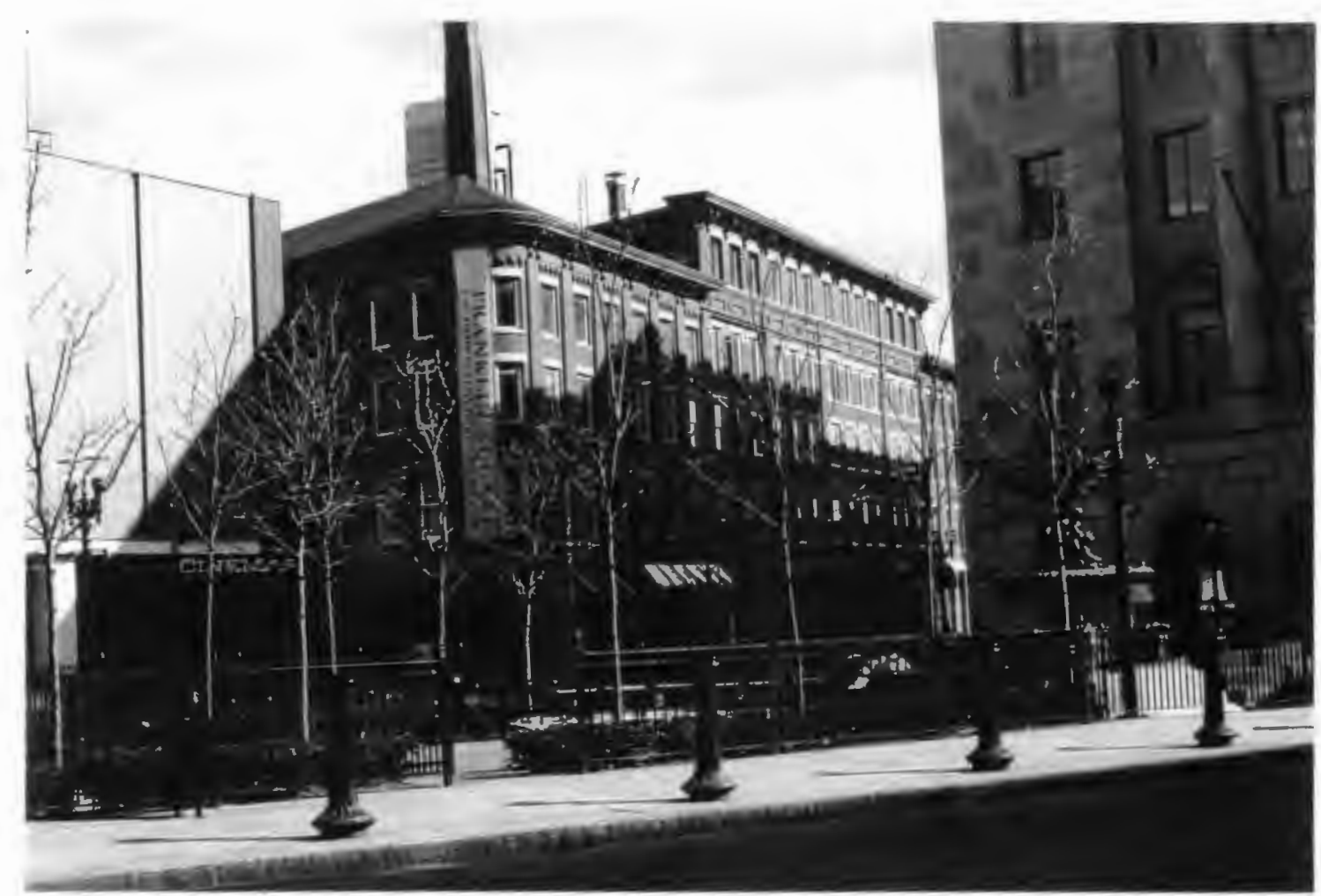

\section{Main Street Commercial District Commercial Signage}


downtown, which is having personalized window signage. This type of sign specifically addresses pedestrians and does not clutter on the facade of buildings, as billboard signs sometimes do. When signage such as this is used the business then also spend a great deal of time designing their window displays because this is what will be seen by motorists rather than the name of the store itself. This approach is very subtle and extremely attractive in most cases. These examples indicate that the signage in the Main Street Area has the potential to work successfully for the district.

There are three common problems with the signage in this district though. First, much of the signage here addresses motorists rather than pedestrians. The signage is larger in order to capture motorists attention, and because more space is needed to accommodate the sign it is often placed high above the shop or use where may not be visible to pedestrians at all. One example of this is the Denholm Building which is located on Main Street where Franklin Street intersects. The signage on this building has been place flush against the facade in the middle of the second story. Because of the height and the canopy structure covering the sidewalk the two signs can not be seen by pedestrians. The sign which is on the right hand side of the building is ideally placed, though, so that motorists traveling down Franklin Street can see it. And there are other buildings in the district on which the signage is placed in an ill-advised location. This signage is too high and is not readily visible to pedestrians who are next to the building. This sign is only visible to pedestrians and motorists who are approaching the building on Franklin Street and only partially visible from Main Street. A smaller sign is provided for pedestrians entering the building.

Limited or a lack of information is another problem with the signage in this district. The Centrum is one example of a building which does has an inadequate amount of signage given the size and scale of the building and the numbers of people who utilize the facility. There are no signs identifying the Centrum on three sides of the building. Instead, these walls are blank and the managers of this facility depend on the massing and height of the building to inform people what it is. Signage could be used to both improve the facades of the Centrum and 
provide necessary information to visitors.

A third problem with the signage in this district is design-related. There is some signage in this district which is outdated and unattractive. While some older signs can add to the character of an area, when not well maintained they can also detract from the overall appearance of a building or a block. For example, the Paris and Loew's Theater signage is distinctive and could add to the character and charm to the district. Unfortunately, the Loew's sign is not maintained and the lettering is falling off. Other distinctive signage in the district include the Olympic Sporting Goods sign and the Jimbo's fast food establishment signs. These sign would contribute to the character of the district more effectively if the facades of these buildings and the shops themselves were upgraded and renovated. Currently the signage for these two commercial uses combined with the poor condition of the facade is not inviting to customers and they do not have the appeal that other popular restaurants and sporting goods have. In today's market, uses such as restaurants and sporting goods establishments must offer the latest in food and equipment. Customers looking for the latest products partially evaluate the store based upon the faced and the design of the display windows. It seems that the unique signage for these two businesses could remain if the facades were updated and improved. Both the facades and the signage of the theaters, on the other hand, if well maintained and taken care of, could remain as long as the seating, services and film presentation meet modern standards.

It is extremely important that the signage in this district and particularly on Main Street fit into the overall context of the city. Unfortunately there are many examples as one walks along the street here, where this is not the case. One example is the Burger King sign. The manager of this store chose to use a projecting sign rather than one which is flush against the wall. This interrupts the flow of commercial signage which have been established in this block, because all of the other signs have been placed flush against the wall. Property and business owners must ensure that the signage selected for the building, business or use is not only appropriate for the building itself and the use it represents, but also should make sure that the signage is integrated into the block scheme and the overall scheme of the district. This will be 
vital if the district and the Study Area as a whole are to have attractive and well integrated signage.

\subsection{Residential Commercial District}

The least amount of signage is found in this district because this is still primarily a residential area. And as such, the signage here should smaller and less obtrusive. There are many businesses found here such as doctors and lawyers offices and insurance companies. This businesses are located in old houses and they have limited amounts of signage. Most of the signs are either flush with the facade of the building or are free- standing signs which have been place in the front yard or parking area. Many of these signs are tastefully designed and do not detract from the residential character of the district. See Figure 8.6.

Two basic problems in this district, related to signage, are the visibility of the building numbers and the amount of information provided on the commercial signage found in certain parts of the district. Figure 8.6. This is still a almost exclusively a residential neighborhood and businesses are rarely identified by driving by or walking along the street. Most people find these businesses through referrals or over the phone. Thus, when people are walking or driving through this area they first try to identify building numbers and then look for the actual business or use. Unfortunately, the numbers on many of these buildings are often too small to identify. The size of the building numbers being perhaps still the same size and design as when the building contained residential uses. Once a residential building is converted to a business, such as the small medical and law offices which are currently located here, more people visit these buildings and many for the first time. Therefore, the numbers need to be easier to read and larger. Currently, the numbers are difficult for motorists and pedestrians to read which can cause traffic problems and be aggravating to potential users of the resources in this area.

The name signage for the commercial uses in this area, that which identifies the use or business in the building, tends to be quite tasteful and well designed. Most of the commercial and office uses in this district are relatively new and so there is little if any outdated signage found here. In addition, care has been taken in designing the signage here so most are attractive 
Figure 8.6

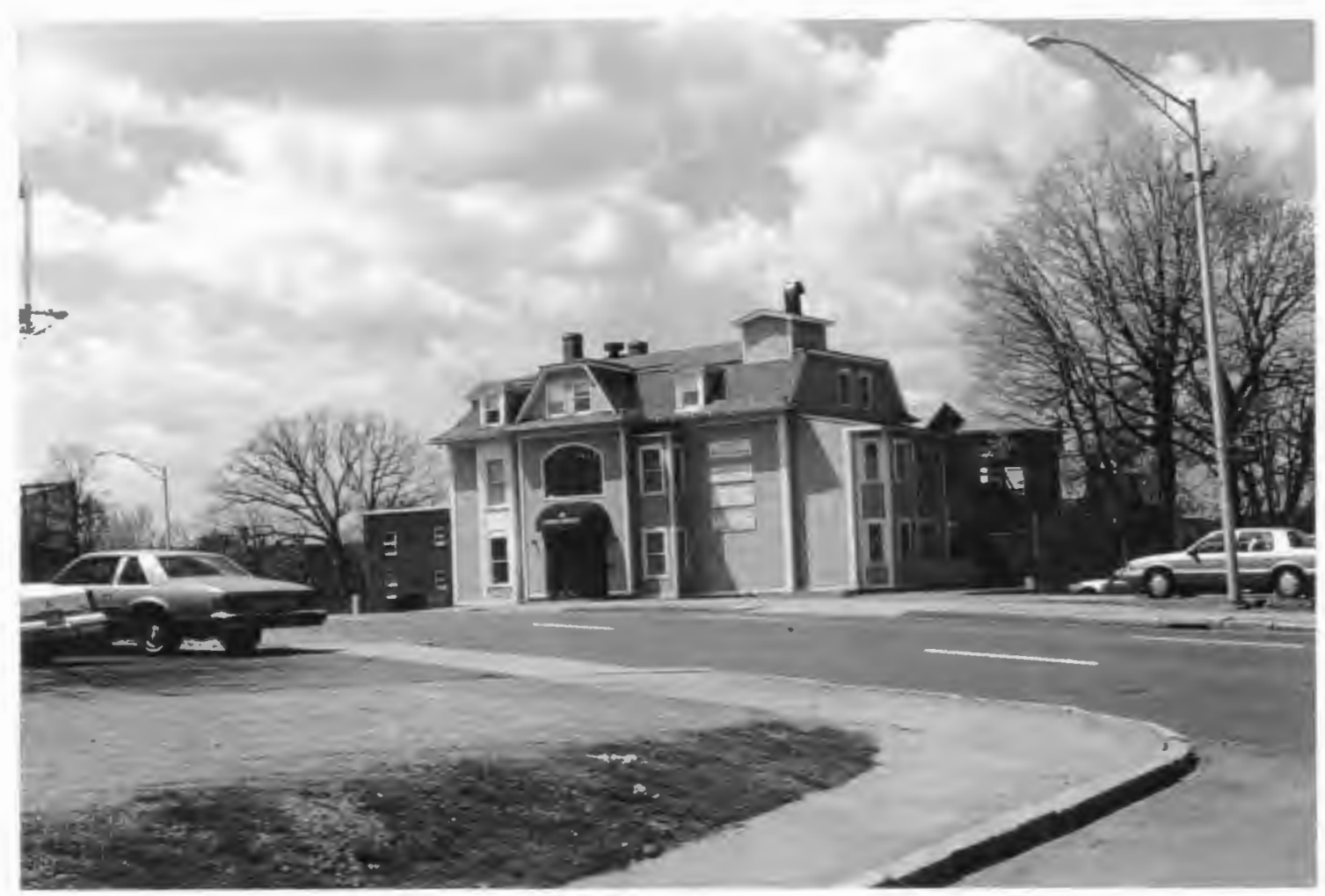

Residential Commercial District Commercial Signage 
and add to the character of the district as a whole. The commercial signage here tends to be small, since most owners of these businesses recognize that they are usually not drawing customers directly off of the street, as retail uses tend to do. Instead the commercial uses found in this district, law and medical offices for the most part, use other means to attract customers, including referrals and the media. The one problem which is evident currently with the name signage is that it is often too cluttered, providing more information than is needed on the sign itself. Because the signs tend to be small, the clutter is less of a problem from a distance and they do not detract from the appearance of the district. In the future, though, cluttered signage could become more of a problem as the number of businesses in this district continues to grow and they begin to compete for attention along the street. Given the types of businesses which exist here there is really little need for more than the name of the company, what type of business it is and perhaps the names of one or two of the principals, for further clarification. As the numbers of commercial uses increases in this district the issue of signage here will need to be addressed more directly.

\subsection{Summary}

Signage is a very important aspect in the design of cities. It should be carefully considered when development or redevelopment projects are undertaken, particularly in dense sections. It is the secondary link between the different businesses and building blocks. It also is a tremendous asset to motorist and pedestrians and thus needs to be carefully designed so that it informs rather than confuses guides rather than suggests. Signage in the Interstate Commercial District should always be designed recognizing the target audience with a particular emphasis towards using a few signs to address as large an audience as possible. The signage in the Main Street Commercial District should stress the need to address both motorists and pedestrians and if a hierarchy exists should perhaps first address the pedestrian and then the motorist. Also owners must place their signage within the larger context of the block and the district as a whole and evaluate the contribution the sign makes or could make to these larger contexts. Owners in the Residential Commercial District should emphasize the streets 
numbers of their buildings as the primary identifier first and the actually name signage only secondarily. This will help integrate the commercial uses with the residential uses which dominate this district and provide the information needed first by the motorists and pedestrians looking for commercial uses in this district. 


\section{CHAPTER NINE \\ PRESERVATION}

"... the City Planning Commission had recognized the need for a balance between preservation and new construction."

(p. 241, Garvin)

\subsection{Introduction}

The loss of historic resources in cities is a significant problem in urban America. As cities have grown and developed over time older buildings and uses have been replaced by newer more modern ones. Growth and development in American cities in recent decades has been rapid and difficult to control. As a result many valuable and important historic resources have been lost, replaced by newer buildings and/or uses. Unfortunately, many of the developers, responsible for substituting the older structures and uses with the new elements, have done so without considering, the value of the old ones. The quantitative methods used to evaluate the value of existing structures, such as a cost benefit analysis, have not adequately been adjusted to account for the non-quantifiable aspects the buildings such as their historic value or potential value in the future. Thus, many elements which integral to a city's history have been lost, some even without documentation. Thus efforts to preserve and protect significant community resources in cities both through documentation and by preserving the actual resource have become important planning activities. Preservationists monitor the many changes in a local environment and try to a reasonable extent to protect important resources.

Preservation policies have become important components in planning efforts particularly in urban areas where growth and change continue to redefine the character, identity and future of cities. The term preservation often brings to mind images of historic structures and landmarks, since a primary function of preservationists is to identify and protect historic structures from being demolished or drastically changed from their original appearance. But today planners and urban designers in addition to preservationists, are involved in preservation activities, together addressing a broader range of issues than previously focused upon. Planners and urban designers also work to preserve significant land uses and activities in a 
community, in addition to protecting and re-using historic structures and spaces.

Not all activities and uses in a community can be preserved no matter how long they have been present so designers must prioritize these activities and places based upon their economic viability and cultural significance. A designer must, "target those (uses) which are ...economically vital and culturally significant...". (Shirvani p.44) Preservation, when used to define, protect and enhance structures and uses in a community, can assist in facilitating revitalization efforts. The Main Street Study Area was analyzed in order to determine which structures and uses should be retained in the three districts.

\subsection{Worcester Preservation Plan}

Preservation planning has typically resulted from, "...the loss of important resources in a local community...". Thus the fact that preservation plays an important role in the City of Worcester indicates that numerous resources have been lost in the past. One of the most dramatic examples of the removal of historic places characteristic to the city happened not only in Worcester but in cities throughout the United States. This removal was the result of the urban renewal programs which existed in the 1960's and early 1970's. Many American cities were destroyed during this period, losing many landmark structures which were particular to that city alone but which were not considered to be an integral part of a technologically advanced society. And Worcester like these other cities lost a number of historical landmarks. Main Street specifically was, "...dramatically altered..." (p. 31 Schuler) by urban renewal. Some of the resources which were lost in the Main Street area include, the 1854 Foster Block which was demolished in 1972, the Levi- Lincoln Block and the Goddard Block both leveled in 1979, the John Woodman Higgins Armory and the Waldo Street Police Station. And although the old Union Station building is still standing, the fact that it was in such an extreme state of disrepair led officials in the city to consider removing it entirely. Further the National Highway Acts which were passed in the 1950's and 1960's did not spare the City of Worcester. In the late 1960's, Interstate 290 was constructed in downtown Worcester. While in other cities such as New Haven highways divided the city from the coast, divided neighborhoods. 
These events led to the creation of two preservation organizations, the Worcester Heritage Preservation Society (WHPS) in 1969 and the Worcester Historical Commission (WHC) in 1975. Since the establishment of these organizations, concern for issues related to preservation have been expressed not only through the efforts of the WHC and the WHPS but by other groups also. This concern is exemplified in the number of research efforts which have been undertaken in recent years. Such studies include a 1981 survey of the triple-decker houses in Worcester. The triple-decker house design is, as expressed in Worcester, is unique to Worcester and continues to be a dominant housing type in the city. Other studies identify the objectives of the Preservation Society in Worcester. For example, in the downtown development program some of the stated objectives include the re-use of downtown buildings for housing, the adoption of guidelines for the orderly development of the city-scape, facade improvement programs, and the creation of historic districts.

Preservation activities in Worcester continue and many of these objectives have been realized. In terms of overall planning the city completed a detailed preservation plan in June 1987 which was written in conjunction with the city's master plan. This plan clearly outlines the history of preservation in Worcester, the relationship between the preservation plan and the master plan, strategies for continuing preservation efforts. The final section of the report divides the city into districts based upon the neighborhood divisions established in the master plan, evaluates the neighborhood in terms of preservation and makes recommendations for future preservation activities. There are six categories of land use for which preservation is defined, most of which can be found in every neighborhood. They are residential, commercial, industrial, institutional, public, and open space/parks. One of the most interesting aspects of this report is that it first considers the original use of the property again using these six categories and then relates that to the use found in the same location today. In the downtown area, the plan notes that in the past, Main Street as well as near by streets while having a significant amount of commercial uses along them also had a great deal of residential uses. On Main Street specifically the residential uses took the form of nineteenth century houses which 
lined the street. These houses now replaced by the current office buildings which recall many architectural styles including classical and Romanesque. The public buildings in the Main Street area have essentially remained the same and they include buildings such as the Peabody and Sterns City Hall, the Worcester County Courthouse and the old Union Station building on Washington Square. Industrial buildings in the area include buildings such as the North Works buildings (1863-1916) and the Compton Loom Works (1860 Green Street). Finally, in terms of open space and parks the plan notes that these areas are minimal in the downtown having been reduced significantly in the past. The most dramatic example being the Worcester Common, which in 1669 consisted of 20 acres and today only occupies 4.4 acres. Having identified the losses in the downtown, the continues on to evaluate the remaining structures and make specific recommendations for the area.

Evaluating the stnuctures in the downtown, the buildings have been found to be in a variety of conditions. The commercial buildings in particular some of which have been renovated back to their original appearance, others while remaining essentially unchanged since they were built have not been maintained such as Union Station, other have been covered over with various materials. The recommendations made in this plan include facade improvements, overlay districts or the listing of specific buildings in the National Historic Registry, reuse of the old Union Station building and a plan for comprehensive revitalization.

The Preservation Plan for Worcester is a very comprehensive and complete report. In terms of preservation alone it identifies accomplishes the task of making recommendations for specific structures in the city. By following the format established in the Master Plan, it also succeeds in laying the groundwork for future integration into the master plan. In terms of urban design and development of the $\mathrm{CBD}$, while offering specific recommendations for maintaining specific buildings and areas within these districts, there is no clear articulation of overall objectives related to preservation for the individual neighborhoods and the city as a whole. In Worcester, preservation activities focus on the preservation of specific buildings, those buildings which have made Worcester a unique and vital city. Land uses have been identified 
as being important include housing, commercial and office uses. Worcester is making great strides in terms of preserving structures after having lost so many. Unfortunately, preservation issues are often not addressed in the plans and proposals for new developments made in the Main Street Study Area.

Looking at Worcester today, one finds uses and activities which emphasize the pedestrian slowly being created as well as those which do not consider the needs of pedestrians. Because preservation activities recall the past these structures more readily address the needs of the pedestrian. Also preservationists, having a thorough knowledge of past uses, understand the advantages and success related to having more pedestrian oriented cities. Therefore, proposals which focus on existing historic structures include a concem for the pedestrian. Many of the recently renovated historic buildings in Worcester offer excellent examples of structures which now not only add to the overall appearance of the city but have also contributed to the street activity and the comfort general comfort of pedestrians. Buildings such as Mechanics Hall, the Five Cents Savings Building and Parlsons Office Supply are all examples of buildings which, as stated in the preservation plan, "...evoke a sense of the nineteenth century streetscape..." (p. 129 Schuler). The pedestrian was addressed first and foremost when these buildings were built since the automobile still had not been invented. These buildings then had shops at the ground level and offices and/or residential above. This commitment has been maintained in recent renovations to certain degree, the building maintaining the commercial uses at the ground level with large window opening and providing retractable awnings which both protect the pedestrian and the interior spaces. Unfortunately, the commitment to the pedestrian is not apparent in the new commercial structures being built and proposed in Worcester.

The newer structures in Worcester are more and more rejecting the pedestrian, in that they are built without windows at street level. Looking at buildings such as the Worcester Centrum this trend is becoming more pervasive as crime has become more prevalent in the downtown. And although, extremely successful in terms of the events scheduled there, 
the Centrum contributes little to city visually or to the daily street activity. This is particularly problematic given the size of the structure. The building has very few windows and most of these are located above street level. The blankness of the walls at the street level creates a very uncomfortable environment for pedestrians who must walk next to the building. There is nothing for the pedestrian to look at while walking past the building and no human scale elements which for the pedestrian to relate to which would assist in providing a sense of comfort.

Clearance and revitalization efforts have had a profound impact of the Main Street Study Area as a whole. During the period of Urban Renewal, buildings and even entire blocks were demolished to encourage revitalization of the downtown. During this period which lasted from the 1960's and into the 1970's a number of structures were demolished which dramatically altered the appearance of the city. Some of the resources lost included the 1854 Foster Block which was demolished in 1972, the Levi-Lincoln Block and the Goddard Block which were both demolished in 1979. Individual buildings have also been demolished, they included the John Woodman Higgins Armory, the Waldo Street police station, the People's Saving's Bank and the Sumner Pratt Building. In addition to losing these very important structures some of the uses found in these buildings were also lost such as important commercial activities at the street level which have yet to be replaced. Demolition of large blocks continues to take place in the MSSA. Most recently, a large portion of the Interstate Commercial District was cleared in order to make room for the new hospital project. Nevertheless, there still exist opportunities for preservation activities. And analyzing the Main Street Study Area as it exists today, there are three basic categories of elements which can identified for preservation purposes. They are; major land uses and activities, buildings and landmarks. Each of these elements will be examined within each individual district.

\subsection{Interstate Commercial District}

The Interstate Commercial District was once a center of manufacturing and industry had many manufacturing buildings and uses. Many of these uses have been gone for a number 
of years, but the buildings which housed these uses have only been torn down recently. Thus the district is defined not by a building type or style but rather by the many vacant lots which currently exist here. Few preservation activities have taken place here given perceived lack of value which the uses have and continue to have. The district has most notably one post office, one housing area, one donut shop and two historic structures. Despite the lack of character and definition in the district, it is the premise of this report, that few remaining uses in the area should be preserved and expanded along with the few remaining historic structures. Somehow they have survived the deluge of demolition and seem to continue to function in spite of the many drastic changes. Closer inspection of these uses and structures leads one to realize that there is some innate value in the few remaining items which are making a positive contribution to the MSSA, although dramatically overshadowed by the desolation of the district as a whole.

There is only one residential area in the district. This is the Plumley Village Housing Complex. Despite the limited amount of residential uses which exist, these play a vital role in activating this district. First the complex provides some of the only street life and evening life which currently exists here on a regular basis. ${ }^{12}$ One can always find people between this development and various downtown locations, the bus stop etc. Second, this development to a limited extent begins to reconnect the district with the residential neighborhood on the western side Interstate 290 . And the divisive quality of the Interstate is minimized the more the connections between the two sides are reinforced and strengthened. Given the impact that this residential complex is having it seems as though residential uses should be preserved and in fact increased in order to strengthen the ties between the neighborhoods and improve the quality of street life on a 24 hour basis. In addition the hospital complex will increase the need for housing nearby in order to meet the needs of doctors and nurses when they are on call.

The continuing success of the donut shop and the post office located at the intersection of Central and Summer streets (diagonally across from one another) suggests two things for

12 There are a number of evening perfomances scheduled at the Worcester. And, while these do create some evening street activity in this district, these performances do not of ten enough enough to generate regular nighttime activity in this district. 
the area. That there is a potential for commercial uses in this location and that the current use of this streets as an entry into the city should be preserved and reinforced. Creating a strong edge on one side of the entry would help to further reinforce this entry sequence. Commuters, in the morning, stop at the donut shop and in the evening stop at the post office on their way out of the city. They are serve to encourage a small amount of pedestrian activity on clear days. A shift towards the train station given current renovation efforts may help to reinforce both the train station and the economic success of the commercial uses. Specifically, the hotel use should be maintained in this district but perhaps could benefit from closer proximity to the rehabilitated Union Station building.

Washington Square is a significant green space in this district which should be preserved for future. In addition to providing a formal entry sequence into Union Station it could be the basis for the creation of additional public, open spaces in the district.. The actual shape and location of the space may no longer be desirable or feasible but creating a similar space in close proximity to the existing one could be explored.

\subsubsection{Specific Buildings to be Preserved}

There are three individual buildings which are noteworthy both in this district and in the Main Street Study Area as a whole. The first and most notable of the three is the original Union Station building pictured in Figure 3.4. The original train station for the city of Worcester, this building is both architecturally and culturally significant to the city. Union Station was constructed in the mid 19th century, was designed in an American Beaux Arts style. It is the only building of this scale and having the intricate architectural detailing, commonly applied to important structures during this period, found in this district. The exquisite craftsmanship and detailing of the original structure and the varied interior spaces illustrate its importance historically both to the district and the city as a whole. See Figure 3.5. The fact that this detailing and scale can not be replicated today, further emphasizes the need to preserve the Union Station building for future generations, not only for its architectural significance and grandeur as a building in the city but also for the spatial contribution it could 
make to the city in the future in re-uniting currently dispersed transportation elements into one location once again.

The other two structures which could also potentially be torn down as the district changes but which should be preserved are the last remaining industrial building in the district, Union Place, and the small congregational church on Summer Street. Union Place, provides a small picture of the industrial past which once defined this district and has been renovated into commercial space and operates fairly successfully today under its new guise. Today it is a commercial center with a number of small stores and offices within. And although renovated for new uses, the exterior of the building was essentially kept the same. Thus the building looks very much as it did when it was first built and provides a small glimpse to viewers of what many the other old mill or industrial buildings which once existed in this district looked like. A small church on Summer Street is the only church of its size in the district and although not architecturally significant the commitment of the congregation there suggests that it is an important resource for the community. Entering a service there one seems to almost be stepping back into the past when church was an integral part of family life. The strength of this congregation suggests that it is important to the community and to the city as a whole.

\subsection{Main Street Commercial District}

Preservation activities in this district are much more prevalent given that there are more distinctive buildings which have been identified as being a significant part of Worcester's history. They include some of the buildings mentioned above such as Mechanics Hall and City Hall. Unfortunately, preservation activities have focused on specific buildings more so than the preservation of specific uses in the district. Currently, the city, specifically the historic preservation society is very active in having individual buildings declared historic and is further contemplating having Main Street declared a historic overlay district. While these are positive steps for this district, there are also a number of activities and uses in this district which should preserved. Perhaps assumed but often not stated it is essential that commercial and retail uses be preserved on the ground level of buildings in this district. Specifically, 
restaurants (of all types) and cafes, pharmacies, and various types of shops should be encouraged here because they generate activity both in the day and evening. A use currently absent from the downtown area is a bookstores. Recently bookstores with extended hours have become very popular, they encourage people to browse and read similar to a library but also contribute economically. Given the many colleges in the city a bookstore would be a positive addition to this district. These activities encourage pedestrian use and help to revitalize the district. Next it is also important to maintain the office and residential uses on the upper stories of these buildings. Clearly business activities help to stimulate the economy and generate pedestrian activity throughout the day. But in the evening it is the residential uses which keep the area active and alive. Currently in this district there is one only one housing project originally called Urban Village it is a 12 story high-rise tower which has 80 apartments inside. There are also some older buildings on Main Street, Pleasant Street and George Street which currently have residential uses above them. It is unclear what condition these spaces are in but the owners should be encouraged to rehabilitate these buildings and maintain the residential uses in them because they could make a significant contribution to the overall vitality of this district in the future. Other uses which could also contribute to the day and evening life of the downtown are the three theaters which are currently found here. They are the Loew's Theater, the Paris Theater and the Loew's cinema. These uses should be preserved.

There are a few food vendors which can be found in the City Hall common these activities should be preserved because they bring people and life into the common. As shown in Figure 3.9, the vendors provide food to many customers but they also provide places, identifiable destination points within the Common, where people can meet one another for lunch and conversation. The vendors, as localized destination points, attract other people also. People who may not be eating lunch or meeting someone, perhaps are alone, will sit close to the vendors so that they can experience some of the activity without directly taking part in it. The vendors should be encouraged to return to the Common each spring and summer. They help populate the Common and create places without having to associated with an actual 
structure.

There are numerous buildings in this district which should be and continue to be preserved. Given the density of this district these buildings are architecturally, culturally and economically significant. These buildings include, Mechanics Hall, the Five Cents Savings Building, and City Hall.

\subsection{Interstate Commercial District}

Preservations efforts in this district should focus upon maintaining residential character of the district. While the interior uses may change in the area directly adjacent to the Main Street Commercial District, the exteriors of the buildings should keep the residential character which defines this district. Housing the commercial uses in structures that are characteristically residential, allows for a subtle transition within the district between the area which is now mostly commercial and the more eastern part of the district which remains primarily residential.

\subsection{Summary}

Preservation will be a fundamental part of the urban design plan. In the Main Street study are of primary importance is the preservation of uses and activities in the study area. In addition to the loss of industrial uses there is a general loss of business in downtown due to crime and declining shoppers. The City should be committed to maintaining and supporting the current uses and supporting similar uses which would further strengthen the downtown area. Considering the factors which make the downtown area unique and active these are the ones which should be promoted and preserved. Pedestrians make downtown areas vital and therefore it is those uses and activities which area geared towards the pedestrian which should be preserved. Housing in the downtown ensures twenty- four hour vitality and therefore housing should be promoted in the downtown. Open spaces in downtown areas provide places where pedestrians can be active as well as passive users. These are areas which should be preserved. Main Street was, in the past, the center of commercial activity for the City of Worcester. Despite the prominence of other areas today, the vitality of this area determines will continue to mark the health of the city for residents and visitors. 


\section{CHAPTER TEN COMMUNITY PROFILE}

"A vital urban environment is identified by people, not cars, landscaping or colorful symbols and banners."

"Humans impart meaning to environments..."

(p.18 Bissell)

(p.55 Shirvani)

\subsection{Introduction}

People are the most important component of any city. Cities which attract people, residents to live in the city and visitors to take advantage of the goods and services provided in the city tend to be the most vital and economically stable. People who live in and visit urban areas generate revenues by utilizing the goods and services provided there. people also enliven the overall atmosphere of an urban area through activity, movement and conversation. But despite the irreplaceable contribution which people offer to areas, the needs of people are often overlooked in the planning and design of the built environment. ${ }^{13}$ Those cities in which planners and designers ignored or failed to understand the needs of the potential users tend to be the least successful. And even with sound planning strategies, people continue to find unanticipated ways to utilize the space, facilities and services which have been provided. Careful planning strategies in cities such as New Haven, Connecticut and Buffalo, New York have still not successfully or adequately revitalized the downtown districts of these cities. These two cities, are similar to Worcester in a variety of ways. One similarity is that, like Worcester, both of these cities have one or more colleges and universities in and around them. And like these other two cities, the continued building and upgrading on the campuses, has contributed little to the revitalization efforts in the downtown. Instead, all three of these

13 The most extreme examples of this oversight are found in the planned cities of Brasila, Brazil and Chandigarh, India. These cities did not evolve and develop over time, but were designed as single entities. And because these places were developed in relatively short amounts of time, the needs of the prospective users and residents were not adequately planned for or addressed. More specifically, the designers were unable or were unaware of the many cultural, spatial and human issues and customs which were integral to these communities and their success in the future. 
downtown areas continue to be places where people work but not places where people choose to live or shop and participate in activities or a regular basis. They are desolate and can be dangerous in the evenings and on the weekends.

Nevertheless, though, these downtown districts, like the Main Street Study Area, do have potential, despite the numerous problems and issues. First, there is a stable employment base and resident population provided by the colleges and universities located in these cities. This provides one starting point which planners can utilize and work with. Second, the suburban areas which surround these cities, continue to grow and thrive. In all three cases, there continue to be people moving to the suburban regions of these cities, for new housing, schools and jobs. Planners can address this population and attempt to attract them to the downtown district. In all cases, though, it is and will be essential that planners and designers respond to the needs of the community and create an environment which will attract new residents and visitors to the downtown. Therefore, this section of the report will provide a brief description and analysis of the resident population in the city of Worcester in order to better understand who lives here.

There are many factors which have influenced and led to changes in the composition of Worcester's population. Three factors which continue to be influential are employment, the fact that there are a number of colleges and universities which are located in the city, and general change in families and family structure which has taken pace in recent decades throughout the United States. Worcester became a large and thriving city during the Industrial Revolution as many people came to the city to find work. During this period, Worcester became a center of business and industry, primarily manufacturing, and correspondingly, the number of jobs available in the city increased. Thus many people, many of them immigrants, came to Worcester to find meaningful employment and to provide a better way of life for their families As a result, the population increased significantly during this period. The largest increase in population took place between 1840 and 1850 when the city experienced and unprecedented $127 \%$ increase in population. Such an increase has not been repeated since that 
time. See Table 10.1 and Figure 10.1. Significant increases continued through the rest of the century bringing the total population to over 118,000 people by 1900 . The people in Worcester were and are very diverse coming from a variety of ethnic backgrounds and is still primarily a working class city. The current census shows that residents of the city of Worcester represent over thirty-five different cultures. Ethnic groups represented include Irish, Italian, Swedish, Finnish, Norwegians and Danes, French and Dutch. "These immigrant groups first settled in the valley areas of the city and as they became more affluent moved 'up the hills' where there was better housing." (p.11 Cohen) The substantial increase in the numbers of immigrants during this period in addition to the rising number of births in the city led to and overall increase in the population which lasted until about 1940. Since the depression the population in the city of Worcester has declined with only two exceptions. See Table 10.1. There was a $5.1 \%$ increase in the population in the 1950 census. This is considered to be "... an aberration caused by the end of Second World War..." (p.3 Chamberlayne) The end of the War brought many soldiers and military personnel home to their existing families and to make new families. Thus there were significant increases in population in many cities across the United States. A second increase of $4.9 \%$ in the population was recorded in the 1990 census. There are many potential reasons for this increase. It could be a sign of economic improvement in the city, this number could mostly reflect the increases seen in the suburban areas, or given the decline recorded for 1992, this could be another aberration, a result of the building boom which took place in the 1980's.

A second important factor continuing to influence the composition of the population is the fact that, like Boston, MA, a number of institutions for higher education are located within the Worcester city limits. This affects student population each year. Colleges and Universities found in Worcester include, Holy Cross, Worcester Polytechnic Institute, Assumption College, Becker and Worcester Junior Colleges, Clark University, Worcester State College, and the Central New England College of Technology. Although not included in the official census reports, these students contribute to the overall vitality of the city and they should be 
Table 10.1 Worcester Population, 1790-1990

\begin{tabular}{|c|c|c|c|}
\hline \multirow[b]{2}{*}{ Year } & \multicolumn{3}{|c|}{ Change from Preceding Census } \\
\hline & Population & Change & \% Change \\
\hline 1790 & 2.095 .00 & $\mathbf{N} / \mathbf{A}$ & N/A \\
\hline 1800 & $2,411.00$ & 316.00 & 15.1 \\
\hline 1810 & $2,577.00$ & 166.00 & 6.9 \\
\hline 1820 & $2,962.00$ & 385.00 & 14.9 \\
\hline 1830 & $4,173.00$ & $1,211.00$ & 40.9 \\
\hline 1840 & $7,497.00$ & $3,324.00$ & 79.7 \\
\hline 1850 & $17,049.00$ & $9,552.00$ & 127.4 \\
\hline 1860 & $24,960.00$ & $7,911.00$ & 46.4 \\
\hline 1870 & $41,105.00$ & $16,145.00$ & 64.7 \\
\hline 1880 & $58,291.00$ & $17,186.00$ & 41.8 \\
\hline 1890 & $84,655.00$ & $26,364.00$ & 45.2 \\
\hline 1900 & $118,421.00$ & $33,766.00$ & 39.9 \\
\hline 1910 & $145,986.00$ & $27,565.00$ & 23.3 \\
\hline 1920 & $179,754.00$ & $33,768.00$ & 23.1 \\
\hline 1930 & $195,311.00$ & $15,557.00$ & 8.7 \\
\hline 1940 & $193,694.00$ & $(1,617.00)$ & $(0.8)$ \\
\hline 1950 & $203,486.00$ & $9,792.00$ & 5.1 \\
\hline 1960 & $186,587.00$ & $(16,899.00)$ & (8.3) \\
\hline 1970 & $176,572.00$ & $(10,015.00)$ & (5.4) \\
\hline 1980 & $161,799.00$ & $(14,773.00)$ & (8.4) \\
\hline 1990 & $169,759.00$ & $7,960.00$ & 4.9 \\
\hline
\end{tabular}

Figure 10.1

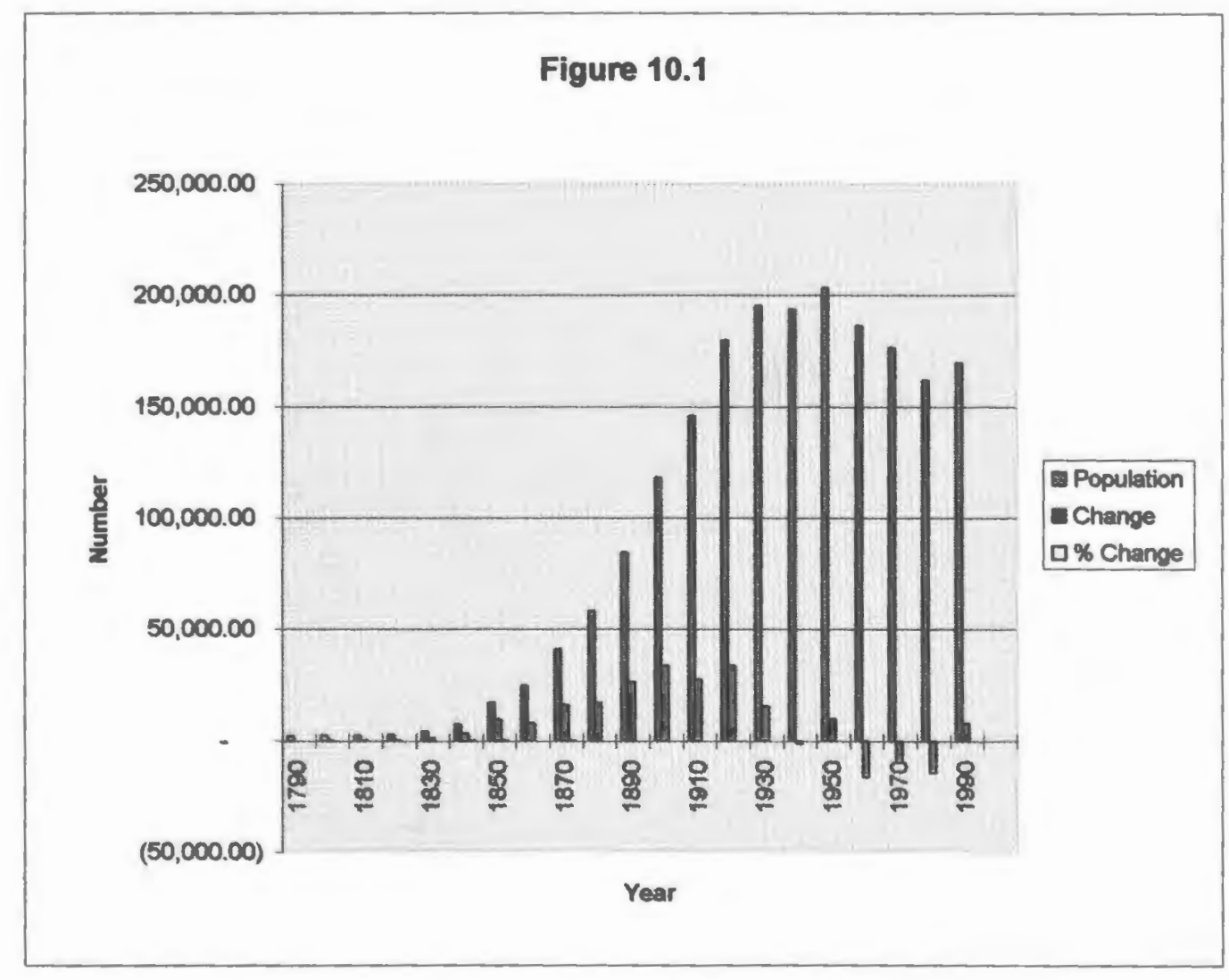


considered in all MSSA and city planning initiative and strategies for the downtown.

A third factor which has changed the composition of the population in recent decades is the general changes in family structure and household types seen in cities throughout the United States. High incidences of divorce, increasing numbers of step-families and singleparent families, in addition to newly recognized alternative living situations have not only changed the perception of family and household types but has also forced the U.S. Census to change the categories, leaving some out and adopting new ones. For example, the U.S. Census now differentiates between families and households in its categorization.

Using secondary data, including the U.S. Census for a variety of years and other social data, a description of the current population will be presented. The central limitation involved in using this data is that this data is only available for the city of Worcester as a whole. Data is not available for the Main Street Study Area alone. Thus this section of the report will abstract the available data and apply it as representative to the Main Street Study Area accepting all potential problems and inaccuracies with using this larger data set. This information will also be used as the basis for recommendations to be made in later chapters of this report so that those recommendations will more closely reflect the needs of the people who live and work in the Main Street Study Area and the city as a whole.

\subsection{Worcester Population}

Just as the population in the city grew in response to the rapid increase in the number of industries and jobs in the city, the population continues to decline as the number of industries in the city has declined in recent years. The most recent population data, from the 1995 Statistical Abstract, shows the population of the city of Worcester to be approximately 163,000 in 1992. This represents a 4\% decline in the population from the 1990 Census report which showed the population in the city of Worcester to be 169,759 . Since 1960 the population in Worcester has continued to decline, with the largest decline, $8.4 \%$, occurring in 1980 . These declines have significantly reduced the tax base in the city and affected development. The building boom of the 1980's encouraged some growth in the city and by 1990 the population 
had increased by almost 8,000 people. Although the most recent statistics show a decline in population, city officials have indicated that they expect a the population in the city to rise over the next ten years.

The declining population based upon primary observations seems to have been most severe in the Main Street Study Area. Outlying suburban areas, some of which are included in the statistics for the city of Worcester, do continue to increase in density. There are new shopping centers and small businesses being built and established outside of the city. There are homes being constructed outside of the city. And most of the workers and business owners in the city who were interviewed for this study live outside of the Main Street Study Area. Thus while there is some progress for the city as a whole. There continues to be little for the Main Street Study Area. Residential uses continue to decline in both the Main Street and the Interstate Commercial Districts. And the two new residential buildings built in the district brought few new people into the city but re-located existing residents.

The age and ethnicity of the population appears to be changing significantly also. As shown on Table 10.2 and Figure 10.2 there are certain segments of the population which are increasing while other are in decline. There continues to be a basic increase in the number of people between the ages of twenty-five and forty-four, sixty-four and over and in the five and under age range. These increases show up in almost every age category differentiated in the census with the exception of the five and under range which had been experiencing significant declines each decade between 1960 and 1980. It is unclear what caused the dramatic change in this age group and whether this trend will continue in the future. One possible answer is the rising housing costs outside of the city which may force younger families and couples to remain in the city until they can afford a larger house outside of the city.

There has been a significant decline in the number of people between the ages of five and nineteen in the city. This suggests that people may be starting their families in the city but are moving either to the suburban areas or out of the city entirely once their children reach a certain age. And similar to other cities throughout the U.S., the remaining population in the city 
Table 10.2 Worcester Population, by Age, 1960-1990

\begin{tabular}{c|rrrr} 
& \multicolumn{4}{|c}{} \\
\hline Age Distribution/Year & \multicolumn{1}{|c}{1960} & \multicolumn{1}{c}{1970} & \multicolumn{1}{l}{1980} & \multicolumn{1}{l}{1990} \\
\hline Under 5 & 17575 & 12937 & 9576 & 12271 \\
$5-14$ & 30418 & 29481 & 20769 & 20136 \\
$15-19$ & 14080 & 16998 & 16364 & 13099 \\
$20-24$ & 11176 & 14923 & 19101 & 17453 \\
$25-44$ & 44085 & 34584 & 36360 & 52339 \\
$45-64$ & 44408 & 41723 & 33304 & 27253 \\
65 \& over & 24845 & 25926 & 26325 & 27208 \\
\hline Total Population & 186587 & 176572 & 161799 & 169759
\end{tabular}

Categories determined by U.S. Census Data and relevance to this report.

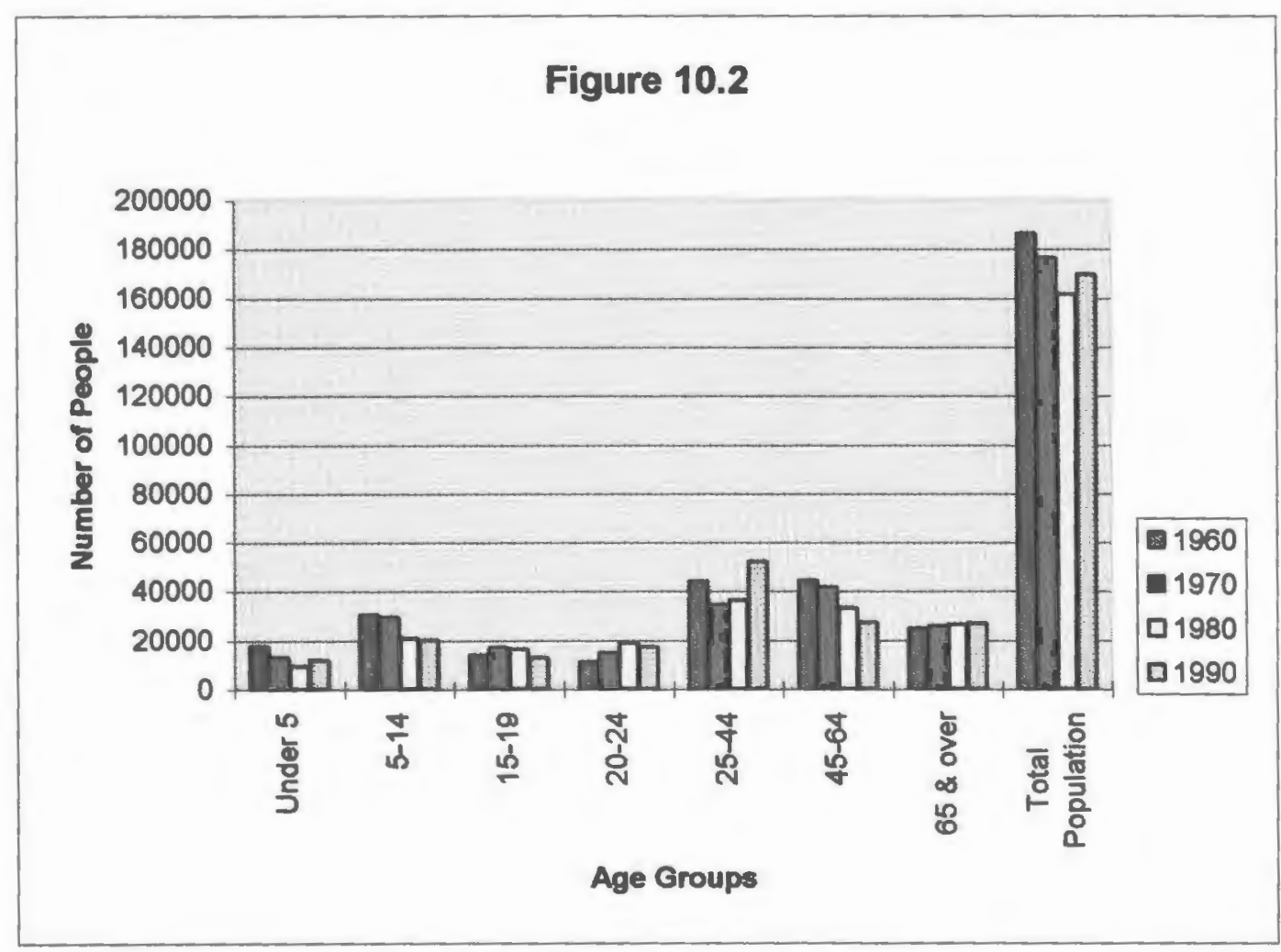


is also getting older. The 1997 budget for the city highlighted the fact that site selection for a new Senior Center was underway. One center has been established at the old St. Vincent's Hospital complex outside of the Main Street Study Area. Provisions need to be made for these and future changes in the population so that the city can best assist its residents.

The racial changes as categorized in the U.S. Census is a little more difficult to follow and keep track of. Each year the census documents have changed the way they record the racial component of the census. In the past the changes merely were the addition of groups not counted in the past. But in the 1990 census, the Hispanic category was removed and instead was disseminated as a part of the remaining ethnic groups, and the remaining individuals were placed in the other category. Thus each of the remaining categories, white, black, Asian etc. is further broken down according to those who consider themselves to be of Hispanic origin versus those of non-Hispanic origin. This is an important category for Worcester because there are a large number of Hispanic people in Worcester. Thus for the purposes of this study the Hispanic origin category has been retained with a note showing how the 1990 Census is actually listed. As shown in Table 10.3 and Figure 10.3, there has been a dramatic increase in the numbers of people of Hispanic origin in the city of Worcester while the number of white people continues to decline. Even using the census categories the decline in the number of white people is present although less severe with increases in the other categories. Thus the city continues to become more and more ethnically diverse. This is represented most dramatically in the Main Street Study Area. The majority of the people residing in the Interstate and Main Street Commercial Districts are not white. Instead, it seems, that other ethnic groups are represented to a much greater degree. Those of Hispanic origin appear to make up the largest percentage of residents in the MSSA while the majority of the white population resides outside of the Main Street Study Area, many in the outlying suburban areas. City officials need to take advantage of the diverse ethnic groups found in the Main Street Study Area and highlight the mix of cultures. Suburban flight is an important issue which must be addressed if the downtown is to survive and become a economically and socially viable place. Ways need to be 
Table 10.3 Worcester Population, by Race, 1980-1990

\begin{tabular}{c|rr} 
Race & \multicolumn{1}{|c}{1980} & \multicolumn{1}{c}{1990} \\
\hline White & 149540 & 141870 \\
African-American & 4498 & 6770 \\
American Indian & 437 & 556 \\
Asian & 786 & 4323 \\
Hispanic (Origin) & 6468 & 15868 \\
Other & 70 & 372 \\
\hline Total & 161799 & 169759
\end{tabular}

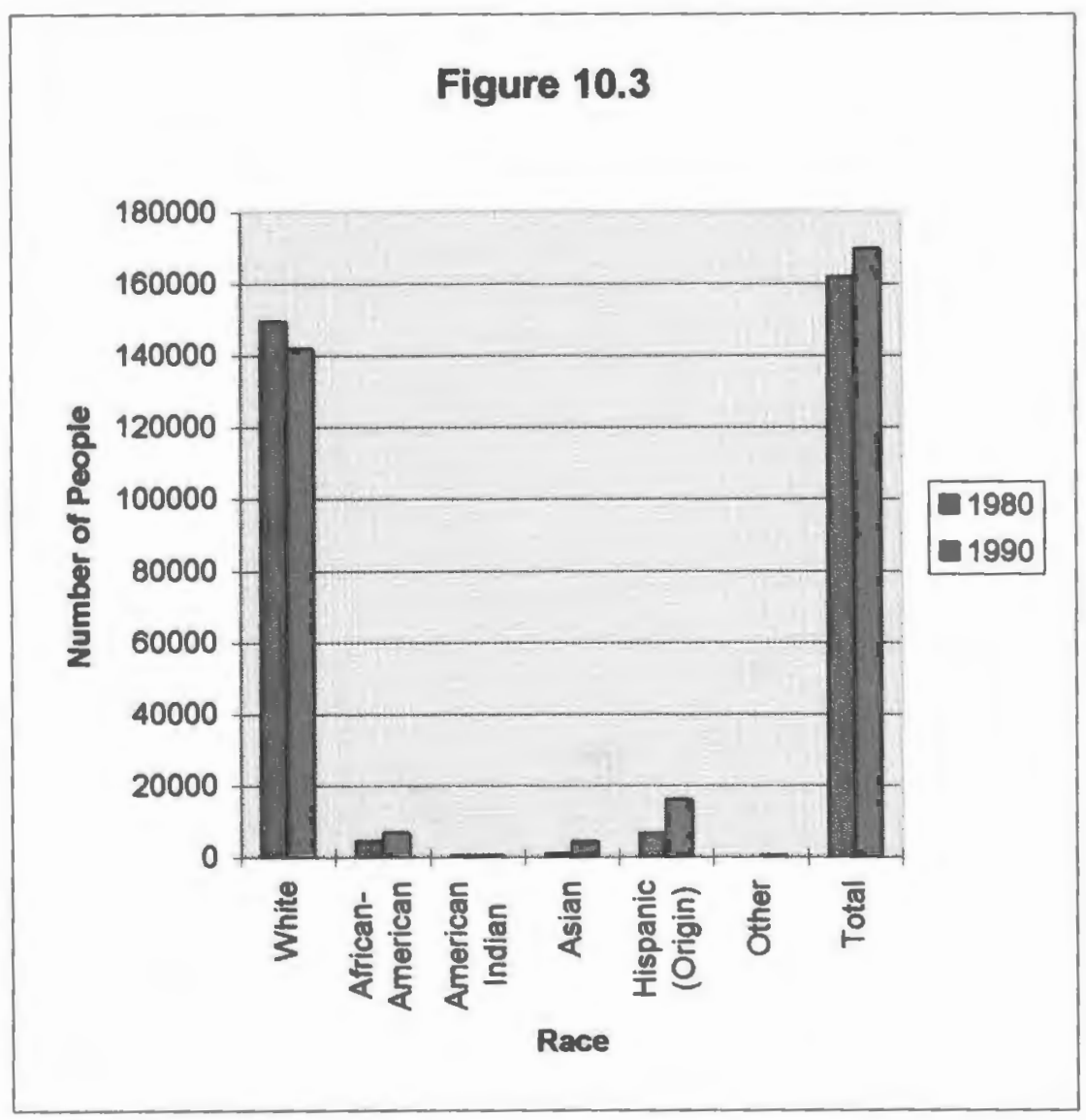


found to encourage people to come to the downtown and make use of the goods and services provided in the MSSA and eventually by making the right provisions encourage people to live in the MSSA again. The separation of housing in the city continues to be a problem in the MSSA and the city as a whole. The neighborhoods here do not reflect the mix of cultures which have been identified statistically. A neighborhood mix could be made in the Main Street Study Area.

\subsection{Analysis of Household Changes}

Households are changing both in the Main Street Study Area, the city of Worcester and the United States as a whole. There are new family types and groupings which required that the U.S. Census Department change its reporting categories. Thus in 1990 the record both the numbers of families and the number of households, recognizing that families and households are no longer synonymous as they once were or were assumed to be. Today unrelated persons who live together in the same dwelling are counted in the household category while related persons are counted in the family category. Table 10.4 and Figure 10.4 show that although the total population increased in 1990, the number of persons per household continues to decline. This is consistent with the changing family types and structures all across the United States. The number of people per household has dropped from 2.94 in 1970 to 2.56 in 1980 to 2.45 in 1990. The number of married couples with children has dropped from 34,871 in 1970 to 29 , 233 in 1980 to 27,775 in 1990 . While the decline were less significant between 1980 and 1990 than between 1970 and 1980, the fact that the number of people per household continues to decline is indicative of the changing household in the City of Worcester. Similarly, the number of female headed households with no husband present continued to increase from 6538 in 1970,8238 in 1980 to 10,021 in 1990 . with the number of male headed households also increasing significantly from 1,656 in 1980 to 2,288 in 1990. In addition, while the numbers

of divorced men and women continues to increase, there is a growing number of persons in the city who have never been married, increasing from 46,266 in 1980 to 50,520 in 1990. This multiplicity and dichotomy of family types creates complex and difficult planning problems. 
Table 10.4 Population, Households, and Housing Stock

Pop. in

Year

1960

1970

1980

1990
Households

186,587

166,212

150,313

156,544
\# of

Units

58,234

58,538

61,615

69,366
\# of

Households

56,708

56,606

58,720

63,884
\# of Persons

per House

3.29

2.94

2.56

2.45

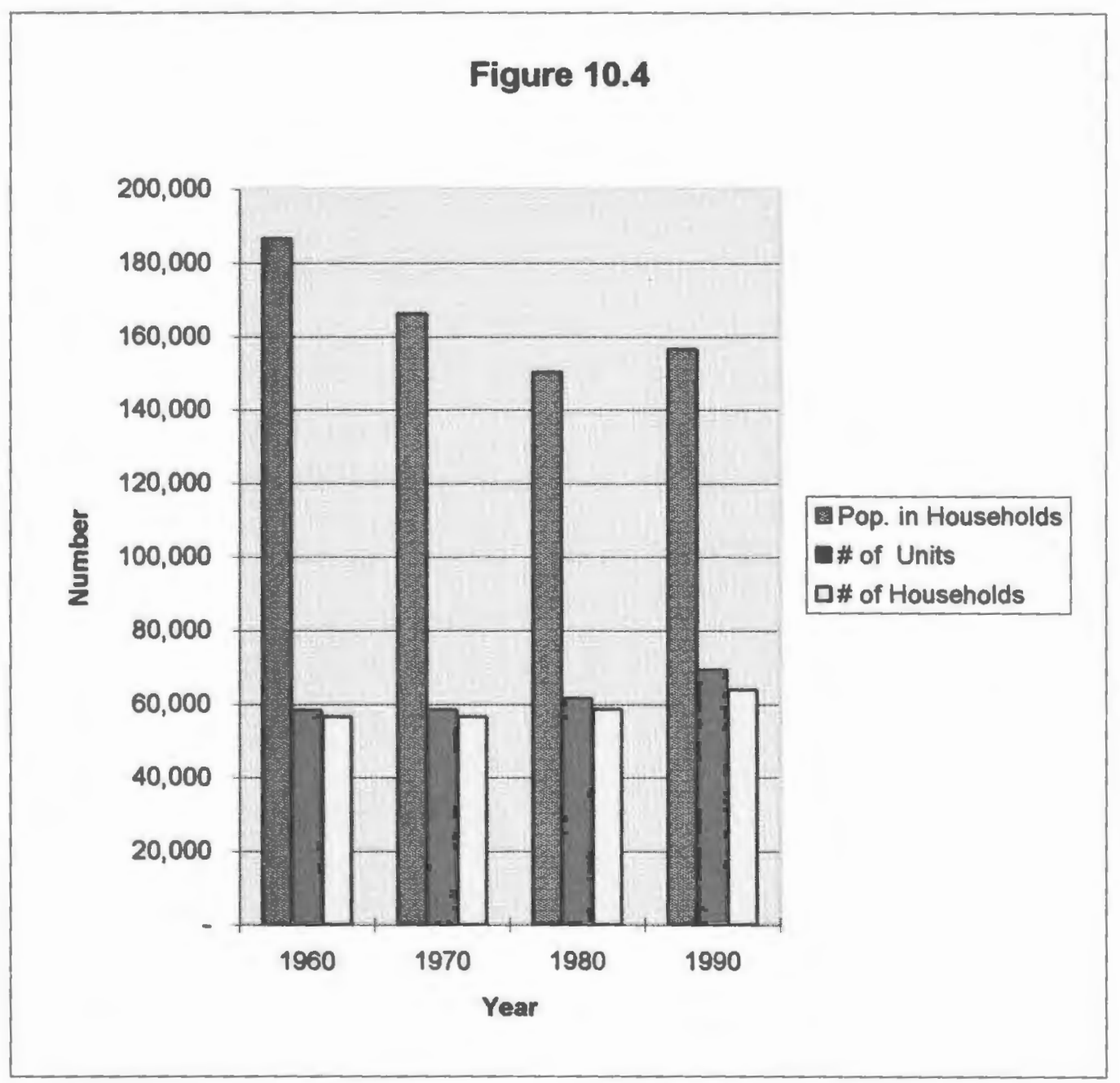


Multiple services are necessary for this variety of household and family types which can be costly.

The Main Street Study Area seemingly has very few two-parent households. There are primarily single-parent headed households and alternative households including single persons, and non-related individuals who live together. When considering placing additional housing in the Main Street Study Area, these alternative family types will have to be taken into consideration. Family support services need to be provided in order to assist existing and future families. More emphasis should be placed on trying to help families and residents through day care and elder care services and financial planning for individuals and families. City officials should continually address the changing family and household types in their policies and urban strategies. Through appropriate services and support groups, the city can assist residents in their struggle to make and keep families and raise children.

\subsection{Income and Residential Housing Permits}

The city continues to change in terms of its population. Income levels have risen following the rising cost of living expenses but no necessarily keeping up with the cost of living index. As shown in Table 10.5 and Figure 10.5, while incomes appear to be rising, almost half of the population is still earns $\$ 24,999$ or below. There appears to be a growing segment of the population earning above $\$ 35,000$ which is a good indicator of a strong economy for the city. Unfortunately, like the other statistics, those earning more money tend to live outside of the Main Street Study Area, in part due to the limited choices of housing and the public school system in the city.

The number of building permits issued in the city has dropped significantly since the 1980's. See Table 10.6 and Figure 10.6. A moratorium on housing permits was issued in 1989 and thus no housing permits were given that year. Since that year, the decline in the number of building permits has continued. In 1990, 405 permits were issued and most recent calculation shows that in 1994 only 186 permits were issued. And when one looks at only the Main Street Study Area, these are hardly applicable. It seems that the fewest residential 
Table 10.5 Worcester Household Income, 1960-1990

\begin{tabular}{c|cccr} 
Income Level & 1960 & 1970 & \multicolumn{1}{c}{1980} & \multicolumn{1}{c}{1990} \\
\hline Less than $\$ 5,000$ & $16,460.00$ & $7,046.00$ & $10,251.00$ & $3,651.00$ \\
$\$ 5,000-\$ 9,999$ & $28,678.00$ & $14,640.00$ & $10,972.00$ & $\mathbf{8 , 7 0 8 . 0 0}$ \\
$\$ 10,000-\$ 24,999$ & $7,580.00$ & $19,954.00$ & $25,026.00$ & $15,452.00$ \\
$\$ 25,000-\$ 34,999$ & 667.00 & $1,603.00$ & $7,455.00$ & $9,418.00$ \\
$\$ 35,000-\$ 49,999$ & N/A & N/A & $3,661.00$ & $11,850.00$ \\
$\$ 50,000-\$ 99,999$ & N/A & 375.00 & $1,465.00$ & $12,863.00$ \\
$\$ 100,000$ and over & N/A & N/A & N/A & $1,646.00$ \\
\hline Total & $\mathbf{5 3 , 3 8 5 . 0 0}$ & $\mathbf{4 3 , 6 1 8 . 0 0}$ & $\mathbf{5 8 , 8 3 0 . 0 0}$ & $\mathbf{6 3 , 5 8 8 . 0 0}$
\end{tabular}

Figure 10.5

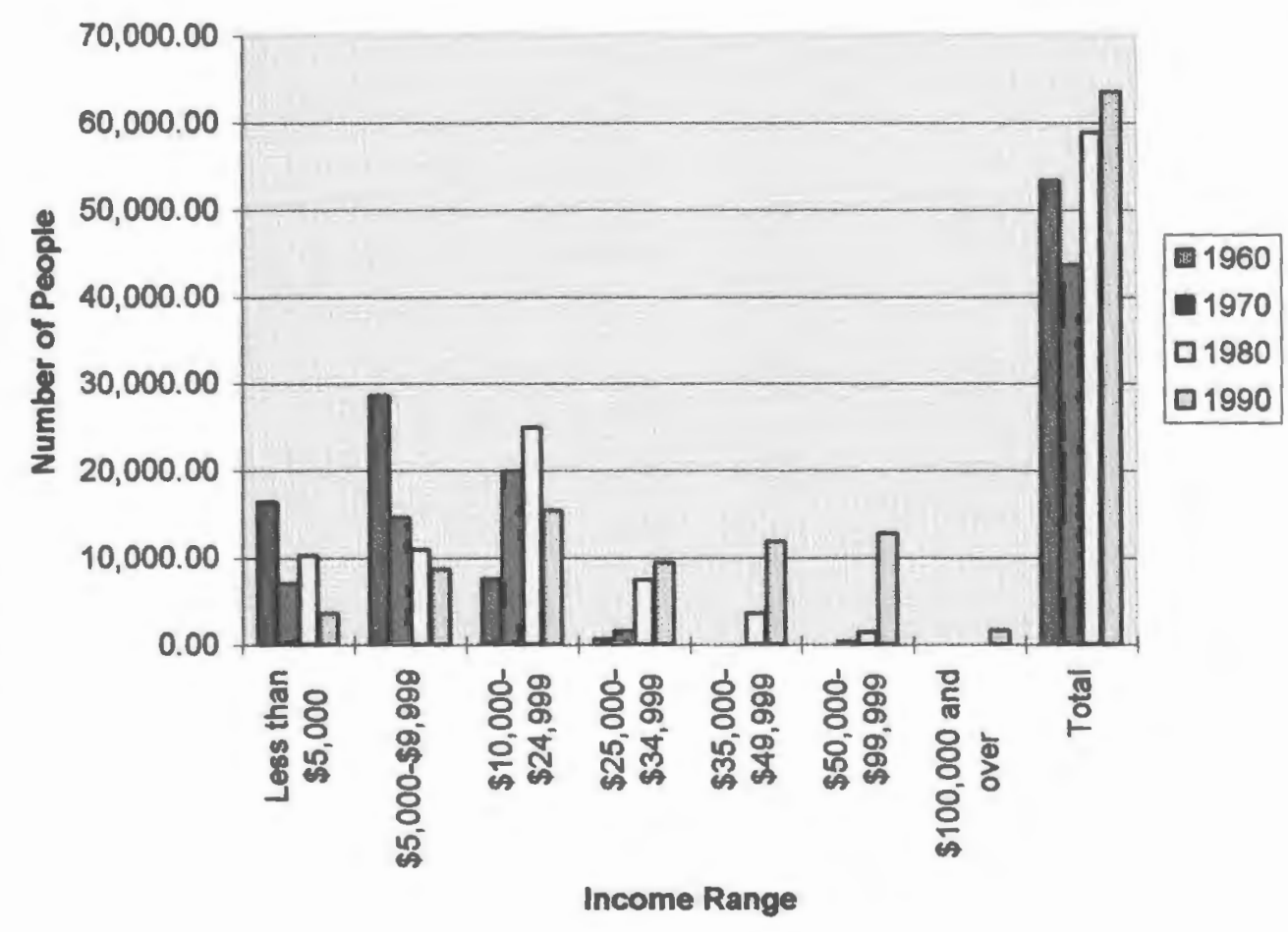


Table 10.6 Residential Building Permits, 1986-1994

\begin{tabular}{c|rrr}
$\begin{array}{c}\text { Residential } \\
\text { Building Permits }\end{array}$ & \multicolumn{1}{|c}{$\begin{array}{c}\text { Single } \\
\text { Family }\end{array}$} & \multicolumn{1}{c}{ Multi- } & \multicolumn{1}{c}{ Family } \\
\hline 1986 & 968 & 1333 & 2301 \\
1987 & 1009 & 322 & 1331 \\
1988 & 507 & 341 & 848 \\
1989 & 0 & 0 & 0 \\
1990 & 276 & 129 & 405 \\
1991 & 267 & 83 & 350 \\
1992 & 300 & 59 & 359 \\
1993 & 312 & 73 & 385 \\
1994 & 174 & 12 & 186
\end{tabular}

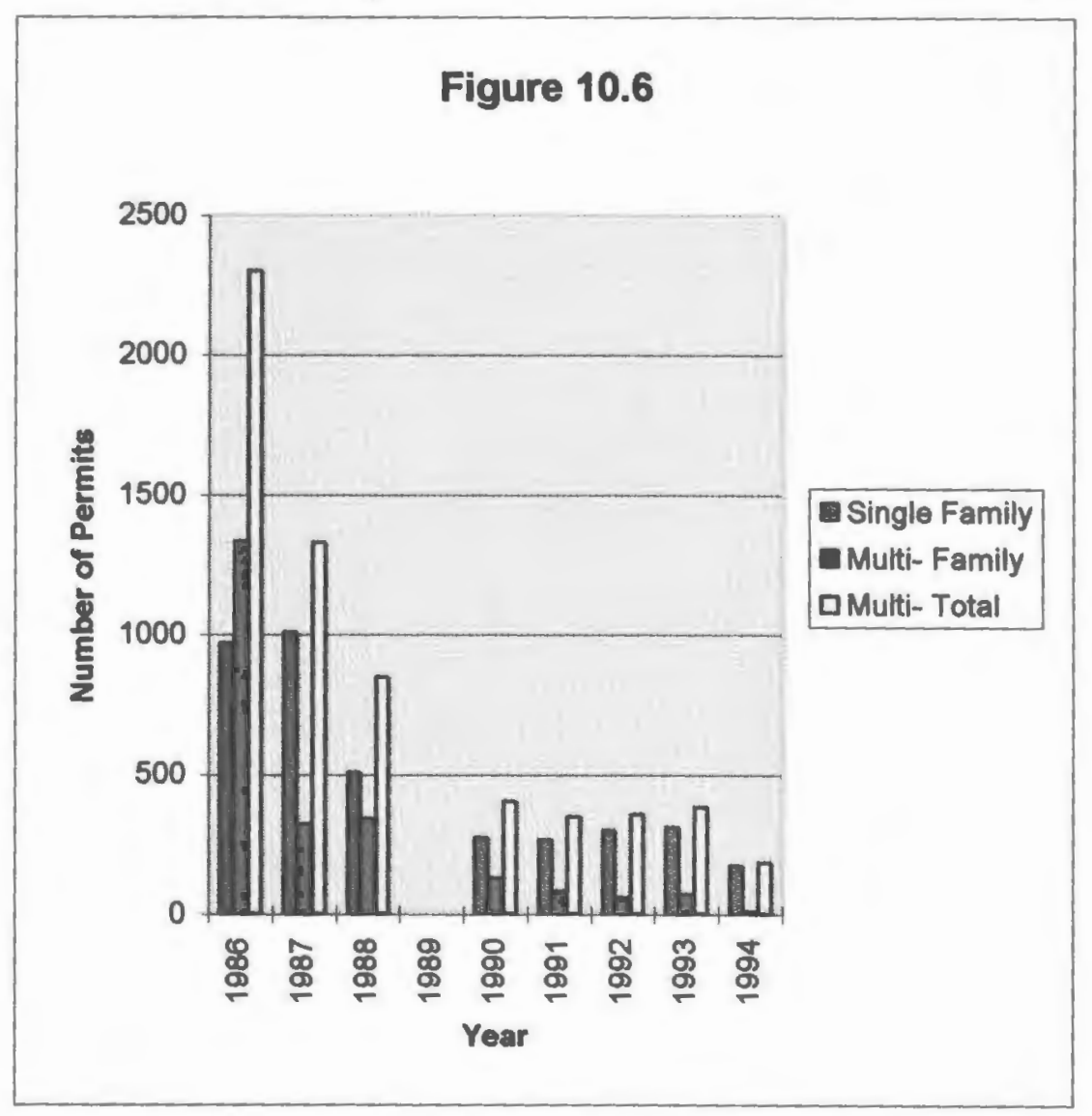


building permits have been issued in the Main Street Study Area. Since 1980 a total of two new housing projects have been built in the MSSA. In addition, a number of older residential units have been lost so the number of residential uses does seem to be declining in the Study Area. This is not a positive trend if the MSSA is to become a safe a prosperous locale which offers a variety of uses. Strategies need to be put into place provide housing option within the Main Street Study Area and to encourage both builders and residents to consider relocating back into the Study Area.

\subsection{Summary}

Planning and design efforts should attempt to address and to a certain predict the needs of the very diverse and changing populations in this community. Appropriate services and uses need to be encouraged to locate in the Study Area in order to maintain the diversity and re-introduce housing options here in the city. Because of the need for greater density in urban locations, the Main Street Study Area can offer housing types which would not be considered in more suburban locations. Types such as loft apartments, duplex apartments and rowhouses and the popular triple-decker types already seen ion other parts of the city. Uses such as a grocery store, pharmacy and elder and day care facilities would be beneficial to existing residents and would attract new residents to housing units in the Study Area. By attracting more visitors and residents into the downtown area, Worcester will be safer and more vital ensuring the continued success of this dynamic community. 


\section{PART THREE \\ THE URBAN DESIGN PLAN}

\section{Introduction}

The Main Street Study Area, described in the previous chapters, is an area with tremendous potential and in the last five years, a number of changes have been made in the area to improve the city as a whole. These changes are intended to solve current problems and provide a viable course for growth and development in the future. The first change was the completion of the Federal Plaza Park, at the intersection of Main and Southborough Streets. This park has increased the amount of public, open space in the downtown area and has been successful in providing a place for pedestrians to walk through and sit in. This park was also cited in a landscape architectural journal as being a positive addition to the city. A second significant change in the Study Area, also now completed and in use, is the renovation of the Worcester Galleria Mall. The Galleria was underutilized and deteriorating in the early 1990's. The interior was dark and uninviting and many stores had closed. In 1994, the Galleria was renovated and the focus was shifted from retail to outlet shopping. This was quite an achievement not only because it took advantage of a cutting edge trend, outlet shopping, but also because it revitalized this downtown mall allowing it to be competitive with the existing suburban malls outside of the city without having to directly compete in terms of product lines. This was also a very ambitious plan because, it has been widely theorized both in the planning and political arenas, in recent years, that downtown malls can not be successful given the advantages which suburban malls provide, including seemingly unlimited free parking and a safe shopping environment. The belief that innovation is still possible and that there are no set rules which can necessarily be applied to all cities is seemingly propelled this project to completion.

Changes which have not yet been realized within the Main Street Study Area include the restoration and renovation of the original Union Station building; a new downtown hospital complex, the Fallon/St. Vincent's Hospital; a new county courthouse and office 
project; and the Worcester Convention Center which is currently under construction. These facilities, it is anticipated, will bring new residents, visitors, and businesses into the city. The proposal for Union Station specifies that the building be re-designed into an inter-modal transportation center which accommodates intercity train and bus traffic, local bus lines, taxis, passengers and pedestrians. The architect is also proposing that ancillary space be used as medium-sized convention space for local business meetings. It is anticipated that the new Worcester Convention Center and the additional conference and meeting space to be provided in the Union Station building along with its restoration will increase the number of jobs in the city and encourage business to visit and locate in the Main Street Study Area as well as the city of Worcester and take advantage of the many other services which they have to offer. The last major project currently in progress is the new Medical Cities Project also called the Fallon/St. Vincent's Hospital complex. This project, occupying a prime downtown location, will provide much needed medical services to residents of and visitors to Worcester County. It is anticipated that this complex will also attract new business to the city. Plans are also underway to renovate the interior of City Hall which is also in dire need of repairs and general upgrading.

There are also changes expected to be made to improve the public amenities and landscaping elements in the city. These changes will coincide with the new larger developments planned and/or underway in the city. Most of the designs are linked directly to the developments, such as the Hospital Complex designs are to include landscape and amenities within the overall design of the complex. The one project which remains separate from these other developments is the upgrading of Main Street which is a project in progress having begun with the renovation of the Courthouse Park project. Proposed improvements for the remainder of Main Street include planting additional trees, providing new and attractive bus shelters, and re-paving sidewalks.

While there are numerous proposals in the works, there are still many areas of opportunity for the City, to make additional and positive changes. There are also opportunities even in the midst of the current proposals to re-evaluate and perhaps determine whether these 
proposals, in their current form, are the best course of action for the City. The purpose of the following chapters of this report is to make recommendations and suggestions which will compliment existing proposals, generate new plans and advance the Main Street Study Area as a whole. This plan is intended to enhance the positive aspects of the study area and provide possible solutions to existing problems found here.

The primary goal of this urban design plan is to provide an overall framework in which improvements can be made to the Worcester Main Street Study Area. The case of Worcester requires more than cosmetic changes in order to ensure long-term progress and stability for the city. Thus the urban design plan presented in the following chapters will move beyond simply providing design-related recommendations. This section of the report will provide recommendations which address a variety of issues including social and economic concerns.

The problems affecting the Main Street Study Area as a whole will be discussed at the beginning of each chapter. Then, the problems associated with the individual districts will be addressed in detail. Recommendations will be made addressing each problem and objectives for the districts and the city will be offered. These objectives will provide specific strategies which can be applied to each development district including a procedural list which could be followed. Issues such as revisions to the zoning code, preservation of open space will be preserved and existing street walls in the downtown area will all be addresses. Recommendations and strategies will attempt to foster and support existing planning and preservation efforts when possible and propose viable changes to the districts.

Circulation problems within the Main Street Study Area will also be addressed in order to improve both the pedestrian and vehicular traffic. Specific recommendations regarding circulation in the districts will be made, both to generate and control pedestrian and vehicular traffic in the Study Area. The recommendations made in this report ideally will make the downtown districts a destination thus encouraging businesses to move back into the Main Street Study Area and encouraging people to come to the downtown area for both residential 
and recreational purposes. People must be interested in visiting and living in the Main Street Study Area and the city must provide the necessary goods and services to attract individuals, businesses and visitors if this is to be a viable destination. Also circulation through the city must be reasonable and clear to encourage both motorists and pedestrians to make use of it. Finally the City should be clean, neat and attractive. So, specific design issues in the Main Street Study Area will be addressed and suggestions will be made to improve both the appearance of specific sites in the Study Area and to improve the appearance of the Study Area as a whole. Therefore, all of these issues will be addressed in the following chapters of the report. 


\section{CHAPTER ELEVEN \\ RECOMMENDATIONS FOR CREATING AN ACTIVE AND VIABLE DOWNTOWN MAIN STREET STUDY AREA}

\subsection{Introduction}

This chapter is intended to provide the basis around which more specific interventions can be made. Important goals such as increasing the number and improving the quality of the activities found in the Main Street Study Area will be the focus of this chapter. Commercial uses are tremendous assets to all downtown areas, but other uses and activities also need to be encouraged to ensure the 24 hour life of an urban center. And the commercial uses, rather than taking away from the other activities in the city should contribute to them. Other uses in cities which attract people on a regular basis include residential uses and cultural programs. Residents need other activities in the downtown to further enhance the attractiveness of the area. Specific uses such as grocery stores and pharmacies are needed by both residents and visitors to an area and are currently unavailable in the Main Street Study Area. Cultural programs and activities can be relaxing and entertaining to residents and visitors.

Recommendations will be made in this chapter which are intended to further the goal of making the Main Street Study Area a vibrant place throughout the day. One objective will be to encourage people to live in the city and to encourage people to visit the downtown area on a more regular basis. Activities, events and uses which will make the Study Area an exciting and attractive destination and encourage people to retum here will also be described in this chapter of the report.

\subsection{Worcester Main Street Study Area}

Problem: A number of committees, businesses and city organizations sponsor events in the Main Street Study Area. But very few of the major events have lasted more than one or two years. Over the years events have been canceled or planned for only one year. Thus, there are very few public events, in the Main Street Study Area, that occur on a regular basis, such as 
every year or every weekend, except those provided in the various civic or public spaces such as Mechanics Hall or the Worcester Art Gallery.

Recommendation: The city officials need to define a few events which could be sponsored on a yearly basis within the Main Street Study Area. By providing activities which occur on a regular basis which are successful and well attended, such events will develop a core of people who would regularly attend the event and thus regularly come into the Main Street Study Area. This is one way to begin to make the Study Area a destination. First Night is one such event but because it occurs during a holiday season, it attracts and serves residents primarily. Unfortunately, many residents often choose to attend First Night in Boston over the First Night Celebration in Worcester because Boston is already perceived as a destination and it offers many more activities. The city should market this event extensively and try to attract high quality venues in order to bring both local residents and visitors here. The smaller size should be considered an asset, allowing groups of people to meet one another and enjoy the festivities as a group rather than as individuals walking around to the different venues, which is what happens in larger cities such as Boston and New York. The positive differences, between the Worcester celebration and those which occur in other cities need to be emphasized.

Events which improve the health and welfare of the residents of the city of Worcester should be considered. Currently there are events held outside of the city, but there are also numerous events which would be appropriate for within the Main Street Study Area. They include:

1. Athletic Events - walking and running events such as a walk-a-thon or a $5 \mathrm{k}$ run. These events often attract athletes from across the country and the world who are training for larger events or meets. Such events can also be used to promote or fund-raise for a cause such as a local shelter, a disease or illness. These types of events often are sponsored by businesses and organizations which help to legitimize the event. Through these events they are able to make charitable contributions and advertise their company. These events if scheduled on a weekend, would help the local economy by bringing people into the downtown area when it 
is usually not busy and encourage people to take advantage of the shops and restaurants there. These types of events are family-oriented activities and thus men, women and children of all ages can participate or watch. Students from the various local colleges should be encouraged to participate in these events also. They can assist in organizing such events and also should be encouraged to participate. The city should consider sponsoring two walks per year and one or two distance running events per year.

2. Antique/Flea Markets - a local bazaar where all types of goods can be bought and sold at modest prices. Markets such as these have become very popular because they allow people to come together in a large group and buy and sell things which are still in relatively good condition. These types of markets can attract visitors from many areas and are always a good option for students looking to furnish a dorm room or sell things at graduation. While antiques offer another type of draw, this market should focus on the more moderately priced items.

3. Fruit and Vegetable Market - provide a popular way for local farmers to raise additional revenues and are an excellent way for local residents to have direct access to fresh and typically less expensive produce. Baked goods are also often included in these markets offered by individuals or businesses with experience. This can be an excellent way for local individuals to advertise their culinary talents. These markets can be offered more frequently than the first two, such as every weekend during specific hours.

\subsection{Interstate Commercial District}

Within the Interstate Commercial District, there are a number of specific changes which can be made to improve this district. The preponderance of available land and new construction allows for dynamic changes to be made and executed here. But all plans for this district meet the goals and objectives established for the Main Street Study Area and the city as a whole.

Problem: The Union Station Restoration and Renovation design does not yet delineate how best to re-negotiate traffic around the Washington Square rotary and provide the necessary parking here. The latest proposal suggested taking the rotary out entirely and making 
a four point intersection. The relationship to the Worcester Galleria is also not well defined.

Potential Benefits: The new Union Station complex will bring additional jobs, both temporary and permanent into the city. This facility, by combining the various modes of public transportation, should also encourage residents and visitors to use the public transportation system in the city, which are currently scattered throughout the city.

Recommendation: While the renovation of the Union Station building itself will be a tremendous asset to the city, it needs to be supported by some additional changes to the surrounding area and perhaps within the building itself. (See Proposal Map, Figure 11.1)

1. New Washington Square - Create a new Urban Square green space directly in front of the newly renovated Union Station Building with a short-term surface parking lot adjacent to it underneath the railroad tracks. Relocate the green space from its current location and re-shape it as a square. This will allow the heaviest traffic, controlled by a new traffic light. to flow unobstructed between Grafton and Summer Streets. Also a new more accessible outdoor square will be created where people can sit and wait when the weather is clear.

2. New Hotel - located adjacent to the highway, the northern section of the Washington Square would be an ideal location for a new hotel with an integrated casino area. Such a use would attract visitors to the city and encourage use of the train station which would also support the hotel.

\section{Re-Design Worcester Galleria Parking Structure - The Worcester} Galleria parking structure create an oppressive wall on the Union Station building side of the Galleria. It is recommended that first the entry ramp to the parking garage be removed to free up space in the area and allow a new parking garage to be built next to the train station. It is suggested that the current Galleria garage be broken up into two smaller parts, as shown on the proposal map, and a new entry to the Galleria be made. This would make the edge facing the train station more open and inviting to pedestrians and provide a destination for station users but it would also allow more light into the Galleria Mall. 
Figure 11.1 Proposal Map

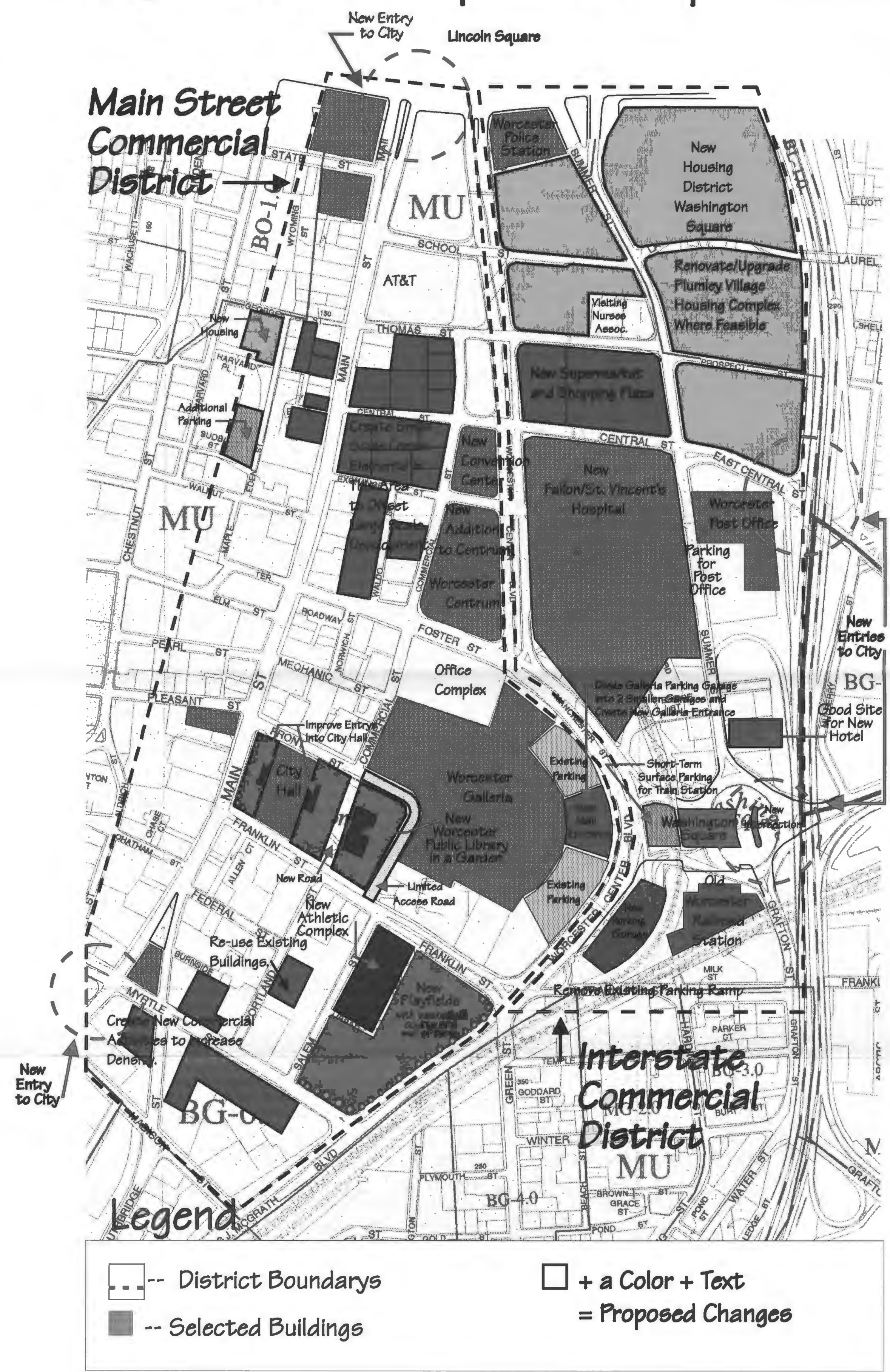


4. Marketing/Promotion - it is assumed that this facility will not be selfsufficient financially once developed. All the benefits of this location need to be considered and promoted to residents and visitors in and around Massachusetts. These include easy access to Boston via the new commuter rail extension, access to ski areas and to western parts of Massachusetts.

Problem: Worcester Galleria Mall is far too upscale given the income level in the city of Worcester and to allow small businesses to locate in the Galleria. Currently there are more advertisements for the mall found outside of the city of Worcester and even outside of the country than one might find in the city itself. During a recent survey of the Galleria a small business owner was in the process of moving out of the Galleria entirely due to the prohibitive rental charges. Unscientific comparisons of prices between the stores in the Galleria and stores in an outlet shopping center in a more affluent part of Connecticut found the prices in the Galleria to be higher on average, partially due to the fact that operating costs in an indoor mall are higher but also because the mix of stores may not be appropriate for this area.

Recommendations: It seems that for any commercial use in the Main Street Study Area, except small shops specifically designed to meet the needs of tourists, should first cater to the local residents in order to develop and maintain a loyal consumer base. This is more likely to ensure consistent profitability in the future than always trying to attract visitors.

1. Developers of the Galleria should make and continue to make a substantial effort attracting a more diverse mix of stores which address a variety of income levels.

\section{Efforts should also be made to provide small business owners with} financial incentives to locate in the Galleria.

3. Encourage other activities in the Galleria which include a variety of people. For example, the morning walking program which took place in the old mall was a wonderful way to bring people of all ages together and utilize the space effectively during off hours. 


\subsection{Main Street Commercial District}

Because of the greater density of this district, there are fewer places where new development projects could take place. Potential opportunities for development do exist in the many surface parking lots which are currently scattered throughout this district. See Chapter 12 for recommendations. But there are other substantive changes which could be made to improve this district.

Problem: The Worcester Convention Center is a potentially high risk development project for the city. Currently, the Worcester Main Street Study Area is not considered to be a destination point for visitors looking for goods or services. Also it faces potentially sharp competition from other cities which have recently built new convention centers. The Worcester Center, for example, does not have the advantage that the new Providence Convention Center has of being located on a major national highway. But the Providence Convention Center, while having some success attracting conventions, it struggles to attract conventions and visitors on a consistent basis. It also does not have the support of a diverse city like Boston, which also houses a fairly new convention center.

Research is now being done to evaluate the many convention centers which are being built in various cities. Having been functioning for a few years one is now able to obtain substantive statistics on some of the convention center built over the past few years. Most notably is an article from the Economic Development Quarterly which evaluates the Jacob Javits Convention Center in New York. This article is very telling about the benefit of this facility and about its ability to generate activity ${ }^{14}$. The Javits Center like the Worcester Convention Center was designed to revitalize the central business district and promote economic development in the area. It specifically concludes that while the Javits Center does attract a substantial number of visitors each year, much of its success is due to its Manhattan location. It is also noted that the expected physical revitalization of the area as a result of the

\footnotetext{
14 Fenich, "New York Convention Center" Economic Development Quarterly Vol. 8 No. 3 August 1994 pp. 245 - 255
} 
convention center has not yet been realized. But construction of the convention center is almost complete and thus must be dealt with as an existing entity rather than as a proposal which could be changed.

Recommendation: The developers of the Convention Center need to carefully study the business trends to see what the need for this type of space will be in the future. Probably they will need to be looking at attracting smaller conventions and seminars which reflect the current trends toward streamlining and efficiency in business. Areas for further investigation include:

1. Training Programs - the convention center should look at companies which provide training programs and seminars as part of their on-going employee training. This could involve computer training and computer expositions which will continue to grow around the country. This could also include the latest trend toward high-tech manufacturing where companies are having trouble finding skilled labor and thus are having to provide their own training courses.

2. Smaller Conventions - those which bring together diverse fields to share and exchange knowledge and ways of doing business, educating etc.

3. Centrum Expansion - coordinate the schedule for the Convention center with that of the Centrum. The Worcester Centrum, already very successful, could utilize available space in the new Convention center as needed.

4. Support Services - tend to be less expensive in Worcester and the MSSA than in other cities such as New York or Boston. Use this advantage to promote use of the convention center. These services will need to be expanded, additional restaurants, a grocery store, pharmacy etc.

Problem: Renovations and repairs to the Worcester City Hall are long overdue and thus the building is in need of many repairs and upgrades. The main problem appears to be, how to re-establish the grandeur of the original building, create spaces which can be cleaned and maintained in the future, and keep the building open to the public during the renovations and in the future. 
Recommendation: The focus of this renovation should be on utilizing quality materials. Materials which reflect of the age and craftsmanship of the original building but that can withstand the daily pressures which are derived from public use. Particular attention should be paid to the entryways, the one facing Main Street and the one facing Worcester Common. Obstructions should be removed and the original grand entry design should be articulated as much as possible.

Problem: How best to revitalize and re-use Worcester Common. This issue has yet to be resolved. Many ideas have been presented such as turning the reflecting pool into an ice ring in the winter but none have adequately suggested how to make Worcester Common a safe and vital space.

Recommendation: Library in a Garden - A new Worcester Public Library building should be built in center of the Worcester Common across from City Hall. The existing Worcester Public Library building is poorly maintained and hence an unattractive addition to the city. It well used attracting people of all ages, families and the elderly, particularly on weekends. The interior of the building is also not well maintained offering crowded and poorly lit spaces. The city should take better advantage of the library which continues to attract many people into the city. See Figure 11.2.

1. Build a new Worcester Public Library approximately in the center of Worcester Common. Re-design the remaining open space using pathways, benches, trash receptacles, plants, trees, flowers, and street lights. This will not only help to bring people into the Common but will encourage use of both the library and the garden areas for reading, having lunch etc.

2. Re-designate the portion of Front Street between the new library and Galleria as a limited access road primarily for delivery purposes. This would help to alleviate the problem of people parking and hanging out in front of the Galleria. 
Figure 11.2

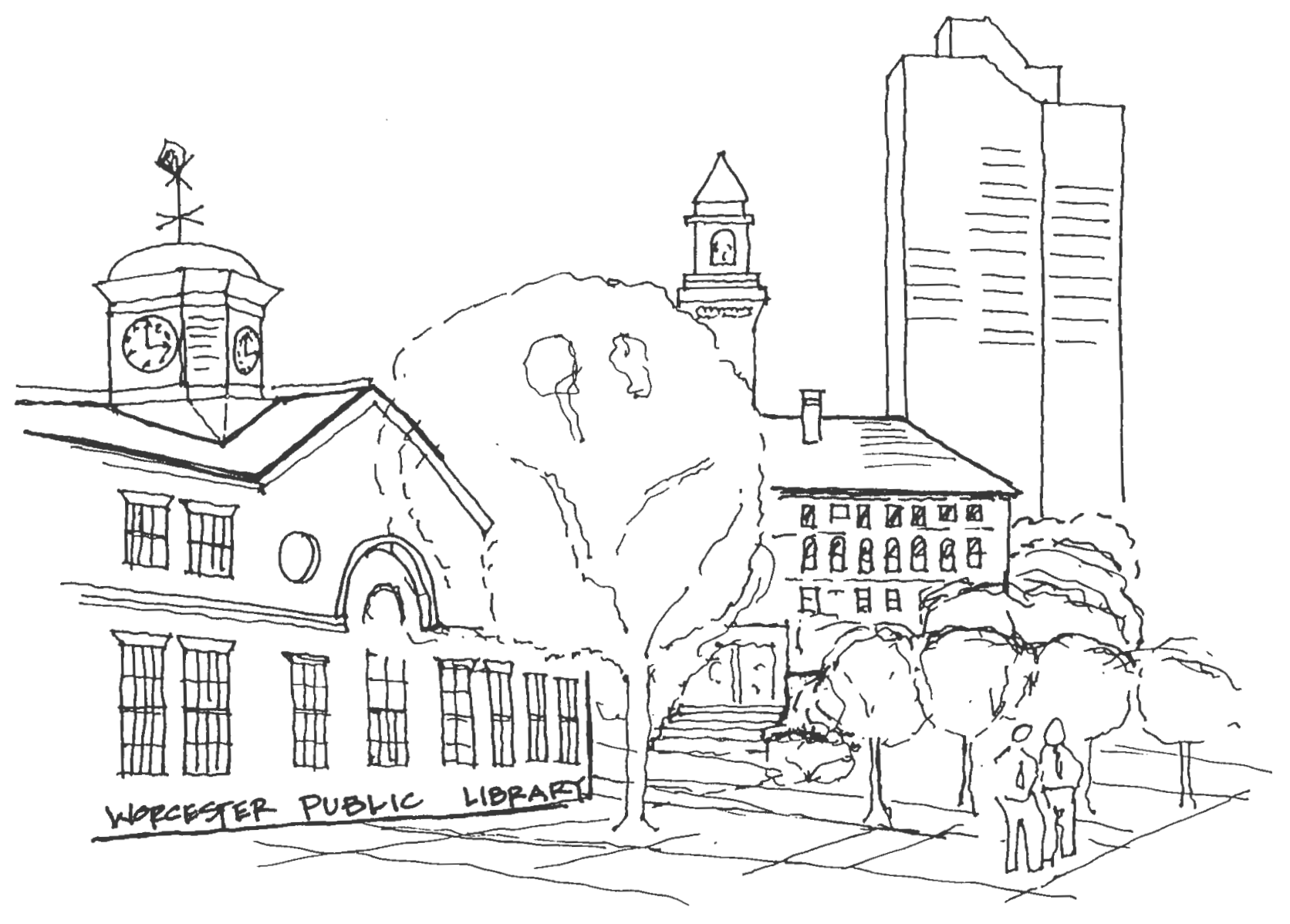

\section{Main Street Commercial District Library in a Garden}




\section{Allow Commercial Street to cut through the Common and connect}

to Portland Street helping to re-activate Portland Street as a commercial route in the city. The new connector road is to be tree-lined and maintain the integrity of the Common. Different paving materials and curbing such as granite curb stones and concrete street would help to reinforce the fact that this part of the street is more closely tied to the urban park rather than to the commercial areas.

Problem: The space currently occupied by the Worcester Public Library and the YWCA is not used as efficiently as it could be. YWCA Way is an under-utilized road and moving the library would free additional space.

Recommendation: Having relocated the library, create a new Athletic Complex with large play fields, basketball courts, and an indoor swimming complex on the site bounded by Franklin and Myrtle Streets to the north and south and by Salem Street and Worcester Center Boulevard to the east and west.

1. This center would provide a health facility which could be used by employees before and after work or during lunch.

2. The play fields could be utilized by local sports teams both after school and on weekends. Unscheduled games could happen on these fields also.

3. Course and activities would be provided for children and adults. After school art and athletic programs as well a CPR training and swimming lessons.

4. A Senior Center could also be included in this complex. The central location, and proximity to the many modes of public transportation make this a good location. And this would create a good mix of young and old people who could learn from one another.

\subsection{Residential Commercial District}

Problem: Re-designation of uses in this district. There are no specific sites in this district which are of concern except as related to this issue but planners and officials should follow and attempt to guide the transformation of this district. Many of the residential uses should be preserved. In addition, the commercial uses should remain on the eastern edge of the 
district closest to the Main Street Commercial District with the residential uses on the western side. Becker Junior College can remain as integrated into the more residential part of the neighborhood. But as the commercial uses and the College continue to grow and develop new boundaries may need to be identified.

Recommendation: Develop a more detailed Land Use Map for this district and monitor changes in the amounts of commercial and educational uses. This will assist the city in planning for potential changes which could occur in this district in the future. Work with planners at Becker Junior College to better assess and keep track of what the colleges spatial needs may be in the future.

\subsection{Housing in the Main Street Study Area}

Problem: There is insufficient housing in the Main Street Study Area to provide the city with safe and appropriate evening uses. The Main Street Study Area specifically needs activities which take place throughout the day rather than simply from nine to five. One of the basic problems with the Main Street Study Area is the lack of housing and the decreasing number of residents found in this area. As shown in the census data, the actual number of residents in the downtown area has been declining. This has greatly reduced the amount of activity which takes place in the Main Street area after working hours. The reasons for this problem are numerous and reflect the great changes which have occurred both in this city and in others throughout the United States. First there has been a significant change in family structure. The changes in the family structure as seen in Worcester show that there has been an increase in divorces in the city and so that there are many more single parent households. There has also been a general decline in the average income level within the city of Worcester as more affluent families continue to move into suburban areas. Thus, there is a greater need for affordable housing, rental units specifically in the city.

Housing which addresses all family types and income levels should be provided

in the Main Street Study Area, both because of the need but also as a means of revitalization of this urban downtown area. The new hospital complex will also create a need for additional 
housing close to the hospital, to serve the needs of the employees who often work very long shifts. The demand for housing by hospital personnel could encourage residential development in the Main Street Study Area and could encourage other workers to back into the Study Area.

\section{General Recommendations:}

1. In general, a variety of housing needs to be provided for a variety of income levels. This encourages diversity in the resident population which is more consistent with the diversity which cities tend to have particularly in downtown locations.

2. Existing structure should be preserved as much as possible. The downtown area has a variety of interesting structures and spaces which already exist above shops. These are ideal living spaces particularly since the nature of the family has changed so dramatically in the past few decades. Therefore, existing buildings in the Main Street Study Area should be renovated maintaining the existing character of the building. The buildings should not be dramatically altered in terms of character and appearance and so materials and colors should be selected carefully. A certain amount of respect must be paid to the context in which this housing is to exist so as stated previously if the structure is on a street with a large amount of commercial activity, then the housing should be placed above and the commercial activity allowed to continue at the ground level.

3. Low Income housing should be provided also in the downtown area. But as is the trend in the suburban communities, the low-income units should be integrated in with middle and upper income units. This helps to create more diverse communities and also assists the low-income resident by rather than branding them with the label low-income. One example of a low-income project which has been unsuccessfully integrated into the community, is the Plumley Village Housing Project, to be discussed later in this section.

Problem: Existing housing stock is poorly maintained

Recommendations: Provide owners with financial incentive to upgrade upper stories of existing buildings into new housing. Encourage owners to maintain the exterior craftsmanship of the original building. 


\subsubsection{Interstate Commercial District}

Problem: The Plumley Village Housing Project in its current state does little to help the image or the reality of housing and specifically low-income housing in the Main Street Study Area. There is often trash overflowing from the various dumpsters which are scattered throughout the parking areas. The buildings themselves are made out of brick which requires little maintenance but the brick construction differs greatly from the wood frame construction of most housing in the city and makes the project stand out. There is no expectation or opportunity for home-ownership in this complex so residents provide little assistance maintaining the interiors or the exteriors of the buildings. The poor location, directly adjacent to Interstate 290 also hurts this project.

\section{Recommendations:}

1. Create a housing neighborhood using much of the land in the northern portion of the Interstate Commercial District including the Plumley Village Housing Complex. The neighborhood would be called Washington Square.

2. Create a variety of new housing types including townhouses, triple deckers, condominiums, and apartments. Provide both home ownership and rental units as well as market rate and low income housing. Materials and housing elements should be controlled in order to provide the image of housing. The buildings should be primarily wood frame construction reflecting the existing housing stock and elements such as windows and doors selected to further the image of housing.

a) Focus on materials and quality of construction. Types of materials and the quality of the construction will determine not only the safety of the structure but also its longevity in the city.

b) Windows and doors. Windows are the other factor which will determine how attractive the building is. Windows for housing should vary in size reflecting the uses on the interior. A variety of uses can be reflected on the exterior of a housing unit including the kitchen, bathrooms, and living area and this can improve the overall appearance of the street 
and surrounding area.

Provide specific guidelines for new housing construction. Using research from other cities, the guidelines could be developed by the Urban Design Committee (to be discussed in the next Chapter) in conjunction with the Planning Department and with final approval from the City Council. There would need to be guidelines to address the various housing types from high density to low density, from high-rise to single family. These guidelines could be very specific, to help preserve the appearance of the city and provide adequate facilities for residents.

\section{Incorporate small gardens and yards and separate entryways as}

much as possible to create privacy and give residents further ownership opportunities. Provide community garden areas and a playground for children.

4. Renovate buildings in Plumley Village complex only if they can be feasibly integrated into the new neighborhood. It is more important to create a neighborhood atmosphere in this district than it is to save any of these buildings.

5. Create block of support services for the new neighborhood. As indicated on the proposal map this would include, a supermarket and pharmacy, day care services, a coffee house and a restaurant such as a Chili's.

\subsubsection{Main Street Commercial District}

There is the opportunity to create new housing on some of the upper stories of buildings in this district. This opportunity should be taken where feasible. Some of the potential lots for housing are identified on the Proposal Map.

\subsubsection{Residential Commercial District}

This district is already mostly housing. The emphasis in this area should be on upgrading the existing housing stock and maintaining the overall quality and character of the district. Some of the housing in this district needs basic upgrading and repairs. The city should develop informational sessions for home owners which offer information about how to do basic renovations, how to hire professionals and identify the various sources of funding which may 
be available. When possible the city should work with local business owners to create new funding sources. Attractive neighborhoods will attract new residents and will be good for business.

Problem: Some of the housing in this district are not well maintained.

Recommendation: Informational sessions and programs should be made available to homeowners both from the public and private sector. These programs can provide instruction and information about how to maintain, upgrade and do renovations. Other programs which encourage and support home ownership would also be beneficial. People tend to take better care of home that they own rather than rent. 


\section{CHAPTER TWELVE \\ GUIDELINES TO IMPROVE CIRCULATION AND PUBLIC AMENITIES}

\subsection{Introduction}

The circulation issues identified chapter three of this suggest that there are opportunities to improve the overall traffic patterns and parking which currently exist in the Main Street Study Area. The problems identified in the Study Area are not insurmountable and in this chapter of the report recommendations will be made to improve the existing circulation and prepare for the future.

\section{Problem: Lack of directional and informational signage in all the districts}

Recommendation: The city should have all streets checked for adequate directional signage and replace missing or damaged signs as needed. The city should acquire the assistance of a graphic designer to coordinate an informational signage program for the Main Street Study Area as a whole. As very developments are completed one sees the developers placing their own signage in areas, such as a sign in Worcester Square identifying the Worcester Galleria. This sign is very out of place. There should be a coordinated color scheme which can be used by multiple departments and developments throughout the city. The city should increase the size of the street signs to make them legible from a greater distance and to better coincide with new informational signage. Some examples of signage which is available are shown in Figure 12.1 .

\subsection{Guidelines for the Main Street Study Area}

Problem: The activities of the Worcester Transportation Department and those of the departments which are involved in initiating and carrying out planning and development projects are not well coordinated. Transportation issues are vital to any development project and so it is important that the Transportation Department be involved in the development process, from the initial proposal stage through completion of the project. This will allow better planning of roads and traffic patterns throughout the city. 
Figure 12.1

Lighting and Traffic Control Modules
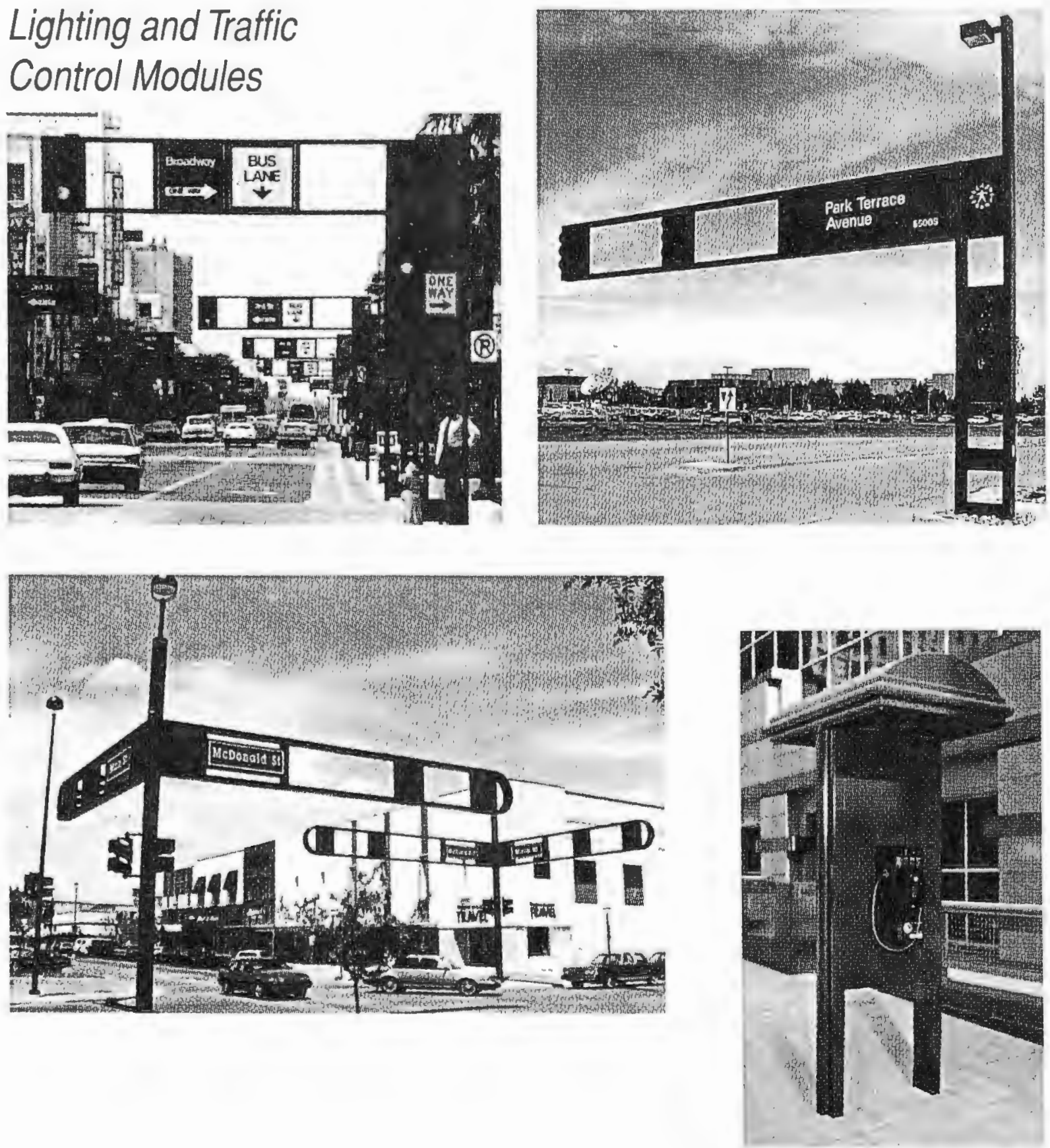

\section{Examples of Signage} Available from Numerous Manufacturers 
Recommendation: The issue of traffic and congestion in cities being so paramount, it is vital for the Worcester Transportation Department to be involved throughout the process. There needs to be a more open dialogue between the transportation department and these groups in order to improve the road conditions in the city of Worcester.

1) When a development project is presented to the City and moves forward and representative from the Transportation Department should be assigned to the project in order to provide input and information.

Problem: On certain streets in the city there is a great deal of congestion due to the increasing number of automobiles and the lack of directional information provided to the motorist and pedestrians.

\section{Recommendation:}

1. Encourage prompt maintenance of all city amenities such as street signs. This includes replacing damaged and stolen ones promptly and repairing signs when appropriate. The minimum requirement for street signage should be that all intersections have street identifying the names of the street one is on and identifying the crossing street. These signs guide both pedestrians and motorists more efficiently through the city which can help reduce the amount of congestion on city streets and therefore they are extremely important.

2. Traffic light lengths should be checked periodically to make sure that they reflect and deal with the current traffic patterns effectively and efficiently.

\section{Encourage smaller scale commercial and residential development} in the Interstate Commercial District and along Worcester Center Boulevard. This will help distribute traffic onto all of the available roadways and ideally encourage use of roads which are currently under-utilized.

Problem: Worcester lacks clearly defined city edges or boundaries. The Main Street Study Area is not clearly identifiable as the central downtown area. Using certain design strategies, the city can both improve circulation and direct motorists and pedestrians into and through the Main Street Study Area. 
Recommendation: Currently a number of Gateway projects have been proposed for the city. The Central Street Gateway Project has received funding and is underway. Defining the boundaries of the downtown area through panting, signage and other amenities will make the city more legible and more attractive.

2. Define the entrances to the City of Worcester so that the boundaries of the city center are more readily identifiable. This is a difficult task in the City of Worcester in that there are clearly a number of ways in which people come into and out of the city on a daily basis It is up to the city to choose those areas it feels serve as the entrances to the city. In this report, five areas were identified as the major entrances to the Main Street Study Area. They are:
a. Federal Plaza
b. Lincoln Square
c. Intersection of Central Street and Summer Street in front of the post office.
d. Intersection of Pleasant Street and Chestnut Street
e. The Old Train Station

The proposed entrances are shown in Figure 11.1. It is recommended that in these selected areas substantial landscaping, including flowers, trees, and signage be placed here which tells visitors that they are entering or exiting the central business district. For example, signs which say "Welcome to the City of Worcester" and which have a symbol which represents the city used in these locations. The symbol could be used on signage throughout the Main Street Study Area to inform visitors that they are still in the downtown. Residents could be encouraged to participate in this design process. A contest could be held for the best phrase or symbol reflecting the City of Worcester and a prize given to the winner.

4. The most important aspect of defining these entrances is that they all be done in the same way. Meaning that each has the same sign using similar materials and similar types of landscaping so that all the entrances look alike. By relating the entrances to the downtown area the city then will begins to read as a cohesive unit. This will help define an 
image for the city and will provide directional assistance to residents and visitors.

\section{Problem: Lack of clarity and comfort for those using the public bus}

transportation system. Signage at the bus stops is small and difficult to read. There are very few bus shelters and those which do exist are not adequately maintained. There are rarely additional public amenities provided near bus stop locations.

\section{Recommendation:}

The key to providing good service to a customer is understanding what the customers needs are. Therefore, it is crucial that the bus company survey its ridership periodically. While surveys are currently done, the ones obtained for the purposes of this report provide little of the type of information which would be necessary to ensure the comfort of the rider. Some key questions which should be asked of riders is age and physical health. Many of the riders of the Worcester bus lines are elderly and/or students under the age of 18 years old. Therefore, comfortable yet durable waiting areas are desirable. Strong graphics which effectively communicate information and provide schedule information need to be integrated in at all bus stops. This will better assist both the elderly and children but also visitors and new riders to the system as well as encouraging continued ridership.

1. The first issue is the lack of clarity of the signage. The old signs identifying the bus stops in the City of Worcester are the same color and of similar design to the other signage found on the streets specifically the "No Parking" signs in t he city. This can be confusing to both pedestrians and motorists. New bus stops signs are appearing on city streets but they are not widespread yet and although their design is more up-to-date still not enough information is provided to riders.

2. The city needs to develop ways to provide riders with bus schedule information. This involves a two step process. First as is appearing in other cities, are large permanent stands which provide enlarged schedule information. These stands should be designed in such a way that they can not be damaged or tampered with but, also should not be so permanent that they can not be changed if the schedule for the bus changes or if it becomes 
discolored and not readable for some reason. The simplest idea is that of a permanent stand which can be opened and an enlarged version of the schedule inserted. The outside of such a stand would be made of some type of strong transparent plastic, through which a pedestrian could read the schedule but not touch it.

3. Provide comfortable bus shelters at major bus stops. Although one does currently find bus shelters in the City of Worcester most are not properly maintained and do little to shelter a person waiting for a bus. particularly if the person is waiting in extreme weather. Therefore it is recommended that existing shelters be replaced and additional shelters be placed at many locations in addition to the locations planned for in the Streetscape Plan.

Bus shelter designs take many forms some of the better examples are seen in the following exhibits. What all of them share are durable seating areas, partial enclosure of the seating area and relevant bus schedule information. See Figure 12.2.

Problem: The absence of a central transportation facility in the City of Worcester. As noted in the second chapter of this report, currently the various modes of transportation are separated throughout the city. The Amtrak and Greyhound bus terminals are not even located in the Main Street Study Area. Therefore, the city is missing an opportunity to bring more activity into the downtown area and further encourage businesses both now and in the future to locate in the Worcester Main Street Study Area.

Restoration and renovation of the Union Station building is currently in the design stages but when this report was started the local government administration supported demolishing this historic building. Fortunately, the decision was made to restore and renovate the structure. Renovating the facility will involve making the building structurally sound, painting. etc. This structure in addition to being a historic landmark, has an ideal location. Ideally located in the Main Street Study Area, it is also directly across from the largest parking area in the city. This parking structure which is currently under utilized would make it unnecessary for additional parking to have to be provided when renovating the structure. The Old Train Station Building is one of the city's most beautiful buildings, and example of the 
Figure 12.2

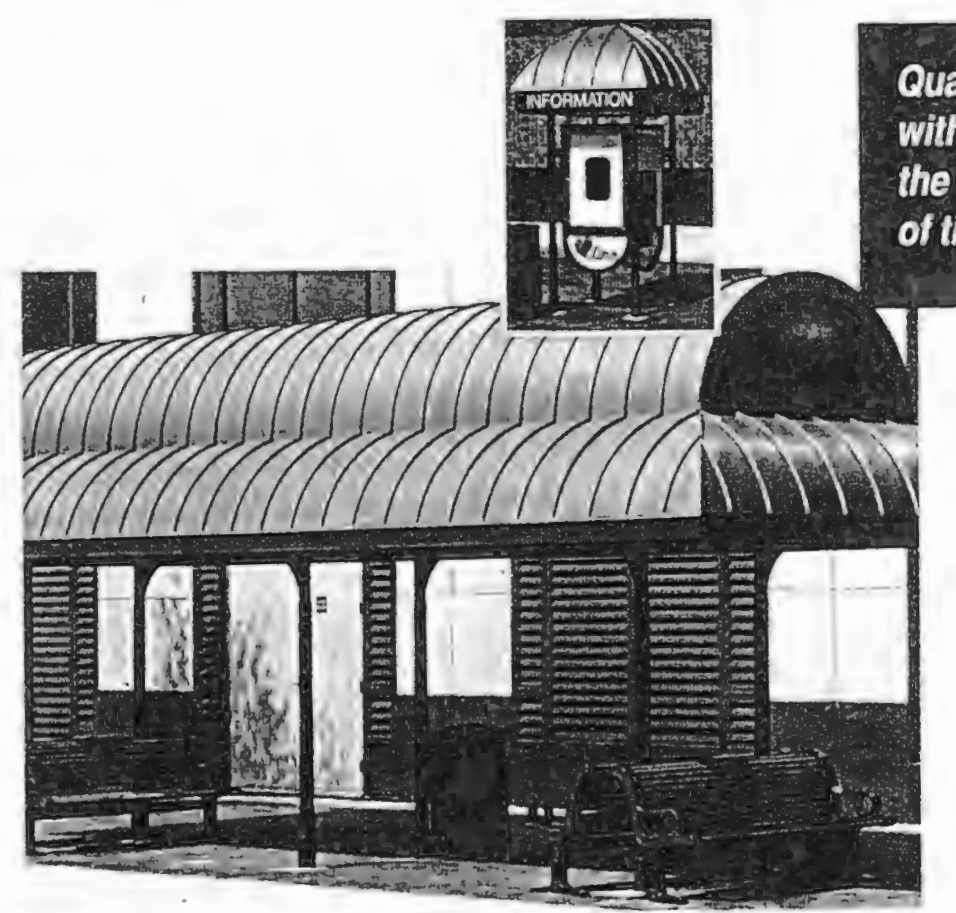

TAMPA, FLORIDA

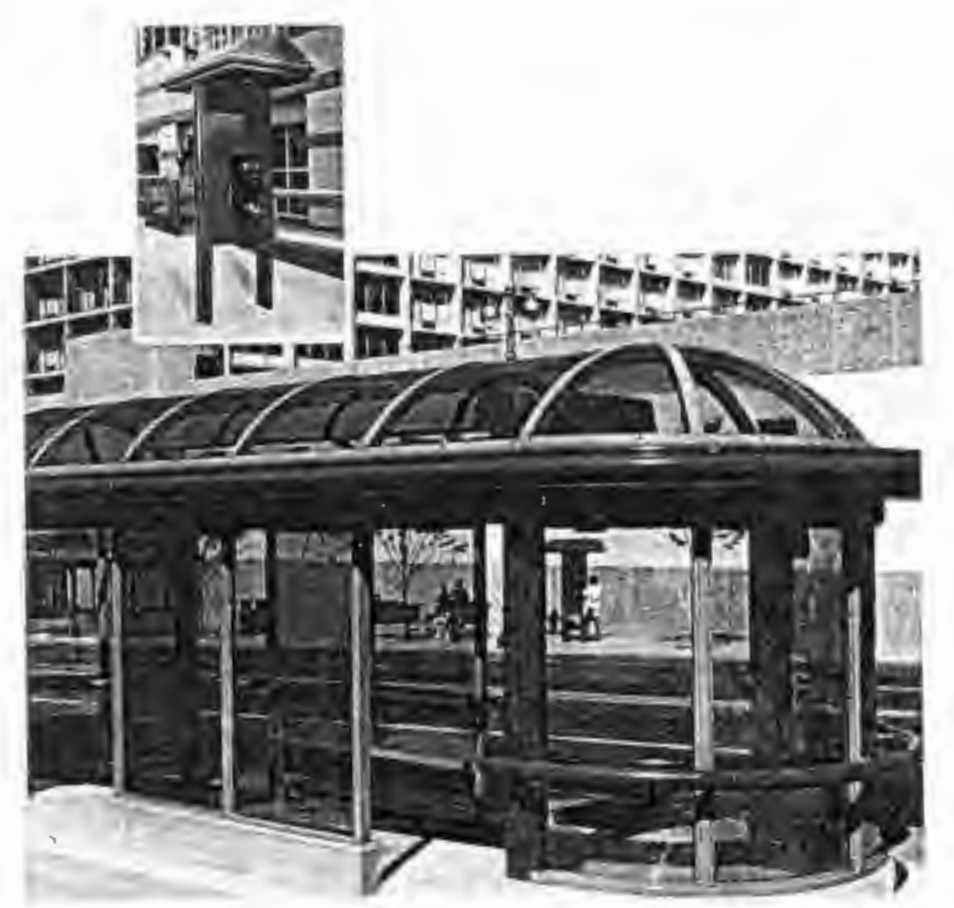

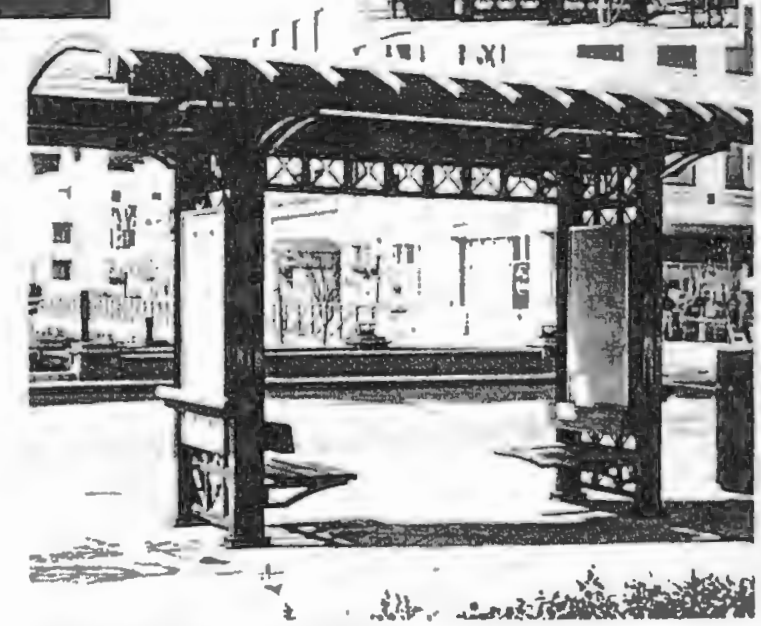
MOUNTAIN VIEW, CALIFORNIA

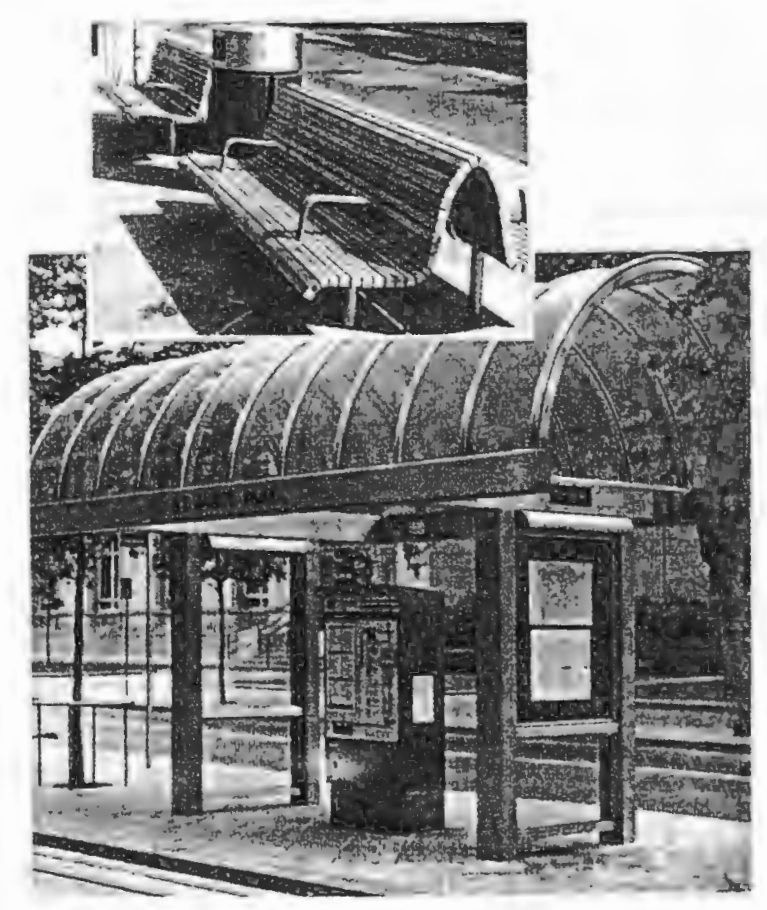

\author{
Examples of Bus Shelters \\ And Other Public Amenities
}


American Beaux Arts Style, and the it is inconceivable that once administrators were considering tearing it down.

\section{Recommendations:}

1. This facility should become another major connection and drop location for the Worcester city bus lines. Buses which come from the outlying areas and suburban townships could drop commuters here and other buses which specifically go to Main Street and downtown would pick up passengers here.

2. Options other than convention and conference space should be considered again for the remaining spaces in the building. This facility should support the new Convention Center without competing with it directly for users.

3. Use of the (newly started) commuter rail system, which currently provides three trains to and from Boston each day, and Amtrak should be further encouraged. Ridership on the commuter railway system has been steady but use of the Amtrak trains has declined in the past few years. When the station is completed, new rail lines to destinations with little service should be encouraged, such as ski areas in New Hampshire and Vermont, points of interest in Main and New York. The central location of the city of Worcester should be used to the fullest extent to increase ridership on the trains and make this station a successful node in the New England transit system

4. Offices for these modes of transportation would be provided in the building and additional office space could be leased out to increase revenues both to maintain this building and for the city.

5. It is recommended that this building be owned and controlled by the City of Worcester and the local transit authority. The city would benefit from profits from this structure as well as assure that all services are provided at reasonable rates to all users.

6. Washington Square should be re-designed, as indicated on the Proposal Map, Figure 11.1, to improve the traffic flow near the train station and still maintain an open green space in front of the Union Station building itself. A short-term parking are could be 
placed next to the green space and across from the Galleria as shown on the map.

7. To encourage pedestrian use of the area as a whole, a pedestrian crosswalk should be designed to link the train station to a newly proposed entry into the Worcester Galleria. This walkway should be at ground level rather than above ground. Connections such as these allow access and give businesses more choices, locating either in Union Station or the Galleria, since customers can easily access both facilities.

8. Renovations should be performed in such a way as to provide adequate space for buses. This includes tumaround space etc. Research should be done particularly assessments of other successful and unsuccessful bus stations to determine available options and assist in selecting the best option for this facility.

Benefits: The benefits of such a transportation center are many. The most important benefit is that it centralizes all transportation modes and make them more efficient and accessible to users. This should help to increase ridership on the various modes of transportation. It also provides a businesses with an incentive to locate in the city, given the ease of access for workers and consumers. the incentive which such a center would be to businesses attempting to choose a location for their businesses. In the past we have seen many large businesses in particular moving out of the City of Worcester, because of the decline in the city and the limited parking availability. By providing a variety of public transportation alternatives into the city which are reliable, more people would look to the city for job opportunities and businesses would also look to a city where workers have easy accessibility to the office as a place to locate.

Problem: Lack of pedestrian amenities in the Main Street Study Area. The lack of pedestrian amenities in this district discourages people from walking through the city. Give the small size of the Study Area, more individuals could park their car and walk to a number of different destinations rather than driving to each. Unfortunately the lack of attract amenities along the streets and sidewalks discourages such activity. The Worcester Common attracts many people because it is a public green space which is centrally located and because it 
is surrounded by businesses and services. yet even it is not used to its fullest potential because there a still too few amenities provided here. In addition, those which are provided are not well maintained.

The fact that a central green space exists in the City of Worcester has in the past encouraged pedestrians to use the city and to gravitate towards this green space, particularly since there is very little open space in the downtown area. Although pedestrian activities such as shops and businesses still encircle this green space it is most closely encircled by the roadways and automobile traffic. Pedestrian need to encouraged further to utilize this open space. Successful pedestrian ways must be located near a focus of activity.

Recommendations: Expand the Streetscape ${ }^{15}$ project to include more of the pertinent streets in the Main Street Study Area. This is an excellent program to begin the beautification of Main Street and the downtown area as a whole. But a larger plan for street and sidewalk improvements needs to be in place even if funding is not yet available or if improvements will be made by developers of new projects. A plan for the Main Street Study Area as a whole should be drafted which documents all of the streetscape changes which the city hopes to make in the future. A plan which shows desired improvements for all streets should be made should so that as development of the three districts progresses, the changes made will be coordinated with the overall goals and objectives of the city.

Problem: The Midtown Mall. Recent upgrades to this building have taken away a functional and unique pedestrian way between Mechanic Street and the Worcester Common. Passage through this building has been limited in order to control loitering in the space but the upgrades have not improved the building visually. The space is still not adequately maintained, and currently is not an attractive addition to the city.

\footnotetext{
15 The Streetscape project is a $\$ 10$ million project whcich will beautify the sidewalks along Main Street between Federal Square and Lincoln Square. New bus shelters, curbing, planters, benches, antique lights and other amenities will be used in this area to improve the appearance of this section of Main Street similar to that shown in Exhibit _...
} 


\section{Recommendations:}

1. Renovate the Midtown Mall to take advantage of this one-of-a-kind inner city block passage way. Recent changes to this facility have made it more closed. Given the short width of the block and the fact that this pat already exists, it cane be used to make connections between City Hall and other city government offices.

a) It is suggested that the remodeling focus on making this a pleasant connector between the two sides of the block. Considering the climate in the City of Worcester it is recommended that this be made into a glass enclosed pedestrian way with attractive shops and businesses lining either side. Because of the long winters in New England, a glass enclosed passageway is thought to be the best option. Using this type of enclosure pedestrians still can be protected from the bad weather while allowing lots of natural light into the space. This space should also be filled with plants and seating areas to further assist in comforting the pedestrian In addition. perhaps the roof could be made operable so that it could be opened in the summer.

b) Economic studies should be completed for this site and an incentive package developed which would attract small businesses to this location. This is an integral part of the redevelopment of this mall because the financial success of such a venture will essentially determine how well the area is maintained in the future. Because of the short width of the block this mall is unique, unlike pedestrian malls created in the past, and could be more successful than those. Longer pedestrian malls such as the one which was once located in the city of Providence tend to be unsuccessful in downtown areas because if active at all they are only so during business hours. This mall is already used as a connector area between Mechanic and Front Streets and this current usage could be enhanced with appropriate shops or businesses.

c) The key to the success of this development would be the attractiveness of the surroundings and the type of small business which were encouraged to locate there. A developer would want to attract small cafes and restaurants, small shops such as hair salons, and other service oriented businesses such as Realtors, banks etc. 


\section{Problem: Poor maintenance of grounds surrounding City Hall do not}

encourage pedestrian use of the pathways. City Hall is in a general state of disrepair and detracts from the overall appearance of the city. Until recently City Hall has been overlooked entirely. The walkways and grounds around the building are not well maintained and the interior offices and halls of the building are poorly maintained. The entrances to the building are confusing and dirty. Currently the city is about to begin renovating the interior of City Hall but is unclear whether these improvements alone help to further encourage pedestrian activity in the downtown, strengthening the building as a city center and focus of activity. The following recommendations rather than focusing on specific interior changes, are intended to make the building a focus of pedestrian activity.

\section{Recommendations:}

\section{Re-design exterior entryways, paths and parks to accentuate}

\section{City Hall as the center of the Main Street Area.}

City Hall Plaza - Specifically re-use the grand stairway facing Main Street and create a entry which is appropriate to the grandeur of the structure itself. Place trees, benches and trash receptacles in the plaza which is a major bus waiting area for pedestrians to make this area a more comfortable and attractive place to be. Place special lighting in this area to serve two purposes. First this will make the are more secure for pedestrians and all users in the evening. Second the certain light fixtures should be directed at the building in order to light it in the evening and reinforce this area as the center of the downtown.

Worcester Common - re-design the Common placing the Worcester Public Library in a central location. (See Library in a Garden details in Chapter 10) Create pathways through the green garden spaces which create views and connect the library to City Hall. Trees, planting benches and pedestrian amenities should be integrated into this design. This renovation should eliminate current under-use of this area and make this an attractive and popular urban space for the city. 


\section{Upgrade path between the Main Street post office and the Fleet}

Bank office building into a pedestrian way. (See Proposal Map for diagram of changes). Ways such as these encourage people to be pedestrians rather than motorists because people can park their cars in parking spaces which are not directly on Main Street itself and walk safely into the center when those visual connections exist. Currently Pleasant street has been made very dark due to the size of the Fleet Tower. By creating an additional pedestrian way on the other side of the tower, it would create an additional visual connection to City Hall and help to create a greater sense of openness in this area. A pedestrian way in this location would provide access to City hall and the major bus stops in the downtown area and would additionally make connections to a number of parking garages and to the residential district.

3. Renovation and upgrading of the Midtown Mall into a through Block connector. This would be a beneficial connection to and from City Hall. (See complete discussion in Chapter 11.) Again this makes an important link between City Hall and the government offices such as the Chamber of Commerce. All paths leading to City hall also helps to strengthen that focus.

4. Provide the necessary public amenities in all walkways. These include, lighting, seating, telephones and trash containers.

5. Hire a maintenance team to take care of the exterior of the building. If City Hall is to be a focus for the city and for visitors, it should be cared for and present a positive image for the city. Currently the City hall reflects the despair of the city. It is a historic building yet, it is not in suitable condition to be toured by visitors to the city, students etc. The City of Worcester needs to put its best foot forward and this is best done as seen in city's throughout the country by maintaining and even overemphasizing the City Hall building.

\section{Design a logo and signage board for the Main Street Study}

Area. The signage can be placed in pedestrian ways and in other locations around the Study Area, providing needed directional information to important sites in the downtown Study Area.

Benefit: The city will have a centerpiece which will assist both residents and visitors 
coming to the city. It will show civic pride and also increase the moral of the city workers. It will make City Hall and the Worcester Common an attractive destination where people can come and relax and do business. There will also be tremendous economic benefit to embarking on this project. Executing repairs to building and grounds now will prevent the need for more expensive repairs in the future.

\section{Problem: Pedestrian activity and traffic is not encouraged in the districts.}

Recommendations: Provide those amenities which assist both pedestrians and motorists and encourage people to walk through the city once they arrive. These include a number of important services and amenities:

1. An central information area. The information center for the city is currently located in the newly remodeled Worcester Galleria. Given the need to create a focus for the Main Street Study Area and the city as a whole it seems that City Hall would be the better location for such a center with a secondary center in Galleria for use in the evening and on weekends

2. Seating areas, trash containers, telephones, planters and informational signage should be designed and planned for areas throughout the three districts to encourage visitors to walk through the city rather than drive.

Benefits: Pedestrian traffic is a sign that there are desirable goods and services in an area and thus is a measure of economic vitality. More pedestrian activity and adding and improving the appearance of the amenities provided in the districts could attract new businesses into the area, contribute to the vitality in the districts and improve the overall appearance of the streets. Problem: Pedestrian ways such as sidewalks and paths through the city are not well designed and maintained. Recently the needs of the pedestrian have been overlooked in order to better accommodate vehicular traffic. But with the decline of activity in cities, new efforts are being made to encourage pedestrian use once again. 


\section{Recommendations:}

1. All renovation and new construction projects in the Main Street Study Area should provide specific provisions which encourage pedestrian use. Spaces provided for pedestrians such as sidewalks should be designed with the necessary amenities to ensure comfort and safety. These include: trees, benches, plants and/or trees, telephones etc.

2. Using attractive paving materials which distinguish this as a walkway rather than a roadway. Understanding the durability of the materials selected and how to them will be most important. For example materials such a brick or cut stones are must be properly laid in the first place and later maintained so that the walking surface remains smooth, comfortable and safe to walk on.

3. Light fixtures are an essential pedestrian amenity not only for their contribution to the overall appearance of a street or walkway but also because help create safe travel ways for pedestrians and vehicles. Thus the light fixtures should be as carefully selected so as both to contribute visually to the area and to provide adequate lighting for safety purposes.

4. Seating should always be provided for pedestrians so that they can relax while walking, if necessary. Seating which is typically in the form of benches, should be durable and securely attached to the pavement.

5. Additional amenities which should be provided include trash containers, landscaping elements such as trees, plants and flowers and telephones. These amenities should all be part of an integrated design so that the materials and colors used in elements such as the trash containers and the signage are similar and complimentary. See Figure 12.3 for some design ideas.

6. Signage to other needed pedestrian services should also be provided in pedestrian ways. Signage to restrooms, information centers or major attractions in the city.

Benefit: Pedestrian pathways are essentially the last major transitional space between the building and transportation ways. Treating them as such will improve the appearance of the 
Figure 12.3
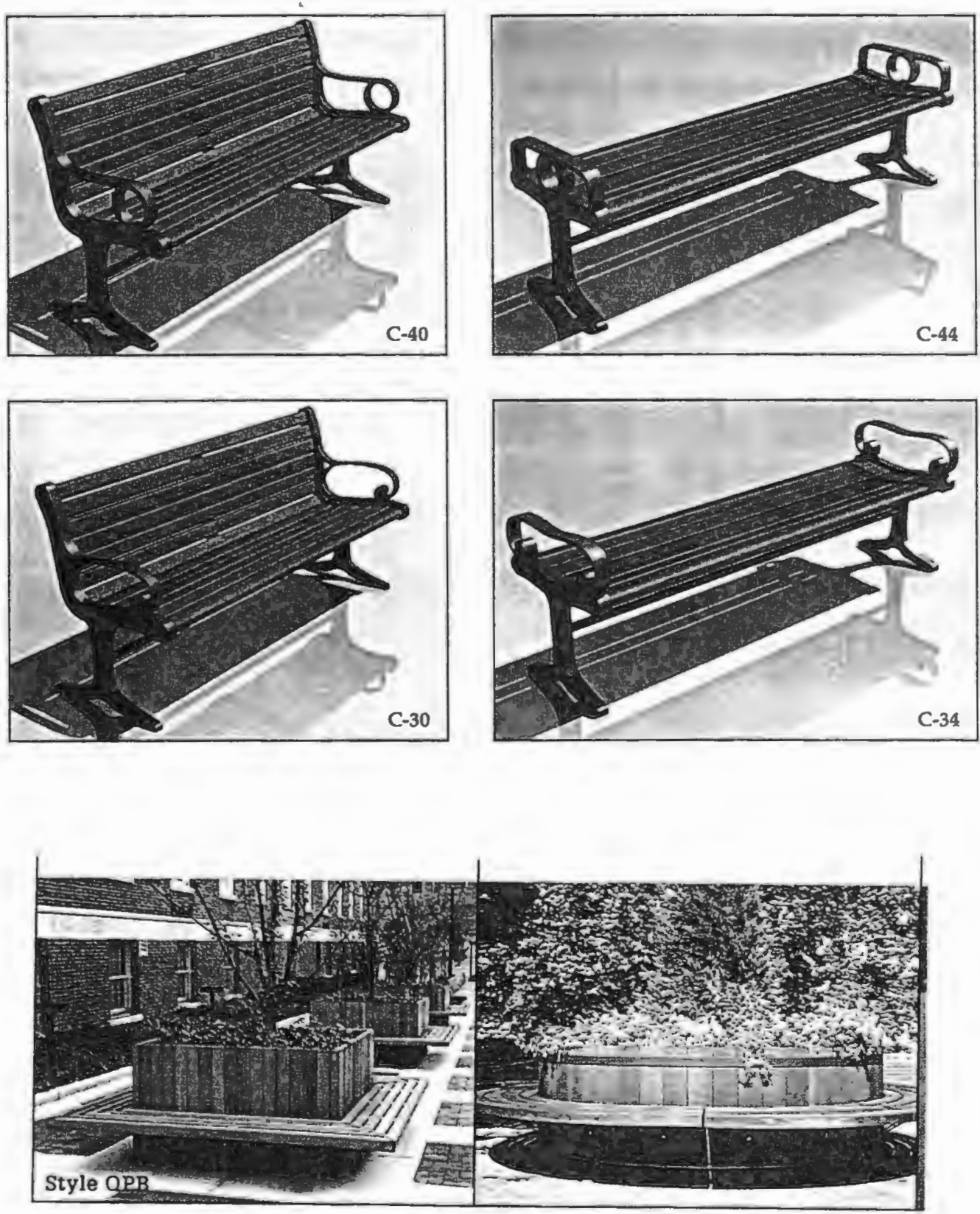

\section{Examples of Planters, Benches And Other Amenities}


buildings and the city as a whole. It could also encourage people to use them and take care of them.

Problem: The public amenities provided in the City of Worcester are poorly maintained and are not sufficient in quantity or quality to satisfy the needs of the residents, workers and visitors to the city. Currently as part of the Streetscape design program amenities have been earmarked for Main Street and some adjoining side streets such as Front Street.

\section{Recommendations:}

The city needs to do a more comprehensive study of the Main Street Study Area and determine what amenities need to provided in the Area as a whole. Such future planning will ensure that new developments, redevelopment and renovations have some basic guidelines to follow in terms of providing such amenities.

1. The City of Worcester should survey the Main Street Study Area and identify the location and the condition of the existing public amenities. A windshield survey could be done and where needed more in depth investigation of the condition and type of amenity at specific locations. A map should be developed which is available to the public. From this a new set of standards and guidelines should be developed which identifies the style and type of amenities which the city will use and encourage private developers to use. A catalog of these items again would be provided to the public.

2. Evaluate the condition of all amenities and determine which should be replaced, Also it will be determined where new amenities are needed and of what type they are. All amenities should be studied including telephones, trash containers, benches, trees and plants.

3. Landscaping should carefully considered, specifically which types of flowers, plants and trees are appropriate, is there enough sunlight, how to keep them alive. Specific places where landscaping is appropriate will be identified in the survey. These natural

elements are of particular benefit because they assist in reducing the amount of carbon in the air and they can be used as a screening device for surface parking areas in addition to beautifying 
an area. See Figure 12.4.

4. Again consider involving the public in fundraising efforts in order to give the public a tangible stake in the longevity of these amenities. This could be done in a number of ways such as having raffles, give-aways etc. Also donations from businesses should be sought. This could be like adopt-a-tree or adopt-a-city amenity, usually one in the same block where the business is located.

5. Maintenance, although often overlooked in planning project will be integral to making sure that these amenities remain available and safe for continuing use. Maintenance will ensure that this investment of resources is well used and continues to be used as planned. It will make sure that these elements continue to make a positive contribution to the area.

Problem: There are very few open green space areas in the City of Worcester and some of those which do exist are not well maintained. See Figure 5.1.

\section{Recommendations:}

1. The city should encourage owners to maintain landscaped areas that currently exist in the down town. Replanting dead trees and bushes and performing overall maintenance activities on the area including watering and pruning.

2. Provide additional landscaping along major roadways, particularly those areas where there is a great deal of traffic such as Main Street and even Worcester Center Boulevard where there is a potential for a significant increase in traffic, trees should be planted along the sidewalk edge between the street and the pedestrian path. This helps to screen the cars from pedestrians walking by.

\section{Landscaping should always be provided to screen surface} parking lots and the cars in these lots from view. This landscaping should be a combination of trees, plants and flowers and also may include some sort of structural element such as a fence or ballards. A variety of landscaping elements are always desirable and should always be present in around both public and private buildings in the City. These elements significantly 
Figure 12.4

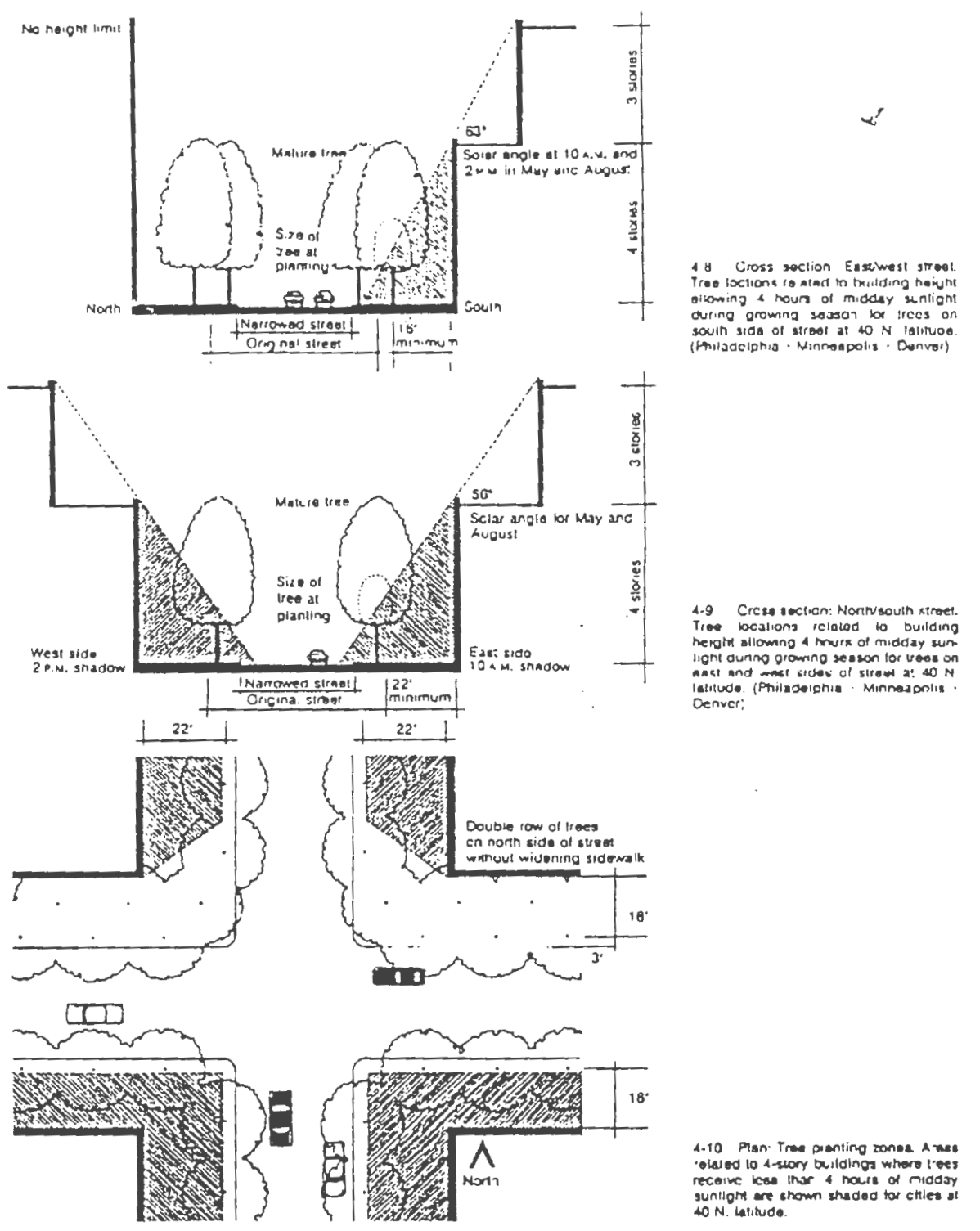

Street Sections

Trees and Landscaping 
enhance the beauty of the area of the buildings and the city as a whole.

Problem: Parking and the Lack of activity in the Main Street Study. The city needs to take a stance on the issue of parking in order to re-vitalize the city of Worcester.

\section{Recommendations:}

1. Use more innovative methods to deal with parking and to make the downtown area a more viable and active destination. In the past Urban theorists have recommended that cities provide more parking. That this attracts visitors and business. A model taken primarily from suburban shopping centers. It is the recommended in this report that perhaps this may not be the best course for the Worcester. First of all, despite protestations to the contrary, the Main Street Study Area, seems to have abundant parking available, parking lots, structures etc. Many or most of which stand empty in the evenings and on weekdays. Some are underutilized during the work day. Thus it is recommended that an opposing plan be adopted. Encourage traffic and minimize the number of parking areas in this district. A recent article in the Wall Street Joumal (See Appendix B for article) describes how this formula has been successful in a number of other cities because it helps to minimize the number of interruptions in the street facade and encourages motorists to drive more slowly through the area. This gives them the opportunity to see the businesses and uses and may encourage them to stop. Many cities try to keep larger parking areas and structures on the edge of the downtown business district, encouraging people to walk into the downtown.

\section{Re-evaluate the current parking requirements imposed on} developers of new projects. Developers are required under their agreements to provide a substantial amount of parking to accommodate new facilities. Perhaps there are ways to better use the parking which already exists in the Main Street Study Area.

3. The Interstate Commercial District due to the many recent development projects should use land use maps and parking studies to ensure that adequate street parking is provided in these areas. On-street metered parking allows people to park for short periods of time and take advantage of the businesses and shops in the area. The 
developers and designers for the three projects currently underway have primarily focused on the garage parking. City planners should develop proposals for the on-street parking using approved designs for the new hospital and changes around Union Station as they become available.

4. Studies should be undertaken in the Main Street Commercial District to see how the parking garages and surface parking lots in this district can be better used. Perhaps providing parking for the other two district and providing shuttle service to various locations in the city. Planning events such as a market or fair on the surface parking lots.

\section{Monitor and assess the Residential Commercial to ensure that} surface parking does not become a major use in the district. Surface parking areas are mapped on the Land Use Map shown in Chapter 2. A map such as this identifies the size and location of the existing lots and allows the city to monitor changes and additions to the amount of surface parking. Parking objectives need to be developed working with college officials to better understand the parking needs around the college. 


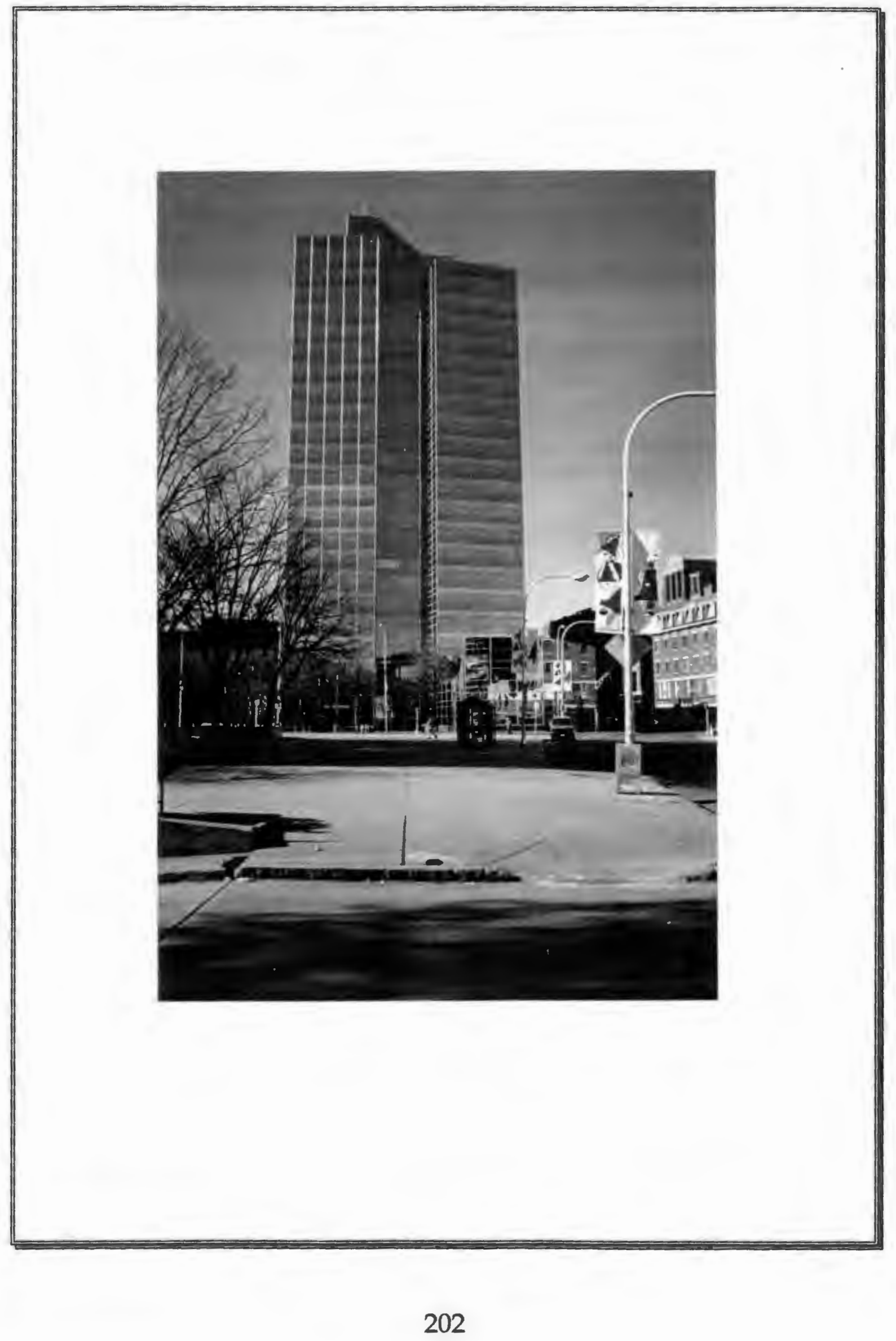




\section{CHAPTER THIRTEEN \\ DESIGN PRINCIPLES TO IMPROVE THE AESTHETIC QUALITY OF THE MAIN STREET STUDY AREA}

"Planning for future development must be responsive to the context of older commercial and neighborhood centers, maintaining their essential physical characteristics while responding to newer requirements." (BRA Guidelines)

\subsection{Introduction}

The design principles which are recommended for the Main Street Study Area will be discussed in two ways. First, a series of general principles will be outlined which apply to a variety of buildings and all three districts equally. The second part of this chapter will identify specific buildings in each district and describe current conditions, both its positive and negative impacts on the street and suggest ways to enhance and improve the appearance of the building and the block.

\subsection{Worcester Main Street Study Area}

Problem: There are insufficient services in the district to support uses 24

hour activities such as the new hospital and any residential uses which may develop in the area. Services such as a supermarket, a pharmacy which is open in the evening, and evening cafe's or ice cream parlor are not currently available in the Main Street Study Area. The City has supported efforts for night-life in terms of bars and dance facilities but more family oriented activities need to be provided if families are to be encouraged to return to the downtown.

\section{Recommendations:}

1. As stated in Chapter Ten, the city should actively work to encourage a major supermarket chain to move into the Main Street Study Area. This will provided a much needed service to existing residents and could be a catalyst for encouraging future residents to come to live in the city. Since renovated, the Star Market on Boylston Street an the new Bread \& Circus have seen tremendous success in terms of their patronage. The Star Market operates on a 24 hour basis serving the needs of students and residents alike. Great 
incentive will have to be provided by the city for Worcester than perhaps were needed in Boston. The city should work with a potential chain on issues of security and safety so that the business can be profitable as well as a much needed service to residents and visitors alike. Studies of supermarkets have shown that it is cheaper and more profitable for them to operate in suburban locations. First there is potentially less crime in most suburban areas so there will be potentially fewer incidence of theft. In addition access is easier since there are more open spaces which allow for parking and delivery bays. These factors make the suburbs more attractive for grocery stores and markets. Thus it is necessary for the administration in the City of Worcester to provide the incentives necessary to encourage such businesses to locate in the city. This may include things such as tax breaks and other financial incentives as well as security for the store. The selected location for a supermarket chain is near the local police station which could make it easier to encourage such a development.

2. Other services which will be required to support housing in the city will include things such as day care facilities, open space areas which provide play areas as well as assisting in improving the overall air quality an area. Schools churches community centers etc. are also needed and many of these things already exist in the downtown section of Worcester. These uses should receive the continued support of the city and enhanced as much as possible.

Problem: There are no design guidelines in place to guide development of projects of any size. Thus there are no mechanisms in place to control development issues such as height and bulk of new buildings, site location or architectural character of the project. And therefore, the potential that new developments and improvements to existing structures would not respect and enhance the character of the Main Street Study Area always exists.

Recommendation: The city needs to adopt a strong set of design guidelines which create a cohesive image for the Main Street Study Area. These guidelines should capture and enhance the potential of the Main Street Study Area and help carry the city into the future. 


\subsection{General Design Guidelines for the Main Street Study Area \\ 13.3.1 Urban Form}

The overall visual impression of the City of Worcester from a distance and up close is an important component towards making the city as attractive and viable as possible. Therefore, a number of objectives have been identified towards improving the overall urban form of the downtown area. Worcester as described earlier has a hilly terrain and the downtown distinguishes itself by the height and density of the area. In this section it is the aim of this report to provide guidelines which will foster a coherent pattern of development in the downtown area. This involves influencing new construction so the height, bulk and overall appearance of the buildings, to a certain extent, conforms to the overall pattern already established in the city through the decades. This involves avoiding "jarring" contrasts which could potentially upset the pattern of the city, taking special care when developing the edges of individual districts, using special care when reviewing plans for tall buildings. Bulk controls should consider the three basic views of the building which are the view from the street or the closest view, the view of the middle section of the building and the skyline view of the top of the building.

\subsubsection{Height and Bulk}

\section{Relate the heights of buildings to important attributes in the}

existing city pattern. This involves having height controls which support the natural terrain of the city. Clustering taller buildings in the Main Street District and reducing height levels in the to adjacent districts. This will enhance the commercial district as both the core and visual center of the city.

2. Encourage designers and developers to detail the massing and facade to create buildings which visually interesting. By encouraging this, building mass can be reduced, making the building a less overpowering addition in the city. In addition the developer has the opportunity to address the three ways in which the building will be viewed, that is from the street, the middle section and from the top and can contribute significantly to 
the appearance of the city from all three of these views.

3. Limit the scale of buildings so that they can be well integrated into the existing street fabric and so that they will encourage pedestrian use in the area. The size of a building can positively influence the pedestrian environment by allowing sunlight to the street level, maintaining human scale, allowing daylight and sunlight to reach public spaces, retaining the richly decorated older buildings which significantly contribute to the charm of the area. Additional height can be added in special cases if the structure does not cast shadows on the pedestrian public ways, if the structure is designed in such a way so as to maintain a graceful transition in height between the adjacent buildings and if the building maintains the existing street wall in the city in terms of its scale and detailing.

4. The City of Worcester should adopt bulk controls which address each of the three basic levels of the conventional commercial building. They are the base, the middle

level and the upper tower portion. Ratios which help to control how these three basic building sections are designed. Address the use of cornices and other decorative projections such as penthouses etc. Criteria for exceptions also should be considered. When will exceptions be made? How will the city avoid allowing exceptions to become the norm rather than exception?

\subsubsection{Sun and Wind}

1. Maintain separation between buildings to allow access for sunlight and air and prevent excessive bulk.

\section{Create and maintain a comfortable pedestrian environment in the} Main Street Study Area. Promote buildings forms which will allow adequate sun access to streets and open space areas. The warmth provided by direct sunlight is essential towards creating a viable and "people-filled" downtown environment especially due to the harsh New England climate. Buildings to the South should be limited in height in general and buildings which adjoin public plazas and areas should be limited in height on the South, East and West sides. Sunlight is also very important in shopping streets and retail areas. Because of the importance of allowing sunlight into these areas, specific criteria should be established which 
will ensure that developers incorporate the necessity of allowing sunlight to reach the street.

\subsection{Design Guidelines for Commercial Buildings}

\subsubsection{Site Planning}

\section{Locate commercial buildings in the Interstate Commercial}

District and the Main Street Commercial District close to the street with parking either to the side or behind the building. This pattern coincides with the commercial image which already exists in the Main Street District and will continue the pattern in order to make a stronger link between these two districts. Siting the buildings close to the street will help to create a sense of enclosure along the street creating a strong street edges. With proper scaling of elements such as awnings, trees etc., this will also make the sidewalks more pleasant for pedestrians, giving them continuous rows of shops to walk along and browse in. It will also improve the quality of the streets making them appear less vast and empty.

\section{Commercial buildings in the Residential Commercial District} should follow the pattern established by the previous residential use or the prevailing pattern along the street. Generally the buildings are set back approximately 10 to 15 feet and have a small yard in front. These front yards should always be grassy lawns similar to the remaining residential uses in the area. Owners of these business should avoid replacing these front yards with surface parking.

\section{Landscaping and screening elements should be used when it is} absolutely necessary to have parking at the street edge. When it is necessary to have parking or commercial uses such as gas stations located at the street edge, plants and trees in conjunction with other screening elements should be provided at the street edge in order to minimize the effects of the large areas of paved open space. Commercial uses which are adjacent to residential uses should also have perimeter screening to ensure that there is adequate separation between different uses.

4. Limit the number of curb cuts per use. Business with under a certain 
amount of frontage should be limited to one curb cut and a maximum width for curb cuts should be established. A common maximum width is 30 feet.

\section{Major renovations to the area should strengthen connections}

and enhance the visual image of the area. New developments should utilize and learn from the mistakes of preceding developments. The new Worcester Convention Center is all glass and open on the ground level in order to encourage pedestrian use around the building. This is in direct contrast to is neighbor, the Worcester Centrum, which was designed with all blank walls.

\subsubsection{Parking lots, Gas Stations and Storage Areas \\ Parking Lots, Gas Stations, Storage Areas should be screened from direct view with landscaping elements and other screening devices such as fences and ballards.}

1. Visual screening between parking or gas stations and primary and secondary thoroughfares should be provided. A combination of fencing or walls and landscaping should be provided. The fencing should be between three and four feet in height and should have divisions which allow partial viewing through it. Landscaping should be provided adjacent to the fence or wall and should be at least 5 feet in width. Trees should be planted every 20 feet. Landscaping should be a minimum of three to four feet in height at maturity.

\section{Visual screening between parking or gas stations and residential} uses should provided. Again a combination of fences or walls and landscaping elements should be used. The fence or wall should be approximately 7 feet high. Landscaping elements should not be less than 5 feet in height at maturity.

\section{Internal landscaping dividers should be used to divide large} parking areas. Parking areas which have an excess of twelve parking spaces should provide internal landscaping elements to divide the space into smaller more attractive parking spaces. Large paved parking areas detract from the overall physical character of a city. At least $7 \%$ of a 
large parking areas should be composed of landscaping elements with at least one tree for every 10 to 12 parking spaces (this is in addition to the trees which would be used for screening purposes from the street or exterior areas to the parking lot). Planting areas should be a minimum of $25 \mathrm{sq} . \mathrm{ft}$ with no individual lengths below 5 feet.

\section{Adequate lighting should be provided in parking lots and large}

paved areas. The lighting should be attractive and be coordinated with other lighting in the Main Street Study Area. The fixtures should provide sufficient lighting to light the entire parking lot but should not impact (spill into) adjacent areas.

5. These areas should always be handicap accessible according to the American Disabilities Act (ADA) guidelines.

\subsubsection{Loading Docks and Trash Storage}

\section{Locate loading docks and trash storage elements away from public view and} streets where possible. The rear of a parking lot is often the best site for these elements in order to avoid congestion and traffic problems. Dumpsters should be screened from both adjacent streets and avenues and from the parking lot itself. Attractive yet functional screening elements are imperative here since these areas are usually used a great deal and difficult to maintain. A combination of elements which are easy to maintain and improve are recommended here. Wood and concrete are examples of materials which are strong and yet easy to maintain and replace or patch as needed.

\subsubsection{Landscaping and Pedestrian Elements}

Landscaping and pedestrians elements should be integrated into each district to make them more attractive and separate unrelated uses. Landscaping elements such as pants, trees and flowers, add color to an area and integrate the natural environment with the paved. In addition, these elements improve air quality in downtown areas by absorbing a significant amount of the carbon dioxide in the air. Screening elements not only separate unrelated uses but also interrupt and create unusual views. Lastly pedestrian elements such as telephones, trash containers and mailboxes help to enliven the street and encourage pedestrian 
activity along it.

\section{Existing trees and natural elements should be retained when}

feasible. Existing natural elements which are healthy and minimally obtrusive should be kept and designed around.

\section{All new development projects should incorporate street trees.} This is one way for the developer to make a contribution to the overall environment of the downtown area. One street should be provided for every 20 feet of street frontage.

\section{Incorporate plants and trees in front yards where the buildings} are setback from the street. Use of trees and plants in the front yards helps to create an attractive transition space between the street and the building.

4. Use the elements for screening when necessary. As stated previously, trees, plants, fences and other screening elements should be used when appropriate.

\subsubsection{Buildings and Facades}

New structures and renovated structures should reflect the architectural character and overall image of the district and the city as a whole. Consistent patterns in terms of height, massing, composition, building materials, signage and colors will contribute to the visual cohesiveness and the overall attractiveness of the district. While it is not necessary to replicate the past, changes should respect the essential patterns an qualities of the district as a whole.

\subsubsection{Building Height}

Building height standards should be provided in the Urban Design Plan in order to ensure that the positive qualities of each district will be enhanced. The Interstate Commercial district can have taller building heights ranging between 8 and 10 stories. This will help to increase the density in the district and will create opportunities to address the raised highway which borders the district rather than having the buildings be dominated by it. The Main Street Commercial District should allow building heights between 5 and 8 stories for new buildings and existing 
structures should not be renovated beyond their existing building heights. This will allow the overall character of the existing district to be maintained and create a pleasing transition between the buildings in the two adjoining districts. The Residential Commercial District should have a maximum height allowance between 3 and 4 stories. This will help to preserve the residential nature of this district while allowing for new construction and renovations as needed.

\subsubsection{Massing}

The massing of the buildings also should vary between the districts. The Interstate Commercial District can accept larger building masses for projects having so much vacant and undefined space. But these masses should allow for multiple readings. Thus within the larger building mass should be smaller components which help in creating pedestrian spaces or a break down of the

\subsubsection{Building Materials}

Building materials should be specified by district. Generally a larger variety of materials can be accepted in the Interstate Commercial District while slightly fewer in the Main Street Commercial District and the most limited number in the Residential Commercial District. Residential District should be restricted to wood construction with accent materials more varied to include brick and stone and other materials.

\subsubsection{Signage}

Signs should be compatible with the building, neighboring buildings, and the district as a whole. Signage should be clear and legible. While these should serve as direct advertising elements, they should not attempt to communicate too much information. Instead a carefully designed building sign and storefront display should communicate necessary information to potential customers. Signs for a series of businesses in one building should be related in terms

of their size and location. While they need not be exactly the same, the colors and lettering style should be complimentary and reinforce the information rather than competing with one another. There are four types of signage which are seen in urban areas. These are: wall or building 
signs, projecting signs, window signs and free-standing signs.

1. Wall or Building Signs - lie flat against the building wall and should be used most of the time. These signs should be designed to be integrated with the building facade and the signage of adjacent stores when possible. When possible similar lettering styles and colors should be used in for uses within the same block to create a coherence along the block.

2. Projecting Signs - can be used periodically. When used too often they become difficult to read and create too many interruptions on the block facade.

3. Colors - Although color is a matter of taste, to many bright or fluorescent colors can clash and make the facades cluttered and unattractive. Color schemes should be studied for the block facade as a whole and business owners within the same block should try to use colors within the same color family. The city should also designate certain colors which need to be approved before they can be used on the exterior of a building.

\subsection{Building Appearance}

\subsubsection{Interstate Commercial District}

Although there are very few buildings in this district, their appearance impacts the district greatly and will continue to do so given their overall size and scale. These buildings should enhance the image of the district and encourage pedestrian use just as in other commercial areas around Main Street. Blocks in this district are still very undefined and thus there are more opportunities to change the nature and character of this district. The city ultimately must decide what the nature of this district should be like. Generally, the uses in this

district should be one of two types, a large residential component to link area back to residential area across the highway and a commercial section which both provides for larger scale commercial activities as well as some smaller scale ones which address the needs of the residents.

\subsection{1.a Commercial Building Facades}

The commercial facades should be of two types. There should be larger commercial buildings in which the entire building reads as a commercial element. In this district this will 
include the new hospital, Union Station and the new hotel and casino proposed in this report. These structures will read as integrated buildings with the front entry having primary emphasis

and any additional entries secondary importance. The signage will be integrated into the overall architecture of the larger structure and with some directional signage not linked to the structure provided along the city streets.

Smaller commercial building uses which occupy only the ground floor of a larger building or are located in buildings which are 1-2 stories high will follow the same recommendations provided in the following section for the commercial facades for the Main Street Commercial District. (See next section)

\subsection{1.b Residential Facades}

Should be small scale designs combining townhouse units with low to mid-rise condominium units. The front yards should be landscaped to make a positive visual connection with the streets and the backs should be a combination of small private yards as well as shared green space. Example of a very successful residential community which is a positive addition to its city is shown in Figure 13.1 Attempts should be made to provide residents with private space. Thus condominium and apartment residents should have balconies or if at ground level direct access to a small yard space. Townhouse residents should be provided with front and back yard space.

This housing should primarily be constructed out of wood in order to relate it to the adjoining residential neighborhood. Other materials should also be integrated into this project including brick and stone. This materials can be used more freely in the larger low and mid-rise buildings which are perhaps steel construction.

The massing of the buildings should allow for multiple readings from an individual townhouse unit to the housing project as a whole.

\subsubsection{Plumley Village}

The facades of these buildings should be integrated into the new housing district which is proposed in this area. These buildings do not contribute in a positive way to the overall image 
Figure 13.1

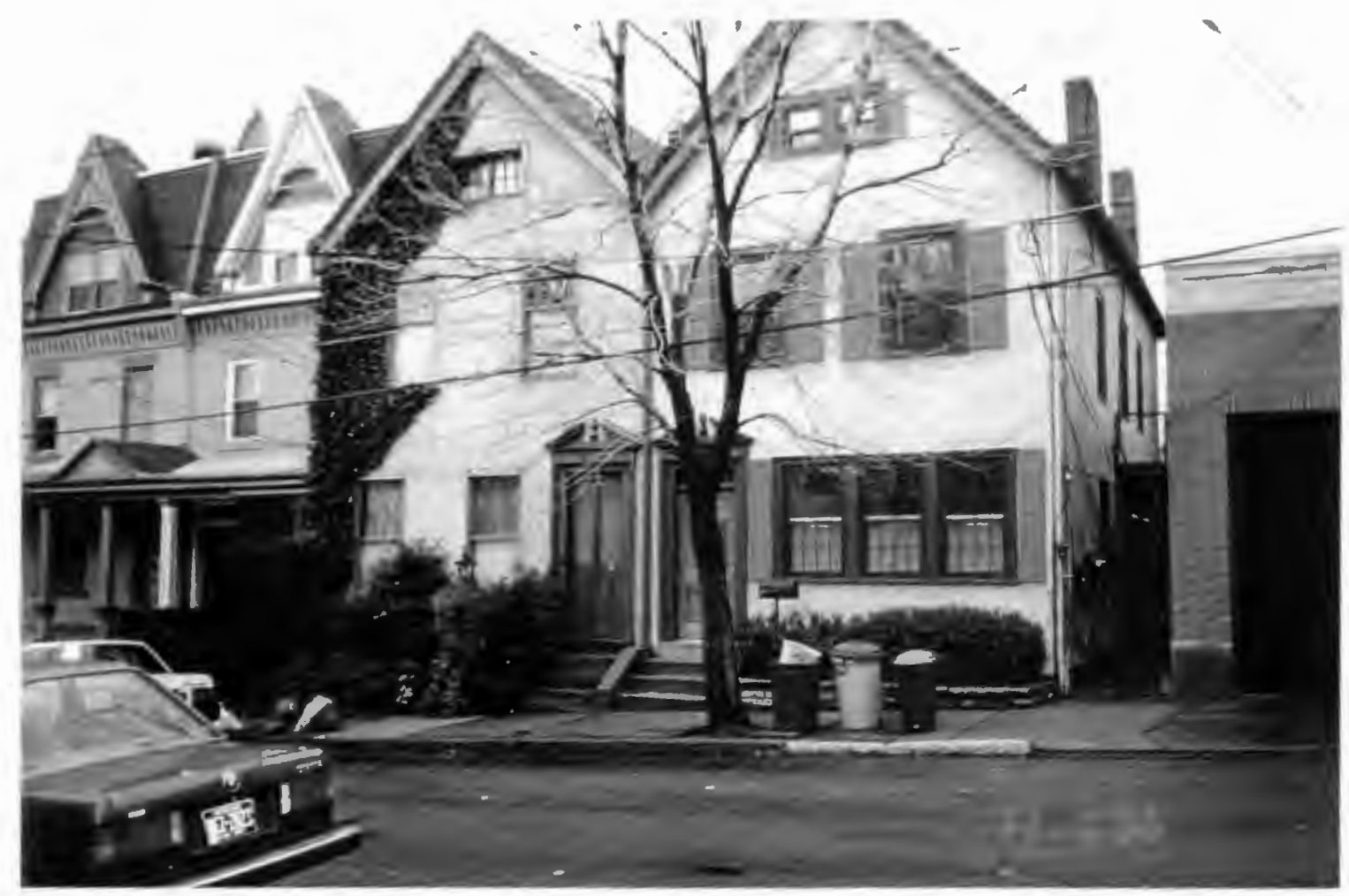

Example of Urban Housing in the

City of Pittsburgh 
of the district though, and have almost no architectural detailing which is worth saving. Thus it is possible to alter the appearance of these buildings dramatically or remove them all together in order to create the new residential area as proposed.

\subsubsection{Union Station}

It can not be stressed enough that this building is integral to the history of Worcester and could be a major component in its revitalization in the future. The facades should be renovated to their original grandeur with great attention paid to the detailing. Windows similar to those of the original building should be used rather than newer cheaper versions, this will significantly detract from the appearance of the building. If feasible the towers, part of the original design of the building, should be re-added to the building. This would give the train station more of a presence in its location next to the raised interstate highway and in the city as a whole. It is important to avoid an all too common mistake made when renovating older buildings of using materials which are too modern and thus neither copy nor complement the character of the existing structure.

\subsubsection{Main Street Commercial District}

Shop facades provide potential customers with their first impression of the store. Thus it is important to improve the store fronts and building facades in this district, both to improve the overall appearance of the district and to encourage people to shop here. Styles and consumer preferences continue to change so it is important that buildings are maintained and upgraded regularly.

Problem: Not all of the Commercial and public uses at the street level are not as well designed and attractive as they could to create a continuous public zone along Main Street. Recommendation: Retail uses should be strongly encouraged on the ground level of all buildings in the Main Street Commercial District. These zones should have some consistent features which are highlighted below.

1. Use durable and attractive materials for entrance ways into the shop. Materials such as marble, tile, and concrete help to accentuate store fronts giving them variety 
in terms of colors and textures. They assist in making the commercial spaces behind the storefront attractive and inviting.

2. Signage is a key component to any store front. It should have contemporary styling which can catch the attention of the pedestrian shopper. But of equal importance it should complement and resemble to a certain extent the signage of the other shops in the block, rather than contrasting dramatically.

3. The placement of the signage is also extremely important. In general, there are two areas which can accommodate the signage. They are just above the shop windows and above the entire shop level portion of the building was indicated in Figure 13.2

4. Store fronts, particularly at grade level, should be mostly transparent glass, allowing pedestrians to see in and view merchandise or exhibits. For example, city officials could decide that storefronts should be $75 \%$ transparent glass because blank walls add to a pedestrians discomfort.

5. Because store fronts are to be primarily glass, a great responsibility is then placed on the shop owner to provide interesting and provocative shop displays which highlight their service and merchandise. Common mistakes made by shop owners include cluttering display windows with paper signage to advertise sales. This can detract from the appearance of the shop facade and the entire street facade.

\subsection{4.a Commercial Building Facades}

Problem: The scale and dimensioning of commercial facade elements are not well considered in many cases in the district.

\section{Recommendations:}

1. Divide the building height into three basic components. The ground floor commercial facade, the upper facade and the cornice or top of the building. The ground floor will have be made up of individual storefronts which are primarily glazing with very little wall surface. The upper stories reflect the actual architecture of the building, being walls with window opening punched into them. The cornice may or may not be an element which 
Figure 13.2
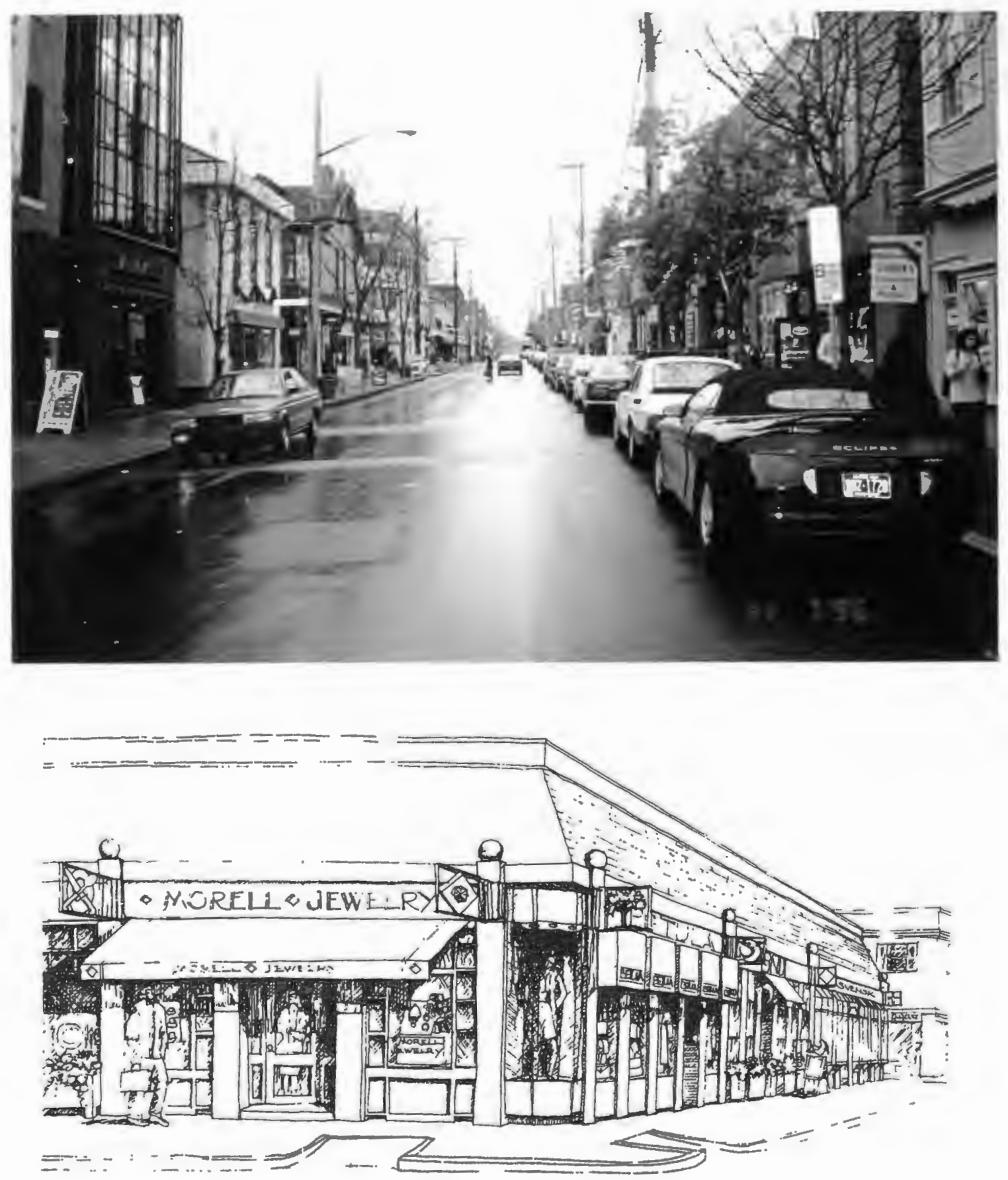

Sample Business Facades Signage is Designed Into Overall Facade 
distinguishes and/or differentiates the building from other buildings. The elements in the upper ad lower stories should be coordinated so as not to create too strong a division.

2. Divide the building width into smaller bays. The divisions between actual buildings should not read at the ground level, instead clear dividing elements should be integrated in the storefront designs to differentiate individual stores. The architecture of the building prevailing on the upper stories, will read and divide buildings on the upper stories.

\section{Coordinate the signage for multiple stores located in one building to} create coherence and continuity along the larger street facade.

4. Integrate awnings and recessed entryways into the storefront design. Project display windows, never recess them. This will attract pedestrians, creating smaller scaled elements on the facade for reference and add additional color to the facade.

\section{The backs of these commercial stores should be designed as a second}

front entrances and should include display windows and awnings when possible.

Sidewalks should also be incorporated when possible to establish an unimpeded pedestrian zone in this area between potential traffic and/or parking. These back door entrances become particularly important in downtown areas, because they often can allow motorists to park close to their destination. In addition these back door entryways often provide a secondary handicap accessible entry to the store.

6. Always provide screening around dumpsters and storage areas. This helps to improve the overall look of the store and the adjacent street. Screening elements include plants and trees and fencing elements. They should be designed both to create a visual barrier and for security.

Problem: The Worcester Centrum because it has no windows at street level is a very oppressive and for pedestrians. Also because the combination of materials and colors used in the exterior cladding is so different from those used on other buildings in the district, the building stands apart. 
Recommendations: Human scale elements need to added to the facade of this building to make it a more attractive and pleasant to walk by.

1. The building should be renovated and windows placed at street level. By placing smaller elements within the larger facade, this will help to reduce the scale of the building at the street level. With windows designed into the facade, the building will look less like a block from a distance, appearing more three dimensional.

2. Landscaping elements should be placed along the edges of the building so that there is a transition space provided between the hard materials of the street and sidewalk and those of the building itself.

3. Signage should be designed for the building. The signage should be provided at two scales. Smaller signage for pedestrians which identifies the Centrum and what events are currently or will be taking place. The large digital billboard signage in the main entry is easy to change and maintain but does little to improve the appearance of the building. Signage could be used in the upper portion of the building to reduce the scale of that portion of the facade.

3. Re-design the entries along Foster Street so that they are more inviting. Plants and railings could replace the concrete walls which frame the stairways or the entry wall could be brought out rather than being recessed.

\subsubsection{Office Buildings}

Mechanics Hall and Parlsons Office Supply are excellent examples of buildings which have been renovated and upgraded, successfully maintaining the integrity of the original facades and creating a more pleasant pedestrian environment on the exterior of the building. Problem: Developers of new buildings, in the past, have ignored the established character and scale of the street using modern materials and designs in an way which detracts from the appearance of the district. For example, the Home Cooperative Bank once an small and inviting storefront business on Main Street became Home Federal Savings Bank. The facade of this building is oppressive and too distinctive. There are no pedestrian scaled elements or other 
smaller scale elements which would relate this building facade to others on the street. In addition, the bank has since gone out of business leaving the building vacant. See Figure 13.3.

Recommendations: The rules outlines above for commercial building facades are appropriate here and could be applied. But the larger problem is how to improve existing facades which can not be easily changed.

\section{It is important that owners work with the city and other owners} particularly in their block to improve the overall appearance of their own buildings and the block as a whole. Owners should think to the future when building or renovating buildings, asking a series of design-related questions. Can the selected design be easily changed and upgraded to accommodate the needs of new tenants and users? What is the appropriate combination of permanent and applied elements? How does the selected design work with the neighboring building and street facades?

2. Appropriate urban design guidelines should be established by the city in order to control changes in the street facades and to assist owners in making decisions.

\subsubsection{Fleet Bank Building}

Glass towers can be both an asset and a liability to an urban area. The Fleet Bank Building is an asset to the city, 'sculpturally' marking the downtown Main Street area and making a beautiful gesture towards the sky. The height of the building enlivens the skyline and simultaneously suggests that this city is about the future and progress.

Problem: At the pedestrian level of the Main Street Study Area though, this building is less successful. There are no human scaled elements on this building which make this a pleasant building to walk near. In addition, reflective is used in most buildings of this type because it minimizes the amount of heat and light that enter the building. Reflective glass is distracting at the street level because it does not allow pedestrians to see into the building like other types of glass do. While helpful to those working on the inside, they do not feel like they are constantly on display, at street level the reflective glass has the same effect that a solid brick wall has. 
Figure 13.3
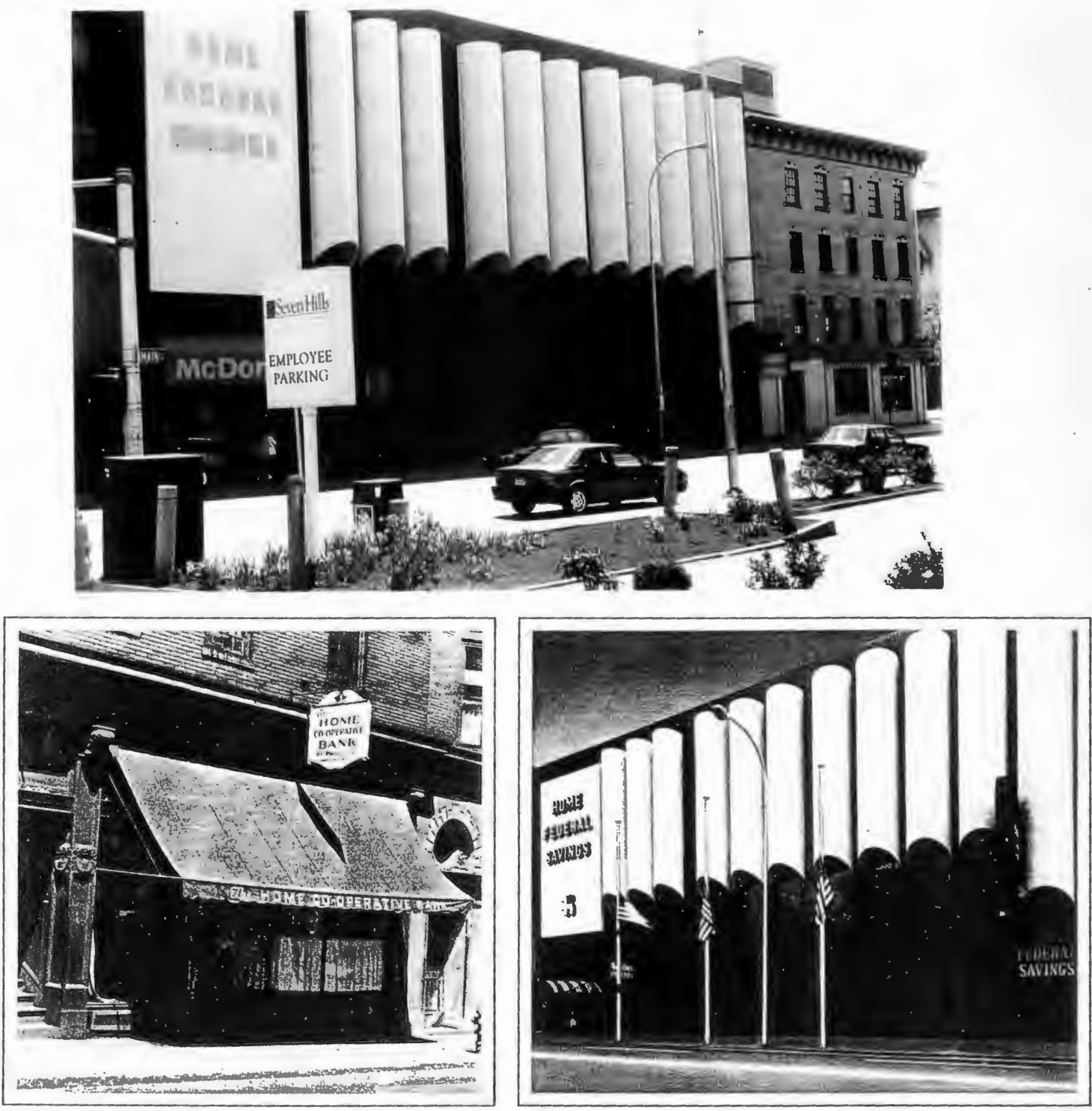

Home Federal Savings Bank

The Original Bank Facade and More Recent Facades Before And After Closing 
Recommendations: Because this building is centrally located and is adjacent to a major bus stop, it is important that an attractive and inviting pedestrian environment be created around this building. Applying amenities, such as awnings, to the building itself is not an option due to the nature of the material and the overall design of the building. Instead the areas around the building should be re-designed to attract pedestrians users.

1. Amenities should be provided in the areas surrounding the Fleet Bank building including telephones, benches and trees. Trees and plants should be placed at the edge of the building in order to provide a scaled elements which will be more inviting to pedestrian. The trees can also be used as a screening device. This should be done particularly along the facades of the building which face Main Street and the southern green space adjacent to the building.

2. Remove the fencing around the adjacent open space. Additional trees and plants, benches and trash containers should be placed in this green space to encourage public use.

\subsubsection{Residential Commercial District}

Although there are fewer architectural problems in this district. It will be important to monitor changes and have established guidelines to control changes here also. Problem: There are few systems in place to monitor and control changes in this district.

\section{Recommendations:}

1. Maintain the scale and pattern established by the existing buildings when approving new construction. Greater efforts need to be made to understand some of the patterns which exist here and maintain them. Currently many of the newer renovations and additions to this have achieved varying levels of success in terms being integrated into the existing context .

2. Existing structures it is important that planners understand how it was originally designed and how it has changed in addition to understanding the quality of the street. Then changes to the building can be made more sympathetically. 
3. Design buildings which are visually interesting and architecturally sensitive, accepting the patterns and styles of the existing buildings, particularly those adjacent to it. This applies to both new construction and renovations of existing structures.

a) Create attractive streetscape patterns for shops and businesses through the use of appropriate signage, building materials, and window displays

b) Ensure that building facades relate harmoniously with previously established patterns when feasible. Encourage local business and property owners to work together to coordinate building and shop facade elements. Figure 13.2 provides examples of coordinated design effort between shop and property owners.

c) Store fronts in the Main Street Study Area should have a human scale rather than addressing vehicular traffic. Building facade improvements can be made in a number of different ways. The following recommendations primarily refer to the Main Street Commercial District but also apply to the commercial portions of the other two districts. 


\section{Summary}

There are a number of strategies which could improve the Main Street Study Area. The recommendations provided in this part of the report suggest possible ways to solve some of the existing problems which exist here. These solutions could improve the appearance of the city and make it more attractive to both residents and visitors. The problems which have been identified with the Main Street Study Area, related to design, specifically, "... reveals an unsatisfactory picture of store fronts which is unrelated to the buildings which house them in most cases." (Mitchell, p. 39) The second basic problem is the limited number of amenities in the downtown area. These are the two major problems which need to be addressed by improving the design standards in the Main Street Study Area.

But all of these suggestions require a investment of time and resources, financial and otherwise. The following section of the report identifies implementation mechanisms which could be used to execute the Urban Design Strategies presented in this chapter. 


\section{PART FOUR \\ IMPLEMENTATION MECHANISMS}

\section{Introduction}

Sound recommendations and the potential benefits of a good Urban Design Plan are insignificant if in the end the plan can not be executed. The implementation of the plan depends entirely on the support of the administration, the design of the legal statutes and the ability to finance the proposals. Below is a current list of the municipal departments for the city of Worcester. It is a basic outline of the various administrative departments and the person currently in charge of that department.

- City Manager

- Cily Council

- Cily Clerk

- Business \& Develonment

- City Assessor

- City Minager's Office of Employment \& Training

- Execulive Office of Elder Affairs

- City Manager - Thomas R. Hoover

- Assistant City Manager - John Orrell

- Assistant City Manager/Finance - William A. Kennedy

- Airport - Richard Foley, Acting Director

- Assessing - Paul Leary, City Assessor

- Auditing - James Delsignore, Auditor

- City Clcrk - Robert J. O'Keefe, City Clerk

- Civic Center Commission - Celeste M. Butcher, Administrative Assistant

- Civil Defence - William Trotia, Director

- Communications - Robert C. Chisholm, Dircctor

- Data P'rocessing - Paul R. Covello, Director

- Elder $\Lambda$ ffairs - Elizabeli Mullaney, Coordinator

- Election Conmission - Anthony F. Ingrisano, Executive Director

- Employment and Training - Stephen R. Willand, Director

- Fire Department - Dennis Budd, Chief

- Health and Code - Arnold Gurwitz, Commissioner - Joseph G. McCarthy, Deputy Comissioner

- Human Resourecs - Janice Borg Silverman, Director

- Law - David M. Moore, City Solicitor

- Library - Penelope Johnson, Head Librarian

- License Commission - Nancy Virzi, Chair

- Parks and Recreation - Thomas W. Taylor, Commissioner

- Planning and Community Development - Stephen P. ONeil, Director

- Police Department - Edward Gardella, Chief

- Public Works - Robert J. Moylan, Commissioner

- Purchasing - Charles T. O'Connor, Purchasing Agent

- Retirement - Elizabeth Early, Executive Secretary

- School Department - James L. Garvey, Superintendent

- Traffic Engincering - Joseph F. Borbone, Acting Administrator

- Trcasurer and Collector of Taxes - Thomas F. Zidelis, Treasurer

- Veterans Services - Anchony Ingrisnno, Agent Director

- Worcester Housing Authority - Michclle Booth, Executive Director

- Worcester Rederclopment Authority - Michael S. Latka, Executive Director 


\section{CHAPTER FOURTEEN \\ ADMINISTRATIVE MECHANISMS}

\subsection{Introduction}

There purpose of this chapter is to explore ways to improve the administrative mechanisms in the City of Worcester. This will allow changes to the urban fabric to be made and help to ensure that those changes meet the expectations of the City and its officials.

\subsection{Office of Planning and Community Development}

Problem: The Worcester Planning Department which once had complete control over planning issues for the city has lost much of its control as many of the plans are being

implemented. The Geographic Information System (GIS) system, on which the city spent a great deal of money, is underutilized. The head planner the person who began all the changes left and was replaced by an new planner. The Worcester Redevelopment Authority which had been closed and integrated into the planning unit is now a separate entity again.

The City of Worcester needs to set into place a stable administrative system which will guide projects through the development and implementation stages. While little development was taking place, the city placed all research and development issues in the planners hands. Now that buildings are actually being constructed control over the project has a whole has been distributed to the developing organizations. Thus each project is being built somewhat in isolation rather than being overseen by one department such as the Office of Planning Community Development.

The Office of Planning and Community Development in Worcester has the strong research component but the department also has other strengths which would allow it to follow projects through the development stages. Either the office was not prepared to manage these projects when needed or had not effectively presented its other strengths when a department was put into place to manage these projects. Thus all of the 
development projects taking place in the city are currently taking place outside of the Planning Office and independently to a great extent. The Worcester Redevelopment Authority has charge of the remodeling of the Old Train Station and is overseeing the Medical City project but even within this office there is little sense that the projects are being coordinated. It also appears that each project is being designed and executed separately. For example, a substantial portion of Interstate Commercial District was demolished to make room for Medical City, which is currently in design development, the environmental approvals having already been obtained. Perhaps if one department such as the Office of Planning had been managing these larger changes then more incremental phasing could have been integrated into the project allowing for a more gradual change in the landscape of this district.

The lack of coordination between these re-development projects was immediately apparent. Each of the major projects has its own time table which it has been designed to meet but there is no coordinated time showing all phases and time table for the various projects. Such as time table would alert officials to potential conflicts and overlaps. The city then chose to hire an outside consultant to manage and coordinate the many projects, and specifically begin to clarify how these projects would work with one another and with the existing developments in the Main Street Study Area. The consultant assists the city in coordinating the projects addressing questions such as, if there is a concert at the new Centrum, a hospital emergency and a sale at the mall will there be adequate parking? How will traffic be regulated? The consulting firm, Chan, Krieger \& Associates though is an urban design practice and thus deals primarily with design-related issues. It seems that this was an unnecessary expense. The Office of Planning and Community Development would have been better suited to monitor and coordinate these development projects having both design skills and political experience. In addition, the staff in the planning office resides in the Worcester area giving them an additional personal and vested interest in the outcome of these projects. 


\section{Recommendations:}

1. Re-empower the Office Planning \& Community Development. The city needs better utilize this office. It is a comprehensive planning unit which can fulfill both the research and managerial needs for the city. It should have both a strong research component but also a strong development component when projects begin to be realized. Through this office subgroups such as the Worcester Redevelopment Authority can operate on an as needed basis which would allow adjustments in staffing to be made as needed, depending on the phase a project is in. But by having the planning office as the umbrella organization, the many aspects of design and development can be coordinated, integrated and completed to benefit the City.

\section{Encourage dialogue between the government organizations to prevent any} one group from becoming too isolated and thus out of touch with the needs of the others. Put the needs of the community before individual and departmental differences. The Office Planning and Community Development has not been adequately involved in the development process in the past. In addition, there have been some internal conflicts between departments which has further discouraged them from working together.

3. Politics is an important part of the Planning process. The in-fighting between Planning and Economic Development led to their own demise during what should be banner development projects for their offices specifically. Instead these projects are being undertaken in absentia, by other bodies put in place to take on the immediate demands these developments required.

4. Commit to the Entire Process. The local administration and specifically the Planning Department needs to follow the project from the planning, and development stages through the design and post-construction evaluation and inspection phases. This will ensure that changes made in these phases of the project will continue to meet the goals and objectives established by and for the city. 
5. Administrative Departments Access to Information. There is a lack of specific quantitative information an $d$ information sharing between the departments. The city needs to make detailed reports including a Market Analysis, an Area Housing Analysis and Housing Demand Analysis. This information is not readily available. In addition, the Planning office did not have information regarding the certain financial mechanisms used to attract development, the information having to be obtained from the Office of Economic Development . Basic information should be part of the knowledge base of both departments both in terms of answering questions but also for completing work in the departments.

6. Create an Urban Design Team. The city should create an Urban Design Team which is responsible for researching and evaluating design proposals for the City. This group would be composed of both administrative office personnel and residents of the city. The team should have members who have a design background and people who do not in order to provide a new perspective and generate new questions and suggestions. The team would review all proposals for new construction, renovation or restoration, evaluating the design proposal itself, quality and types of materials, scale and general impact on the community. They would make recommendations to the City manager and the Planner as to whether the project should be accepted or rejected. The Urban Design Team would also be responsible for developing an Urban Design Plan.

7. Develop an Urban Design Plan. The Urban Design Team would develop and urban design plan which would offer basic guidelines for development. it would recommend building materials and appropriate styles for various parts of the city. Such a plan could make recommendations regarding height and bulk requirements, window and door types and styles, percentage of glass at street level and even building materials. The plan would also offer similar design suggestions for things such as trash containers, signage and telephone booths. All physical components in the city should be addressed. This plan although a guide would assist developers and architects when designing a 
project and help make the city cohesive visual environment. This document would not be a binding legal document like the zoning code but once approved should be generally accepted as the standard for the city.

Problem: There exists a lack of coherence in development and execution of projects in the city of Worcester. A number of projects have been proposed and undertaken in Worcester, but all of the project are being executed by different groups and there has been no attempt to relate these projects to one another either in terms of appearance, circulation, or usage by people.

Recommendation: There is the need for the city to designate an Urban Design Team which would be in charge of overseeing and approving the final designs of all projects to be built in the city. This team ideally would have an architect, planner, urban designer and then other lay people who have an interest in design issues. The team would establish general design guidelines to be followed by developers and private businesses doing renovations in the downtown area. They would follow all projects and ensure particularly that projects taking place in the same block would relate to each other in order to further efforts by city officials to improve the appearance of the city. Particularly on large projects the Urban Design Team would assess future impacts of the project and ensure that the project would visually enhance the city as a whole. For example the Team would never have allowed the Worcester Centrum to be built with blank walls all the way around. it would have ensured that there were shops placed at ground level even it was simply the offices for the Centrum. This would have prevented the Centrum from being such an oppressive addition to the city. During the day, when events are not taking place in the Centrum and offices are open it is very unpleasant to walk around the Centrum.

Equally as important, the Urban Design Team would be an additional coordinating body when multiple projects were taking place. Thus needed pedestrian ways or open spaces would be coordinated and when possible shared rather than repeated between multiple projects and uses when possible. This would also avoid the end of site 
problem, of how to negotiate a new path or lace in an existing problem. The Urban Design Team could help resolve these issues and prevent spaces which go nowhere or are under-utilized from being created. One example of such a space is the Fleet Bank Building Park. which given its central location in the Main Street Study Area, is tremendously under-utilized. Future coordinated efforts could pedestrian connections between the new Union Station Terminal and the Worcester Galleria, not simply to provide access to the mall but also as another means of entering the heart of downtown Worcester. The Urban Design Team could also assist in efforts to coordinate parking and parking usage between various activities. In addition, to providing basic design input and representing the City as a whole the Team could intervene between various interest groups such as the developers and the community in making design related decisions and promoting them once decisions are finalized. Currently no such group exists.

Problem: Too much control is given to the developers of projects by the city once the project has advanced past the planning stages. By relinquishing a substantial amount of their power and control over these developments, it is very difficult to predict the outcome of the project since many changes take place in the design and development while the project is under construction. Issues such as scheduling and follow-through to completion are of particularly vague during the process.

\section{Recommendation: Worcester should develop a format for monitoring project}

development, particularly for large-scale developments in the City. This format while flexible would provide guidelines which developers would follow in carrying out the project. The primary component to such a document would be the scheduling on the project. The developer would present to the City a detail schedule not only for the phasing of the project but also the schedule for making presentations to the City. These meetings would update the various groups involved on any progress and/or problems encountered and provide a formal indication of the times that input and feedback on various decisions would be solicited. This would keep the City involved throughout the 
process of design and development and allow for formal input into the proceedings. The document could have an outline similar to a project proposal with a budget schedule, and meeting schedule, meetings both with the City and other design-related personnel. Also summarized in this document would be expectations for the City, Impacts on the City an Benefits of the project to the City.

Problem: Not enough community involvement in efforts to revitalize the downtown district.

Recommendation: The City should better publicize its efforts and solicit participation from the residents. For example, the city could involve the public in its efforts to renovated restore City Hall. Residents could help financially by participating in phonathons. And because the renovations will impact people's ability to use the building, an extensive advertising campaign could keep residents informed about the changes and progress in this restoration and in other projects in the City. This will make people feel a part of the process and that they have a vested interest in the positive outcome.

Problem: The city needs to expand expectations when offering density bonuses to developers.

Recommendations: Elaborate expectations when granting incentive zoning to developers. Density bonuses should continue to be offered to developers, but the city should benefit to a greater degree than seen in past development projects. The benefits should cover all areas including public amenities, landscaping and building detailing. In addition development controls should be imposed on the developers. These mandatory controls would require that the developer meet specific conditions in order to increase the FAR on the building. By achieving these mandatory conditions, a developer building in a BG-6.0 district would then be eligible to increase the FAR of the building from what is currently allowed in the zoning code. The conditions required to make this increase should include some of the following suggested controls:

1. All developments must front on at least two streets. Each street 
should have a minimum width such as 25 feet. This would help to minimize the impact of parking, loading and the required services which would accompany this building. This would also help to accommodate the increase in pedestrian traffic.

2. "A critical mass of contiguous public space must be provided. This public space can be in the form of open areas, plazas, gardens, atriums etc. For example, a requirement that $30 \%$ of the buildable site be designed as open could be included in the mandatory controls package. Additional conditions could be placed on the open space requirement. First the city could require that the open space must be maintained by the owner of the building and open for public use. And that public amenities be designed and integrated into the public open space. Amenities such as benches, trash containers and plants and trees.

3. Sites which are adjacent to major transit areas such as bus stops and train stations should provide access to these facilities from the new development or building.

\section{Buildings which are over a certain square footage could also have}

additional requirements. For example, building which are over 150,000 SF must provide retail space on the ground level to encourage pedestrian traffic on the surrounding streets. When it is not feasible to have shops, display windows should be provided at the street level. Along Main Street retail and service oriented businesses should be encouraged if not required. Retail kiosks, carts and cafe areas could also be provided as a means of generating activity in and around the building although this may not be mandated.

5. Standards to allow air and light to reach the street should be imposed. These standards should require that as the building becomes taller its overall mass be reduced in order to allow sunlight to reach the street and prevent severe shadows.

6. Open loading areas should be prohibited. They should be incorporated into the building's structure. 


\section{CHAPTER FIFTEEN \\ LEGAL MECHANISMS}

The single legal mechanism available to the city to control development is the zoning code. Recently revised Worcester Zoning code for the area encompassing the Main Street Study Area has been relaxed in order to encourage new development. Most of the first two districts have been re-zoned given an $\mathrm{MU}$ designation which allows for multi-use commercial development. As described in the Chapter Two of this report, although there are restrictions in areas with this designation, the restrictions are minimal in order to encourage development. The Residential Commercial District retained much of its original zoning designation. The code does allow for overlay district which offer more stringent guidelines but there is potential for more direction regarding specific parts of the main Street Study Area.

\section{Recommendations:}

1. Consider Amendments to the Zoning Code. The Urban Design team should make recommendations which can be attached to the zoning code. These would suggest the types of uses which they feel would be appropriate in specific locations or city blocks. While these guidelines would not be binding as in the code itself, this would help define for developers the direction in which the city is trying move, goals to be accomplished.

\section{Innovative requirements for incentive zoning should be developed. In} addition to the typical requests for open space and public amenities, the city should incorporate even more specific needs of a district. For example, a developer in the Interstate Commercial District may be asked to work with the city to make sure a supermarket or grocery store comes to the area or they could contribute to a fund for another future use.

2. The city should also implement an Urban Design Plan which will provide necessary guidelines for future development in the city. While many of these recommendations would not be binding, they would provide a framework for developers 
to follow in the future. Included in the Urban Design Plan should be :

\section{Sample Urban Design Plan}

1. The Urban Design Plan should address all design-related topics. All of the topics discussed in previous chapters of this report should be included in the Plan and any others which the Team feels may be appropriate. It should address topics such as open space and building form in a way deemed appropriate by the Team for the City of Worcester.

2. Certain components of the plan should be binding. For example the city should have a signage ordinance. The team would select appropriate locations, colors and designs for signage, offering enough variety so as not to be restrictive or create an uninteresting landscape. And those proposing to use other colors or styles would have to get approval from the Team.

3. The Team should create a detailed Land Use Map. This would delineate the land uses on each floor of each building in the city. This should be coordinated with a database which identifies square footage's, number of rooms and other information about the building. 


\section{CHAPTER SIXTEEN \\ FINANCIAL MECHANISMS}

\subsection{Introduction}

Currently the city seems to have taken advantage a number of financial mechanisms in order to finance or facilitate the financing of current development projects in the downtown area. Large commercial development projects are less in need of financial mechanisms and more in need of incentives for business to develop in the Worcester area. These incentives seem to in place but need to have more controls placed on them to encourage developers to contribute in other ways to the city.

\subsection{Existing Financial Incentives for Business}

\subsubsection{Micro-Loan Program}

Economic Development office designed this program for to assist small businesses owners with viable projects who are having difficulty obtaining funding and have been denied conventional loans. Once the viability of the project has been established in terms of its potential benefit to the community, and proof loan rejections has been substantiated the city may provide loan money similar to GAP financing up to $\$ 30,000$ on a flexible term basis. This provides a new business owner with loan funding for 5,10 of even 15 years at a substantially lower interest rate, currently approximately $5 \%$, than is offered at commercial lending institutions.

\subsubsection{Section 108 Loan Guarantee Program}

This program is designed for larger commercial development projects. The city is allowed to designate 5 times the $\$ 6$ million it currently receives from HUD, \$29 million, give to financing agencies who lend to developers in the city. Thus far $\$ 12$ million has been secured for Biotech Park which is outside of the Main Street Study Area and $\$ 430,000$ was set aside for the new Brewhouse Pub on Main Street.

\subsection{Government Incentives}

\subsubsection{Density Bonus}


Permits a developer to increase the square footage of the project above what is normally allowed in the zoning. This could be of particular use in relationship to housing in return for housing where unit numbers could be increased to increase profit margin for the project.

Need financial mechanisms which further encourage development by both large companies and small alike. Currently the city offers tax credits for businesses to move into the city and to encourage business to stay. More efforts need to be made to support small businesses.

\section{Encourage commercial lending institutions to offer small business loans}

more readily. Flagship Bank has pioneered programs specifically designed for residents. These need to be further encouraged.

2. Additional financial incentives need to be offered to encourage needed businesses to locate in the Main Street Study Area. Incentives should be offered to Supermarkets and drug stores are two retail uses needed in the Main Street Study Area. By encouraging these needed uses the downtown area will become more vital and stable.

3. Encourage housing. To make this city vital housing is going to have to be encouraged. Financial incentives should be made for government workers who live in the city of Worcester and specifically in the downtown area.

\section{Local commercial lending institutions should develop special loan} programs to encourage residents to maintain and upgrade their homes. Banks need to offer mortgages to people to encourage redevelopment of existing buildings into housing in the downtown area and building of housing. These incentives could be linked to the projects adherence to the principles outlined in the Urban Design Plan.

5. The city could establish its own saving and loan institution specifically for the development of the city center. A bank managed and operated by the city offering competitive rates to business and property owners there. 


\subsection{Mechanisms to promote Housing in the Main Street Study Area}

16.4.1 Land Write-Downs - The city used this to encourage the Fallon Corporation to develop a hospital in the city. Such write down can also be used to encourage the development of housing in the downtown area. This is a more simple matter when the city already owns the land. The city should create an account specifically for the purchase of land to encourage development.

16.4.2 Development Expediting. A fast-track processing tool, allows for the processing of plans, permits and other documents in a shorter period of time.

16.4.3 Inclusionary Zoning. This tool allows a developer to build only if a certain number of low and moderate income units are included in the project.

16.4.4 Reduce the Cost. The can be accomplished in three basic ways

1. Reduce the Debt Service Amount either through lower monthly amortization or by reducing interest rates.

2. Reduce Real estate Taxes either through tax abatement or tax exemption. An example of tax exemption might be $100 \%$ exemption for the first year with a $20 \%$ reduction every 2 years so that by the 11 th year full taxes are paid.

3. Reduce the Amount of Cash a Developer must put at risk. This could be done with a capital write-down - a direct subsidy for the gap between the development cost and the mortgage amount. 


\section{SECTION FIVE}

CONCLUSION

The city has changed drastically over the past five years. New developments are under construction and other significant steps towards revitalization are being taken. The Worcester Galleria has re-opened as a outlet center offering a vital shopping alternative to residents and more significantly no longer directly competing with the suburban malls, which offer different types of products. While its initial vitality seems a positive sign for the city, one should still be concerned when analyzing this facility. Important questions which should be addressed include, "Is the Galleria too upscale for the residents of the city? Can the Galleria survive over the long term without addressing the needs of the resident population first? Will the Galleria benefit the city in the future if residents are 'locked out' of this mall financially?

There are many other positive efforts being made to revitalize the city. Older buildings are being restored and renovated rather than torn down, in addition to the new developments which are being initiated. One example not mentioned in the report is the former Marriott Hotel. Underutilized at one time, the building was purchased by Holiday Inn and is being renovated so that the building can be integrated with the adjacent uses and into the downtown Study Area in general. These are positive changes and such changes should be continued in the future. The one pervasive affecting many of these developments projects is that they are taking place in a vacuum. There is no unit coordinating and monitoring the many changes, physically, politically and economically, which are currently taking place as a result of these new development projects.

The City of Worcester needs to provide detailed guidelines for design and development. There is an immediate need for an Urban Design Team which can act in an advisory capacity. The Urban Design Team should develop an Urban Design Plan to coordinate design-related issues and identify recommended materials and styles. Through the Urban Design Team the design-related goals and objectives for the city can be 
articulated and adhered to.

The City needs to make better use of the Office of Planning and Community Development. The staff in this department has the ability follow projects to completion and ensure that the overall goals and objectives for projects and the city are met. Responsibilities regarding land use and development currently appear to be too segmented and objectives are not being met. For example, when Urban Villages was first proposed, the intention was to renovate some of the existing buildings in the Main Street Study Area into housing. Instead a high-rise tower was built. Such changes could be monitored by the Planning Department to make sure that all changes continue to meet the goals and objectives of the city.

The Main Street Study Area has the potential to become a dynamic center for the City of Worcester and for the State. Taking advantage of its many assets and unique qualities will help forward this goal. Finally. planning for, monitoring and coordinating all change in the city will be vital to the success of the City of Worcester. 


\section{APPENDIX A}

Worcester Bus Routes

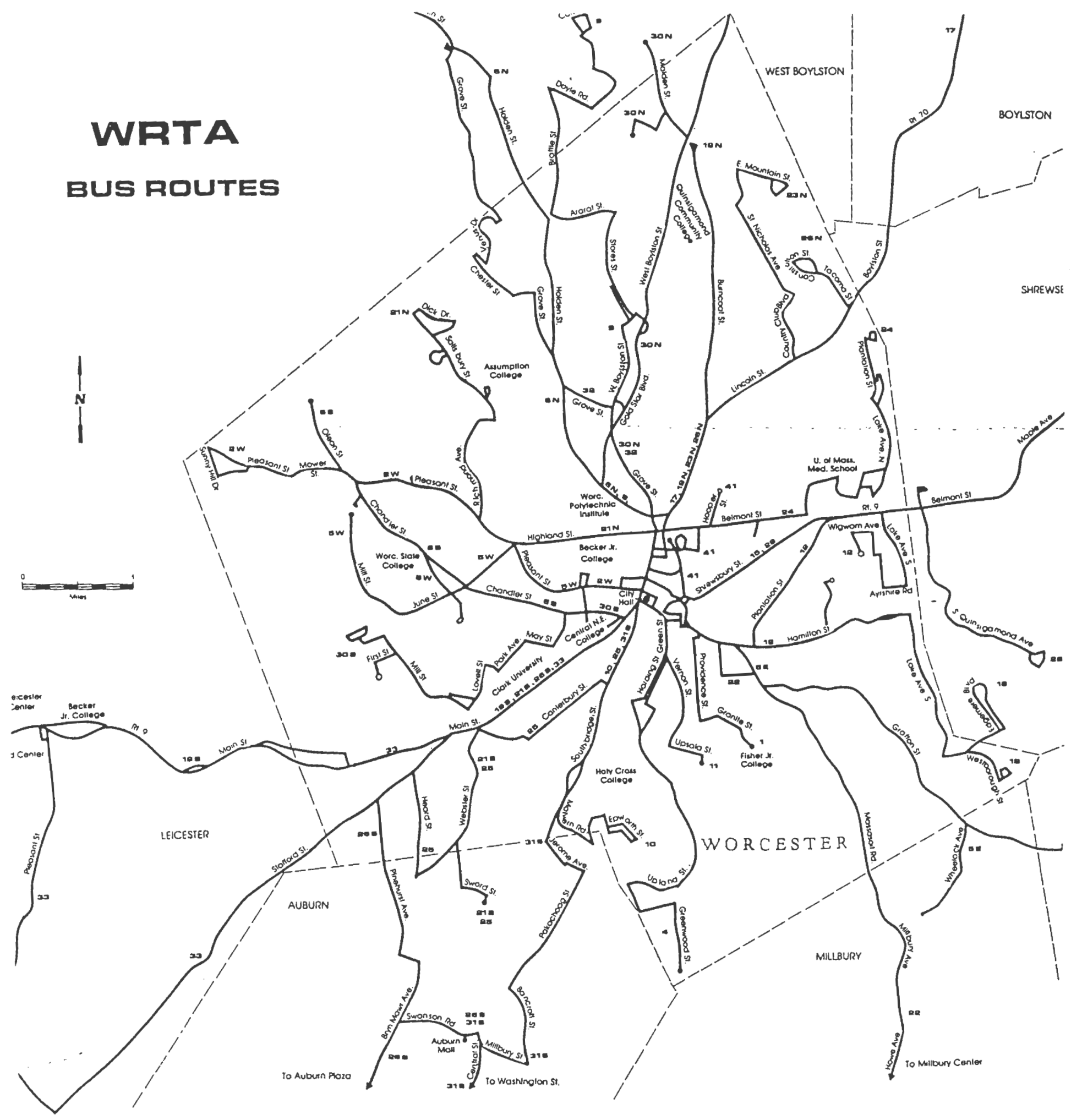




\section{APPENDIX B}

\section{Wall Street Journal Article}

VOL. CCXXVIII NO. 27 .

'Traffic Calming' Some Urban Planners Say Downtowns Need A LotMoreCongestion

Supporters Claim Slower Pace Will Help Businesses, Though Skeptics Scoff 'Speed of a Horse and Buggy'

By Mitchell PACELle

Staff Reporter of TIIE WALL STRFET JOURNAL The average American car commuter spends about $3 \frac{1}{2}$ hours a week fighting traffic between home and office.

Walter Kulash wants drivers to spend even more.

Nosing his Chrysler through a snarl of traffic on the main drag in Winter Park. Fla, near Orlando, the traffic engineer is rhapsodizing about how the narrow twolane road, on-street parking, tree-lined curb and vibrant retail scene have conspired to reduce traffic to about 15 miles per hour.

"From a traffic-engineering point of view, it's a poorly performing street," he acknowledges. "But in a more im. portant sense, it's a very high-performing street. I'll bet a lot of these people don't even have to be on this street," he says, "They choose to, because it's enjoyable."

Mr. Kulash and a small band of radical traffic engineers have set out to shatter urban-plan-

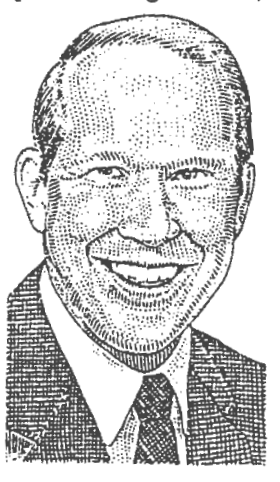

Walter Kulash ning dogma by applying "traffic calming" lessons learned in thriving communities like Winter Park to dying downtowns. Racing traffic and the absence of curb-side parking have degraded center-city streets, they argue, chasing away potential customers of street-level stores and restaurants. Narrowing the wide, one-way streets that crisscross most downtowns, and adding on-street parking, they insist, will make urban streetscapes far more appealing to shoppers, diners, and sightseers.

\section{Crawling Cars}

Flourishing, traffic-congested neighborhoods like New York's Greenwich Village, Miami's South Beach, and downtown Santa Fe, N.M., they say, offer proof that city streets need traffic crawling through at $20 \mathrm{mph}$.

"Anywhere that doesn't have congestion, you probably wouldn't want to be there," says Toronto urban planner Ken Greenberg, who, as the city's design director in the $1980 \mathrm{~s}$, halted the construction of freeways and narrowed numerous streets. In successful downtowns, he says, cars should move "at the speed of a horse and buggy."

For a generation of engineers to whom the free flow of traffic has been high religion, such notions border on sacrilege. Government transportation officials, who control road-building funds, often insist that planners conform to standards intended to maximize traffic flow.

"I don't think you bring more life to [center cities] by increasing the congestion and accident hazards," says Paul Box, a prominent traffic engineer who helped write current national road guidelines. Narrowing city streets is "stupid," he says, and on-street parking in downtowns will only increase accidents.

\section{New Urbanists}

The abandonment of many city centers by all but the people who work there, $\mathrm{Mr}$. Box contends, is an irreversible product of suburbanization, and no amount of street alterations will change that. "What we need, typically, are wider streets."

This debate between traffic engineering's old and new guard could alter the way America's cities handle their traffic. Maverick engineers like Mr. Kulash have been embraced by an influential group of planners called the New Urbanists, who see the traditional town center as a model for modern development. They have gained the ears of a handful of mayors who are grasping for new ways to reverse the generation-long flight of retail, residential living, and office jobs from the cities to the suburbs.

The reasons people have left many cities, of course, include a host of economic and social factors, and no one contends that changing traffic patterns alone can reverse that trend. But making city streets an attractive place to slow down, some argue, is a necessary component of revitalization.

\section{Roads, Not Ramps}

The "pro-highway mentality" of stal traffic planners meant city streets "ju: served as external ramps off the freeway, Milwaukee Mayor John Norquist say: Now, "our local city engineers are startin to understand that their job is to add valu to the streets."

Milwaukee has added parking to down town streets, restored two-way traffi to some, and has studied tearing dow deteriorating freeway spurs and replacin them with boulevards. Other traffic-caln ing projects are being considered or ar under way in numerous cities, includin St. Paul, Minn., Portland, Maine, Prov dence, R.I., West Palm Beach, Fla., an Birmingham, Mich.

Even the federal Department of Trans portation is reconsidering accepted nc tions about road design. "Transportatiol Please Turn to Page A6, Column 1 


\section{APPENDIX B Wall Street Journal Article (cont'd)}

Continued From First Page should serve community needs," says John Horsley, the department's deputy assistant secretary for governmental af fairs. "Too often we've delegated Iroad designl to professionals who thought their only goal was to move regional traffic."

As he wheels around the Orlando area at a pace that leaves impatient drivers climbing up his tailpipe, $\mathrm{Mr}$. Kulash concedes that traffic calming inevitably riles commuters.

"A lot of people are furious about tampering with their ability to drive fast." he says. "But they aren't politically organized. And it would look really bad (to complain]. They aren't about to show up at a lpublic planning meeting."

\section{A Drive-By}

The 54-year-old Mr. Kulash has a theory about why people drive fast, which he says he arrived at through road. side interviews: The inore altractive and engaging the road, the slower a person will drive. As Mr. Kulash accelerates onto a four-lane, sun-blasted commercial strip outside Winter Park, he points out what he sees as design flaws: no trees or roadside landscaping, vast roadside parking lots with wide mouths, and a string of unattractive buildings set back far from the road.

"There should be fabulous value here. But the frontage has been poisoned" by the design, he says. "It's such a bleak, unrewarding scene that drivers deserve to get by it as fast as possible." Traffic is indeet flying.

Mr. Kulash insists he isn't anticar, just in favor of a better balance between cars and pedestrians. He is adamantly opposed, for example, to closing streets to traffic. All but a few of the pedestrian malls installed in many cities during the 1970s have been a complete bust, he notes, because shopners don't like to walk far from their cars. Many of those malls are now being torn out.

\section{Rethinking Suburbia}

For two decades, Mr. Kulash toiled in obscurity as a traditional traffic engineer. helping clients like the state of Arizona lay down highwilys. In 1991, a partner at Glatting Jiakson Kercher Anglin Lopez Rinehart, the planuing firm where he works in Orlando, introduced him to the New Urbanist theories. Intrigued, Mr. Kulash set out to analyze whelher the grids of nitrrow neighborhood streets would outperform the wide, high-speed, suburban arteries which caryy traffic between a series of cul-de-sacs.

He claims his computer analysis demonstrated that the grid of narrower streets allowed for shorter travel times and fewer delays. Although those conclusions are llotly disputed by some, a paper $\mathrm{Ml}$. Kulash prepared on the topic attracted the attention of many urban planners, bring. ing his firm plenty of business.

Mr. Kulash is working with engineers in St. Paul, Minn., to transform Wabasha Street, a down-on-its-luck commercial drag into a pedestrian-friendly central street. Last month, the city took the first step, eliminating a lane of traffic and adding parking.

St. Paul Mayor Norm Coleman points an unlit cigar to a vintage print on his office wall showing an architect's design of the city, in which a central boulevard linked the state capital to the banks of the Mississippi River. But when a freeway was built, it divided the capital area from the

city center. "In the 1960s, the traffic engineers thought they had it all figured out. And they did, because moving traffic was their goal." But their success, he insists, "is Inextricably tied to urban decline."
Empty Evenings

St. Paul, a city of 272,000 has become a quintessential nine-to-five conimuter town. The 50,000 people who work downtown "come into work, they stay in the buildings for lunch, and they go home," says Department of Public Work Director Stacy Becker. Most evenings, the downtown is practically deserted by $5: 30 \mathrm{p.m}$.

Like many cities, St. Paul converted a number of downtown streets to one-way in the $1950 \mathrm{~s}$, so they could handle more traftic. In the 1960s, a ring of highways was added around the center city. Then, in an effort to separate pedestrians from traffic and the harsh winter weather, the city built a system of enclosed, elevated walkways that now link 50 blocks.

On a recent midmorning walk along Wabasha Street, Ms. Becker gestures to the featureless office-building facades and side streets without storeflonts: "Why would you want to walk down here?" she asks. Rather than encouraging visitors to stop. Wabasha "is a great street to get out of town."

Indeed, cars zip along the street at an average of $28 \mathrm{mph}$ - lightning fast, by urban standards. It is so efficient that 15 minutes after work lets out, rush hour is over.

But changing the strect's contiguration wasn't easy. State regulations set miniinum widths for urban streets, and cities that didn't comply faced the loss of gasoline-tax revenues. Eventually, the state granted variances allowing the removal of one lane of Wabasha, the addition of on-street parking and a bike lane. The city is planning to line the street with trees, and is considering the restoration of two-way traffic.

City planners hope that physical changes to storeironts, coupled with coordinated narketing, will entice workers to spend more time downtown, and altract visitors from the suburbs.

sibll, skeptisism ahout the plan abounds. "Everyone has al silver bullet," says John S. Adams, al protessol" of planning and public alfalls at the University of Minnesota. "Most of the plamers don't understand the cconomics of" the decline of the center city, which he attributes to tax and public-policy incentives favoring the suburbs. "I really don't think that traffic patterns make much of a difference."

The merchants on Wilbasha, who lave seen redevelopment plans cone and go. remain wary. But they are enthusiastic, at least, about the added parking. Denise Roseland, manalger of a downtown bagel shop, says she has heard "a lot of comments from custorners saying, 'It's so much easier to get to you now. I can just pull up out front and run in."

"Traffic really slowed down. I was shocked," says a pleased Alan Bloom, the director of leasing for the downtown mall. "I didn't think we'd see this nuch of a difference."

As Ior the commuters, "I'n not sure fancy lights and pretty trees are going tc satisly people that are sluwed down," concedes Michael Klassen, a city engineer "It's going to take some getting used to." 
APPENDIX C

Views of Worcester

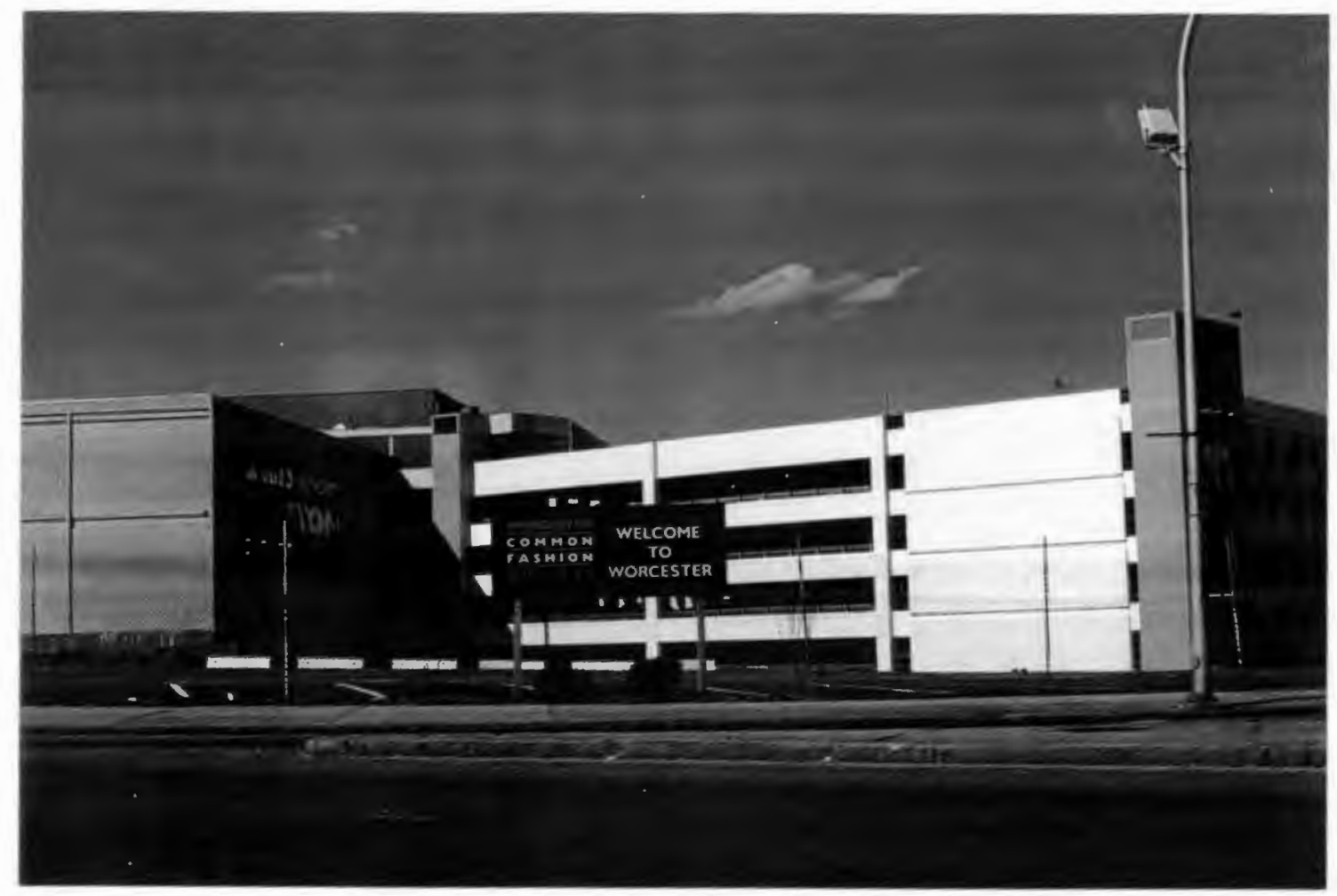


APPENDIX C

Views of Worcester

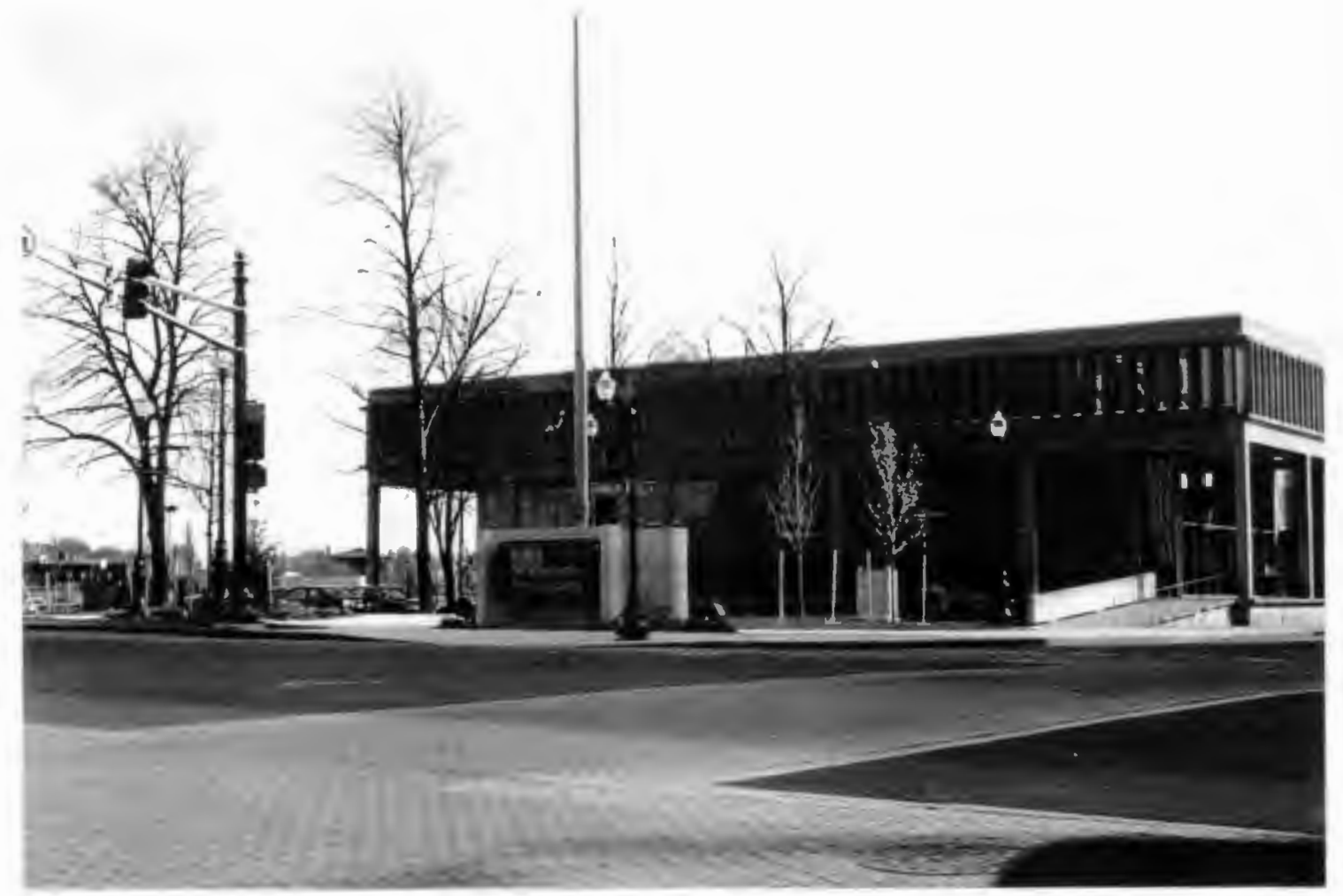


APPENDIXC

Views of Worcester

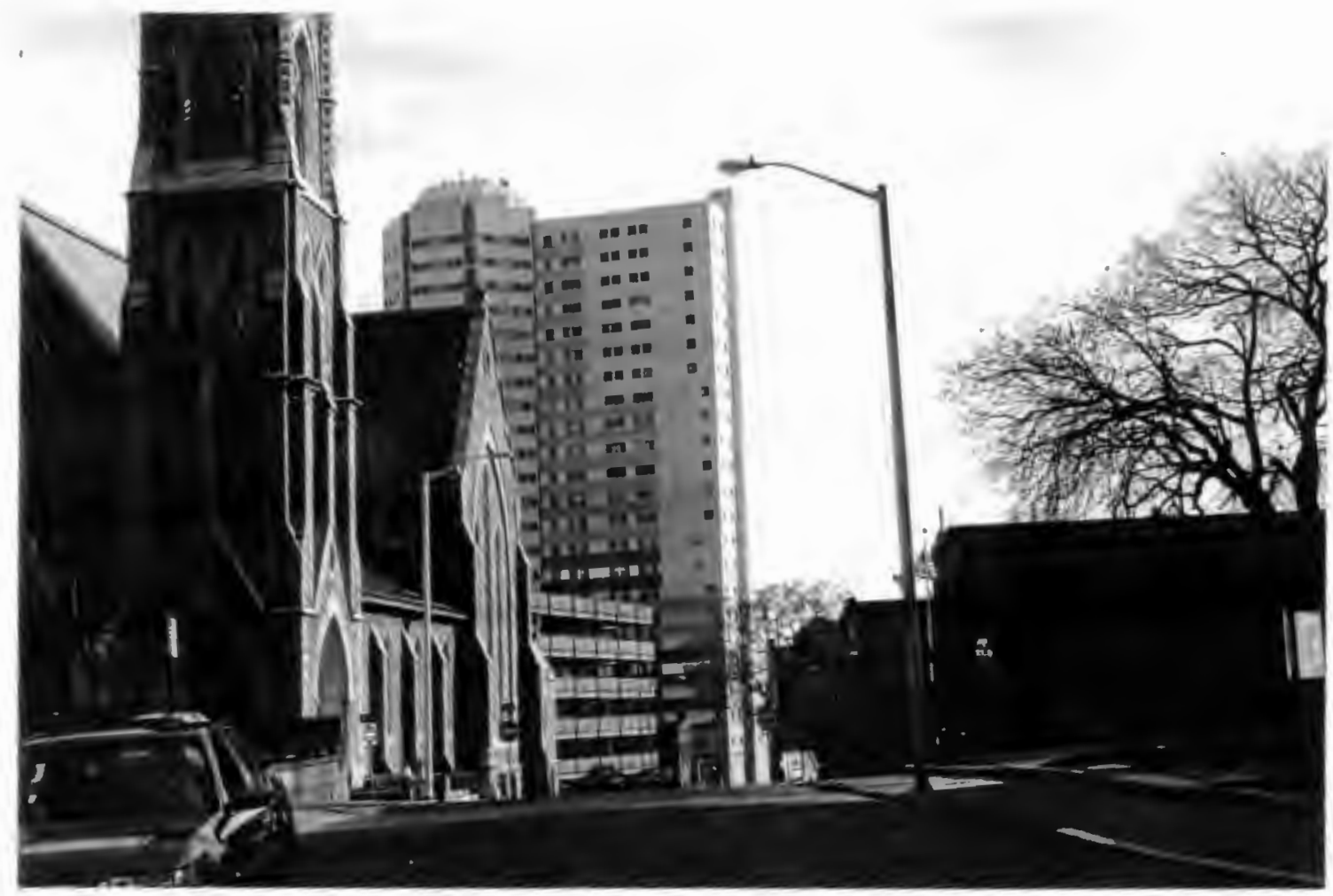


APPENDIXC

Views of Worcester

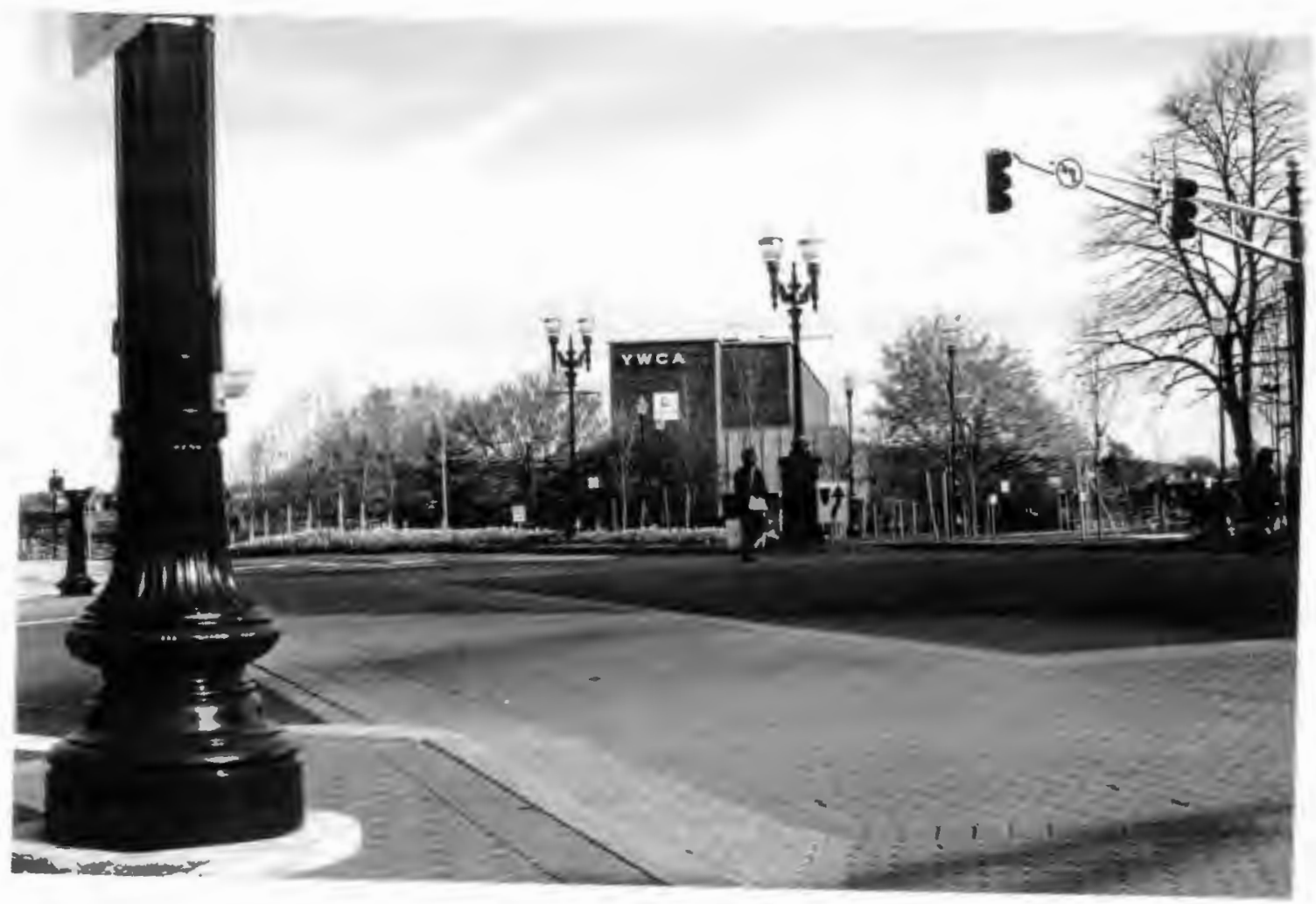


APPENDIX C

Views of Worcester
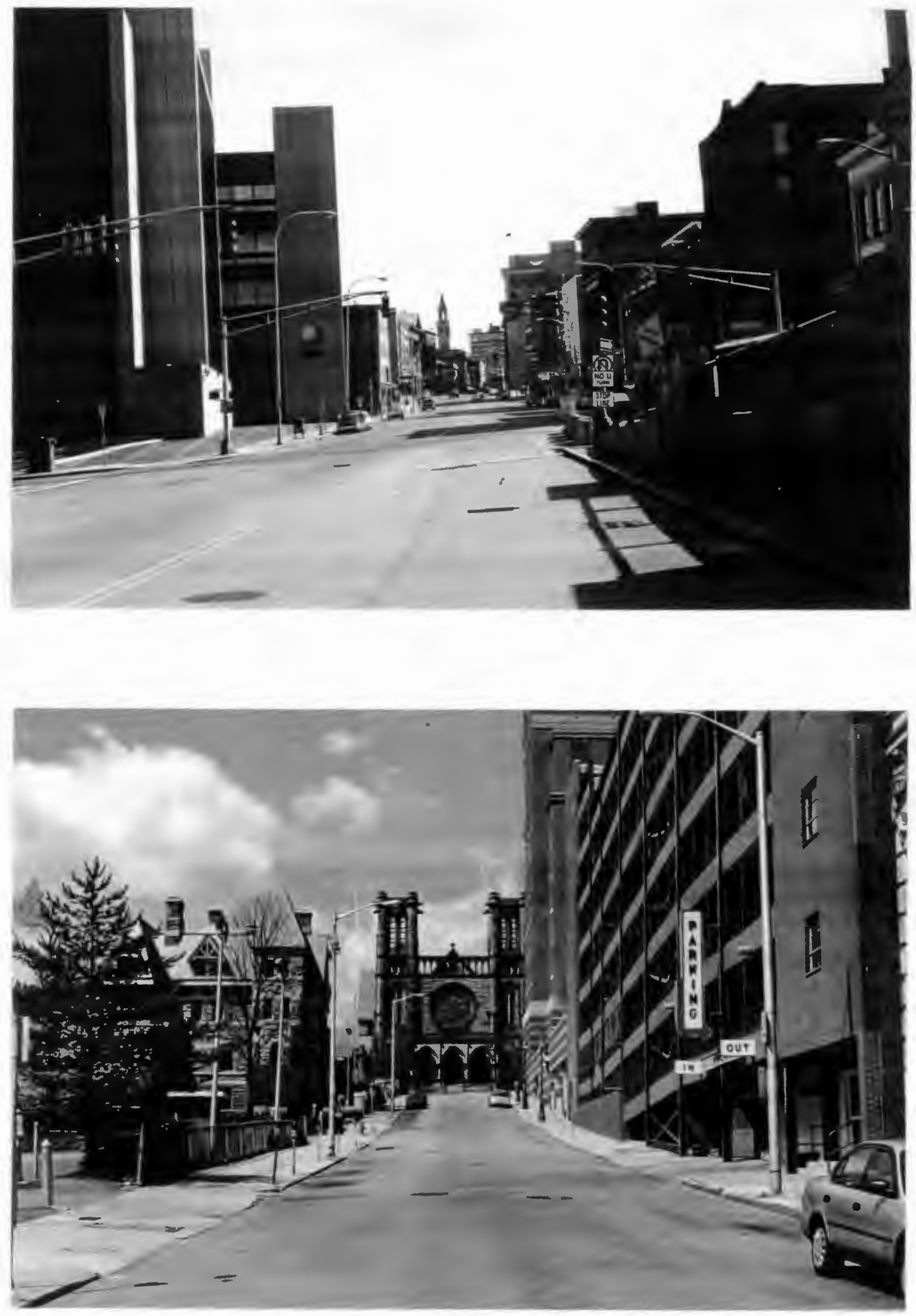
APPENDDX C

Views of Worcester
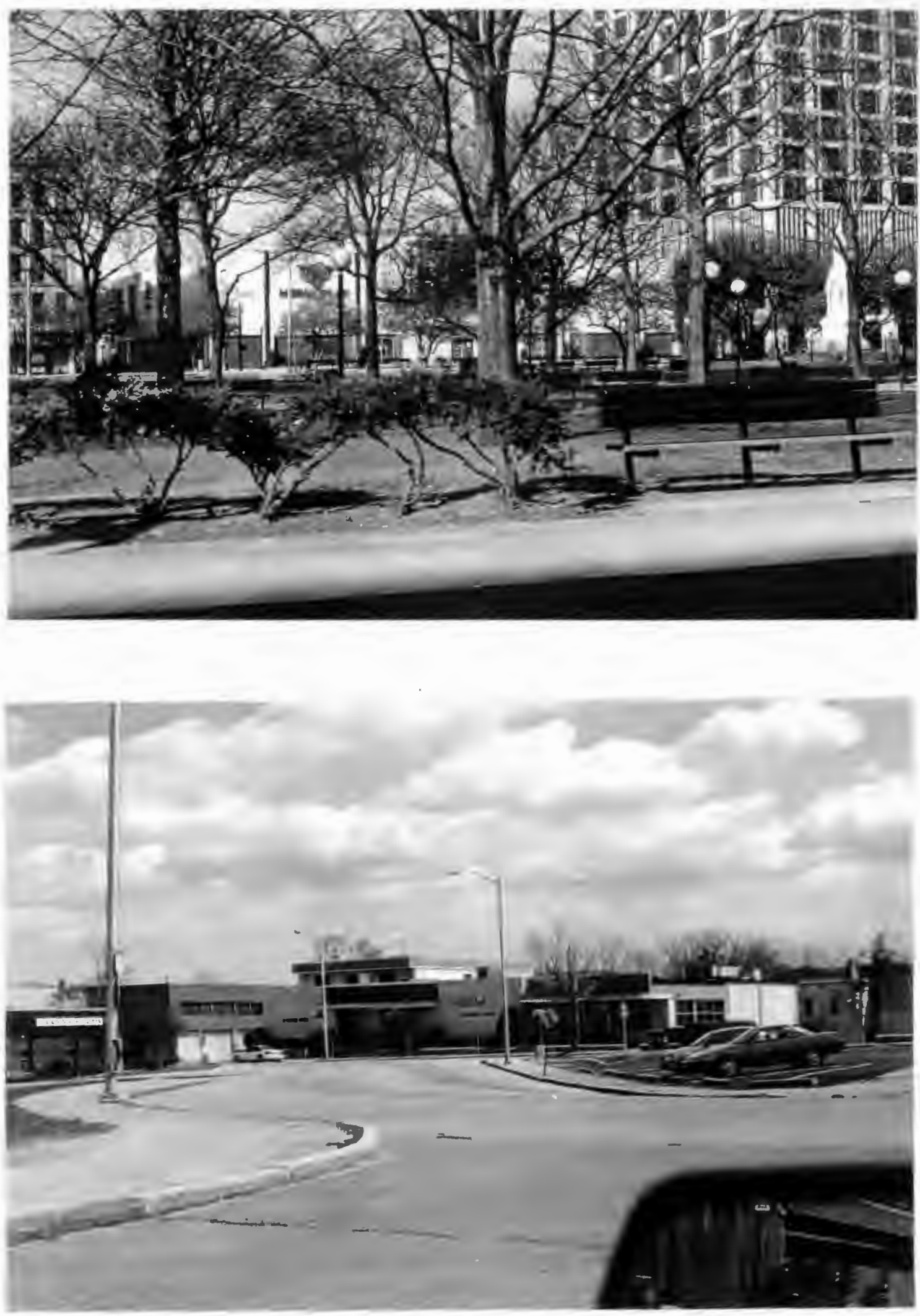


\section{BIBLIOGRAPHY}

Chamberlayne, Donald W. Worcester's Changing Population: An Analysis of the Declining Size of the Population and the Changing Composition of City Households. The Social Service Planning Corporation, Worcester, MA. June 1982.

Erskine, Margaret A. Heart of the Commonwealth, Worcester: An Illustrated History. Windsor Publications. Woodland Hills, California. 1981.

Fenich, George G. "An Assessment of Whether the Convention Center in New York Is Successful as a Tool for Economic Development." Economic Development Quarterly Vol. 8 No. 3 August 1994. pp. 245-255.

Garvin, Alexander. The American City: What Works, What Doesn't. McGraw-Hill, Inc. New York, 1996

Leicht, Kevin T. and J. Craig Jenkins. "Three Strategies of State Economic Development." Economic Development Quarterly Vol. 8 No. 3 August 1994. pp. 256-269.

Nickel, Denise R. "The Progressive City? Urban Redevelopment in Minneapolis." Urban Affairs Review, Vol. 30, No. 3, January 1995. pp. 355-377.

Office of Planning and Community Development. Downtown Worcester Development Plan: Boulevard District Study. City of Worcester. March 1990.

Pacelle, Mitchell. "Traffic Calming: Some Urban Planners Say Downtowns Need A Lot More Congestion". The Wall Street Journal. August 7, 1996.

Rich, Michael J. "UDAG, Economic Development and the Death and Life of American Cities." Economic Development Quarterly Vol. 6 No. 2 May 1992. pp. 150-172.

Schuler, Gretchen. Preservation Plan for Worcester Massachusetts. Worcester Heritage Preservation Society, Worcester, MA. 1987.

Shirvani, Hamid. The Urban Design Process. Van Nostrand Reinhold \& Company, Inc. New York. 1985 
Tools and Techniques for Housing Development. Office of Community Planning and Development, Department of Housing and Urban Development, Washington, D.C. 1983.

Trancik, Roger. Finding Lost Space. Van Nostrand Reinhold Company, Inc. New York. 1985.

1970. 1970 United States Census.

1980. 1980 United States Census.

1990. 1990 United States Census.

1960. 1960 United States Census.

Varady, David P. "Middle-Income Housing Programs in American Cities." Urban Studies. Vol. 31, No. 8. October 1994. pp. 1345-1366.

Wegener, Michael. "Operational Urban Models." Journal of the American Planning Association." Vol. 60, No. 1, Winter 1994. pp. 17-27.

Worcester Redevelopment Authority. Union Station: Intermodal Transportation Center, Worcester Massachusetts. Worcester, Massachusetts. September 1994.

Wrede, Stuart andWilliam Howard Adams. Editors. Denatured Visions: Landscape and Culture in the Twentieth Century. The Museum of Modern Art.

New York. 1991. 